\title{
The effectiveness of community schools: evidence from the Netherlands
}

Citation for published version (APA):

Heers, M. (2014). The effectiveness of community schools: evidence from the Netherlands. [Doctoral Thesis, Maastricht University]. Maastricht University. https://doi.org/10.26481/dis.20141003mh

Document status and date:

Published: 01/01/2014

DOI:

10.26481/dis.20141003mh

Document Version:

Publisher's PDF, also known as Version of record

\section{Please check the document version of this publication:}

- A submitted manuscript is the version of the article upon submission and before peer-review. There can be important differences between the submitted version and the official published version of record.

People interested in the research are advised to contact the author for the final version of the publication, or visit the DOI to the publisher's website.

- The final author version and the galley proof are versions of the publication after peer review.

- The final published version features the final layout of the paper including the volume, issue and page numbers.

Link to publication

\footnotetext{
General rights rights.

- You may freely distribute the URL identifying the publication in the public portal. please follow below link for the End User Agreement:

www.umlib.nl/taverne-license

Take down policy

If you believe that this document breaches copyright please contact us at:

repository@maastrichtuniversity.nl

providing details and we will investigate your claim.
}

Copyright and moral rights for the publications made accessible in the public portal are retained by the authors and/or other copyright owners and it is a condition of accessing publications that users recognise and abide by the legal requirements associated with these

- Users may download and print one copy of any publication from the public portal for the purpose of private study or research.

- You may not further distribute the material or use it for any profit-making activity or commercial gain

If the publication is distributed under the terms of Article $25 \mathrm{fa}$ of the Dutch Copyright Act, indicated by the "Taverne" license above, 
The Effectiveness of Community Schools: Evidence from the Netherlands 
(c)Marieke Heers, Maastricht 2014.

All rights reserved. No part of this publication may be reproduced, stored in a retrieval system or transmitted in any form, or by any means, electronic, mechanical, photocopying, recording, or otherwise, without the prior permission in writing, from the author.

ISBN: 978-94-003-0084-2

Cover Design: Raadhuis voor creatieve communicatie, Alkmaar.

The author acknowledges financial support from NICIS/Platform31.

This book is no. V of the TIER Research Series, a PhD thesis series published by TIER. 
The Effectiveness of Community Schools: Evidence from the Netherlands

\section{Dissertation}

to obtain the degree of Doctor at Maastricht University on the authority of the Rector Magnificus, Prof. dr. L.L.G. Soete in accordance with the decision of the Board of Deans, to be defended in public on Friday, October $3^{\text {rd }} 2014$, at 10:00 am

by

Marieke Heers 
Promotors:

Prof. dr. W. N. J. Groot

Prof. dr. H. Maassen van den Brink

Co-promotor:

Dr. J. Ghysels

Evaluation committee:

Prof. dr. H. Coonen (Chairman)

Prof. dr. A. Dyson (University of Manchester)

Prof. dr. H. Heijke

Prof. dr. I. Nicaise (Katholieke Universiteit Leuven)

Prof. dr. I. de Wolf 


\section{Acknowledgements}

"Perseverance pays off in the end", Wim and Henriëtte, this is a quote that you wrote to me once during the creation of my thesis. Today, it proves how correct you were not only with this statement, but also how much more you have taught me during the last years. I am very grateful that you gave me the great opportunity of writing a dissertation at TIER.

Joris, I have learned so much from you about the various aspects of the academic life. Thank you, for not only being my academic advisor, but also for being an indispensable guide through the immense jungles of the life of a $\mathrm{PhD}$ student.

Chris, thank you for providing me with the essential help to jumpstart my first 'evidence-based' research steps. What you taught me is a highly valuable foundation for my future endeavours.

I am also very grateful for my 'partners in crime', seeking the $\mathrm{PhD}$ : Carla H., Sofie, Erik, Dimona, Eline S., and Mieke. Having you around for a chat, good advice and a coffee break, no matter how much work was piling on your desks was an incredible support for me. Bregje, thank you for your practical and Dutch linguistic support during my first year in the Netherlands. Kristof, thank you for always giving useful feedback and spreading a good mood throughout the hallways. Carla L., thank you for arranging the small and big things and always having an open door. I also thank Astrid, Hans, Eline V., and all the other staff in TIER and TA. All of you made my working days and lunch breaks a pleasure. 
On the other side of the Atlantic, I am highly grateful to Professor Levin and Ilja Cornelisz for offering me an unforgettable time at the Teachers College at Columbia University in New York City. This was not only a unique academic but also an amazing personal experience.

Despite the many hours I spent in Kapoenstraat 2, there was also a life outside and some people made Maastricht my Dutch-German home! If friends are the family you choose, I could not have chosen a better one. Simone, I think it must have been some kind of miracle that put us together; first in the same Econometrics class and then into one apartment. I'll always appreciate how we can just switch from the most serious discussion to the most joyful nonsense. Iryna, Diana and Eszter, you know how much I appreciated every single evening on my couch, with you, good food, and wine. Without you, Maastricht would have definitely felt less like home. Vera, Christine, Inge, and Sabrina, thank you for sharing with me the best coffee and weekends to regain my energy. Meisjes van de Nederlandse les, dank jullie wel for improving my knowledge of the Dutch-German language and supporting the queen and king in every possible way.

While enjoying the Netherlands, I never forgot where my roots are! Nathi, Nele and Anna, on our first day of university, we were told, Hauptsache ihr habt Spaß! Oh yes, we do! Thank you for believing in me and putting my feet back on the ground whenever necessary. Käthe, Nassi and Eva, thank you for all traditional celebrations we shared and making me feel at home even if it was just for a few hours.

Finally, I would not be where I am now without having the support of greatest family. Mama, Papa, Anne, Teresa, and Oma, Danke! Alex, thank you for always providing me a desk and the perfect reason for a break. 


\section{Contents}

Page

1 Introduction 1

1.1 General introduction . . . . . . . . . . . . . . 1

1.1.1 How can community schools improve learning outcomes? . . . . . . . . . . . . . 4

1.2 Problem statement . . . . . . . . . . . . 6

1.3 Community schools in the Netherlands . . . . . . . 9

1.3.1 Emergence of Dutch community schools: enforcement of local communities . . . . . . . 9

1.3.2 Community schools in primary and secondary education . . . . . . . . . 10

1.3.3 Community school policymaking and governance 11

1.3.4 Dutch community schools in practice . . . . . 12

1.4 Aims and contributions of the dissertation . . . . . . 14

1.4.1 Scientific contribution . . . . . . . . . 15

1.4 .2 Societal contribution . . . . . . . . . . 16

1.5 Dissertation outline . . . . . . . . . . . . . . 17

2 Community Schools Disaggregated: A Review of the Literature 21

2.1 Introduction . . . . . . . . . . . . . . . . 21 
2.2 Methodology . . . . . . . . . . . . . . 22

2.2.1 Literature search procedures, inclusion criteria and data extraction procedures . . . . . . . 23

2.3 Community school activities and outcomes . . . . . . 25

2.3.1 The major community school activities: What do community schools do? . . . . . . . . . 26

2.3.2 Community school outcomes: What do community schools want to achieve? . . . . . . . . 30

2.4 The relationship between the major community school activities and the community school outcomes . . . . 33

2.4.1 Results for cooperation between schools and external institutions . . . . . . . . . . . . . 34

2.4.2 Results for parental involvement . . . . . . . . . 42

2.4.3 Results for extracurricular activities . . . . . . . 53

2.5 Discussion and conclusion . . . . . . . . . . 67

2.5.1 Do community schools achieve their goals? . . . 67

2.5.2 The contribution of community schools . . . . . 69

2.5.3 Further exploring the effectiveness of community schools . . . . . . . . . . . . . . 72

3 The Contribution of Community Schooling to Children's Educational Progress in Primary Education 73

3.1 Introduction . . . . . . . . . . . . . . . . . 73

3.2 Community school subsidy and setting . . . . . . . 75

3.2.1 The community school subsidy allocation and activities . . . . . . . . . . . . 76

3.2.2 Schiedam population and community schools . . 81

3.3 Data . . . . . . . . . . . . . . . . 82 
3.4 Identification strategy $\ldots \ldots$. . . . . . . . . . . . 84

3.4.1 Hypotheses on the working mechanism of community school subsidies . . . . . . . . . . . . 84

3.4.2 Outcome measures for educational progress . . . 85

3.4.3 Treatment indicators for community schools . . 87

3.4.4 Identification of the treatment effect of community schools by matching . . . . . . . . . . . . 89

3.4.5 Matching estimator . . . . . . . . . . . . 89

3.4.6 Estimation model . . . . . . . . . . . . . . . . . 94

3.5 Estimation results . . . . . . . . . . . . . . . . . . 95

3.5.1 Comparability of pupil characteristics after matching . . . . . . . . . . . . . . . 95

3.5.2 Estimation results for the length of community school attendance . . . . . . . . . . . . . . . 98

3.5.3 Estimation results for the community school subsidy . . . . . . . . . . . . . . . 101

3.5.4 Estimation results for the community school activities . . . . . . . . . . . . . 105

3.6 Discussion and conclusion . . . . . . . . . . . . 111

\section{Differentiated Effects of Community Schooling in Pri-} mary Education

4.1 Introduction . . . . . . . . . . . . . . . . . . 117

4.2 Community school subsidy and target groups . . . . . 119

4.2.1 Community schools for differentiated pupil groups . . . . . . . . . . . . . . . . 119

4.3 Data and hypotheses . . . . . . . . . . . . . . 123

4.3 .1 Data . . . . . . . . . . . . . . 123 
4.3.2 Hypotheses about the working mechanisms of community schools . . . . . . . . . . . . 123

4.4 Identification strategy: matching . . . . . . . . . . 124

4.5 Descriptive statistics . . . . . . . . . . . . . 125

4.5.1 Differentiated pupil groups . . . . . . . . . . 125

4.5.2 Outcome variables . . . . . . . . . . . . 126

4.5.3 Treatment variables . . . . . . . . . . . . . . . 128

4.6 Estimation strategy . . . . . . . . . . . . . . . . . . . 132

4.6.1 Community school attendance . . . . . . . . . 133

4.6.2 Community school subsidy . . . . . . . . . . . 134

4.6.3 Community school activities . . . . . . . . . . 135

4.6.4 Estimation procedure . . . . . . . . . . . 136

4.7 Results . . . . . . . . . . . . . . . . 136

4.7.1 The effect of community school duration . . . . 137

4.7.2 The effect of the community school subsidy . . . 141

4.7.3 The effect of community school activities . . . . 145

4.7.4 Carepupils . . . . . . . . . . . . . . . . . 146

4.8 Discussion and conclusion . . . . . . . . . . . . . 151

5 The Impact of Community Schools on Student Dropout in Lower Secondary Pre-Vocational Education $\quad 157$

5.1 Introduction . . . . . . . . . . . . . . . . . . 158

5.2 Dutch secondary education, data, and descriptives . . . 162

5.2.1 Dutch secondary education . . . . . . . . . . . 162

5.2.2 Community school subsidy . . . . . . . . . . 165

5.2 .3 Data . . . . . . . . . . . . . 167

5.2.4 Student characteristics . . . . . . . . . . . 170

5.3 Selection into community schools . . . . . . . . . 175 
5.4 Identification strategy and estimation model . . . . . . 179 5.4.1 Matching procedure . . . . . . . . . . . . . . 184

5.4 .2 Iterative matching procedure . . . . . . . . . . 184

5.4.3 Matching results and changes in background characteristics over time . . . . . . . . . 187

5.5 Estimation results . . . . . . . . . . . . . . . . 188

5.6 Discussion and Conclusion . . . . . . . . . . . . . 195

6 Conclusions and Discussion 199 6.1 Conclusions . . . . . . . . . . . . . . . . . 201

6.2 Contextualization of the results of the dissertation . . . 211

6.3 Policy implications and valorization . . . . . . . . . . 214

$\begin{array}{ll}\text { References } & 238\end{array}$

$\begin{array}{ll}\text { Summary } & 239\end{array}$

$\begin{array}{ll}\text { Samenvatting } & 251\end{array}$

$\begin{array}{ll}\text { Biography } & 261\end{array}$ 


\section{List of Tables}

Page

1.1 Community school concepts in the Netherlands . . . . 13

1.2 Structure of the dissertation . . . . . . . . . . . 19

2.1 Studies on the relationship between cooperation and academic performance . . . . . . . . . . 36

2.2 Studies on the relationship between cooperation and student dropout . . . . . . . . . . . . . . . . . 39

2.3 Studies on the relationship between cooperation and risky behavior . . . . . . . . . . . . . . . 40

2.4 Studies on the relationship between parental involvement and academic performance . . . . . . . . . . 46

2.5 Studies on the relationship between parental involvement and student dropout . . . . . . . . . . . . . 49

2.6 Studies on the relationship between parental involvement and risky behavior . . . . . . . . . . . . 51

2.7 Studies on the relationship between extracurricular activities and academic performance . . . . . . . . 55

2.8 Studies on the relationship between extracurricular activities and student dropout . . . . . . . . . . . . 60 
2.9 Studies on the relationship between extracurricular activities and risky behavior . . . . . . . . . . . . 64

3.1 Community school subsidy as a percentage of the general government grant by year and school board . . . .

3.2 Number of teacher FTEs corresponding to the costs of the community school subsidy by year . . . . . . . 81

3.3 Standardized outcomes by percentiles . . . . . 86

3.4 Pupil- and school-level characteristics after matching for community schools (CS) and regular schools (RS), mean and standard deviation . . . . . . . . . . . . . . 97

3.5 Length of exposure to community school education, number of pupils and percentages, cognitive sample . . . . 98

3.6 The effect of the length of community school attendance on cognitive outcomes . . . . . . . . . . . . . . 99

3.7 Length of exposure to community school education, number of pupils and percentages, social-emotional sample 100

3.8 The effect of the length of community school attendance on social-emotional outcomes . . . . . . . . . . . 101

3.9 The effect of the community school subsidy on cognitive outcomes . . . . . . . . . . . . . . . 102

3.10 The effect of the community school subsidy on socialemotional outcomes . . . . . . . . . . . . . . . . 104

3.11 Community school activity offer between 2000 and 2007 for the cognitive sample . . . . . . . . . 106

3.12 The effect of community school activities on cognitive outcomes . . . . . . . . . . . . . . 107 
3.13 Community school activity offer between 2003 and 2010 for the social-emotional sample . . . . . . . . . . . 109

3.14 The effect of community school activities on social-emotional outcomes . . . . . . . . . . 110

4.1 Percentages of pupil groups by community schools and regular schools . . . . . . . . . . . . . . . 125

4.2 Standardized outcomes by percentiles _ . . . . . . 127

4.3 Differences in cognitive outcomes between community school and regular school pupils . . . . . . . . . . 128

4.4 Differences in social-emotional outcomes between community school and regular school pupils . . . . . . . . . 129

4.5 Community school activity offer between 2000 and 2007 for the cognitive sub-samples . . . . . . . . . . . . 131

4.6 Community school activity offer between 2000 and 2007 for the social-emotional sub-samples . . . . . . . . . . 132

4.7 The effect of community school duration . . . . . . . 138

4.8 The effect of the community school subsidy . . . . . . . 142

4.9 The effect of community school activities for carepupils and non-carepupils . . . . . . . . . . . . . . 147

4.10 The effect of community school activities for pupils with lower-educated parents and for pupils with relatively higher-educated parents . . . . . . . . . . . . . 149

4.11 Summary of the hypotheses tested in this chapter . . . 152

5.1 Dropout in Rotterdam by educational track and school year (in percentages) . . . . . . . . . . . . . 163

5.2 Educational tracks in Rotterdam and in the Netherlands by school year (in percentages) . . . . . . . . . . . . 164 
5.3 Community school subsidy allocation by school type and school year . . . . . . . . . . . . . . . 168

5.4 Structure of the observed student cohorts . . . . . . . 169

5.5 Student characteristics by school type and school year . 172

5.6 Educational tracks in pre-vocational education by school type and school year . . . . . . . . . . . . . 174

5.7 Socioeconomic characteristics of first graders by school type and school year . . . . . . . . . . . . . 177

5.8 Educational tracks attended by first graders by school type and school year . . . . . . . . . . . . . . . . 179

5.9 Intuition of the difference-in-differences identification strategy . . . . . . . . . . . . . . . . 180

5.10 Results for the difference-in-differences estimation for the full population . . . . . . . . . . . . . . . 189

5.11 Student characteristics for the full population (F) and the matched sample (M) by school type and school year 191

5.12 Results for the difference-in-differences estimation for the full population and the matched samples . . . . . . 194

6.1 The main contributions of the dissertation . . . . . 200 


\section{List of Figures}

Page

2.1 The relationship between cooperation with external organizations and the community school outcomes . . . 42

2.2 The relationship between parental involvement and the community school outcomes . . . . . . . . . . . 53

2.3 The relationship between extracurricular activities and the community school outcomes . . . . . . . . 67

2.4 Evidence from the literature on the effects of the major community school activities on the defined community school outcomes . . . . . . . . . . . . . . . . . 68

3.1 The six community school activities from the RISBOmodel . . . . . . . . . . . . . . . . . 77

3.2 Subsidy allocation over the six community school activities in the school year $2007 / 2008 \ldots \ldots$. . . . . 79

5.1 Distribution of the average treatment effect on the treated . . . . . . . . . . . . . . . . 192 


\section{Chapter 1}

\section{Introduction}

\subsection{General introduction}

In many industrialized countries the academic achievement of children strongly depends on the socioeconomic status (SES) of their family: children from low-SES backgrounds face a variety of problems that, compared with children from relatively higher SES-backgrounds, put them in a disadvantaged position (Bower, 2011; Duncan, BrooksGunn, \& Klebanov, 1994; Duncan, Yeung, Brooks-Gunn, \& Smith, 1998; Evans \& Kantrowitz, 2002; McLoyd, 1990; OECD, 2011; Wilson, 2010).

Policymakers, educationalists and researchers have increasingly recognized that to best support children from lower SES-backgrounds both educationally and socially, and to eliminate the achievement gap with higher SES children, the traditional school is not powerful enough. Therefore, broadened school-based initiatives have been implemented. In addition to a traditional curriculum, they offer children before- and after-school care, extended social services (such as the availability of 
school social workers and psychologists), and extracurricular activities. Parents are closely involved in these activities. In this way, these schools embed education in children's broader learning and living environment. This is considered critical in reducing and, at a later stage, eliminating the achievement gap between children from different social backgrounds.

In the Netherlands, schools following this approach are referred to as 'broad schools'; ; the label reflects their broadened approach towards children and education. The international literature refers to such schools as 'community schools' because they are integrated in their community or neighborhood, where they play an important role.

So far, evidence on the effectiveness of community schools is lacking. Therefore, this dissertation provides evidence on the effectiveness of community schools that complements the relatively large amount of descriptive studies, and adopts quasi-experimental designs to identify the causal effects of community schools.

Providing evidence on the effectiveness of community schools is important, as expectations about them vary. However, from the public discussion it is often not clear what exactly community schools are supposed to achieve. For the Netherlands, it is clear, however, that more equal educational opportunities, and, as a consequence, increased academic performance, are outcomes that community schools seek to achieve (Hermanns, 2006; Spee \& Seuren, 2003). It is also assumed that, with their 'broader' educational approach, community schools can play a role in better developing social-emotional skills than traditional schools. This assumption has arisen against the background of the demand that schools be responsible not only for the transfer

\footnotetext{
${ }^{1}$ Dutch: brede scholen.
} 
of cognitive but also for the development of social-emotional skills. Other commonly proclaimed outcomes are better educational quality, stronger social cohesion and an improved quality of life in their neighborhoods and less risky behavior (e.g. in terms of reduced criminal involvement) amongst children and adolescents.

Several social developments have favored and reinforced each other, and led to an increasing number of community schools. For the Netherlands, the major reason was the aforementioned aim for equal opportunities for children from different socioeconomic backgrounds (Emmelot, Van der Veen, \& Ledoux, 2006; Hermanns, 2006; Spee \& Seuren, 2003). An additional driver for the establishment of community schools was the increasing demand for day-care, mainly because a larger share of women have joined the paid labor force. Consequently, schools are increasingly taking responsibility for the supervision of children during the entire day. Therefore, children spend more time in school, which implies that schools have more time to develop the children's skills and talents. The latter has reinforced the development of a broad range of activities offered in schools. Another driver for the spread of community schools was their attractiveness to policymakers, educationalists, and the public, who developed positive expectations about the potential achievements of community schools. This led to an increase in community school subsidies provided by municipalities throughout the Netherlands. 


\subsubsection{How can community schools improve learn- ing outcomes?}

Several potential working mechanisms may favor the improvement of the learning outcomes of community school students. These can be categorized as: (1.) the holistic educational approach of community schools; (2.) the active involvement of parents; (3.) the creation of activity accessibility and formalization of out-of-school time. The next paragraphs describe how each of these working mechanisms can be expected to contribute to improved learning outcomes.

\section{A holistic educational approach that is embedded in the socialization process of the child}

Community schools involve more stakeholders than traditional schools do. These are, for example, school social workers, school psychologists, youth care institutions, and health services. Together with the school, these institutions can have a broader view of the child and his/her problems, as well as of his/her strengths and talents, than traditional schools. Community schools should account for the fact that social needs, such as feelings of safety and security, need to be met before children can perform to their full capacity. The assumption is that by such close cooperation children's problems can be solved, and, as a consequence, their conditions for learning improve. For ethnic minority families, for example, these can be language-related problems. Within community schools their services are bundled and often offered 'under one roof'. Many municipalities in the Netherlands have built multifunctional accommodation that houses different childand education-oriented institutions. It is assumed that these ini- 
tiatives facilitate processes such as sending a child with a speech problem in a language class to a speech therapist.

\section{Taking parents 'by the hand'}

Often, parents from different socioeconomic statuses (SES) have different views on education (Chin \& Phillips, 2004; Lareau, 2003). Generally, parents from lower SES backgrounds are less aware of their critical role in the educational process, and are less involved in it. Community schools may play an important role in improving educational success, by involving parents more and raising awareness about their decisive role in education, and by stimulating parents' interest in, and appreciation of, education. However, changing parents' values and perceptions about education is difficult, and takes a long time. Therefore, community schools take parents 'by the hand', and facilitate their involvement in educational matters. They offer direct and active support to parents which may be beneficial for children's improved learning conditions in the short run.

\section{Facilitated access to activities and formalization of out- of-school time}

A vast amount of the literature states that children from lower SES backgrounds do not have the same out-of-school time experiences as children from relatively higher SES backgrounds (Dumais, 2006). Traditionally, for most children from lower SES backgrounds, education finishes with the end of the official school day. For children from higher SES backgrounds, it often continues in the form of extracurricular activities, such as sports and music or cultural activities. Such activities are supposed to con- 
tribute to children's educational and social-emotional development. However, given restricted financial resources or parental values, often lower SES children do not have easy access to such activities. Community schools offer a broader access to extracurricular activities and out-of-school experiences (Ministerie van Onderwijs, Cultuur en Wetenschap, 2014). There, the curriculum and free time are closely integrated, and learning is put in a positive context which may enhance children's motivation and pleasure in going to school. This, in turn may facilitate the learning process. At the same time, this extended activity offer, together with children spending more time in school, can be considered a 'formalization' of out-of-school time. The latter implies that differences in out-of-school-time experiences by children from different social backgrounds may be reduced.

Most activities that community schools initiate are not new. For example, extended school days, educational support for parents and day-care already existed. The innovative characteristic of community schools is that they structurally embed and combine these previously separated activities and projects in order to offer better educational opportunities (Valkestijn, 2002). However, so far, there is no causal evidence on the effectiveness of community schools.

\subsection{Problem statement}

Expectations towards community schools are high and diverse (Emmelot et al., 2006). Simultaneously, they attempt to tackle problems that arise beyond the school, such as educational inequalities. By im- 
plementing a holistic approach they are expected to positively affect children, as well as the environment in which children live and grow up.

These schools often have to cope with the disadvantaged background of their population which, compared with schools that have less disadvantaged populations, makes it harder for them to achieve similar student performance.

The positive assumptions about community schools have led to an increase in the number of community schools, which has been supported by considerable financial investments in these schools. In some countries (e.g. in the US), community schools are financed through different public and private channels that fund specific services (Coalition for Community Schools, 2013); in other countries, subsidies are provided by municipalities (e.g. in the Netherlands).

Despite the positive expectations about community schools, the mechanisms of how these schools are actually supposed to improve children's educational outcomes are not exactly clear. Little is also known about the impact and the effectiveness of community schools. Overall, the increase in the number of community schools and the financial investments are remarkable, given that there is no evidence that community schools are addressing and tackling educational and social problems better than regular schools. For example, the Municipality of Schiedam invested approximately $€ 4.6$ million in community school subsidies between 2000 and 2012. Considering the knowledge gap, on the one hand, and high public spending on community schools, on the other, insight into the effectiveness of community schools is needed.

The current evidence on community schools is very limited in this respect. For community schools many case studies are available. Many 
of these case studies are used as a marketing tool for implementing additional community schools, in particular for the US. Studies, both case studies and descriptive ones, on community schools in the US, are often carried out by their advocate group which does not ensure objective evaluation. For the Netherlands, the literature on community schools is also mainly descriptive (e.g. De Vos, Severins, De Boom, Meeuwisse, \& Hermus, 2010; Oomen, Kruiter, Van der Grinten, Van der Linden, \& Dubbelman, 2009); an annual report is published that describes the current state of community schools (e.g. Kruiter et al., 2012; Oomen et al., 2009). These studies are generally positive about community schools. So far, only one study using an experimental design is available which has evaluated a broad-scale community school intervention in Harlem in New York City. It finds positive effects on learning outcomes (Dobbie \& Fryer, 2009).

For several reasons measuring and evaluating community school effectiveness is not straightforward. First of all, identifying community schools is difficult. Often a clear distinction between community and regular schools is not possible, as many schools have some community school elements. Additional factors hampering evaluations of community schools are the non-availability of reliable data, and the lack of clearly defined goals for community schools. Moreover, studies evaluating community schools face the limitation that randomization is not possible, and the identification of valid control groups is difficult. These, are, however, critical to derive conclusions about the effectiveness of community schools. Finally, community schools are not a single educational intervention but combine different activities to achieve positive outcomes for children and their families. This also makes it hard to identify just the effects of community schools. 


\subsection{Community schools in the Netherlands}

As the focus of this dissertation is on community schools in the Netherlands, the next subsections (1.3.1 to 1.3.4) elaborate on the context of Dutch community schools. Their emergence, their position in primary and secondary education, and their governance and practices are discussed.

\subsubsection{Emergence of Dutch community schools: enforcement of local communities}

Community schools in the Netherlands have evolved from local practice and not from a general plan. The development of community schools started in the middle of the 1990s. This development was enhanced by the fact that, from the 1990s onwards, municipalities in the Netherlands have increasingly had the freedom to develop their own policies. In particular, welfare policies, policies towards children with educational disadvantages and school housing policies, as well as the financing of educational support services, have been decentralized. It has increasingly been put forward that community development ${ }^{2}$ has to happen at the local level, as at that level problems are best understood. Consequently, municipalities could take the lead in developing community schools. Another motivation was that schools were supposed to play a central role in policies dealing with disadvantages. This development does not mean that schools alone are responsible

\footnotetext{
${ }^{2}$ Dutch: wijkaanpak.
} 
for remedying disadvantages, but that the different institutions in the neighborhood that are involved in raising and educating children have to cooperate (Valkestijn, 2002).

Driven by the slogan 'it takes a whole village to raise a child', the first community schools in the Netherlands were set up in Rotterdam in 1996 (De Vos et al., 2010). Almost simultaneously the establishment of what are called 'Window schools' was initiated in Groningen. In Rotterdam, community schools emerged as educational institutions which were closely cooperating with other institutions, while in Groningen the 'Window schools' were initiated by the municipality. 'Window schools' accommodate as many institutions as possible 'under one roof'. For this purpose, new buildings have been built and older ones have been reconstructed. In Rotterdam, the different cooperating partners were hosted in different buildings. Quickly, other municipalities followed Rotterdam and Groningen and set up similar initiatives. For example, in Utrecht, 'Forumscholen' have been established (Spee \& Seuren, 2003; Valkestijn, 2002).

\subsubsection{Community schools in primary and secondary education}

In the Netherlands, community schools are set up both in primary and secondary education. In 2011, there were 1,600 community schools in primary education out of a total of 7,480 and 420 out of a total of 646 in secondary education (Kruiter et al., 2012; Van der Veen, 2011). For several reasons community schools are more prevalent in primary than in secondary education. Many municipalities have decided to introduce community schools stepwise and have started with children aged 0 to 
12 years. In the Netherlands, pupils attend primary education until the age of 12 . The idea is that disadvantages can best be counteracted if this begins at a young age. While primary schools are usually attended by pupils living in the school's neighborhood, most secondary schools have students from several neighborhoods. Therefore, a neighborhood approach is more difficult to achieve for secondary schools. Moreover, compared with primary schools municipalities have relatively little grip on secondary schools. Community schools in secondary education are initiated mostly by the schools and not by the municipalities (Ministerie van Onderwijs, Cultuur en Wetenschap, 2014; Valkestijn, 2002).

Municipalities throughout the Netherlands have implemented community schools with different intensity and speed. For example, the Municipality of Schiedam wants to convert all its primary schools into community schools. While the Municipality of Schiedam can be characterized as a frontrunner for community school development in primary education, the Municipality of Rotterdam is a frontrunner in secondary education. As outlined above, community school implementations vary according to the local context in which they are situated. Therefore, in its empirical chapters, this dissertation focuses on the specific situation of community schools in Schiedam and Rotterdam. Whether wider conclusions can be drawn from these case studies, is a matter for discussion.

\subsubsection{Community school policymaking and gover- nance}

In 2000, the Ministry of Education, Culture and Science (OCW), together with the Ministry of Health, Welfare and Sport (VWS), intro- 
duced the White Paper on 'Brede scholen' (Tweede Kamer der StatenGeneraal, Overheid, 2000). In this Paper, community schools are described as a network of education, welfare, and care for children and their parents. The pronounced objective is to let children actively participate in society, to offer a good day division, to tackle disadvantages, and to increase their social competences. In the Paper, the ministries emphasize that the responsibility for developing community schools lies with the local authorities. They encourage this development by the targeted use of available instruments, such as regulations, support, communication and research. The ministries themselves do not provide extra income for community school activities, except by offering programs in the context of pre- and early school education.

While community schools are advocated by the national government, they are implemented and governed at the municipality level. It is also at the municipality level that community school subsidies are provided. Not surprisingly, community schools and their financing vary widely across the country (Valkestijn, 2002).

\subsubsection{Dutch community schools in practice}

The design of a community school in a particular neighborhood depends on its specific population. For example, if in the neighborhood there are many disadvantaged families, these are the focus of the development of the community school and the choice of partners with whom to cooperate. In this case, the offer typically includes programs for pre- and early school education, extended school days, different types of educational support for parents, and school social work. In neighborhoods with no or few vulnerable children, more attention is 
paid to cooperation between the school, day-care and providers of afterschool activities in order to develop an encompassing offer. Secondary community schools mostly organize activities themselves, in particular in the fields of sports and culture (Valkestijn, 2002).

Schools similar to community schools have also been established, under different names. Table 1.1 provides an overview of Dutch educational initiatives that closely relate to community schools but are labeled differently. This dissertation elaborates on community schools, but the schools shown in Table 1.1 are comparable in many respects, and, therefore, the findings also relate to those schools to some extent.

Table 1.1: Community school concepts in the Netherlands

\begin{tabular}{ll}
\hline Name & Translation \\
\hline (Open) wijkschool & (Open) neighborhood school \\
Vensterschool & Window school \\
Brede buurt school & Broad neighborhood school \\
Plusschool & Plus school \\
Forumschool & Forum school \\
Kantoorurenschool & Office hours school \\
Bedrijfstijden school & Business hours school \\
Magneetschool & Magnet school \\
Tweede thuis school & Second home school \\
Brede samenlevingschool & Broad society school \\
Brandpunt school & Focus school \\
Multifunctionele onderwijs- & Multifunctional education \\
en zorgcentrum & and care center \\
Scholen in de Samenleving, & Schools in society \\
SIS-en & \\
\hline Own overview. & \\
\hline
\end{tabular}




\subsection{Aims and contributions of the disser- tation}

The aim of this dissertation is to determine the effects of community schools on learning outcomes in the Netherlands. Based on the previous sections, this aim is broken down into five objectives:

1. So far, no systematic literature review on the effectiveness of community schools and their activities is available. Therefore, the first objective is to investigate and document the current evidence base on the impact of community school activities on student outcomes.

2. Policymakers and educationalists, as well as the general public, expect community schools to contribute to children's educational and social-emotional development. However, evidence of this is lacking. Therefore, the second objective of this dissertation is to describe the effect of exposure to community school education on pupils' cognitive and social-emotional development.

3. Community schools offer a multitude of activities to children, their parents, and, often, also to residents from the neighborhood. From the literature it is not known how the different community school activities affect children's cognitive and social-emotional development. Therefore, another objective of this dissertation is to describe the effect of various community school activities on pupils' cognitive and social-emotional development.

4. In the discussion about community schools, it is often stated that they are supposed to support disadvantaged pupil groups 
in particular. As evidence verifying this assumption is not yet available, the fourth objective of this dissertation is to determine the extent to which community schools are effective for pupils with different levels of educational and social care needs, and for pupils with different parental educational levels.

5. Another expectation towards community schools is that they support students in graduating from secondary education. So far, empirical research has not elaborated on this question. Therefore, the final aim of this dissertation is to investigate the impact of community schools on students' probability to drop out of prevocational secondary education.

\subsubsection{Scientific contribution}

This dissertation provides empirical evidence on community schools. Knowing whether community schools work in terms of benefitting children's educational development is necessary given the gap in our knowledge. The dissertation includes both an international literature review and a multitude of empirical analyses of the effects of community schooling in the Netherlands.

Furthermore, community schools are analyzed from different angles, because of their heterogeneity. First, different types of community schools are considered by focusing on several examples in the Netherlands. Second, different age groups and pupils at different stages of their educational careers are considered. Third, several outcomes of community schools are considered: namely, educational as well as social-emotional outcomes. Finally, the focus is invariably on the student. Thereby, this dissertation considers both the 'average' child and 
children from social-economically disadvantaged backgrounds, and explores how both groups can benefit from community schooling. By providing insight into whether, and for whom, community schools work from a cognitive and social-emotional perspective, this dissertation fills the gaps in the current literature.

\subsubsection{Societal contribution}

In the Netherlands, there is much debate about community schools. From advocates of community schools, such as political parties, educationalists, and aldermen in cities, as well as from the media, the impression emerges that community schools can be a remedy for many current social challenges. The question whether children actually benefit from attending community schools is critical not only for the individual child enrolled in these schools but also for society as a whole. Education concerns each and every member of a society and a society should provide the best education possible for its children. Therefore, knowing whether, and for whom, community schools can contribute to improving educational opportunities and achievement is critical.

Not all community schools in the Netherlands focus exclusively on disadvantaged children. Some community schools, for instance those in Rotterdam, aim at developing the talents of all children (Gemeente Rotterdam, 2008). Policymakers in Rotterdam argue that, by offering extended hours and activities, all students can develop their talents to their full capacity. For future policymaking on community schools it is important to know whom they affect in what way. If community schools can contribute to give every child the same opportunities in education and, thereby, improve their overall life chances, further im- 
plementations of these schools should be promoted, so that the achievement gap between higher and lower SES children can be reduced.

Furthermore, for an economy it is important to provide its citizens with high-quality education, as the latter is a prerequisite for economic development. Moreover, community schools are more costly to run than regular schools. In the Netherlands, they are mainly financed with subsidies provided at the municipality level, and, thus they are financed via taxes paid by the general public. Given the vast amount of subsidies invested in community schools, and the increasing pressure put on municipalities to cut costs, it is critical to quantify the benefits of community school investments. If community schools do not achieve their goals, the money could, and should, be invested more effectively. Therefore, it is important to provide evidence on whether the money invested in community schools is well-spent.

\subsection{Dissertation outline}

This dissertation evaluates the extent to which community schools are effective in terms of improved learning and social-emotional outcomes. It examines the effectiveness of community schools from four different angles that are dealt with in the following chapters. Table 1.2 shows the structure of this dissertation.

Chapter 2 reviews the international literature on the effectiveness of community schools. Its focus is on the three community school activities (schools' cooperation with external organizations; parental involvement; and extracurricular activities) and how these relate to the three community school outcomes (academic achievement; dropout; and risky behavior). In the subsequent chapters, community schools 
in primary education are distinguished from community schools in secondary education. First, community schools in primary education are considered. Chapter 3 analyses the working mechanisms that may drive an effect of community schools on children's educational progress. Chapter 4 elaborates on whether these working mechanisms differ for different pupil groups that are expected to benefit from community school education in particular. Chapters 3 and 4 focus on primary community schools in Schiedam. Next, community schools in secondary education are analyzed; here, the focus is on secondary pre-vocational education in Rotterdam. Chapter 5 elaborates on the impact of community schools on students' probability to drop out of school.

Table 1.2 illustrates that, in the empirical chapters (Chapters 3, 4, $5)$, different econometric techniques such as Ordinary Least Squares, probit regressions, matching techniques, and difference-in-differences estimations are used to provide robust estimates of the effects of community schooling on educational outcomes.

The findings and conclusions from Chapters 2 to 5 are combined in the final chapter and discussed as concluding research findings based on which policy recommendations are given.

Community schools must be evaluated locally as their implementation depends largely on the local context. The focus on Schiedam and Rotterdam in Chapters 3, 4, and 5 is not only because both cities are frontrunners in community school development. In addition, both municipalities provide detailed data in terms of information on community school subsidies. Furthermore, these data allow a focus on student-level outcomes, and even more on the contribution of community schools to students' cognitive and social-emotional development. 


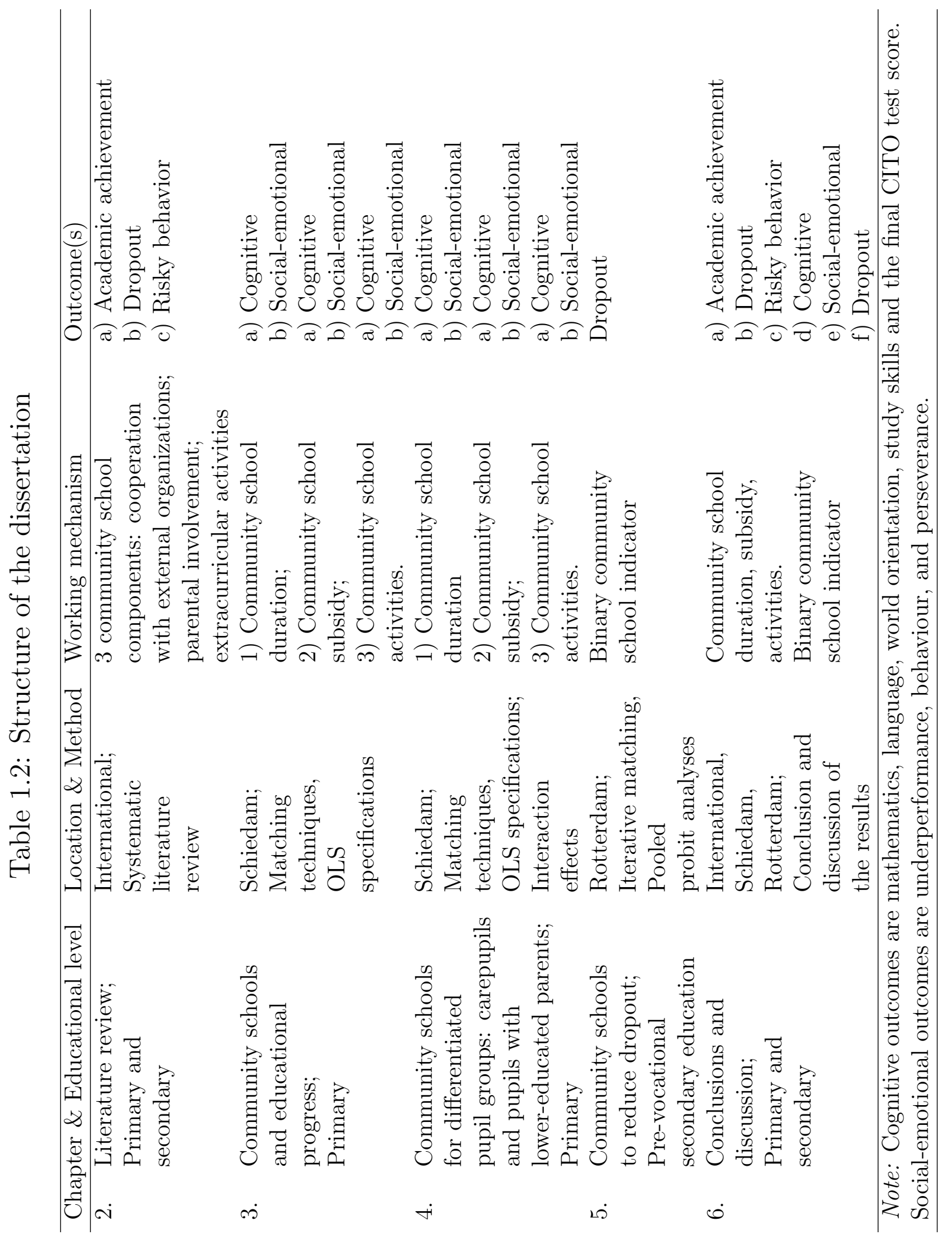


Chapter 1. Introduction 


\section{Chapter 2}

\section{Community Schools Disaggregated: A Review of the Literature}

\section{$2.1 \quad$ Introduction}

The previous chapter has provided an extensive introduction to community schools and their current situation in the Netherlands. Generally, community schools are established to improve the learning and living conditions of children, in particular those from lower socioeconomic backgrounds. Community schools are popular in several Western countries. Today, in the US, there are about 5,000 community schools (Coalition for Community Schools, 2013) in 44 states and the District of Columbia, which serve approximately 5.1 million students (Coali- 
Chapter 2. Community Schools Disaggregated: A Review of the Literature

tion for Community Schools, 2009). Considering equivalent schools in Europe, in England, all 23,000 schools are supposed to be transformed into what are called 'extended schools', which is the English equivalent of community schools. For this purpose, the government has committed $\$ 2.9$ billion between 2003 and 2011 (Bireda, 2009). In Sweden, all schools can be categorized as community schools. However, they differ from those in the other countries as they are not exclusively targeted towards disadvantaged children (Claassen, Knipping, Koopmans, \& Vierke, 2008; Verheijke, 2003).

This chapter provides a review of international evidence on community schools in terms of their major activities and outcomes. Community schools are disaggregated into their three main activities and the existing evidence regarding the relationship between the activities, cooperation with external organizations, parental involvement and extracurricular activities, and their three major outcomes, academic achievement, reduced dropout, and reduced risky behavior is reviewed. In the final section, conclusions are drawn with respect to the effectiveness of community schools, conditional on the total evidence.

To the best of the author's knowledge, this chapter provides the first systematic review of community schools and their effectiveness.

\subsection{Methodology}

The literature on community schools is mainly descriptive, and there are hardly any studies that explicitly examine the causal impact of community school attendance on the three community school outcomes (Claassen et al., 2008; Walraven \& Van Wissen, 2001). Therefore, in 
2.2. Methodology

the first part of the review, literature is selected that characterizes community schools in terms of their major activities and their objectives. Based on this characterization, it is possible to define the three major community school activities. This literature is, however, limited in quality and quantity. In the second part, studies are selected that empirically examine the link between the major community school activities and the outcomes that community schools often seek to improve. The focus of the second part is not specifically on community schools, but on the activities they undertake in order to improve the pursued outcomes. This part focuses on the relationship between community school activities and their outcomes. The aggregate of the evidence identified in the second part is viewed as a proxy for the effectiveness of community schools, and is discussed in the final section. The empirical studies discussed in the second part are described in detail in tables accompanying each section.

\subsubsection{Literature search procedures, inclusion cri- teria and data extraction procedures}

The literature was collected by first searching the following databases: Sage Journals Online, JStor, PsychINFO, EconLit, Google Scholar, and Google Search. The following search terms and their variants have been used in different combinations: community school, cooperation, external institutions, comprehensive service, integrated services, parental involvement, extracurricular activities, achievement, performance, dropout, early school leaving, delinquency, crime, risky behavior, drug use, substance, effect, experiment. In a second step, the 'snowball' principle has been applied. This implies that the reference 
lists from the identified literature have been searched for more relevant studies. This process is repeated for these studies until no new relevant studies are found.

The identified literature is used in the two review parts as follows. In order to identify and provide a good conceptual idea of community schools, in the first part descriptive literature is used that refers to community schools, their activities, and outcomes. Some of the ideas were raised in Chapter 1, and are discussed in more detail and from the perspective of the international literature base. Academic articles, reports, and case studies, about community school implementation in different countries are included. The second part builds on the community school activities and the goals that are identified in the first part. This section elaborates on the extent to which community schools can achieve their goals with the activities they undertake. The inclusion criteria for this part are more restrictive than those in the first part. In particular, in the latter part, the review distinguishes between experimental and quasi-experimental studies and correlational and qualitative studies.

For the second part, the following inclusion criteria are formulated:

1. Studies are informative about one of the community school activities with respect to at least one of the outcomes.

2. The studies are either peer-reviewed articles, working papers, or draw on large data sets.

3. The literature was available in October 2013.

4. The literature is written in English. 
The search procedures as described above have been carried out and the identified articles were read. During the reading process data was extracted by summarizing the articles according to the following criteria: The tables elaborate on the population from which each study draws, the data, and method used, the dependent and independent variables, and the major findings from each study. During the review process these criteria were constantly revised and refined. The tables are included in Section 2.4 of this literature review. The results from the data extractions were also used to assess the quality of the literature. This was done by subdividing the studies into descriptive and empirical studies, where the latter have further been subdivided into correlational and causal studies. In the analyses below, most weight is given on causal studies, followed by correlational studies and descriptive studies.

Overall, the above procedure and criteria led to two experimental or quasi-experimental and 43 non-experimental empirical studies that were included in the second part of the review.

\subsection{Community school activities and out- comes}

Chapter 1 has shown that, compared with traditional schools, community schools aim to go beyond the standard educational process. They integrate education with the social services that they provide to children and their families, in particular to those from deprived backgrounds (Van Velsen, 2011).

Therefore, every community school is unique and "place-based" 
Chapter 2. Community Schools Disaggregated: A Review of the Literature

(Blank, Jacobson, \& Melaville, 2012, p. 1). This also holds with respect to their populations. Traditionally, community schools have focused on deprived children. Today, there are also community schools that focus on children who are not deprived, with the goal to develop the talents of all children by offering a broad range of activities. Thus, because of the specific needs in their environment community schools vary greatly.

\subsubsection{The major community school activities: What do community schools do?}

Overall, there is a great variety in community schools, and as "community schools typically arise as unique responses to the specific needs of their communities, no two are exactly alike" (Blank, Melaville, \& Shah, 2003, p. 2). Consequently, there is no uniform definition for community schools or a prescribed model. Nevertheless, community schools can be characterized by three main characteristics that distinguish them from traditional schools: They cooperate with external organizations such as social activity providers (e.g. sports clubs, cultural institutions, such as theaters and libraries) and welfare institutions; they involve parents; and offer a wide range of extracurricular activities (Bireda, 2009; Blank et al., 2003; Coalition for Community Schools, 2009; Dryfoos, 2008; Jacobson \& Blank, 2011; Van Velsen, 2011). These three activities represent the basic and essential community school components. However, their nominal presence alone is not sufficient to constitute a community school. Community schools have a mindset where a holistic view on children plays a central role. 
2.3. Community school activities and outcomes

\section{Cooperation between schools and external services}

Community schools offer "comprehensive services delivered in conjunction with a school" (Bower, 2011, p. 25). In this sense, they do not work "as isolated educational institutions, but as part of a network of other schools and community agencies supporting each other and pooling their resources in a sustained effort to address disadvantage in the areas they serve" (Raffo \& Dyson, 2007, p. 270). Building on the demands in the neighborhood, the most common services include welfare, and health services, after-school care, and the provision of educational and recreational activity, culture (e.g. library), and sports activities (Bireda, 2009; Claassen et al., 2008; De Blaay et al., 2007; Dyson, 2011; Picard, Ruelens, \& Nicaise, 2004; Walraven \& Van Wissen, 2001). Often, pre-, primary and secondary schools cooperate (Dobbie \& Fryer, 2009; Van Velsen, 2011). Furthermore, cooperation is established with other community residents who can make use of the community school services (Bireda, 2009; Blank et al., 2003; Bontje, Studulski, \& Van der Vegt, 2006; Emmelot et al., 2006; Jacobson \& Blank, 2011).

The number of cooperating institutions and service providers differs, and in some countries ranges from three to 20 (Blank et al., 2003; Coalition for Community Schools, 2009; Van Velsen, 2011). Van Velsen (2011) refers to Dutch community schools and describes four types of cooperation which are ranked by the intensity of the cooperation: backto-back; face-to-face; hand-in-hand; and cheek-to-cheek (Van Velsen, 2011). In back-to-back cooperation, buildings are shared, but there is no cooperation in terms of content, whereas in cheek-to-cheek cooperation, the different institutions consider each other as one common organization. The other two types fall between these two extremes 
Chapter 2. Community Schools Disaggregated: A Review of the Literature

(Van Velsen, 2011). Most Dutch community schools can be categorized as face-to-face or hand-in-hand. Finally, many community schools have a coordinator who is responsible for the development and maintenance of the collaboration with other institutions (Benson, Harkavy, Johanek, \& Puckett, 2009; Blank et al., 2003; Dryfoos, 2005, 2008; Van Velsen, 2011).

\section{Parental involvement}

Parents play a salient role in the cognitive and social-emotional development of their children (e.g. Desforges \& Abouchaar, 2003; Fan, 2001; Harris \& Goodall, 2008). Community schools recognize this, and involve parents more than traditional schools do.

Parents from different social classes may have different parenting strategies (Chin \& Phillips, 2004; Lareau, 2003). Involving them in the educational process is particularly difficult in environments where, traditionally, they have not been much involved in education, or where they feel separated or estranged from schools (McMahon, Ward, Pruett, Davidson, \& Griffith, 2000). Constraints such as language problems may keep them from actively interfering. They may feel intimidated or past negative experiences may prevent them from getting involved (Becker \& Epstein, 1982; Lareau, 1987; McNeal, 1999). Parents from relatively higher SES backgrounds have more financial resources, and may attach more importance to their involvement in their children's education (Chin \& Phillips, 2004; Lareau, 2003).

Research suggests that parents are more inclined to visit schools when services, such as doctors, psychologists, and social workers are available (Crowson \& Boyd, 1993; McMahon et al., 2000). A school's 
success in meeting migrant parents' needs on a daily and ongoing basis, in terms of psychological support and physical resources, has been shown to be a prerequisite for successful parental involvement (López, Scribner, \& Mahitivanichcha, 2001). Overall, with their comprehensive approach, community schools connect schools to parents who traditionally are less involved in the education of their children. Community schools do more to initiate parental involvement in school, and parents are more frequently invited to be physically present in the school, for example, to help with organizing activities or to participate in these activities (Blank et al., 2003; Dobbie \& Fryer, 2009). Thus, in community schools, parents have a double function; first, to support their children and to be more involved with them; and, second, to benefit themselves from community schools. The concomitant regular communication between parents and the school is considered important, as it helps to establish a trustworthy relationship between schools and parents, and may help parents to develop a positive attitude towards their children's school (Brown, 2006; Fan, 2001; López et al., 2001), and raises overall awareness of what their children do, so that parents can better monitor their children's behavior and performance.

\section{Extracurricular activities}

In general, students from higher SES families are more likely to participate in extracurricular activities than those from lower SES families (Covay \& Carbonaro, 2010; Dumais, 2006; Holland \& Andre, 1987; McNeal, 1995). From the literature it is not clear whether this is because high-SES parents tend to be more attentive to the needs of their children (Lareau, 2003), or because financial and time constraints keep 
Chapter 2. Community Schools Disaggregated: A Review of the Literature

low SES-parents from encouraging their children to participate in extracurricular activities (Chin \& Phillips, 2004). At the same time, low-SES students are found to benefit more from extracurricular activities than high-SES students, as for many low-SES students such activities provide a new learning experience, which may not be the case for high-SES students (Covay \& Carbonaro, 2010). However, researchers and practitioners observe that in low SES-neighborhoods, there is a lack of opportunity to participate in good quality activities (Covay \& Carbonaro, 2010). Community schools create access to a variety of extracurricular activities, and thereby "can provide lowincome children with experiences more similar to those experienced by middle-class children" (Posner \& Vandell, 1999, p. 877).

Typical activities are sports (e.g. Broh, 2002; McNeal, 1995; Zarrett et al., 2009), the performing arts (e.g. Marsh, 1992), journalism, vocational clubs (e.g. Broh, 2002), tutoring, mentoring, technology, civic engagement, and health-promoting activities (Little, Wimer, \& Weiss, 2008). Often, community schools offer extended education activities hours, during which students receive additional classes (Bireda, 2009; Dobbie \& Fryer, 2009; Dryfoos, 2008; Jacobson \& Blank, 2011). These latter activities are not formal instruction time but added to the actual curriculum.

\subsubsection{Community school outcomes: What do com- munity schools want to achieve?}

Community schools have multiple aims and "plan their activities and services based on the results they want to achieve for students, families, and the community" (Jacobson \& Blank, 2011, p. 65). These results 
2.3. Community school activities and outcomes

can be very heterogeneous. To operationalize community school effectiveness, three outcomes are generally seen as positive benefits for children who attend community schools: namely, increased academic performance; a lower dropout rate; and reduced risky behavior (Adelman \& Taylor, 2008; Bireda, 2009; Blank et al., 2003; Dryfoos, 2000, 2008; Melaville, Berg, \& Blank, 2006; Shah, Brink, London, Masur, \& Quihuis, 2009).

The first aim of community schools is to increase students' academic performance. Evidence on the relationship between children's SES and academic achievement shows that children from lower SES families are usually outperformed by their peers with a higher SES background, which results in an SES-achievement gap (Baker, Goesling, \& LeTendre, 2002; Blau, 1999; Crane, 1996; Dahl \& Lochner, 2012; Duncan et al., 1994; OECD, 2011; Sirin, 2005). Community schools are supposed to compensate for this SES-disadvantage (Benson et al., 2009; Blank et al., 2003; Dryfoos, 2008).

Second, community schools aim at preventing dropout (Adelman \& Taylor, 2008; Bireda, 2009; Blank et al., 2003; Shah et al., 2009). Community schools may be better suited for this than regular schools, as dropout is frequently the result of an accumulation of problems that students experience at home, in their neighborhood, and at school (Rumberger, 2011). Dropout rates are linked to the well-being of communities (Alspaugh, 1998), and, in this sense, community schools may provide a more supportive social structure with incentives for students to stay in school. Usually, student dropout does not suddenly occur but is mostly a final step in a longer chain of events that students experience. Common predictors of dropout are the extent to which students feel attached to their school and the absenteeism rates they 
exhibit (Alexander, Entwisle, \& Horsey, 1997; Archambault, Janosz, Fallu, \& Pagani, 2009). Therefore, studies focusing on such indicators are included in the below analysis.

Third, community school neighborhoods often have characteristics that may motivate students to engage in negative behaviors (Franzini, Caughy, Nettles, \& O'Campo, 2008; Hoffmann \& Xu, 2002). However, students attending community schools are believed to be less likely to exhibit risky behavior (Adelman \& Taylor, 2008; Blank et al., 2003; Coalition for Community Schools, 2009). Children who spend more time in school-related activities have less time to spend on other unsupervised risky activities (Jordan \& Nettles, 2000). Furthermore, an attractive and supportive learning environment may reduce risky behavior, because children are better able to develop their talents, and become more responsible for their behavior (Ofsted, 2006). In this review, 'risky behavior' is defined as students' engagement in substance use (alcohol, marijuana and other drugs) and crime (delinquency). Youngsters are more at risk of engaging in risky behavior in early adolescence (Coley, Morris, \& Hernandez, 2004; Moffitt, 1993). Moreover, peers play an important role in adolescents' engagement in risky behavior (Barnes, Hoffmann, Welte, Farrell, \& Dintcheff, 2006; Covay \& Carbonaro, 2010).

The empirical chapters $(3,4,5)$ in this dissertation focus on the first two outcomes; academic achievement and dropout. The literature review in Chapter 2 also elaborates on the outcome risky behavior; because data on this outcome is not available, it is not empirically studied. 


\subsection{The relationship between the major community school activities and the community school outcomes}

The next sections discuss the empirical findings of the relationship between the three major community school activities (cooperation between schools and external organizations; parental involvement; and extracurricular activities) and the three outcomes (academic achievement, dropout, and risky behavior). Most of the studies focus on one of the activities and not on community schools as such, and, therefore, the literature is discussed for the community school setting. Each subsection provides a descriptive table of the empirical studies that are discussed and distinguishes experimental and quasi-experimental studies. The tables provide information on the population, the method, the (in)dependent variable, and the findings of the respective study. To easily distinguish (quasi-)experimental, other empirical and nonempirical studies, in the text (quasi-)experimental studies are marked with two asterisks, and other empirical studies with one asterisk, when they are mentioned for the first time. Note that some studies inform about more than one relationship, for example about the relationship between extracurricular activities and academic performance as well as student dropout. These studies are summarized in the first table in whose context they are mentioned for the first time. 


\subsubsection{Results for cooperation between schools and external institutions}

\section{The relationship between cooperation and academic perfor- mance}

Overall, there is little evidence on the impact of offering extended services on students' academic performance. One exception is the Harlem Children's Zone (HCZ) which is a case of close service integration yielding positive effects on educational outcomes (Bower, 2011; Dobbie \& Fryer, 2009**). HCZ is an exemplary community school implementation. This social experiment was set up in Harlem, New York City, and aims "at doing nothing less than breaking the cycle of generational poverty for the thousands of children and families it serves" (Harlem Children's Zone, 2013). HCZ is a comprehensive strategy for children from birth to college graduation, in which students are exposed to community services along with educational interventions that range from a longer school day and year via after-school programs to mental and physical health services. Causal evidence on the effects of investments in $\mathrm{HCZ}$ on educational outcomes (i.e. high-stakes exams, state tests) shows that for elementary schools the initial black-white achievement gap has been closed in both mathematics and in English Language Arts (ELA). The effects are large. For middle schools the achievement gap has been reversed in mathematics, and reduced by almost one half in ELA. The gains are similar for different subgroups, e.g. those with below or above the median test score before entering, and those having free lunch status. At the same time, the study shows that highquality schools are more important than the community programs in the project (Dobbie \& Fryer, 2009). 

and the community school outcomes

Similar to HCZ, 'full-service extended schools' in the UK cooperate with external institutions to provide a comprehensive range of services, including access to health services, adult learning, study support, and community activities. These are considered to be community schools in the UK. Their cooperation with the above services is associated with smaller attainment gaps in standardized tests between students who have learning difficulties and those who do not have such difficulties (Cummings et al., 2007*).

Community schools offer services not only to families but also to other residents. Overall, research on how community integration in children's education relates to academic achievement shows positive associations. Good relations between the school, the family and the community, as initiated by community schools, have a statistically significant relationship with higher standardized test scores in reading and writing, mathematics, and social studies amongst third graders (Epstein, Clark, Salinas, \& Sanders, 1997*). Lieberman and Hoody (1998*) focus on 40 schools that have integrated the school environment into formal education, implying that the natural and the sociocultural environment of the school is used as a context for learning. They find a better performance in standardized tests in reading, writing, mathematics, science and social studies.

Overall, the above evidence suggests that the cooperative nature of community schools can indeed contribute to improve academic achievement.

Table 2.1 provides an overview of the discussed studies. 


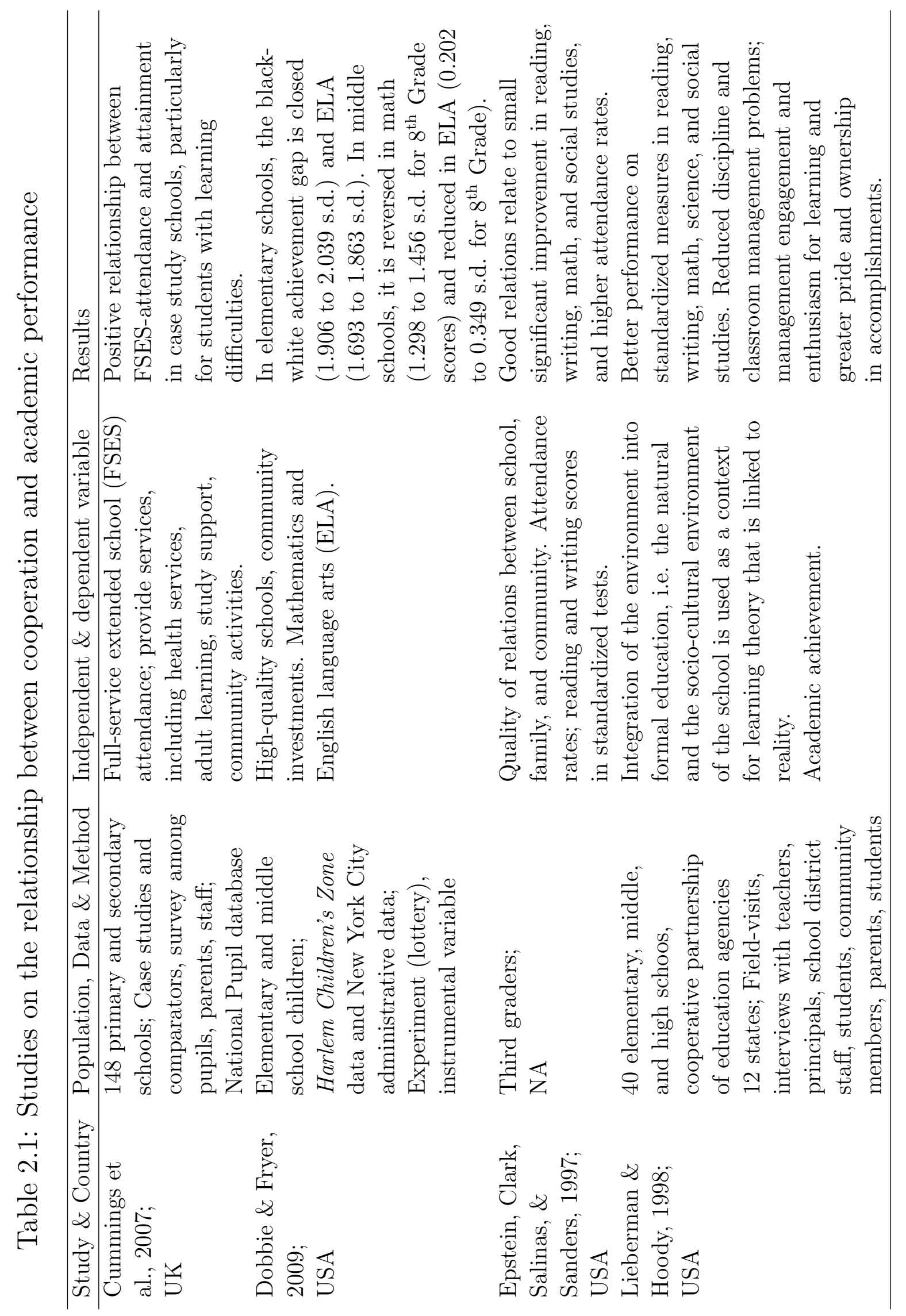




\section{The relationship between cooperation and dropout}

In community schools when cooperation with school-external stakeholders is initiated, it is assumed that this can prevent students from dropping out. Table 2.2 summarizes the literature on this relationship. Research has shown that cooperation between schools, families and communities, defined as practices to improve or maintain student attendance, correlates with higher attendance rates and lower chronic absenteeism (Epstein \& Sheldon, 2002*). This requires that families are provided with data of the responsible contact person in the school regarding attendance and other policies. Other studies consider students at risk of dropping out. For example, one study investigates how a community-based truancy prevention program mediates against absenteeism, truancy, and dropping out, with a focus on Black and Latino middle-school students. It finds that the "program's commitment to bridging the gap between the community and the school can be an effective approach to curbing truancy and dropout" (Rodríguez \& Conchas, 2009, p. 244*). This is also suggested by Fries, Carney, Blackman-Urteaga, and Sava's (2012*) evaluation of a wraparound approach to support high-risk teens (aged 11 to 20, pregnant or parenting, and having additional risk factors, e.g. mental health problems or being involved with juvenile courts) as a dropout prevention strategy. In this wraparound approach, high-risk youth's individual strengths are identified and, based on this, personal goals are set. The authors suggest that high-risk teens reconnect with educational goals and recognize the importance of continuing education once their lives become more stable (Fries et al., 2012). While these are high-risk students, the above finding may also be valid for community school populations, 
Chapter 2. Community Schools Disaggregated: A Review of the Literature

albeit to a lesser extent. In this sense, community schools, with their holistic approach, offer access to necessary services that help students with their basic needs before educational problems can be tackled.

All this suggests that community schools, with their intense cooperation, may make an important contribution in terms of reducing dropout risks.

\section{The relationship between cooperation and risky behavior}

There is little evidence on the relationship between cooperation and risky behavior. One commonly available service in community schools is health services (Benson et al., 2009; Bireda, 2009; Dryfoos, 2008). The presence of health services in schools correlates with improved health knowledge, but the estimated impact on risky behavior is inconsistent (Kisker \& Brown, 1996*). The authors suggest that more intense or different services are needed in order to significantly reduce risky behavior. Community schools may be powerful in this respect as they combine health services with different services such as school social workers.

Considering delinquency, Limbos and Casteel (2008*) suggest that school violence prevention efforts should involve both school and community partnerships as both school- and neighborhood-level factors are related to increased crime rates in secondary schools. Thus, community schools which build partnerships with their local communities may be helpful in reducing delinquency rates. 


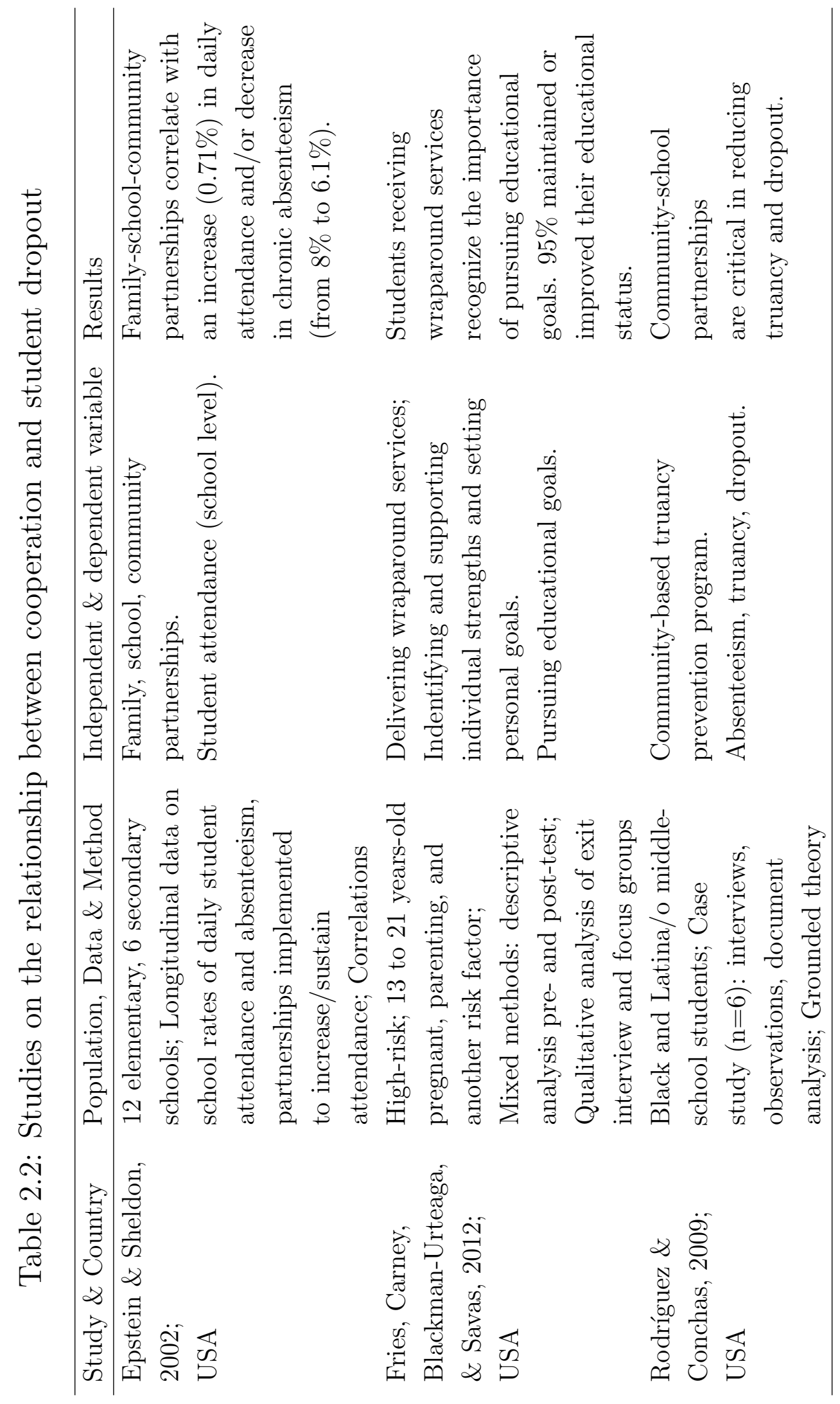




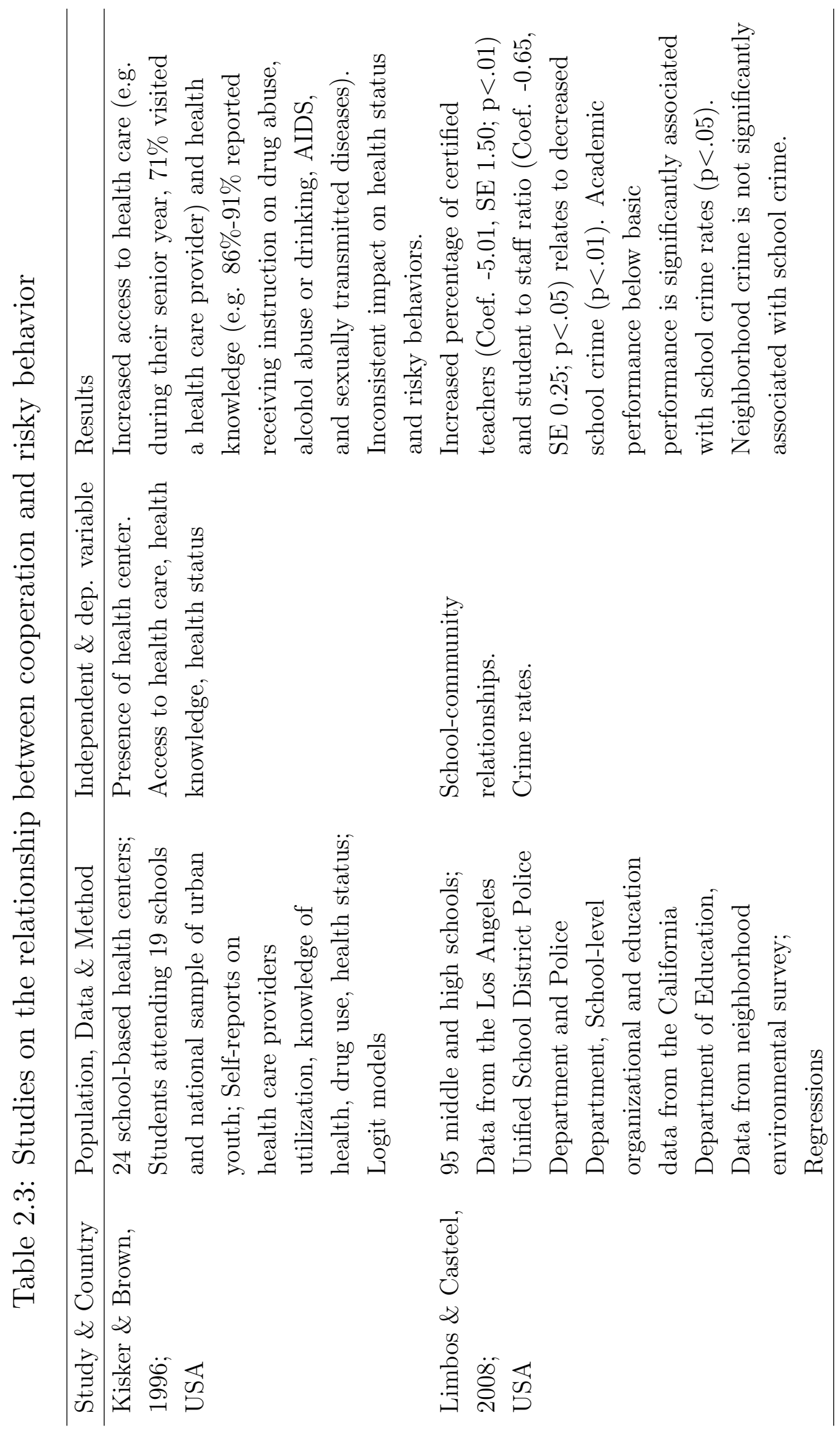




\section{Conclusion from cooperation}

Cooperation with external institutions is the least-studied community school activity in the current literature. At the same time, it is a critical component of community school implementations. Apart from Dobbie and Fryer's study (2009), the literature that describes the relationship between cooperation between schools and external services is sparse, tends to be descriptive, and is non-causal (Dawson \& Zunderdorp, 2002; Muijs, West, \& Ainscow, 2010; Spee \& Seuren, 2003). Overall, the literature suggests a positive association between cooperation between schools and external institutions and the three outcome variables. Figure 2.1 summarizes the results from the reviewed literature for cooperation with external organizations (on the left-hand side), and their relationship with the community school outcomes (on the right-hand side). The different types of arrows reflect the varying quality of the literature. The one-sided arrow shows that the relationship with academic performance has been researched experimentally and, therefore, allows the strongest conclusion. This is based on the evaluation of the HCZ which has revealed positive effects. The bidirectional arrows show that the studies on dropout and risky behavior are correlational or qualitative in nature. Overall, from the existing literature, it can be concluded that community schools, in terms of cooperation with external institutions, can increase academic performance, and be related to reduced dropout and risky behavior. 
Chapter 2. Community Schools Disaggregated: A Review of the Literature

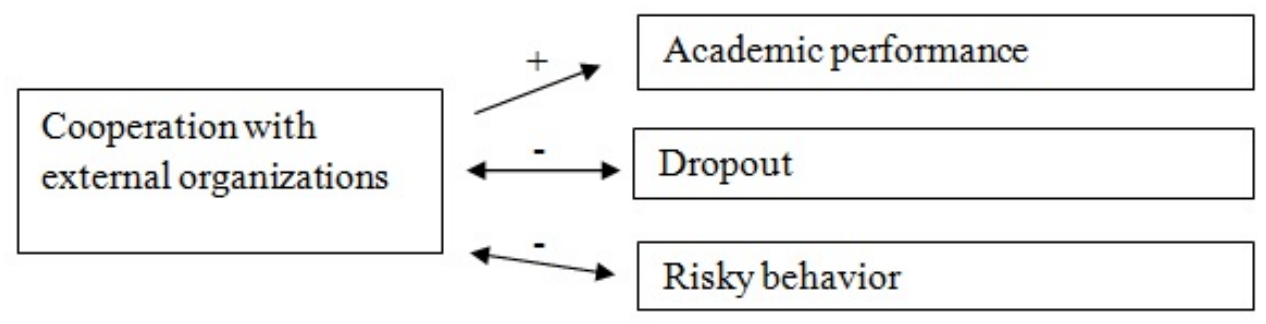

Figure 2.1: The relationship between cooperation with external organizations and the community school outcomes

The literature also highlights the pitfalls relating to cooperation between schools and other service providers. A first identified problem is that sharing responsibilities is difficult because the parties concerned may not want to either give up or take responsibility (Nettles, 1991; Spee \& Seuren, 2003). Furthermore, schools and external institutions may differ in their views on children and education, which may hamper a successful integration (Muijs, 2007). Finally, as community schools are demand-driven, different community schools cooperate with different partners (e.g. Jacobson \& Blank, 2011; Van Velsen, 2011), so the above-mentioned relationships may not apply to all community schools.

\subsubsection{Results for parental involvement}

The second major activity of community schools is that they intensively involve parents in the educational process of their children. Therefore, the next subsections describe the literature on the relationship between parental involvement and the three community school outcomes. Again, for each subsection a table is provided that summarizes the discussed studies. 
2.4. The relationship between the major community school activities and the community school outcomes

\section{The relationship between parental involvement and academic performance}

Overall, the literature suggests a positive association between parental involvement and student performance (e.g. Christenson, Rounds \& Gorney, 1992; Desforges \& Abouchaar, 2003; Fan, 2001*; Fan \& Chen, 1999*; Harris \& Goodall, 2008*; Ho Sui-Chu \& Willms, 1996*; Miliotis, Sesma \& Masten, 1999*). For example, Jeynes $(2003,2007)$ conducted two meta-analyses on parental involvement and academic achievement and found a positive relationship for minority students and secondary school students. Table 2.4 provides detailed information about the studies of the relationship between parental involvement and academic performance.

Regarding parental involvement in the community school-context, it is particularly informative to focus on the role of SES. The above suggested positive association between parental involvement and academic achievement has been confirmed when students' academic abilities and family SES are accounted for. In their review, Henderson and Berla (1994) show that parental involvement is a better predictor of academic achievement than family income or SES. Similarly, supporting socialeconomically disadvantaged parents in interacting with their children, in learning at home, and in learning from each other can help their children to perform as well as middle-class children (Cochran \& Henderson, $\left.1986^{*}\right)$. Further studies show that children tend to have higher mathematics and language test scores if parents encourage learning, irrespective of their income and education (Fan \& Chen, 1999; Henderson \& Berla, 1994; Ho Sui-Chu \& Willms, 1996). For example, discussion of educational topics at home increased achievement by 12 of a stan- 
Chapter 2. Community Schools Disaggregated: A Review of the Literature

dard deviation (s.d.) (Fan \& Chen, 1999). Ho Sui-Chu and Willms (1996) support this finding and find that home discussion increases mathematics and reading achievement by 12 percent of a standard deviation.

On the one hand, these findings suggest a huge potential for parental involvement amongst community school populations. On the other hand, it is also stated that at comparable levels of engagement, single, minority, and lower-SES parents "get less" (McNeal, 1999, p. 136*) for their involvement. The author suggests that this is either because the quality of their involvement is lower or because members in the educational institutions have more negative or defensive attitudes to these parents. Community schools approach parents more positively (e.g. Blank et al., 2003; Dobbie \& Fryer, 2009), and may be more successful than regular schools in overcoming barriers between parents and school staff, and thereby positively affect academic achievement.

Community schools encourage parental involvement at several levels.Thus, it is interesting to note that previous research points towards potentially different effects of parental home- and school-based involvement. Both parental home- and school-based involvement have been argued to relate to children's enhanced educational achievement (Hill \& Taylor, 2004; Hoover-Dempsey et al., 2001; Pomerantz, Moorman, \& Litwack, 2007). For example, encouraging parents to support learning at home is associated with higher percentages of students who score at or above 'proficient' in standardized mathematics achievement tests at the school level (Sheldon \& Epstein, 2005*). Harris and Goodall (2008) argue that parental engagement at home is most likely to result in positive learning outcomes, while school-based involvement has more of a social and community function. The latter 
finding is, however, not supported by Pomerantz et al. (2007), who conclude from their extensive review that the evidence is consistent in showing that school-based involvement benefits children in terms of their achievement, which is not accounted for by parents' SES or educational attainment (Miedel \& Reynolds, 1999*). With respect to home-based parental involvement, however, their findings are less consistent. Involvement which is directed at children's intellectual enrichment but is not directly school-related predicts enhanced achievement, while school-related involvement does not show beneficial effects. The authors conclude that parental school-involvement creates an environment for children which fosters their skills and motivational development, while home-involvement does not necessarily do this (Pomerantz et al., 2007).

The overall picture of the relationship between parental involvement and educational achievement is positive. However, the actual mechanism of how parental involvement influences achievement is not clear (McNeal, 1999). 


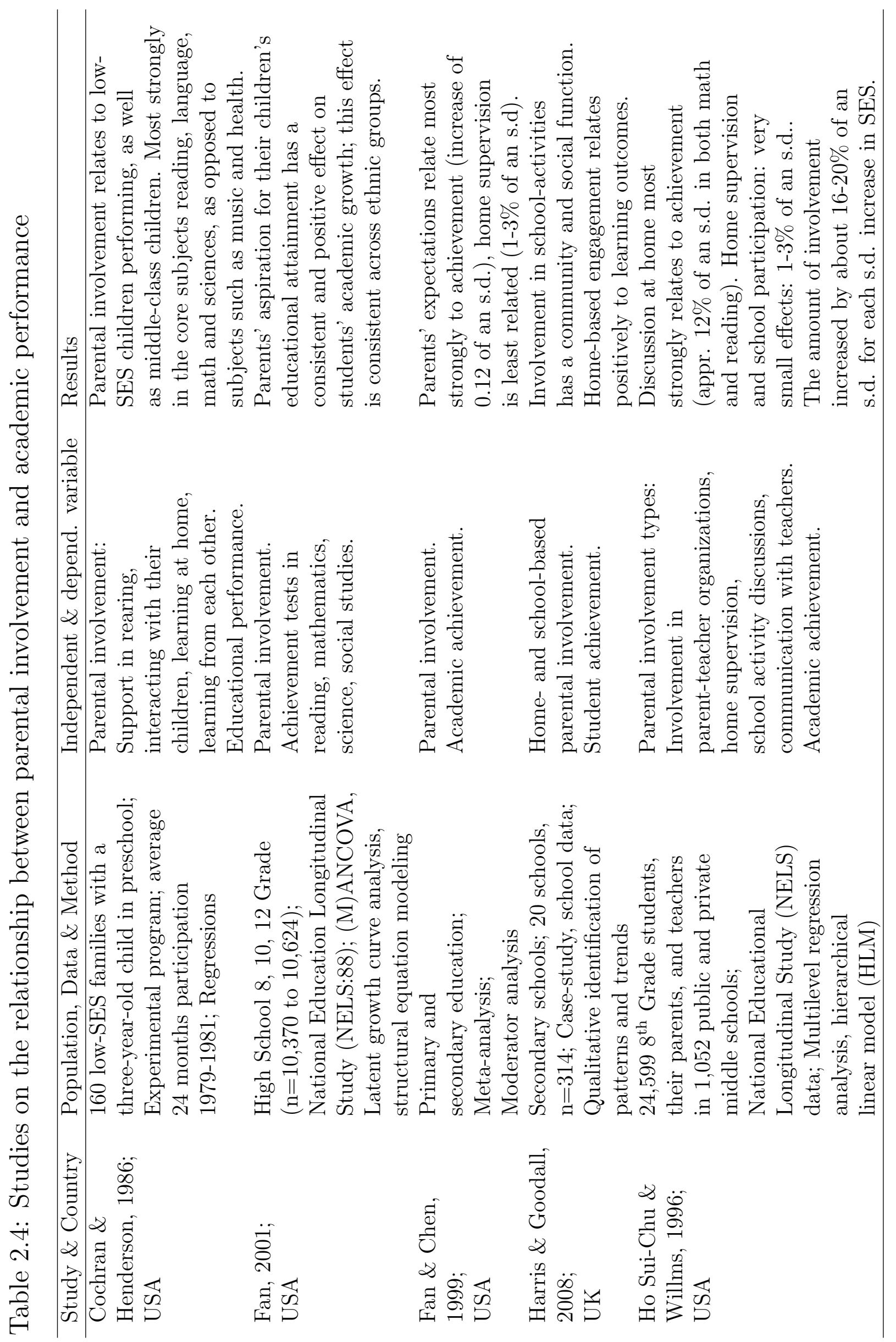




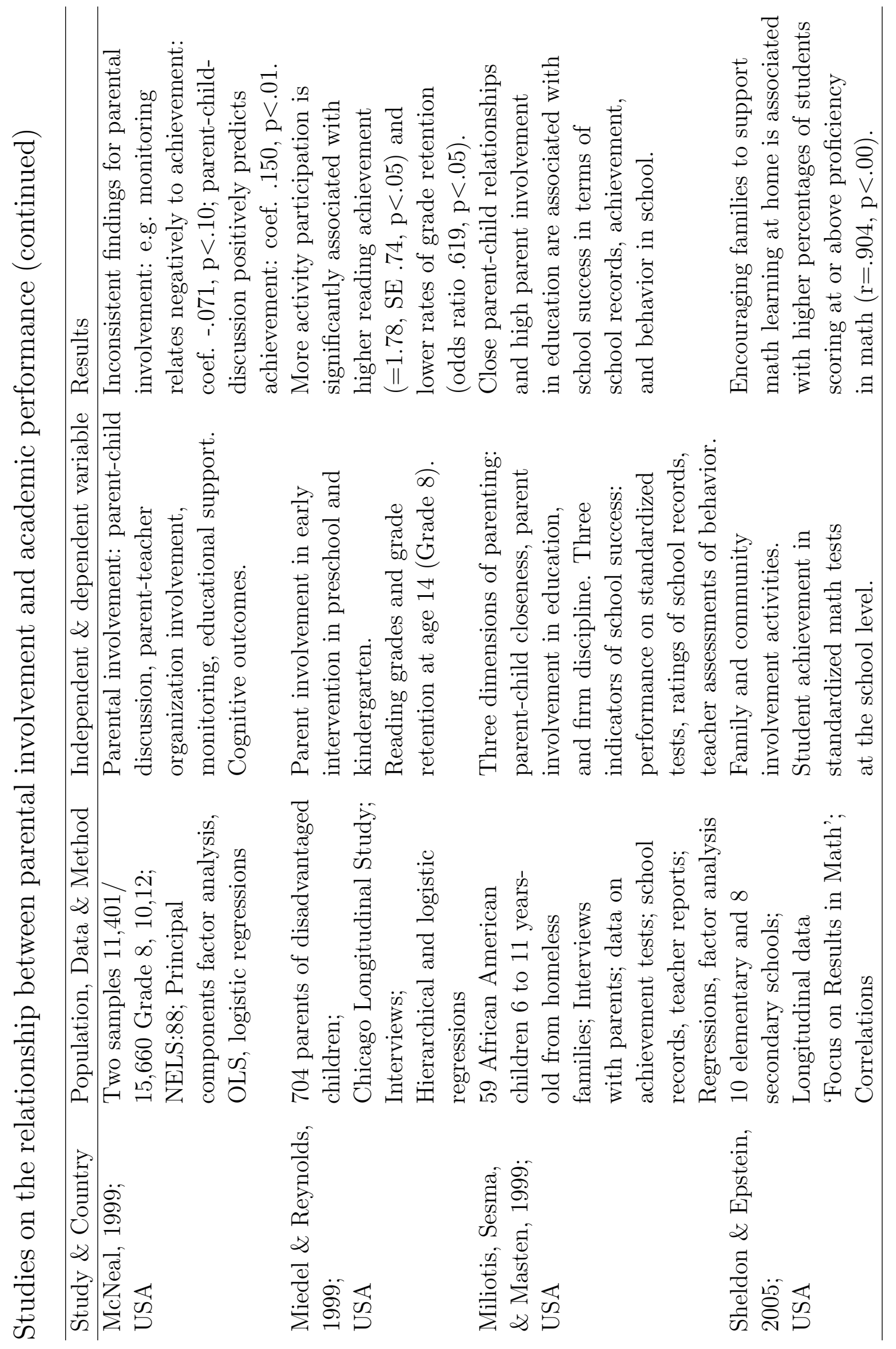




\section{The relationship between parental involvement and dropout}

Students from lower SES families who are a major target group of community schooling run a higher risk of dropout (Rumberger, 1987). However, little is known about how families may influence this (Rumberger, Ghatak, Poulos, Ritter, \& Dornbusch, 1990*). To shed light on this mechanism Rumberger et al. (1990) adopt a matched-pair design to establish similarity in the background characteristics of students, and find that students are significantly more likely to drop out when they come from families in which they have to take decisions on their own, and in which parents are less involved in their education.

Usually, dropout does not suddenly occur, but is a consequence in a longer process. Therefore, research on parental involvement has also analyzed the dropout-predictors 'attendance' and 'feeling attached to the school'. Family-school-community partnerships (as described above) relate to higher student attendance (Epstein \& Sheldon, 2002). Students, moreover, tend to be more involved in school activities, and feel more attached to the school if their parents are more involved in school (Thompson, Iachan, Overpeck, Ross, \& Gross, 2006*). Such a feeling of connectedness is an important predictor of early school dropout. The evidence is sparse, but what there is, consistently points towards a negative relationship between parental involvement and dropout. These findings suggest that community schools can play a mediating role in the dropout prevention process, by more intensely involving and cooperating with parents in addition to other stakeholders. 


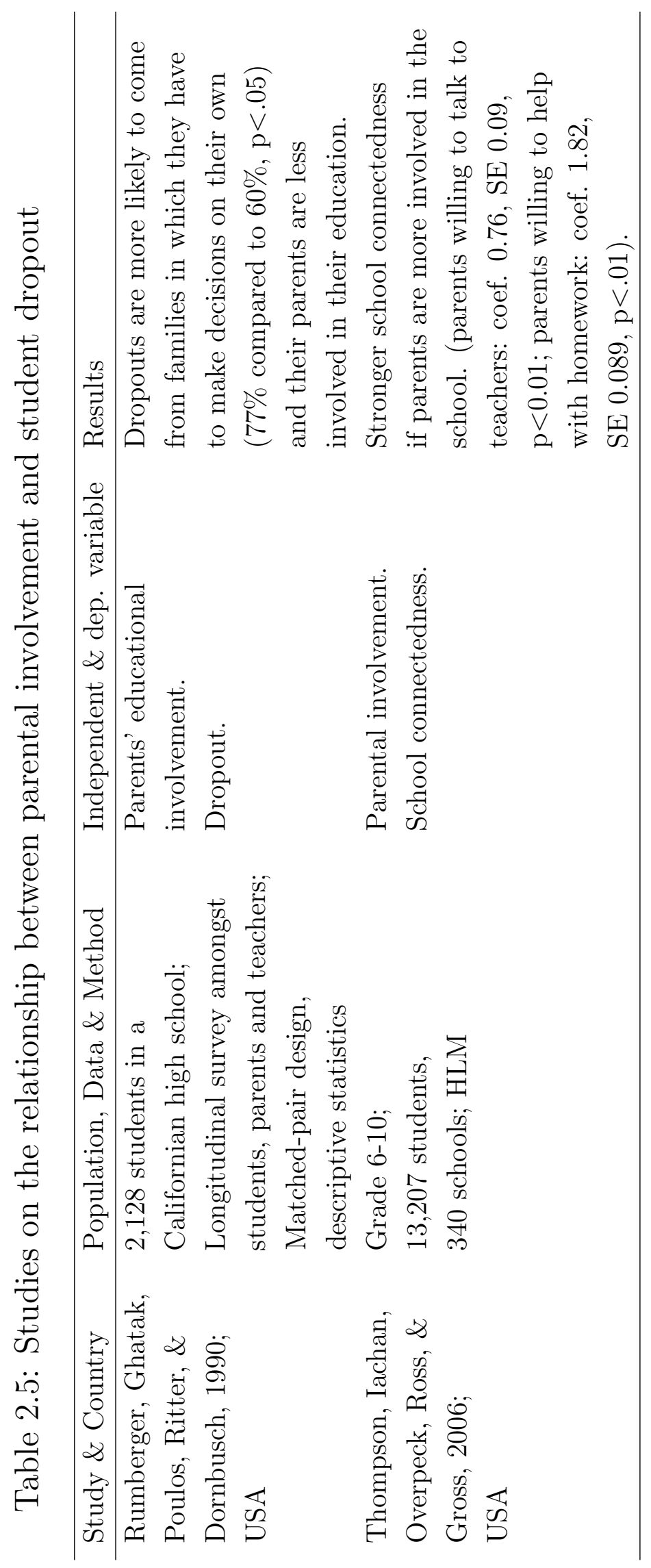




\section{The relationship between parental involvement and risky be- havior}

By initiating more parental involvement than regular schools, community schools are expected to contribute to reducing students' risky behavior. This assumption is based on the knowledge that parents play a critical role in preventing their children from getting involved in unhealthy lifestyles (Nelson, 1989). As Table 2.6 shows, research has mainly considered parental monitoring, defined as the extent to which parents are aware of their children's associations and activities (Bahr, Maughan, Marcos, \& Li, 1998; Dorius, Bahr, Hoffmann, \& Harmon, 2004*; Mounts, 2002). Parental monitoring and family support are protective factors against substance abuse (e.g. Anderson, Sabatelli, \& Kosutic, 2007*; Broman, Reckase, \& Freedman-Doan, 2006*; Coley et al., 2004*; Denton \& Kampfe 1994; Dorius et al., 2004; Mayberry, Espelage, \& Koenig, 2009*; Siebenbruner, Englund, Egeland, \& Hudson, 2006*). Parental monitoring also buffers the relationship between peer drug use and marijuana use (Dorius et al., 2004). It predicts alcohol misuse and buffers the detrimental effect of peer deviance on alcohol misuse (Barnes et al., 2006).

Parents have a similarly critical role with respect to delinquency. Parental monitoring consistently correlates with lower levels of serious delinquent behavior (Coley et al., 2004). It predicts delinquency and buffers the detrimental effect of peer deviance on delinquency (Barnes et al., 2006*). Overall, the above suggests that, by raising parental awareness of what their children do and more involvement in the educational process as such, community schools can contribute to less engagement in the risky behavior of their children. 


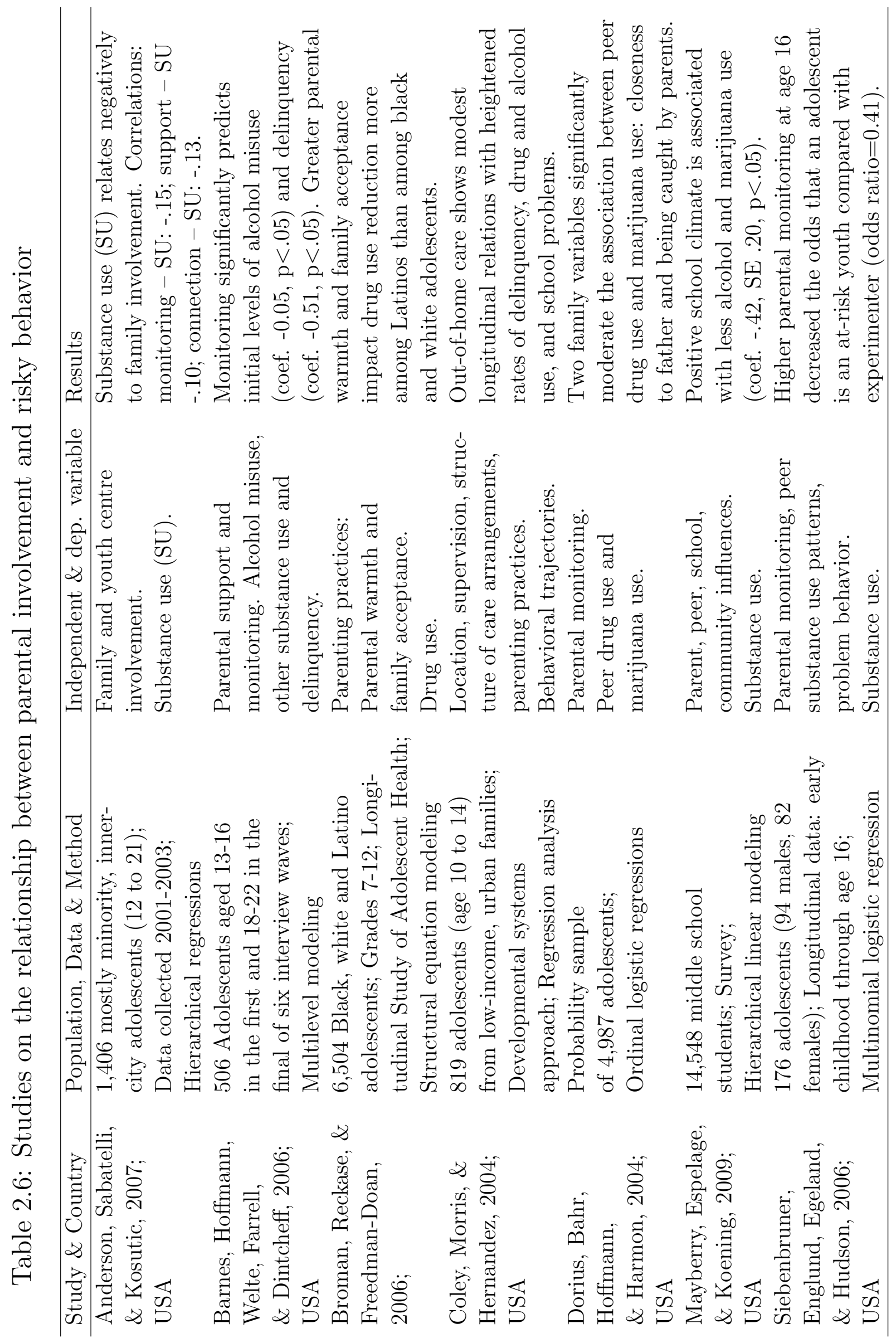


Chapter 2. Community Schools Disaggregated: A Review of the Literature

\section{Conclusion for parental involvement}

Community schools and their comprehensive educational and social approach provide an incentive for parents to engage more in schoolrelated issues, particularly for those who otherwise would not engage. In this sense, community schools link parents to education (Jacobson \& Blank, 2011). Overall, the correlational literature suggests a positive relationship between parental involvement and the outcomes. Based on the reviewed literature Figure 2.2 illustrates the relationship between parental involvement and the community school outcomes. The bidirectional arrows show that the current evidence base is correlational. The literature is positive: parental involvement correlates with higher academic performance and with reduced dropout and risky behavior. The relationship of parental involvement with academic achievement has been researched most extensively, but provides the least consistent, but an overall positive, picture. An important factor may be students' age: namely, the identified associations are more consistent for younger than for middle- and high-school students (Fan, 2001).

While it seems that parental involvement can make an important contribution to the student outcomes, from the literature, it is unclear how schools can alter family dynamics, and it has been suggested that their potential is rather limited in this respect (McNeal, 1999). When considering community schools to be an intervention that promotes parental involvement in schooling, some skepticism regarding the effectiveness of the induced involvement is reasonable. Research on such interventions suggests a less positive picture of the effects of parents' involvement than research on naturally occurring involvement (Pomerantz et al., 2007). 

and the community school outcomes

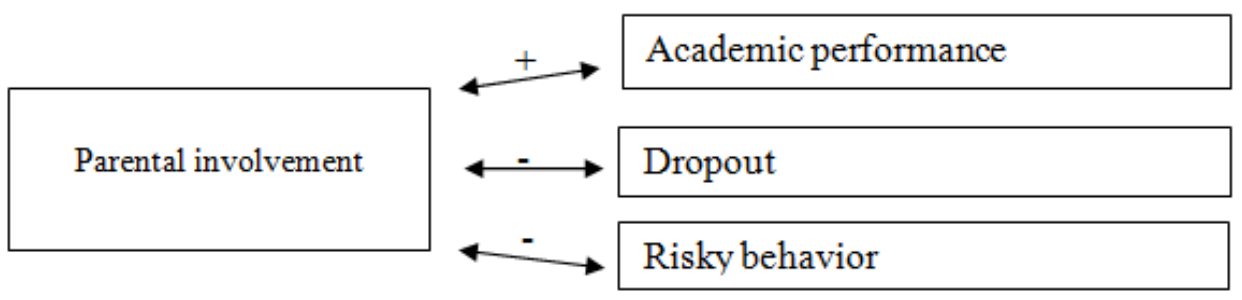

Figure 2.2: The relationship between parental involvement and the community school outcomes

\subsubsection{Results for extracurricular activities}

An important contribution of community schools is the chances they offer to children from lower SES backgrounds, who, for financial or other reasons, often do not have the opportunity to participate in such activities.

\section{The relationship between extracurricular activities and aca- demic performance}

With respect to extracurricular activities, the research on their relationship with academic achievement has received most attention. This is also shown in Table 2.7. Studies on the relationship between extracurricular activities and academic performance are generally correlational, and mainly find positive associations between extracurricular activities and academic achievement (e.g. Broh, 2002*; Clark, 2002*; Jordan \& Nettles, 2000*; Klein \& Bolus, 2002*; Lauer et al., 2006; Vandell, Reisner, \& Pierce, 2007*; Shulruf, Tumen, \& Tolley, 2008*; Zarrett et al., 2009*). For example, Vandell et al. (2007) report significant gains in test scores with effect sizes of .73 of a standard deviation, and improvements in work habits with effect sizes between .31 and .35 
of a standard deviation. Most studies, however, focus on middle- and high-school students. This positive association is confirmed by studies that focus on elementary school-age children (e.g. Covay \& Carbonaro, 2010*; Fletcher, Nickerson, \& Wright, 2003*), where one, for instance, indicates that low-SES students receive a boost in mathematics from participating (Covay \& Carbonaro, 2010).

A nuanced look at different student groups and activities yields interesting but inconsistent findings. Some studies indicate that there are distinct educational benefits of participation in extracurricular activities for at-risk students (Feldman \& Matjasko, 2005; Mahoney \& Cairns, 1997*). It is argued that students with lower SES benefit more from participation in music lessons in terms of reading gains than students with high SES (Dumais, 2006*). Other studies, however, do not find distinct educational benefits from participation (Davalos, Chavez, \& Guardiola, 1999*; Feldman \& Matjasko, 2005; Spreitzer, 1994*). Furthermore, Shulruf et al. (2008) suggest that, while sports activities positively affect literacy, hobby activities negatively affect attitudes towards literacy. Therefore, in terms of extracurricular activities, community schools may not be equally effective for all student groups.

Most studies that examine the effect of extracurricular activities on student performance are correlational, and indicate positive associations. But the mechanism at work behind these associations is not clear (Broh, 2002; Covay \& Carbonaro, 2010). A difficulty in interpreting most studies is that selection is not considered. This is problematic, as for instance, students learn and play differently (Feldman \& Matjasko, 2005). Therefore, research on the effect of extracurricular activity participation on academic achievement in community schools is required. 


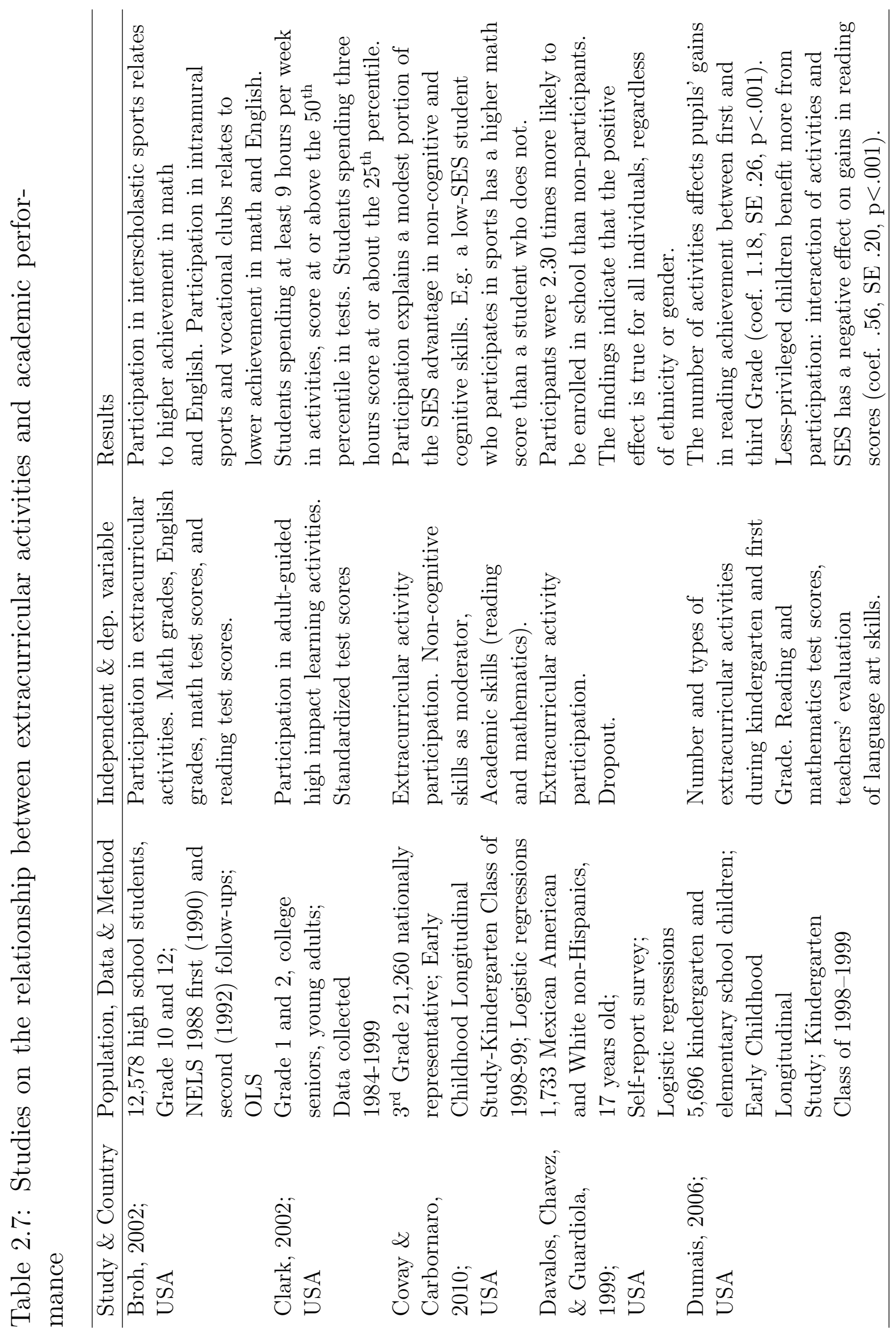




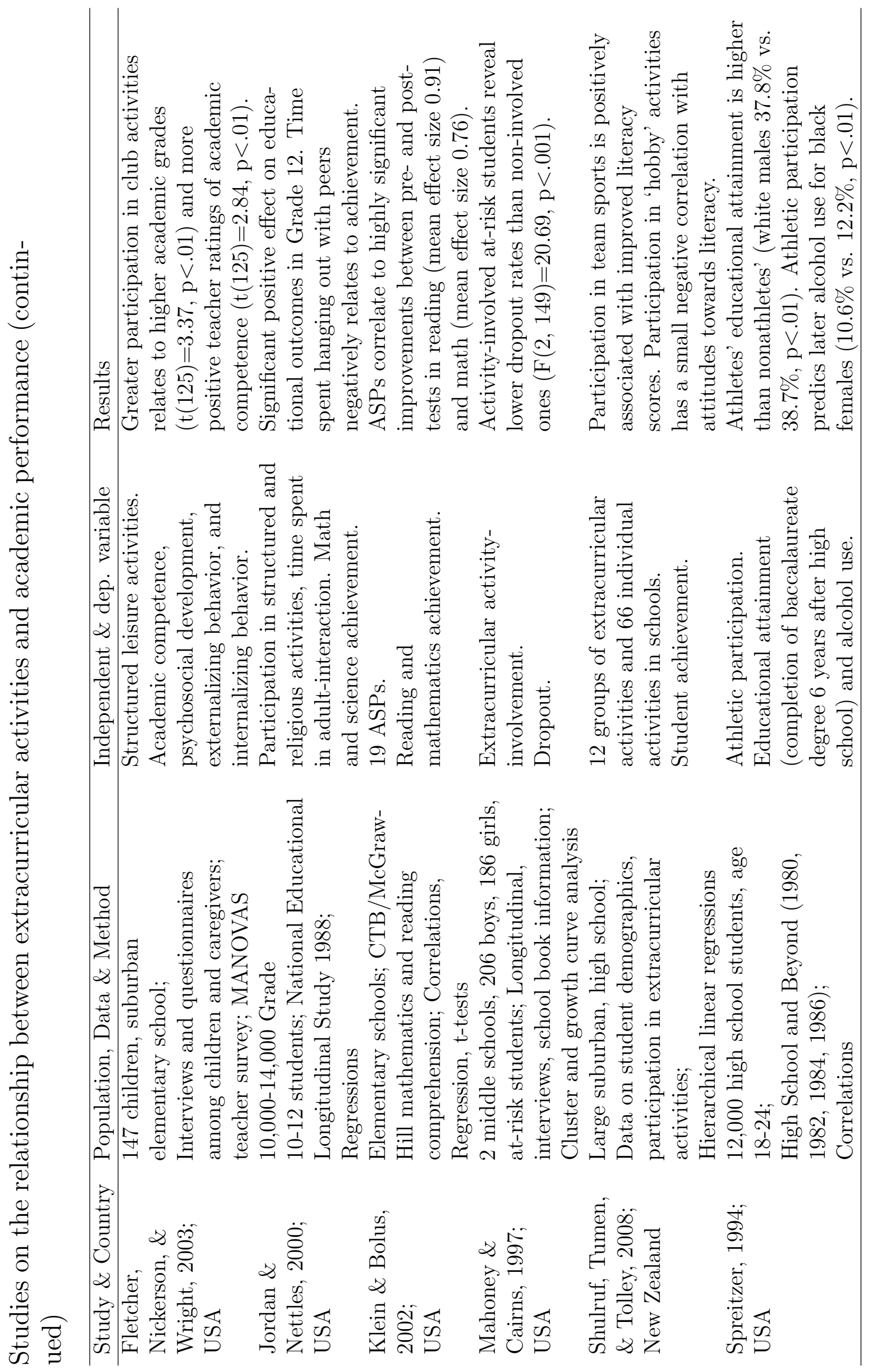




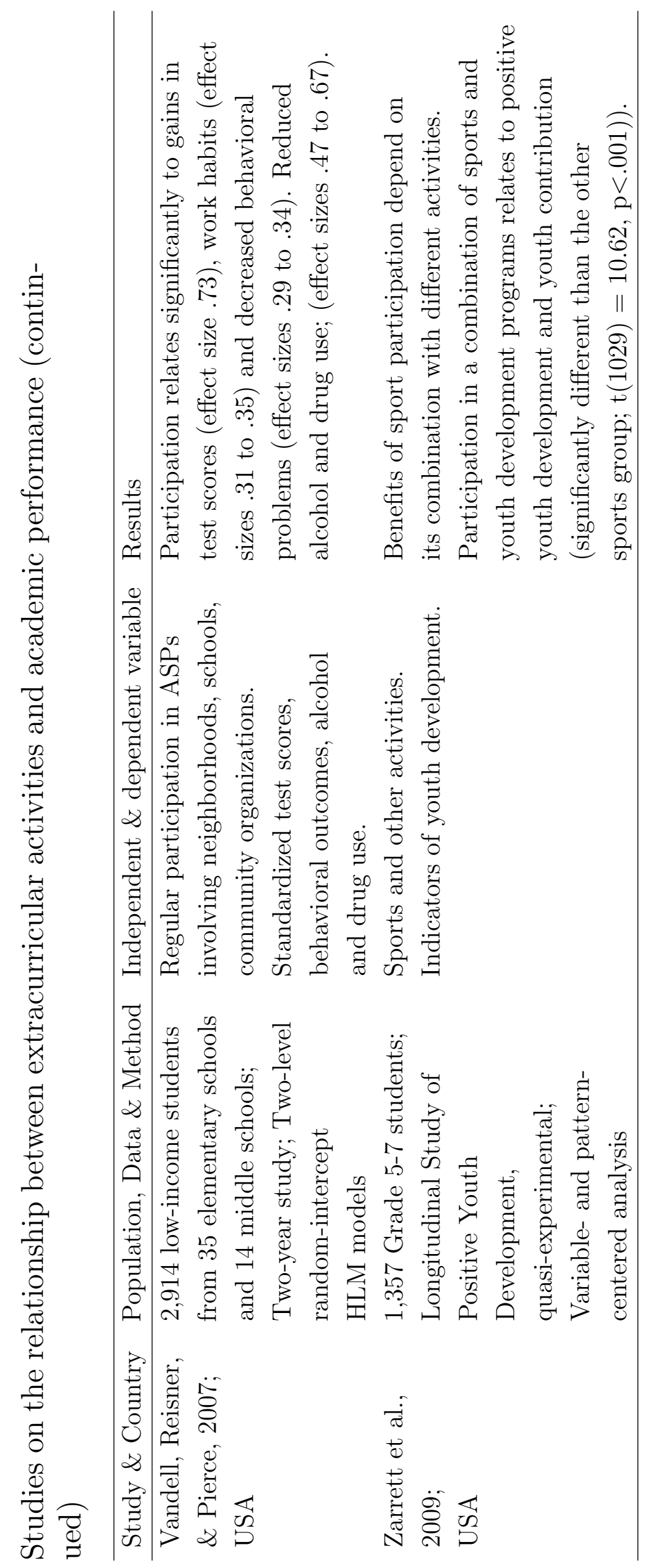


Chapter 2. Community Schools Disaggregated: A Review of the Literature

\section{The relationship between extracurricular activities and dropout}

Another expected positive outcome of community school education is that it may prevent students from dropping out by offering a wide range of extracurricular activities. The evidence on the relationship between extracurricular activities and dropout is based on correlational research, and is rather positive but inconclusive. Research on predictors of dropout points towards positive associations between extracurricular activities and these predictors. Participation in extracurricular activities relates to higher levels of student motivation, engagement, and connectedness, which correlate negatively with student dropout (Archambault et al., 2009*; Cooper, Valentine, Nye, \& Lindsay, 1999*; Eccles \& Barber, 1999*; Eccles, Barber, Stone, \& Hunt, 2003*; Mahoney \& Cairns, 1997; Mahoney, Lord, \& Carryl, 2005*; Thompson et al., 2006).

When considering the relationship between extracurricular activities and dropout, several studies identify an association between participation in extracurricular activities and lower dropout probabilities (Mahoney \& Cairns, 1997; Mahoney, 2000*; McNeal, 1995*). For example, McNeal (1995) finds that participants in athletics are 1.7 times less likely to drop out than non participants, and participants in fine arts activities are 1.2 times less like to drop out, while he does not find an effect of academic or vocational clubs. Research on community schools has to examine which activities can benefit children attending community schools the most, in terms of reduced dropout probabilities.

Some authors argue that the positive association between extracurricular activities and reduced dropout is not driven by the activity it- 
self, but by the engagement with the school through social networks (Mahoney, 2000), and hypothesize that, for instance, sports participation relates to a stronger identification with the school (Alspaugh, 1998). Others argue that the explanation for this positive association may be that the extracurricular activities prevent children from spending time on less-beneficial activities (Blum, Beuhring, \& Rinehart, 2000). For instance, Jordan and Nettles (2000) find that hanging out with peers is consistently and negatively associated with average achievement in mathematics and science in Grade 12, and it is a more important predictor for school failure than income, race, and family structure. 


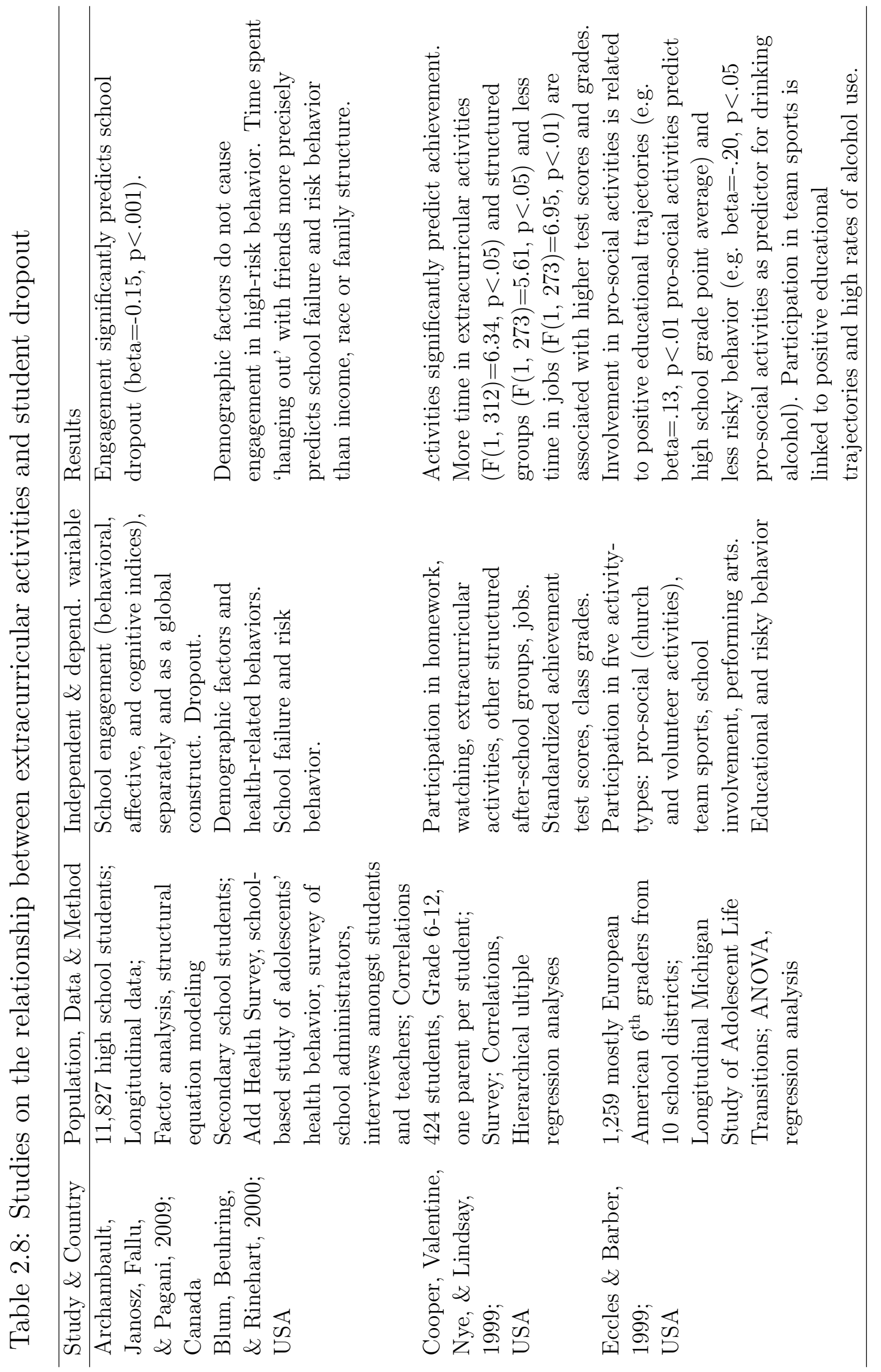




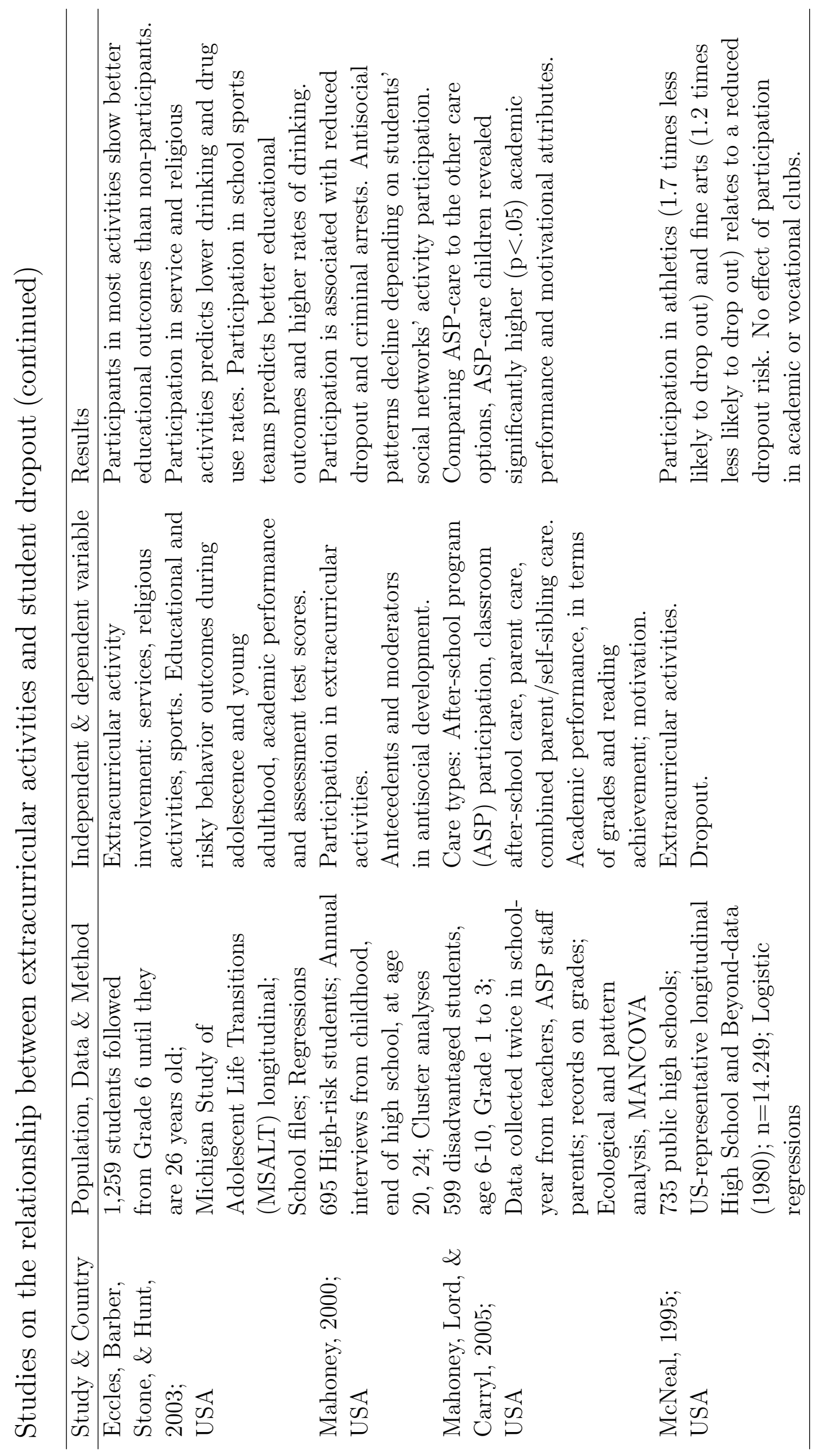




\section{The relationship between extracurricular activities and risky behavior}

Extracurricular activities keep adolescents occupied and active, and time spent in these activities cannot be spent on risk-taking activities (Blum et al., 2000; Little et al., 2008). Considering that community schools usually offer before- and after-school care, the latter may count even more for them than for regular schools. This is beneficial because, again, hanging out with peers better predicts adolescents' risky behavior (in terms of, amongst other things, drug use and criminal involvement) than income, race, or family structure (Blank et al., 2003; Blum et al., 2000). For example, children from lower SES backgrounds who tend to participate more often in extracurricular activities that involve residents, schools, and community organizations are less likely to use drugs (Vandell et al., 2007). More studies have identified an association between participation in extracurricular activities and lower rates of substance use, some even into young adulthood (e.g. Blum et al., 2000; Eccles \& Barber, 1999; Feldman \& Matjasko, 2005; Little et al., 2008; Perry-Burney \& Takyi, 2002*). If sports are distinguished from other activities, their association with respect to drug use shows mixed results (Feldman \& Matjasko, 2005). Some assume that participation in sports is associated with a lower probability of drug and alcohol use (Perry-Burney \& Takyi, 2002). Other studies find an association with more alcohol use (Eccles \& Barber, 1999; Eccles et al., 2003; Hoffmann, 2006*). Yet, a less frequent use of drugs such as marijuana and cocaine is found (Eccles \& Barber, 1999; McHale et al., $\left.2005^{*}\right)$. Finally, the associations are not identical for all students. For example, Hoffmann (2006) finds a positive association between athletic 
involvement and alcohol consumption that is stronger among females in schools with lower SES students and among males in schools with higher SES students. Overall, a clear picture with respect to substance use has not yet emerged: the mixed results may be due to unidentified mediators and moderators, such as gender. Moreover, mostly small, non-representative samples are used (Feldman \& Matjasko, 2005).

Another rationale is that participation in extracurricular activities is associated with less criminal involvement, as these activities are prosocial (Feldman \& Matjasko, 2005). Confirming this assumption, extracurricular activity-participation has been found to be associated with a lower incidence of juvenile crime (Blum et al., 2000; Goldschmidt, Huang, \& Chinen, 2007**; Mahoney, 2000) and fewer criminal arrests (Mahoney, 2000). The study of Goldschmidt et al. (2007) is quasi-experimental, and, therefore, suggests a causal negative effect of participation on delinquency. The researchers have carried out a cost-benefit analysis, and find for their program average savings of $\$ 2.50$ per $\$ 1$ invested. Participation in highly structured activities (bands, orchestras, choirs, plays, and musicals) relates to lower levels of delinquency (Agnew \& Petersen, 1989*; Mahoney, 2000; Mahoney \& Stattin, 2000*). Involvement in sports is associated with a higher risk of delinquency (Landers \& Landers, 1978*). The research context may account for the different findings (Hoffmann \& Xu, 2002*).

Leisure activities with peers relate negatively to delinquency (Agnew \& Petersen, 1989), and it is argued that the benefits of activities with respect to engaging in risky behaviors depend on the attitudes of the other participants; thus, depending on the group, participation may be detrimental, regardless of the activity (Mahoney, 2000; Mahoney \& Stattin, 2000). 


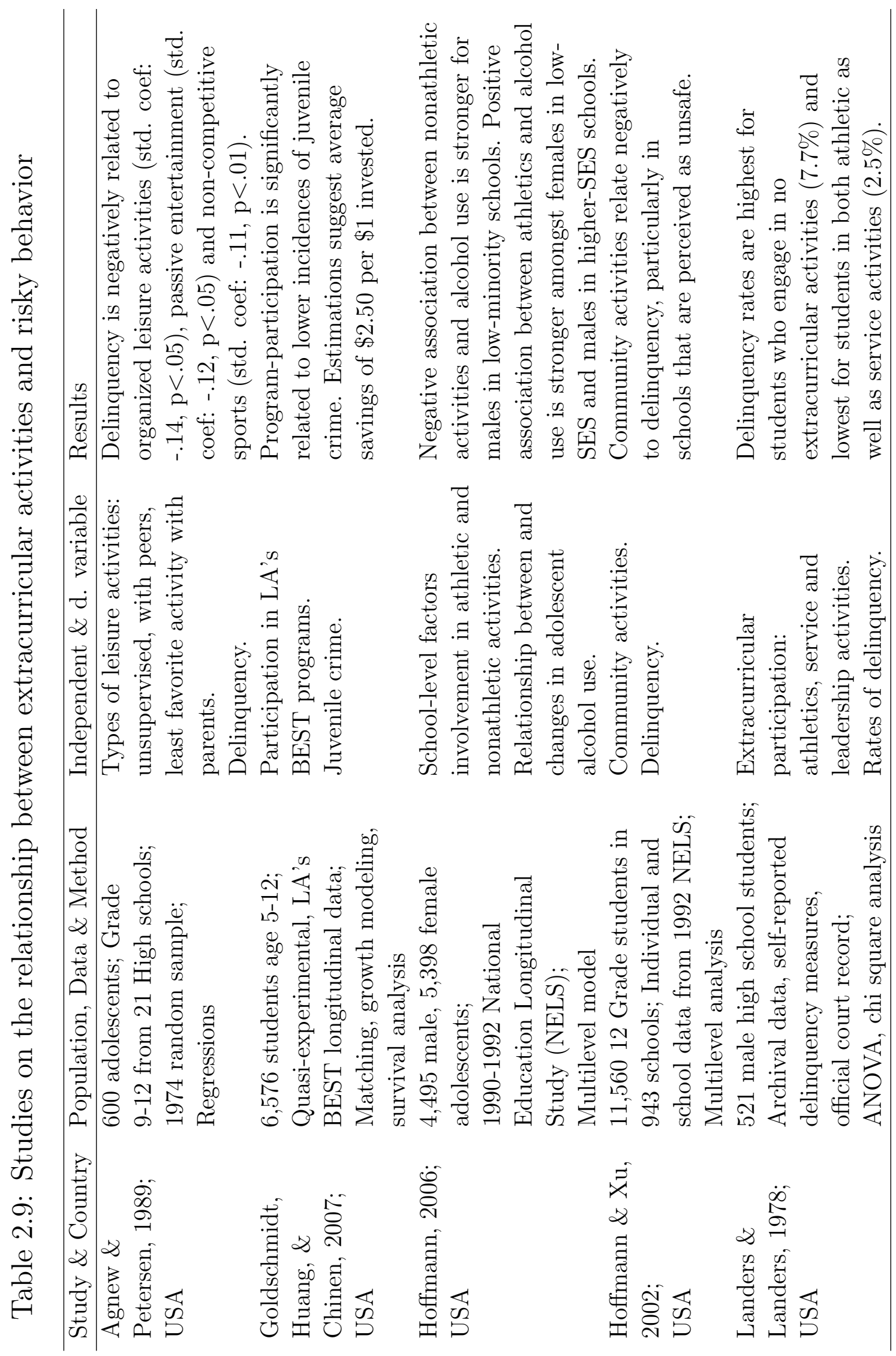




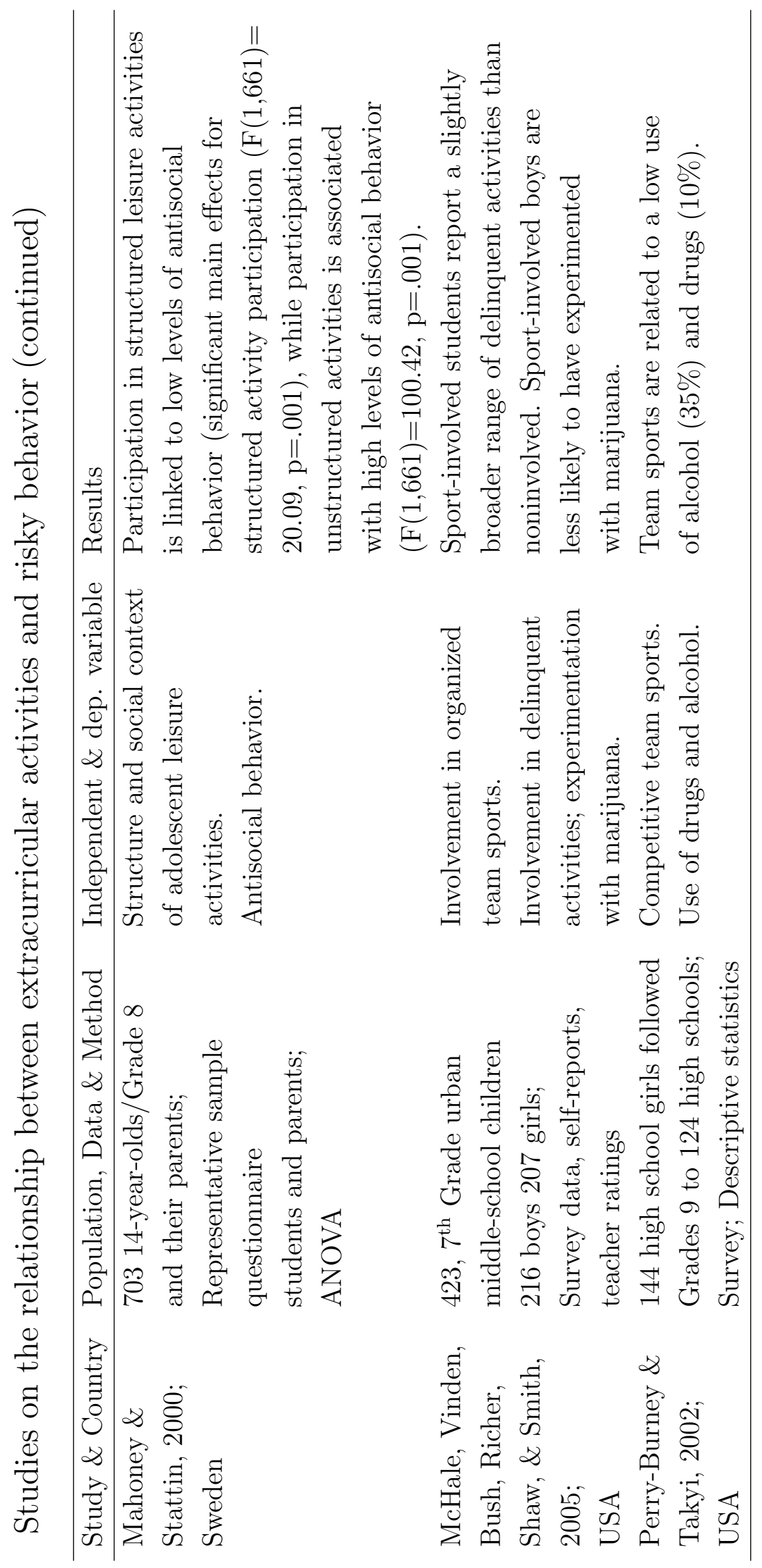




\section{Conclusion from extracurricular activities}

Figure 2.3 illustrates the major findings from the literature on the relationship between extracurricular activities and the student outcomes. Just as for the other two components (cooperation with external institutions and parental involvement), the literature is rather positive on these relationships and points towards a positive relationship between participation in extracurricular activities and negative ones with dropout and risky behavior. The study of Goldschmidt et al. (2007) on risky behavior is causal; however, for drug use, causal literature is not available, therefore a two-directional arrow is shown for risky behavior.

There are some inconsistencies in the literature, however. Research on the effects of extracurricular activities is complex, as they are diverse in composition and realization. Causal effects are hardly ever identified (Mahoney, 2000; Shulruf et al., 2008). This is because of methodological and endogeneity problems. Nevertheless, it is considered a major contribution of community schools that they create access to such activities.

From the above it can also be concluded that with respect to community schools, studies that differentiate between activities, contexts, and different populations are needed (Broh, 2002; Feldman \& Matjasko, 2005; Guest \& Schneider, 2003). Most studies consider the group of participants as a whole, regardless of gender or race. Moreover, extracurricular activities take place in different contexts, and are "nested in schools and neighborhoods and are functions of the resources of those contexts" (Feldman \& Matjasko, 2005, p. 195). 
2.5. Discussion and conclusion

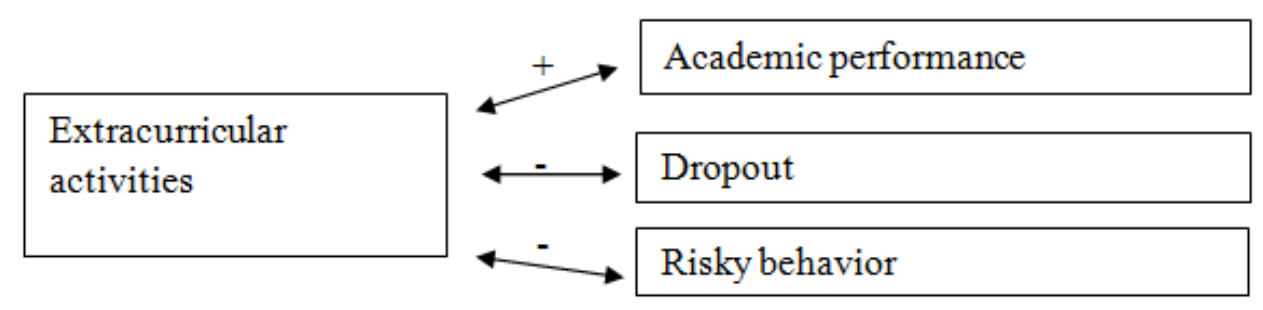

Figure 2.3: The relationship between extracurricular activities and the community school outcomes

\subsection{Discussion and conclusion}

\subsubsection{Do community schools achieve their goals?}

This chapter has provided a review of the relationship between community school activities and their outcomes. It yields insights into the contribution that community schools can make to children, adolescents and their families, and thereby constitutes an important starting point for the subsequent empirical chapters of this dissertation.

In the subsequent paragraphs conclusions are derived on whether community schools influence the three outcomes, academic achievement, dropout, and risky behavior, by the activities they undertake. These activities are: cooperation with external organizations; parental involvement; and offering extracurricular activities.

Figure 2.4 summarizes the findings of the literature presented in this chapter, on whether the community school activities influence the three outcomes. It combines Figures 2.1, 2.2 and 2.3 that have been developed throughout the review. On the left-hand side, it shows the three activities, and, on the right-hand side the outcomes. As above, for each activity an arrow illustrates the direction of the relation identi- 
Chapter 2. Community Schools Disaggregated: A Review of the Literature

fied by the literature. Bi-directional arrows indicate that the literature is correlational, and uni-directional arrows indicate causal evidence. A + , or - indicate, respectively, a positive or negative association/effect.
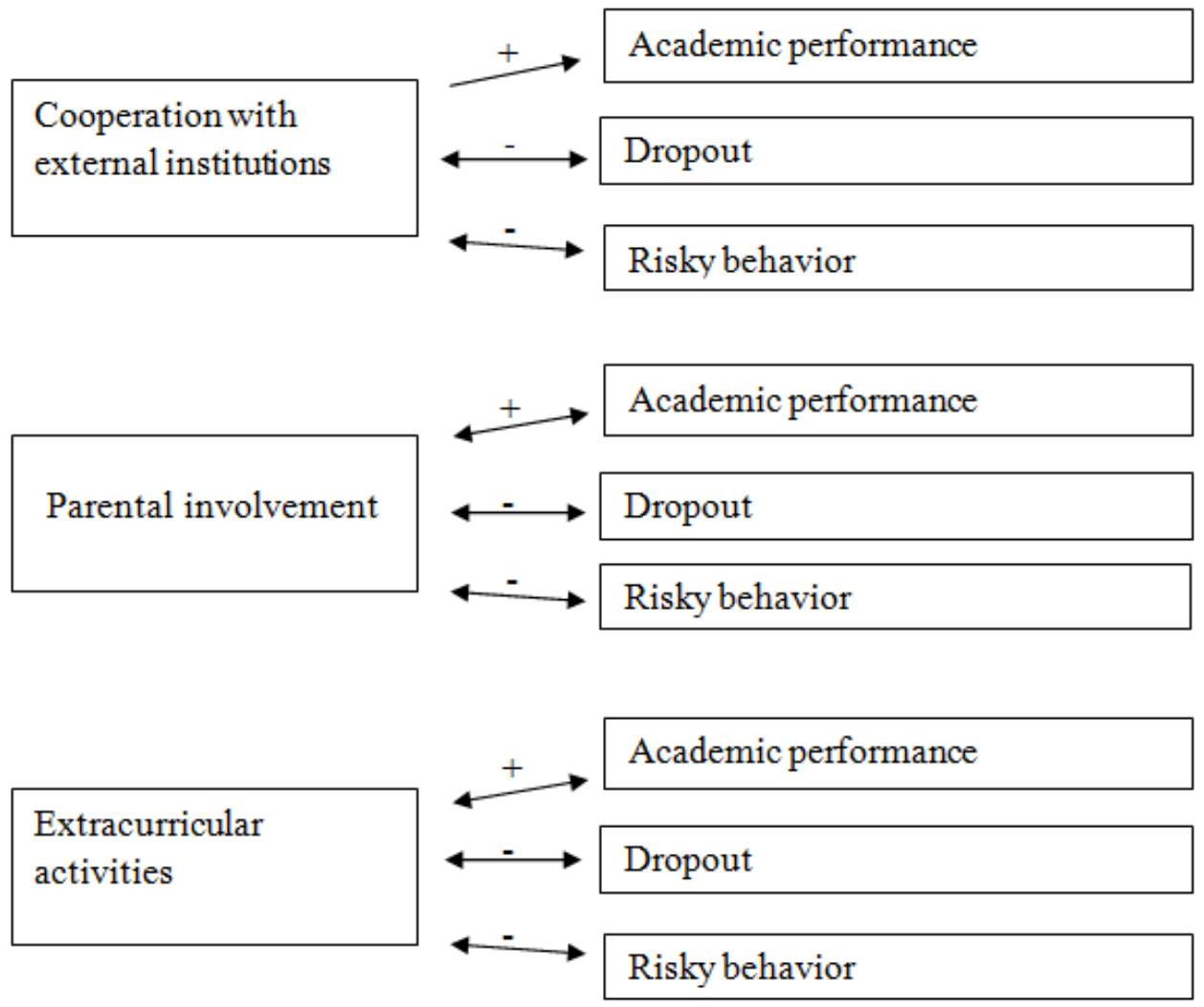

Figure 2.4: Evidence from the literature on the effects of the major community school activities on the defined community school outcomes

The large number of bi-directional arrows shows that most relationships are correlational. The study on the Harlem Children's Zone provides causal evidence; therefore, a one-sided arrow is shown for the relationship between cooperation and academic achievement. Parental involvement and participation in extracurricular activities 
2.5. Discussion and conclusion

correlate mostly positively with academic achievement. The literature further indicates that extracurricular activities correlate with reduced dropout and risky behavior. With respect to risky behavior, the quasi-experimental study of Goldschmidt et al. (2007) provides causal evidence for a reduction of delinquency based on activity participation. As, for drug use, such causal studies are not available, the figure includes a bi-directional arrow. Cooperation with external institutions and parental involvement correlates negatively with dropout and risky behavior, suggesting that students benefit from these activities. Overall, the correlational nature of the evidence may not point at effective community school activities, but instead represent a reversed causality, and other (unobserved) factors may simultaneously influence the outcome variables and the presence of the community school activities.

Given the evidence base, it is difficult to draw overarching conclusions about the effects of the community school activities. More solid evidence on causal relations is needed to be able to conclude that the activities affect the outcome variables.

\subsubsection{The contribution of community schools}

The literature indicates that the presence of extracurricular activities and parental involvement are better predictors of student achievement than parental income or education (Blum et al., 2000; Henderson \& Berla, 1994). This may point to the fact that community schools succeed in counteracting disadvantages for children from low SES backgrounds. This is supported by the literature which points towards heterogeneous effects, and which shows that not everyone is equally affected. The community school may, therefore, be particularly promis- 
ing for at-risk students, who have learning problems (Cummings et al., 2007).

Moreover, the literature indicates that it may be difficult for community schools to get parents actively involved (for example, due to language problems), and to establish a sustainable relationship with external institutions (owing to different views about responsibilities, education, and child development). If community schools are more capable of addressing these problems, then it could be that community schools will become more effective in pursuing their goals. Additionally, community schools provide early, comprehensive, and continuous support by establishing an environment for children that stimulates their positive development from a young age onwards.

From the above, it can be concluded that a major contribution of community schools is that they create access to services and experiences that otherwise tend to be withheld from their pupils. Fries et al. (2012) argue that the traditional model of referring potential clients to an agency somewhere else in the community functions as a liability for students that they are sometimes unable to overcome, and advocate schools as an entry point for services such as mental health and child welfare. Research indicates that, if activities are offered, then students will use them (Stearns \& Glennie, 2010).

Moreover, a particular strength of the community school is the potentially reinforcing interactions of its major activities. For example, Feldman and Matjasko (2005) find in their review that connections between variables such as parents and involvement in extracurricular activities foster development. Parents are also important regarding selection into activities, as their involvement in community activities is a strong predictor of adolescents' own involvement in school- 
2.5. Discussion and conclusion

or community-based extracurricular activities (Feldman \& Matjasko, 2005). Moreover, if parents are involved more in both the school and the community this can positively affect students' school achievement (Nettles, 1991). Simultaneously, it is suggested that parental support is not sufficient in these settings to ensure that their children will maintain a positive attitude towards school (Anderson et al., 2007).

So far in this chapter, it has not been mentioned that the discussed community school outcomes are interrelated and that, as a consequence, in reality it may not always be straightforward to consider the outcomes independently from one another. Several studies refer to the simultaneous occurrence of drug use and delinquency (Barnes et al., 2006; Coley et al., 2004). Moreover, dropout is motivated by academic failure, problematic behavior (e.g. school violence), and substanceabuse problems (Fries et al., 2012), and problematic behavior and substance use are predictors for dropout (Hart, O'Toole, Price-Sharps, \& Shaffer, 2007). Therefore, the outcomes considered in the review are likely to be correlated. In this chapter, they have been considered independently as the objective was to shed light on how the three most common community school activities affect the community school outcomes (as identified in Section 2.1). This also illustrates the complexity of measuring relationships of dependent and independent variables in the context of community schools.

Another issue that requires discussion is that the results presented above are based on different and varying contexts. The above, and in particular the tables, show that results based on a variety of data are considered, most of them are based on US-samples. Furthermore, the studies draw on different populations, which, for example, face different poverty levels. As a consequence, the results cannot straightforwardly 
Chapter 2. Community Schools Disaggregated: A Review of the Literature

be translated into the Dutch context. In the remainder of the dissertation it will be explored if and to what extent Dutch community schools perform according to the expectations raised by the reviewed literature. In Chapter 6, the results from the empirical chapters will be put into the context of this review.

\subsubsection{Further exploring the effectiveness of com- munity schools}

The above analysis has provided a thorough overview on what, based on the literature, community schools may be able to achieve by the three major activities they undertake. Evidence focusing specifically on community schools is lacking, however. Therefore, the following chapters in this dissertation empirically evaluate how community schools impact students' cognitive and social-emotional outcomes in terms of duration, subsidies invested, and their multiple activities. Community schools in both primary (Chapters 3 and 4) and in secondary education (Chapter 5) are considered. Thereby, the subsequent chapters contribute considerably to the current evidence base on community school effectiveness. 


\section{Chapter 3}

\section{The Contribution of}

\section{Community Schooling}

to Children's

\section{Educational Progress in}

Primary Education

\subsection{Introduction}

Chapters 1 and 2 have shown that community schools are believed to favour pupils' educational progress in terms of both cognitive and noncognitive skills. For example, it is believed that, because of the more attractive learning environment, pupils are more motivated and, therefore, perform better. Another assumption is that closer communication between the school and parents favors the educational development of 
Chapter 3. The Contribution of Community Schooling to Children's Educational Progress in Primary Education

pupils. However, as outlined in the previous chapter, empirical evidence on the contribution of community school activities to children's educational progress is lacking. Therefore, this chapter provides an empirical analysis of the contribution of community schools to children's educational progress. In this, as well as in the subsequent chapter, the focus is on community schools in primary education.

As is common in the Netherlands, the community schools that are evaluated in this chapter receive additional resources to implement their activities, in the form of subsidies allocated by their municipality. Earlier research has shown that school resources can indeed play an important role with respect to improving educational attainment (Gibbons, McNally, \& Viarengo, 2012). However, research on the effects of increasing school expenditures is not clear about its impact on learning outcomes.

This chapter evaluates the impact of community school attendance on several indicators of educational progress in a Dutch town, namely Schiedam. Moreover, it compares various types of community school activities, in order to evaluate their relative efficiency, and elucidates on the mechanisms driving the results of community schooling. In broader terms, this chapter evaluates the impact of additional resources allocated to schools, and sheds light on the usefulness of topping up subsidies in general, and earmarking the recipients of the subsidies as community schools in particular. This is the first evaluation of the effects of community school education in primary education, as well as of the allocation of a higher subsidy to education in community schools. It is also the first evidence-based evaluation of activities of primary community schools and their impact on educational progress in the Netherlands. In this chapter, pupils' educational progress is di- 
3.2. Community school subsidy and setting

vided into cognitive and social-emotional outcomes, and the effect of attending a community school on these outcomes is evaluated. In particular, the effect of the duration of community school attendance, the community school subsidy, and the frequency of the community school activity offer is analyzed. As such, the findings are critical for further policymaking on community schools, particularly with respect to the allocation of community school subsidies. The findings are also useful beyond the context of community schools, and apply to policymaking on school funding in general.

The remainder of this chapter proceeds as follows. Section 2 explains community schooling in Schiedam, the town on which this chapter focuses. Section 3 describes the data. Section 4 elaborates on the identification strategy. Section 5 presents the results. Section 6 discusses the findings and concludes.

\subsection{Community school subsidy and set- ting}

In this chapter, the focus is on community schools in the Dutch town of Schiedam. Currently, Schiedam has a population of approximately 76,000 inhabitants. The Municipality of Schiedam has decided to generalize community schooling in primary education, so that all primary schools are transformed into community schools. Therefore, community school subsidies are provided by the municipality of Schiedam. Hence, in Schiedam, community schools are defined as those which receive a community school subsidy. The first community schools were introduced in the school year 2000/2001 (hereafter referred to as 2000, 
Chapter 3. The Contribution of Community Schooling to Children's Educational Progress in Primary Education

the same applies to the other school years), when those schools with the most low-performing pupils became community schools first.

With this strategy, Schiedam became a frontrunner in terms of community school development in Dutch primary education: approximately 16 percent of all Dutch primary schools were community schools in 2010 (Oberon, 2010; Van der Veen, 2011), whereas by 201215 of the 24 primary schools (63 percent) in Schiedam had received a community school subsidy.

\subsubsection{The community school subsidy allocation and activities}

Since the introduction of the subsidy, the Municipality of Schiedam has stimulated the development of community schools by allocating to them an additional subsidy. This chapter focuses on the period between 2000 and 2010. During this period the total amount of the subsidy rose from approximately $€ 85,000$ in 2000 to $€ 513,024$ in 2010. After this period the municipality has continued to provide subsidies, but the amounts are slightly lower than those in 2010. In addition to the increase in the total amount spent, the amount per pupil almost tripled (from $€ 57$ to $€ 155$ ). Hence, the expansion of community schooling in Schiedam during the last decade coincided with a considerable intensification in monetary terms. The subsidy is provided as a lump sum at the beginning of the school year. 
3.2. Community school subsidy and setting

\section{Community school activities}

As outlined in Chapters 1 and 2, community schools are not a single intervention, but combine different educational and pedagogic activities. This is also reflected in the way the subsidy in Schiedam is allocated. Schools are asked to report on the use of the subsidy in specific activities, which are grouped into the six categories of the commonly-used RISBO-typology, illustrated in Figure 3.1 (Kruiter, Kooij, Klein, Kieft, \& Steerneman, 2009).

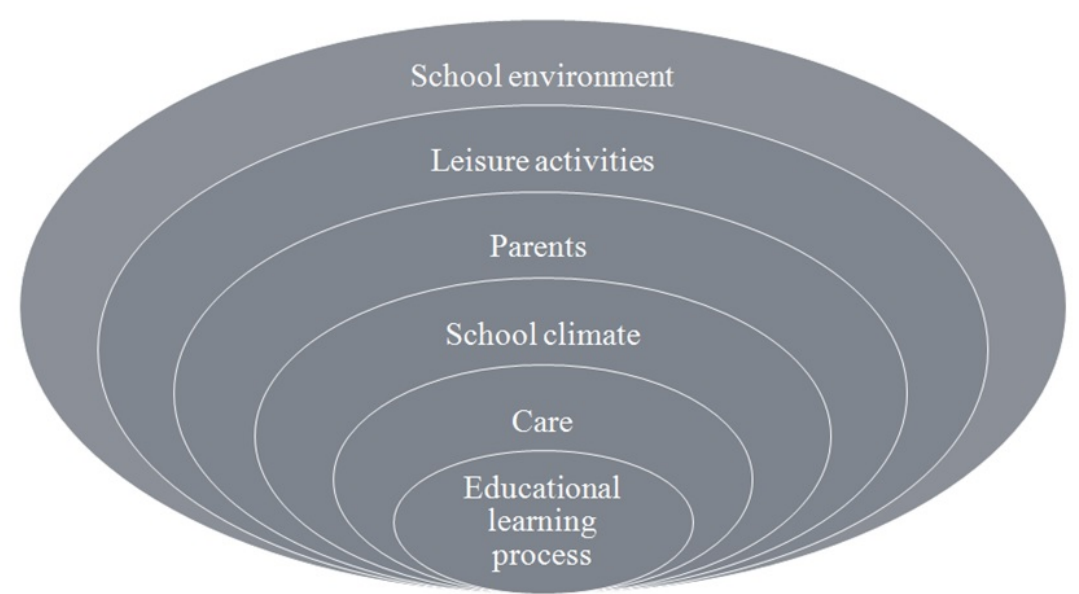

Figure 3.1: The six community school activities from the RISBO-model

In the RISBO-approach, the educational learning process (ELP) represents the centre and is surrounded by the other community school activities: care, school climate, parents, cultural activities, and the school environment. The basic assumption is that the closer an activity is to the centre, the educational learning process, the more beneficial it is to children in terms of improved educational outcomes. In this sense, one may assume a hierarchy among the community school activities. 
Chapter 3. The Contribution of Community Schooling to Children's Educational Progress in Primary Education

Examples of the activities may clarify the meaning of the categories. 'Educational learning process' activities include additional activities on reading and mathematics, such as remedial teaching. 'Care' offers, for instance, school-social work and speech therapy. The activity 'school climate' includes, amongst other things, assertiveness training and citizenship activities. Activities for 'parents' aim at actively involving them, for instance, by offering meetings, involving them in reading projects, and offering language and educational courses. In the context of 'cultural activities', pupils are offered extracurricular activities in arts, culture, and music. Activities focusing on the 'school environment' encourage contact with the neighbourhood, e.g. in terms of cooperation with the community centre. Another example of a school environment activity is that residents redecorate the schoolyard and establish a more pleasant and safer school environment (Kruiter et al., 2009). By allocating different shares of the subsidy to the activities in each school year, each school puts a different emphasis on their specific community school education. These activities are not substituting any regular teaching hours, and are offered in addition to the regular curriculum.

A factor analysis of the subsidy allocation for the different activities over time reveals surprisingly few patterns across schools. Over the years, schools cannot be typified by categories of activities. Schools do not seem to specialize in particular fields of community schooling. ${ }^{1}$

From the total picture, however, it is clear that the most pupiloriented category of activities, the educational learning process, attracts a large part of the subsidy (e.g. 36 percent in the school year 2007). Figure 3.2 illustrates this general finding for the school year

${ }^{1}$ The results of the factor analysis can be obtained from the researcher. 
2007. Moreover, cultural activities receive relatively much. Activities to improve the school climate and the school environment receive least.

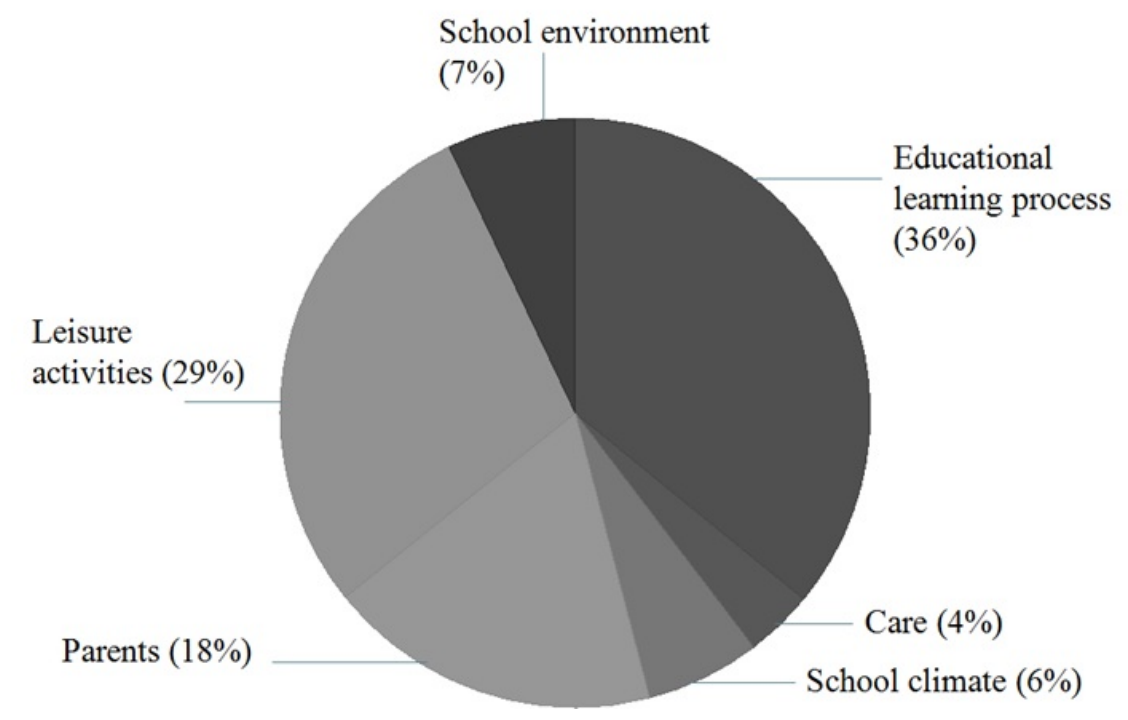

Figure 3.2: Subsidy allocation over the six community school activities in the school year $2007 / 2008$

\section{Community school subsidy put in perspective}

To have a better idea of how meaningful the subsidy is for schools, it is put in the perspective of the general subsidy that primary schools receive as a government grant. Table 3.1 shows the percentage of the government grant to which the subsidy corresponds. The percentages are shown on a school board level, of which there are four in Schiedam. 
Chapter 3. The Contribution of Community Schooling to Children's Educational Progress in Primary Education

Table 3.1: Community school subsidy as a percentage of the general government grant by year and school board

\begin{tabular}{lcccc}
\hline School board & 2007 & 2008 & 2009 & 2010 \\
\hline 1 & 2.29 & 1.59 & 3.88 & 3.59 \\
2 & .84 & .70 & .68 & .49 \\
3 & 1.43 & 1.06 & 1.10 & 1.41 \\
4 & 1.13 & 1.57 & 1.80 & 1.45 \\
Town level & 1.48 & 1.63 & 1.94 & 1.56 \\
\hline Own calculations based on DUO (2012) \\
and information from the Municipality \\
of Schiedam.
\end{tabular}

Table 3.1 clarifies that, in relation to the total resources of the school the community school subsidy is rather small. Moreover, there is considerable variation over the school boards, and some variation over time within the school boards (Dienst Uitvoering Onderwijs, 2012, DUO).

It is also interesting to see what the spending alternatives are for schools. An important indicator of these alternatives is the number of teacher full-time employees (FTEs) that schools could employ for the same money. With an approximate monthly cost of $€ 5,786$ (average for an FTE teacher in primary education), Table 3.2 shows that the money invested in community school subsidies corresponds to a considerable number of teacher FTEs (Ministerie van Onderwijs, Cultuur en Wetenschap, 2013b). Again, this is shown at the school board level. For example, in 2009, the community school expenditures correspond to almost nine additional teacher FTEs for an entire year. The latter perspective reiterates that it is critical for the municipality to evaluate whether the subsidy allocated to community schools is indeed effective. If not, alternative policy measures may be considered. 
3.2. Community school subsidy and setting

Table 3.2: Number of teacher FTEs corresponding to the costs of the community school subsidy by year

\begin{tabular}{|c|c|c|c|c|}
\hline \multirow[t]{2}{*}{ School board } & \multicolumn{4}{|c|}{ FTEs } \\
\hline & 2007 & 2008 & 2009 & 2010 \\
\hline 1 & .8 & .6 & 1.5 & 1.5 \\
\hline 2 & .9 & .8 & .8 & .6 \\
\hline 3 & 1.3 & 1.8 & 1.9 & 1.4 \\
\hline 4 & 2.8 & 3.9 & 4.6 & 3.9 \\
\hline Town level & 6.3 & 7.1 & 8.8 & 7.4 \\
\hline \multicolumn{5}{|c|}{ Own calculations based on DUO (2012), } \\
\hline \multicolumn{5}{|c|}{ OCW (2013b), information from the } \\
\hline \multicolumn{5}{|c|}{ Municipality of Schiedam. } \\
\hline \multicolumn{5}{|c|}{$1 \mathrm{FTE}=€ 69,432$} \\
\hline
\end{tabular}

\subsubsection{Schiedam population and community schools}

Having elaborated on the community school subsidy, it should be stressed that the frontrunner position of Schiedam is not a coincidence. Most community schools have populations that are considered disadvantaged in terms of their socioeconomic characteristics, and are established in neighborhoods characterized by a large share of rather deprived populations (Dyson, 2011; Dyson \& Raffo, 2007). This is observed in Schiedam when it is compared with the average Dutch population. The population in Schiedam differs with respect to socioeconomic status from the average Dutch population in a number of ways (Statistics Netherlands, 2012). For example, average income is slightly below the national average (€28,800 vs. $€ 29,600)$. Relatively more people receive social benefits ( 3 vs. 2 percent), and there are more single parent households ( 8.7 vs. 6.6 percent). The unemployment rate is higher than the national rate (6.3 vs. 5.4 percent). Finally, there 
Chapter 3. The Contribution of Community Schooling to Children's Educational Progress in Primary Education

are considerably more people with a non-Western immigration background (25.1 vs. 11.2 percent). 38.1 percent of the five to ten year-old children have a non-Western immigration background (nationally 16.3 percent; all based on Statistics Netherlands, 2012). Moreover, relatively many pupils have rather low-educated parents (Claassen, 2009). The latter characteristics are important in two ways: First, the analysis accounts for them; second, they define to what extent the results can be generalized.

From the above sections, two main conclusions can be drawn. First, the Municipality of Schiedam is increasingly investing in community schools; with respect to both the total amount spent and the amount spent per pupil. Moreover, the total amount of the subsidy is significant when expressed as an equivalent of teacher salaries. Yet, for schools the amount is minor relative to the regular subsidy they receive from the Ministry of Education.

The second conclusion relates to the observed distribution of the subsidy over activities, which does not follow a regular pattern. The distribution of funds across schools and activities seems to be rather haphazard. In the remainder of the chapter, this variation in subsidy allocation to different community school activities is used to investigate whether being exposed to different treatments impacts pupils' educational progress differently.

\subsection{Data}

To estimate the effect of a community school education on pupils' educational progress, three data sources are used. First, detailed subsidyinformation on the community school activities per pupil is used. This 
3.3. Data

includes information on the evolution of community school activities and their intensity over the school years 2000 to 2010. All primary schools in Schiedam are observed.

Second, the COOL ${ }^{5-18}$-data ${ }^{2}$ are used. These data derive from a longitudinal cohort study that follows pupils aged 5 to 18 throughout their educational careers in primary, secondary, and vocational education. The data are based on repeated surveys amongst pupils, parents, and school staff, and provide information on pupil, family, and school characteristics including several indicators of pupils' educational progress. This chapter particularly focuses on pupils' cognitive and social-emotional development. The data include a nationally representative sample of schools and an additional sample of schools with a high concentration of pupils from lower socioeconomic environments. Moreover, municipalities can decide to participate in the study with all the schools in their town. Schiedam decided to do this, and therefore, this data set includes the full pupil population of Schiedam. This chapter uses data on primary school children of the first and second wave of the COOL ${ }^{5-18}$ cohort study, which refers to the interview periods of 2007/2008 and 2010/2011 (Driessen, Mulder, \& Roeleveld, 2012). Due to the large number of schools leaving the national panel and pupils switching schools, it is not possible to exploit the panel structure of the data.

Third, school information on school size and budgeting provided by the Dutch Ministry of Education is used.

\footnotetext{
${ }^{2}$ CohortOnderzoek OnderwijsLoopbanen van 5 tot 18 jaar (Cohortresearch Educational Careers, 5 to 18 years).
} 
Chapter 3. The Contribution of Community Schooling to Children's Educational Progress in Primary Education

\subsection{Identification strategy}

\subsubsection{Hypotheses on the working mechanism of community school subsidies}

Assuming that pupils benefit from the richer learning environment in community schools, three hypotheses guide the analyses in this chapter.

- (H.1) The first hypothesis relates to an exposure effect: The longer the community school treatment, the more effective it is. Thus, the longer community school attendance, the more it should impact pupils' educational progress.

- (H.2) The second hypothesis relates to the intensity of the community school subsidy, and states that the more money is invested, the better is pupils' educational progress. This assumes that the community school subsidy is invested effectively.

- (H.3) Finally, two hypotheses relating to the community school activities are put forward.

(H.3a) First, an activity exposure effect is assumed: The more extensive the treatment, the more effective it is. Thus, if a specific community school activity is offered more frequently, it should more strongly affect pupils' educational progress.

(H.3b) The second hypothesis is that the closer an activity relates to the educational learning process, the stronger this activity impacts pupils' educational progress. In this sense, activities focusing on the educational learning process should have the 
3.4. Identification strategy

strongest effect, and care activities should have a stronger effect than activities focusing on, for example, the school environment.

\subsubsection{Outcome measures for educational progress}

In this chapter pupils' educational progress is divided into cognitive and social-emotional outcomes. The observed cognitive outcomes originate from results from the national CITO test which Dutch primary school pupils take in the final year of primary education, Grade 8. In this grade, pupils are usually between 11 and 12 years old. They are tested in language, mathematics, world orientation, and study skills. World orientation deals with topics related to history, geography, and biology. Study skills deals with understanding study texts, using information resources, and reading tables, diagrams, graphs and maps. The joint final score on the tests plays an important role in the transition to secondary education, as it is used to select pupils into the tracks of Dutch secondary education. Therefore, the test result is a highly relevant learning outcome. To estimate the impact of community school education on these cognitive outcomes, data from the 2007 wave are used. In this school year, 13 of the 23 primary schools in Schiedam were community schools.

Second, three social-emotional outcome variables are considered. Teachers have been asked to rate the behavior of their pupils on a 1 to 5 scale for 13 questions (see Appendix of this chapter). Three underlying social-emotional factors have been identified and rescaled to 1 to 5 measures (Jungbluth, Roede, \& Roeleveld, 2001): Underperformance, behavior, and perseverance. 'Underperformance' includes information on whether a pupil performs below his/her ability as per- 
Chapter 3. The Contribution of Community Schooling to Children's Educational Progress in Primary Education

ceived by the teacher. This variable is coded reversely. Therefore, a negative coefficient has to be interpreted positively as it implies less underperformance. 'Behavior' measures whether a pupil is often impertinent, and wether a pupil does not behave according to the rules. Finally, 'perseverance' reflects whether a pupil is eager to learn or if $\mathrm{s} /$ he gives up when something does not work out easily. The information on the social-emotional outcomes for pupils in Grade 8 is based on the second wave of the COOL $^{5-18}$-data from the school year 2010/11. In that school year, 14 of the 23 primary schools in Schiedam were community schools.

All outcome variables are standardized, and therefore have a mean of zero and a standard deviation (s.d.) of 1 . Table 3.3 shows the $25^{\text {th }}$, $50^{\text {th }}$ and $75^{\text {th }}$ percentile for each of the outcomes variables, and reveals that all measures, except language and underperformance, are slightly positively skewed.

Table 3.3: Standardized outcomes by percentiles

\begin{tabular}{lcccc}
\hline Outcome & $25^{\text {th }}$ percentile & $50^{\text {th }}$ percentile & $75^{\text {th }}$ percentile & $\mathrm{n}$ \\
\hline Cognitive & & & & \\
Mathematics & -.717 & .097 & .731 & 366 \\
Language & -.702 & -.028 & .800 & 366 \\
World orientation & .637 & .083 & .652 & 366 \\
Study skills & -.710 & .086 & .881 & 366 \\
Final score & -.849 & .063 & .874 & 366 \\
& & & & \\
Social-emotional & & & & \\
Underperformance & -.577 & -.196 & .568 & 732 \\
Behavior & -.476 & .100 & .676 & 732 \\
Perseverance & -.814 & .255 & .611 & 732 \\
\hline Note: The variables are standardized: mean=0, standard deviation=1. \\
\hline
\end{tabular}




\subsubsection{Treatment indicators for community schools}

To evaluate the extent to which community schools affect pupils' educational progress, and to test the hypotheses, three types of treatment indicators of community schooling are used. First, to test H.1, a general treatment indicator is used which compares pupils who have experienced community schooling in Schiedam with a comparison group of similar pupils. This indicator considers how long a pupil has attended a community school. For the control group this sum is zero. For robustness, a dummy indicator specification is tested as well (with 1 for community school pupils, and 0 for regular school pupils).

Second, to test H.2, the average community school subsidy that has been spent per pupil during the years s/he has attended primary education is considered. As shown in Section 3.2, the allocation of the subsidy by the Municipality of Schiedam has changed considerably over time and between schools, which accounts for interesting variation in the subsidy data. As it may be the case that it is not the per pupil share of the subsidy that is effective but the total subsidy a school receives, the latter is used as an alternative budget indicator.

A third strand of the analysis elaborates on the mechanism that explains how pupil outcomes may be influenced by the six community school activities. As community schools are not a single intervention, it is argued that analyses on community schools should be broken down into specific activities to find out whether they are effective. Some activities may be significant, while others are not. To identify the contribution of the activities, a measure of how often an activity has been offered by the school of the observed pupil is used. Hence, the time intensity is taken into account and the variance of exposure time 
Chapter 3. The Contribution of Community Schooling to Children's Educational Progress in Primary Education

is exploited.

The above treatment indicators reflect a pupil perspective. This is because the number of years a pupil has experienced community school education is considered. From an educational production function perspective, it holds for all three treatment indicators that for community schools to be effective what is critical is the period over which the school had the community school experience and not so much how long the pupil has been exposed to it. The underlying intuition is that schools learn and gain experience and, consequently, improve in community schooling over time. Therefore, indicators reflecting this school experience are also used. More precisely, instead of measuring the community school experience at the pupil level (hereafter referred to as Approach 1), the sum of years a school has received a community school subsidy is employed, and this is used to measure the school experience (hereafter referred to as Approach 2). Approach 2 also better captures the fact that community schools are a schoollevel intervention. For the cognitive sample, the pupil and the school experience are the same, as subsidies have been allocated since 2000 and pupils who are in Grade 8 in 2007 would have entered primary education in the year when the subsidy was first introduced. For the social-emotional outcome measures, however, some schools have longer community school histories than those of the Grade 8 pupils at the moment of observation (2010). For these cases, estimations that consider the pupil as well as the school experience are presented.

For a correct interpretation of the results of the analysis, it should be stressed that the data do not allow individual treatment indicators to be elaborated on. All treatment indicators are observed at the school level, whereas the outcomes are evaluated at the individual level. 
3.4. Identification strategy

Consequently, effects are averaged over all community school pupils.

\subsubsection{Identification of the treatment effect of com- munity schools by matching}

The Municipality of Schiedam has implemented community schools such that schools with more low-performing pupils became community schools first, implying that spending is negatively related to pupil attainment. Consequently, by definition, community schools in Schiedam differ systematically from regular schools. Moreover, the regular school population does not accurately represent the counterfactual outcome vis-à-vis community school pupils because characteristic differences influence the probability of attending a community school, and are simultaneously important predictors for pupils' educational progress.

As a consequence, if the impact of community schools is to be evaluated, pupils attending community schools cannot be compared with pupils attending regular schools in Schiedam. If this is done and a difference in their educational learning progress is found, this could be due to: (1) the differences in background characteristics, or (2) the community schools. It must be ensured that (1) does not impose a bias on the estimation result. Therefore, in this chapter a matching procedure to identify a control group for community school pupils is adopted.

\subsubsection{Matching estimator}

In order to accurately estimate the community school effect, a valid control group is needed. This chapter adopts a nearest-neighbor match- 
Chapter 3. The Contribution of Community Schooling to Children's Educational Progress in Primary Education

ing approach using Mahalanobis distances. ${ }^{3}$ Essentially, this matching approach matches each community school pupil to the best look-alike regular school pupil based on a vector of observable background characteristics, $\mathbf{x}$. The characteristics $\mathbf{x}$ are described in the next section.

Let $y_{1}$ and $y_{0}$ denote the outcomes for the treatment and control group respectively. $N_{C}$ and $N_{R}$ denote the number of pupils in, respectively, community schools $(C)$ and regular schools $(R)$. The matching approach gives weights to the $j^{\text {th }}$ observation that could serve as a potential match for the $i^{\text {th }}$ community school observation. The weightfunction is denoted by $w(i, j)$ with $\sum_{j} w(i, j)=1$. The matching estimator of the average treatment effect on the treated is then:

$$
\Delta=\frac{1}{N_{C}} \sum_{i \in\{I=1\}}\left[y_{1, i}-\sum_{j} w(i, j) \cdot y_{0, j}\right],
$$

where $0<w(i, j) \leq 1 ; I=1$ is the set of community school pupils; and $j$ is a pupil of the set of regular school pupils. The weights are obtained by using a Mahalanobis distance measure that minimizes the distance between the observed characteristics of pupils:

$$
w(i, j)=1 \text { if } j=\arg \min _{j=1, \ldots, N^{R}}\left(\mathbf{x}_{\mathbf{i}}-\mathbf{x}_{\mathbf{j}}\right)^{\prime} \Sigma^{-1}\left(\mathbf{x}_{\mathbf{i}}-\mathbf{x}_{\mathbf{j}}\right),
$$

where $\Sigma^{-1}$ represents the within-sample covariance matrix, and where $w(i, j)=1$ if a match is possible.

A major advantage of the Mahalanobis distance measure is that it is fully non-parametric. Therefore, the established matches do not rely on any functional form or distribution, which is convenient as

${ }^{3}$ This subsection relies on Cameron and Trivedi (2005) and De Witte, Van Klaveren, and Smets (2011). 
there is no a priori information on the relationship between observable characteristics and pupil performance (Yatchew, 1998). Assuming a functional form could impose a specification bias on the estimated community school impact.

Alternative estimators, such as kernel or propensity score estimators could have been used. These alternative matching estimators are not necessarily inferior to Mahalanobis matching (see Cameron and Trivedi (2005) and Zhao (2004) for an elaborate description of the advantages and disadvantages of different matching estimators). ${ }^{4} 5$

The matching procedure is carried out with replacement, which allows regular school pupils to be matched to community school pupils more than once.

\section{Matching variables}

Community schools are a school-level intervention, but their effectiveness is evaluated at the pupil level. Hence, the identification strategy has to account for the fact that two levels are at play: the individual and the school level. The matching strategy can be considered a double process as it captures school level, as well as pupil-level characteristics. Including school-level characteristics in the matching is important, as

${ }^{4}$ In addition, a stepwise matching approach was considered; first community schools are matched to regular schools based on the above-mentioned school characteristics, and in a second step pupils within the matched schools are matched based on the pupil characteristics. However, due to the relatively low number of observations in the matched schools, there are not enough pupils with which to properly match community school pupils, i.e. the control and intervention groups remain statistically different on observed characteristics.

${ }^{5} \mathrm{~A}$ propensity score-matching procedure without replacement was carried out. This attempt failed, however, as it led to a group of community school pupils and regular school pupils who differed in some characteristics. These differences remained while testing different specifications. 
Chapter 3. The Contribution of Community Schooling to Children's Educational Progress in Primary Education

it accounts for the additional financial means that schools receive in order to compensate for particular characteristics of school populations.

The pupil-level characteristics used in the matching are gender, age, and socioeconomic status (SES). SES reflects the educational level of the parents and their ethnic background. Further, the matching takes into account whether the pupil is a 'carepupil', which refers to pupils with special educational needs, including children with learning and behavioral problems or limitations of a physical or sensory nature, that complicate following education (Smeets \& Rispens, 2008). Indicators of whether pupils' parents are non-Western immigrants, and whether a father is present are also included.

To account for school characteristics, the number of pupils in a grade, and an indicator of whether a playgroup is present in the school are incorporated in the matching. The latter is included as this is a particular characteristic of many community schools. As an additional school-level variable, the degree of urbanization is included, to account for neighborhood characteristics of the school location. Moreover, as often, it is difficult to differentiate community schools from regular schools only control schools are selected that are not preparing to become a community school. This choice is made because these regular schools are expected to not offer community school activities. Finally, three degrees of school score are used (low, medium, high). This school score variable provides an indication of the social-ethnic composition of the pupil population of a school: The higher the school score, the higher the social-ethnic disadvantage of the school (Driessen et al., 2012). This latter variable is particularly valuable for this evaluation as it is based on the 'student weighting' in Dutch primary education. For Dutch primary schools a weighted student funding system 
applies which aims to combat the educational disadvantage of particular groups of pupils. The central government provides resources to primary schools on a per pupil basis; this amount differs according to the educational disadvantage of the individual pupil (Ladd \& Fiske, 2009). Based on this weighting, schools receive additional resources. Schools only qualify for extra funding if they meet several additional criteria, such as a minimum percentage of pupils with a certain weighting (Ladd \& Fiske, 2009; Noailly, Vujiv, \& Aouragh, 2009). The weighting is based on the educational level and ethnic origin of the parents. Therefore, accounting for the weighting by using the school-score variable in the matching is critical, as it accounts for the additional money that schools receive based on their population. Therefore, it is assumed that the matching captures potential differences in money allocated to pupils different from receiving a community school subsidy from the Municipality of Schiedam.

\section{Matching samples}

As described in subsection 3.4.2, to evaluate the community school impact on cognitive and social-emotional outcomes two subsamples are used. For the cognitive outcomes the COOL $^{5-18}$-data wave 2007/2008 is used. The social-emotional outcomes are observed in the data-wave 2010/2011. The group from which control pupils are identified includes pupils from Schiedam who do not attend a community school as these may be the best match for community schools pupils in Schiedam. 
Chapter 3. The Contribution of Community Schooling to Children's Educational Progress in Primary Education

\subsubsection{Estimation model}

Once comparable samples are obtained by the matching procedure described above, the community school impact on educational outcomes can be estimated by using the following regression model:

$$
y_{i}=\alpha_{0}+\alpha_{1} T_{i}+b X_{i}+e_{i} \quad i=1, \ldots, N,
$$

where $y_{i}$ are the educational outcomes that may be influenced by the treatment; $T_{i}$ is the treatment indicator; $X_{i}$ are pupil and school background characteristics that may influence $y_{i}$. These are the pupillevel characteristics gender, age, socioeconomic status, an indicator of whether the pupil is a carepupil, ethnic background of the parents, presence of a father; and the school characteristics, grade size, presence of a playgroup, and an indicator of whether the school participates in an extended school-day program. $e_{i}$ is a normally distributed zeromean constant variance error term. $T_{i}$ is defined in the three ways described above, considering the length of exposure to community school education, the community school expenditure, and the frequency of the activity offer. $a_{0}$ is the constant, and $a_{1}$ is the coefficient of interest (or a vector thereof). The standard model assumes that the individual error terms, $e_{i}$, are independently distributed. This assumption is unlikely to hold. Therefore, the standard errors are clustered at the school level; this accounts for the fact that the error terms are correlated within schools. 
3.5. Estimation results

\subsection{Estimation results}

In this section, the results are described. First, the focus is on the comparability of the matched samples. Second, the estimation results for using the duration of community school attendance as a treatment variable are presented. Third, the budget spent per pupil is considered. Finally, the exposure to the six community school activities is analyzed. For all estimations Ordinary Least Squares (OLS) with the school cluster corrections as described above is used.

\subsubsection{Comparability of pupil characteristics after matching}

To establish comparable samples, community school pupils are matched to regular school pupils. First, community school pupils with full information on their cognitive outcomes are matched to regular school pupils. Second, community school pupils with full information on their social-emotional outcomes are matched to regular school pupils.

Table 3.4 shows the means and standard deviations for pupil characteristics for the matched samples. $t$-tests on all variables confirm that, after the matching, no significant differences between the community school pupils (CS) and the regular school pupils (RS) in terms of observable characteristics remain.

Note that the social-emotional sample is larger than the cognitive one. This is explained by a smaller number of missing values in the outcome variables. Several schools did not administer the cognitive tests, while almost all participated in the teacher rating from which the social-emotional scores derive. Moreover, compared with 2007, the 
Chapter 3. The Contribution of Community Schooling to Children's Educational Progress in Primary Education

year for which the data for the cognitive sample is used, by 2010 more schools had become community schools.

As a robustness check, propensity score matching is applied as well. This procedure also provides equal groups, but, generally, the differences between community and regular school pupils are larger than those from the Mahalanobis distance matching. 


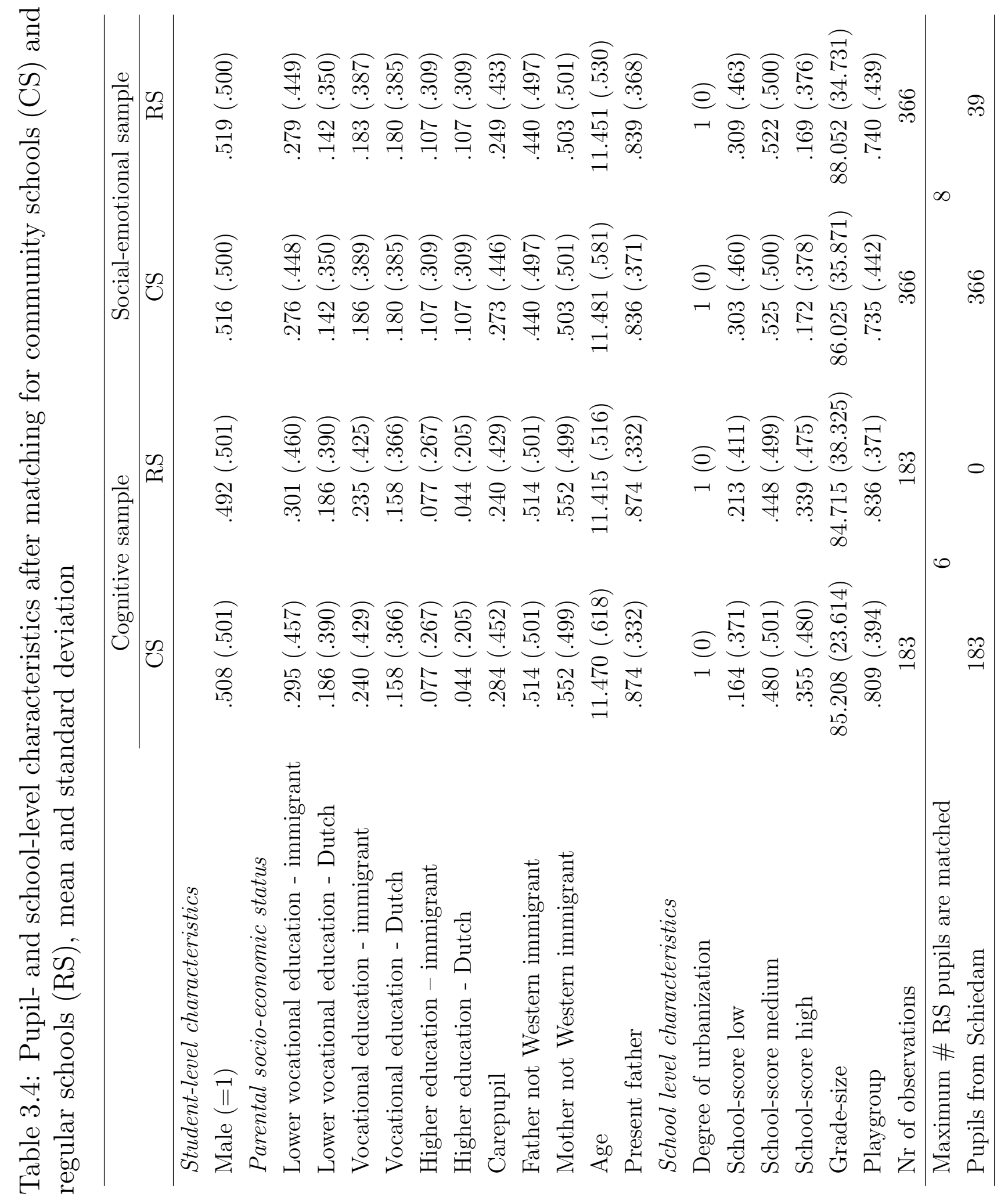


Chapter 3. The Contribution of Community Schooling to Children's Educational Progress in Primary Education

\subsubsection{Estimation results for the length of commu- nity school attendance}

\section{Cognitive outcomes}

First, the cognitive sample is considered. Table 3.5 shows the descriptive statistics for this indicator. The table clarifies that pupils in the treatment group have experienced either 1, 4, or 7 years of community schooling. In effect, the pupils are fairly evenly distributed between pupils attending a school that was an early adopter of community schooling and pupils at schools that converted only recently to community schooling. On average, the 366 pupils in the sample attended a community school for 1.852 years with an s.d. of 2.608. When considering only the 183 community school pupils, they attended community schools for on average 3.705 years (s.d. 2.596).

Table 3.5: Length of exposure to community school education, number of pupils and percentages, cognitive sample

\begin{tabular}{lcc}
\hline Years of community school education & N & Percentage \\
\hline 0 & 183 & 50.00 \\
1 & 78 & 21.31 \\
4 & 45 & 12.30 \\
7 & 60 & 16.39 \\
Total & 366 & \\
\hline
\end{tabular}

Table 3.6 shows the results for employing this duration indicator in the OLS specification. While the coefficients are all positive, none of them is statistically significant. Therefore, Table 3.6 does not provide evidence that attending a community school for a longer time affects pupils' cognitive outcomes. The same analysis was carried out 
with a dummy which is 1 for community school pupils, and 0 for regular school pupils. The results lead to the conclusion that attending a community school in the final year of primary education does not affect the outcomes. Hypothesis H.1 which states that longer exposure to community school education has a positive effect on pupils' development is rejected with respect to cognitive learning outcomes.

Table 3.6: The effect of the length of community school attendance on cognitive outcomes

\begin{tabular}{lccccc}
\hline & $\begin{array}{c}\text { Mathematics } \\
\text { Coefficient } \\
(S E)\end{array}$ & $\begin{array}{c}\text { Language } \\
\text { Coefficient } \\
\text { CS }\end{array}$ & $\begin{array}{c}\text { World orient. } \\
\text { Coefficient }\end{array}$ & $\begin{array}{c}\text { Study skills } \\
\text { Coefficient }\end{array}$ & $\begin{array}{c}\text { Final score } \\
\text { Coefficient }\end{array}$ \\
\cline { 2 - 6 }$($ in years $)$ & $(.038$ & .013 & .025 & .027 & .028 \\
Constant & 4.218 & $(.027)$ & $(.027)$ & $(.023)$ & $(.027)$ \\
& $(1.222)^{* * *}$ & $(1.002)^{* * *}$ & $(.892)^{* * *}$ & $(1.009)^{* * *}$ & $(1.015)^{* * *}$ \\
$\mathrm{R}^{2}$ & 0.307 & 0.342 & 0.344 & 0.291 & 0.350 \\
Nr of obs & 366 & 366 & 366 & 366 & 366 \\
\hline Note: Standard errors are clustered at the school-level (41 clusters: 8 Schiedam, \\
33 control schools). Multiple pupil and school characteristics are
\end{tabular}

\section{Social-emotional outcomes}

Table 3.7 shows the descriptive statistics for the length of exposure indicator for pupils in the social-emotional sample. For the individual pupil, the duration of the treatment depends on the point in time when a school became a community school.

The 732 pupils attended a community school for on average 3.098 
Chapter 3. The Contribution of Community Schooling to Children's Educational Progress in Primary Education

Table 3.7: Length of exposure to community school education, number of pupils and percentages, social-emotional sample

\begin{tabular}{lcccc}
\hline & CS pupil experience & $\mathrm{N}$ & Percentage & Years of subsidization \\
\hline & 0 & 366 & 50.00 & 0 \\
2 & 29 & 3.96 & 2 \\
& 65 & 8.88 & 3 \\
& 6 & 50 & 6.83 & 6 \\
& 7 & 61 & 8.33 & 7 \\
& 8 & 161 & 21.99 & 10 \\
\hline $\mathrm{N}$ & 732 & & \\
(CS) & $(366)$ & & \\
\hline
\end{tabular}

Approach 1: Pupil experience

Approach 2: School experience

years (s.d. 3.463). For the 366 community school pupils the average is 6.197 years (s.d. 2.183). The table also refers to the two different perspectives that can be taken: namely, the pupil and the school experience (Approach 1 and Approach 2, respectively). For the school experience, the averages are higher compared with those of the pupil experience, as the total duration of the subsidization of the school is considered: Considering all 732 pupils, they attend schools with an average community school experience of 3.538 years (s.d. 4.123); for community schools the average is 7.077 years (s.d. 2.989).

The estimation results are shown in Table 3.8. The linear treatment indicator is not statistically significant for any of the outcome measures, and therefore implies that community school pupils perform as well as regular school pupils. These results reject Hypothesis H.1 that a longer exposure to community school education has a positive effect on the social-emotional outcomes. The model is also tested for Approach 2, the school experience. The results confirm those in Table 3.8. A dummy specification is tested as well; it gives different results, 
showing that the coefficient for underperformance is slightly negative and that for behavior slightly positive. Hence, if the duration of the experience is not taken into account, but the treatment and control group are compared as a whole, the treatment correlates with improvements in two out of three social-emotional outcomes. Amounting to less than 20 percent of a standard deviation, these improvements are comparatively small.

Table 3.8: The effect of the length of community school attendance on social-emotional outcomes

\begin{tabular}{|c|c|c|c|}
\hline \multirow{3}{*}{$\begin{array}{l}\text { Community school } \\
\text { (in years) }\end{array}$} & $\begin{array}{l}\text { Underperformance } \\
\text { Coefficient } \\
\text { (SE) }\end{array}$ & $\begin{array}{c}\text { Behavior } \\
\text { Coefficient } \\
\text { (SE) }\end{array}$ & $\begin{array}{c}\text { Perseverance } \\
\text { Coefficient } \\
(S E)\end{array}$ \\
\hline & -.017 & .017 & -.014 \\
\hline & $(.013)$ & $(.016)$ & $(.017)$ \\
\hline \multirow[t]{2}{*}{ Constant } & -.029 & -1.951 & 1.684 \\
\hline & $(1.062)$ & $(1.066)$ & $(1.184)$ \\
\hline $\mathrm{R}^{2}$ & 0.078 & 0.130 & 0.266 \\
\hline $\mathrm{Nr}$ of obs & 732 & 732 & 732 \\
\hline \multicolumn{4}{|c|}{$\begin{array}{l}\text { Note: Standard errors are clustered at the school-level (121 clusters: } \\
17 \text { Schiedam, } 104 \text { control schools). }\end{array}$} \\
\hline \multicolumn{4}{|c|}{ Multiple pupil and school characteristics are controlled for. } \\
\hline \multicolumn{4}{|c|}{$* / * * / * * *$ means statistically significant at the $10 / 5 / 1$ percent level. } \\
\hline
\end{tabular}

\subsubsection{Estimation results for the community school subsidy}

\section{Cognitive outcomes}

The second treatment indicator is the subsidy allocated to community schools. The mean subsidy received over the primary school career 
Chapter 3. The Contribution of Community Schooling to Children's Educational Progress in Primary Education

of the pupils is applied. For the cognitive sample, this is the entire period during which community schools have been established, that is, the school years 2000 to 2007. The average per pupil budget is $€ 259.59$ with a standard deviation of $€ 403.17$. When considering only community school pupils, the mean is $€ 519.18$ (s.d. $€ 436.44$ ).

Table 3.9: The effect of the community school subsidy on cognitive outcomes

\begin{tabular}{|c|c|c|c|c|c|}
\hline & $\begin{array}{l}\text { Mathemat. } \\
\text { Coefficient } \\
\quad(S E)\end{array}$ & $\begin{array}{l}\text { Language } \\
\text { Coefficient } \\
\quad(S E)\end{array}$ & $\begin{array}{l}\text { World or. } \\
\text { Coefficient } \\
\quad(S E)\end{array}$ & $\begin{array}{l}\text { Study skills } \\
\text { Coefficient } \\
\quad(S E)\end{array}$ & $\begin{array}{l}\text { Final score } \\
\text { Coefficient } \\
\quad(S E)\end{array}$ \\
\hline CS subsidy & .010 & -.002 & .007 & .007 & .005 \\
\hline$(€ 100)$ & $(.017)$ & $(.016)$ & $(.016)$ & $(.016)$ & $(.017)$ \\
\hline Constant & 4.044 & 5.394 & 4.098 & 4.391 & 5.219 \\
\hline & $(1.244)^{* * *}$ & $(.981)^{* * *}$ & $(.866)^{* * *}$ & $(1.016)^{* * *}$ & $(1.022)^{* * *}$ \\
\hline $\mathrm{R}^{2}$ & 0.302 & 0.341 & 0.341 & 0.288 & 0.347 \\
\hline $\mathrm{Nr}$ of obs & 366 & 366 & 366 & 366 & 366 \\
\hline \multicolumn{6}{|c|}{$\begin{array}{l}\text { Note: Standard errors are clustered at the school-level (41 clusters: } 8 \text { Schiedam, } \\
33 \text { control schools). Multiple pupil and school characteristics are controlled } \\
\text { for. } * / * * * * * \text { means statistically significant at the } 10 / 5 / 1 \text { percent level. }\end{array}$} \\
\hline
\end{tabular}

Table 3.9 shows the results for estimating the impact of the subsidy per pupil on the cognitive outcomes. The subsidy coefficients are shown in hundreds. The results show that allocating an increasing budget to community schools does not impact pupils' cognitive learning outcomes. It may also be the case that that the subsidy affects the outcomes nonlinearly: After a certain amount, the effect of an additional subsidy unit on the outcome may become increasingly smaller. Moreover, the estimation has to ensure that the results do not depend on the functional form. Therefore, the model is estimated with an added square term of the subsidy as well as a cube term. Both alter- 


\subsection{Estimation results}

native estimations confirm the results in Table 3.9: namely, that the subsidy does not have a significant impact on the outcome.

As outlined above, one may also argue that it is not the pupil subsidy but the full budget allocated to a school which is decisive with regard to the outcomes. For the cognitive sample, this has a mean of $€ 70,906$ (s.d. of $€ 111,628$ ). Carrying out the same analysis with the model specifications above, the results for the full budget confirm that budget does not significantly affect the outcomes.

\section{Social-emotional outcomes}

Next, the social-emotional sample is considered. The average amount of community school subsidy for these pupils is $€ 487.07$ (s.d. €589.81); considering the pupils in community schools only the average is $€ 974.14$ (s.d. €470.06). Table 3.9 shows how allocating an increasing budget to community schools impacts pupils' social-emotional skills.

The estimation results show a negative effect on underperformance, implying that pupils underperform slightly less. No significant effect is found for the other indicators. Overall, the evidence rejects Hypothesis H.2 which states that more money is beneficial with respect to pupils' social-emotional outcomes. In terms of Cohen's (1988) effect sizes, the negative effect on underperformance refers to a (very) small effect $\left(\eta^{2}=.040\right)$.

The alternative assumption that the full budget may be more decisive than the amount spent per pupil is estimated as well. From the pupil perspective, for pupils referring to the period 2003 to 2010, the average total subsidy is $€ 123,857$ (s.d. $€ 152,878$ ). For community school pupils, the average is $€ 247,714$ (s.d. $€ 126,658$ ). The results 
Chapter 3. The Contribution of Community Schooling to Children's Educational Progress in Primary Education

Table 3.10: The effect of the community school subsidy on socialemotional outcomes

\begin{tabular}{|c|c|c|c|}
\hline & $\begin{array}{c}\text { Underperformance } \\
\text { Coefficient } \\
(S E)\end{array}$ & $\begin{array}{c}\text { Behavior } \\
\text { Coefficient } \\
\text { (SE) }\end{array}$ & $\begin{array}{c}\text { Perseverance } \\
\text { Coefficient } \\
(S E)\end{array}$ \\
\hline Community school & -.016 & .010 & -.008 \\
\hline subsidy $(€ 100)$ & $(.007)^{* *}$ & $(.010)$ & $(.010)$ \\
\hline Constant & .066 & -1.944 & 1.683 \\
\hline & $(1.054)$ & $(1.062)$ & $(1.184)^{*}$ \\
\hline $\mathrm{R}^{2}$ & 0.082 & 0.129 & 0.267 \\
\hline $\mathrm{Nr}$ of obs & 732 & 732 & 732 \\
\hline \multicolumn{4}{|c|}{$\begin{array}{l}\text { Note: Standard errors are clustered at the school-level (121 clusters: } \\
17 \text { Schiedam, } 104 \text { control schools). }\end{array}$} \\
\hline \multicolumn{4}{|c|}{ Multiple pupil and school characteristics are controlled for. } \\
\hline$* / * * / * * *$ means sta & istically significant a & the $10 / 5 / 1$ & ercent level. \\
\hline
\end{tabular}

for the full budget confirm those in Table 3.10: namely, a negative effect on underperformance, and no effect on behavior and perseverance. Modeling the effect of higher expenditure on the social-emotional outcomes with a square and cube indicator also confirms the results shown in Table 3.10.

The school experience, i.e. the total subsidy of the school over the period considered, can be analyzed as well. On average, this is $€ 140,851$ (s.d. $€ 180,614$ ). For community school pupils, it is on average $€ 281,702$, (s.d. $€ 159,830$ ). Moreover, estimations following Approach 2 (the school experience) confirm the conclusion that higher expenditure is not beneficial; in this alternative specification higher expenditures are not beneficial with respect to underperformance. 
3.5. Estimation results

\subsubsection{Estimation results for the community school activities}

The third strand of treatment indicators are the activities offered in community schools, as reported by the schools in their yearly report on the use of the subsidy. As outlined in Section 3.2.1, schools allocate the subsidy differently every school year without a clear observable pattern. The activities that schools offer are not stable over time, and frequently community schools offer activities in one school year but not in the next, or, more precisely, report that they use the municipal subsidy for a type of activities in one year, but not in the next.

\section{Cognitive outcomes}

To estimate the effect of the activity offer on the cognitive outcomes, the sum of how often each activity has been offered in the school that an individual pupil attends is used. Table 3.11 shows the descriptive statistics for the activities. Column 1 shows that each activity has been offered between 0 and 8 times. 50 percent of the pupils in the sample (the control group) have not been exposed to any of the community school activities. The subsequent columns show the number of pupils and the percentages of how often each of the activities has been offered in the school the pupil attends. The table shows a large variation across the frequency of activity offer which is exploited in the analysis. Cultural activities have been offered to all community school pupils (i.e. each community school pupil has been exposed to an offer at least once); educational learning process activities rank second. School environment and school climate are least popular. 


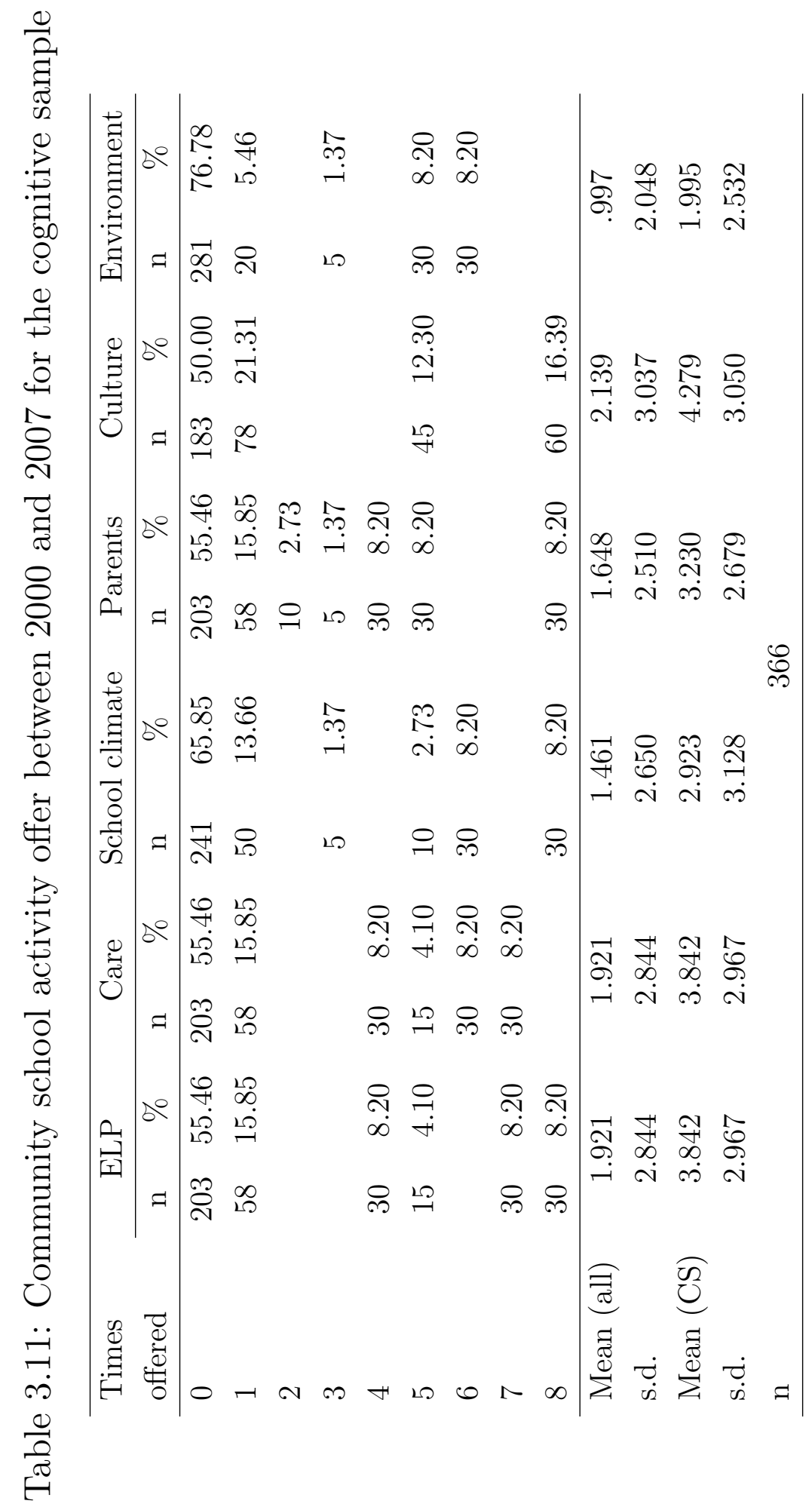


3.5. Estimation results

Table 3.12 shows the results for estimating the effect of these linear intensity indicators on the cognitive outcomes.

Table 3.12: The effect of community school activities on cognitive outcomes

\begin{tabular}{lccccc}
\hline & $\begin{array}{c}\text { Mathemat. } \\
\text { Coefficient }\end{array}$ & $\begin{array}{c}\text { Language } \\
\text { Coefficient }\end{array}$ & $\begin{array}{c}\text { World or. } \\
\text { Coefficient }\end{array}$ & $\begin{array}{c}\text { Study skills } \\
\text { Coefficient }\end{array}$ & $\begin{array}{c}\text { Final score } \\
\text { Coefficient }\end{array}$ \\
\cline { 2 - 5 } ELP & $($ SE) & $(S E)$ & $(S E)$ & $(S E)$ & $(S E)$ \\
\cline { 2 - 6 } Care & 1.231 & 1.259 & 1.062 & .781 & 1.281 \\
& $(.186)^{* * *}$ & $(.234)^{* * *}$ & $(.211)^{* * *}$ & $(.265)^{* * *}$ & $(.211)^{* * *}$ \\
School clim. & -2.388 & -2.203 & -1.932 & -1.940 & -2.503 \\
& $(.305)^{* * *}$ & $(.327)^{* * *}$ & $(.255)^{* * *}$ & $(.276)^{* * *}$ & $(.324)^{* * *}$ \\
Parents & .511 & .488 & .573 & .427 & .560 \\
& $.095)^{* * *}$ & $(.104)^{* * *}$ & $(.094)^{* * *}$ & $(.103)^{* * *}$ & $(.100)^{* * *}$ \\
Culture & .841 & .820 & .618 & .723 & .928 \\
& $.115)^{* * *}$ & $(.130)^{* * *}$ & $(.103)^{* * *}$ & $(.130)^{* * *}$ & $(.124)^{* * *}$ \\
Environm. & .329 & .133 & .110 & .413 & .294 \\
& $(.177)^{*}$ & $(.211)$ & $(.226)$ & $(.215)^{*}$ & $(.199)$ \\
Constant & $(.059)^{* * *}$ & $(.064)^{* * *}$ & $(.051)^{* * *}$ & $(.045)^{* * *}$ & $(.062)^{* * *}$ \\
& 4.350 & 5.570 & 4.473 & 4.606 & 5.445 \\
$\mathrm{R}^{2}$ & $(1.254)^{* * *}$ & $(1.102)^{* * *}$ & $(.903)^{* * *}$ & $(1.056)^{* * *}$ & $(1.074)^{* * *}$ \\
Nr of obs & 0.367 & 0.390 & 0.380 & 0.336 & 0.414 \\
\hline
\end{tabular}

Note: Standard errors are clustered at the school-level (41 clusters: 8 Schiedam, 33 control schools). Multiple pupil and school characteristics are controlled for. $* / * * / * *$ means statistically significant at the $10 / 5 / 1$ percent level. The activities are measured as count variables ranging from 0 to 8 .

The results suggest that the community school activities have both positive and negative effects. Significant positive effects of the educational learning process on all five outcomes are observed. The same holds for both school climate and activities involving parents. Cultural 
Chapter 3. The Contribution of Community Schooling to Children's Educational Progress in Primary Education

activities have a positive effect on mathematics, language, study skills and the final score. Care and school environment have a negative effect on all outcomes. In terms of effect sizes (Cohen, 2005), all significant effects are large effects (often surpassing $100 \%$ of the standard deviation of the outcome), except cultural activities which have small effect on mathematics and a medium effect on study skills.

Overall, the results do not consistently support Hypothesis H.3a that a more frequent exposure to community school activities is better for pupils' educational progress, in terms of cognitive learning outcomes. The results do show that the effects, both positive and negative, increase with an increasing exposure to the treatment. Yet, the finding that some activities are related with negative, rather than positive impacts is unexpected, and will be discussed in Section 3.6. Hypothesis $H .3 b$ which states that activities that are closer to the centre in Figure 1 are more effective is rejected as well, as the second most central activity (care) has a negative effect throughout.

\section{Social-emotional outcomes}

Next, pupils in the social-emotional sample are considered. Again the pupil perspective is taken, and Table 3.13 shows how many pupils (in absolute numbers and percentages) were exposed to the community school activity offer between 2003 and 2010, the years during which pupils were in primary education. In this period, all community school pupils were exposed to cultural activities (at least three times). The same holds for educational learning process, care, and parental involvement activities. School environment is least popular. 


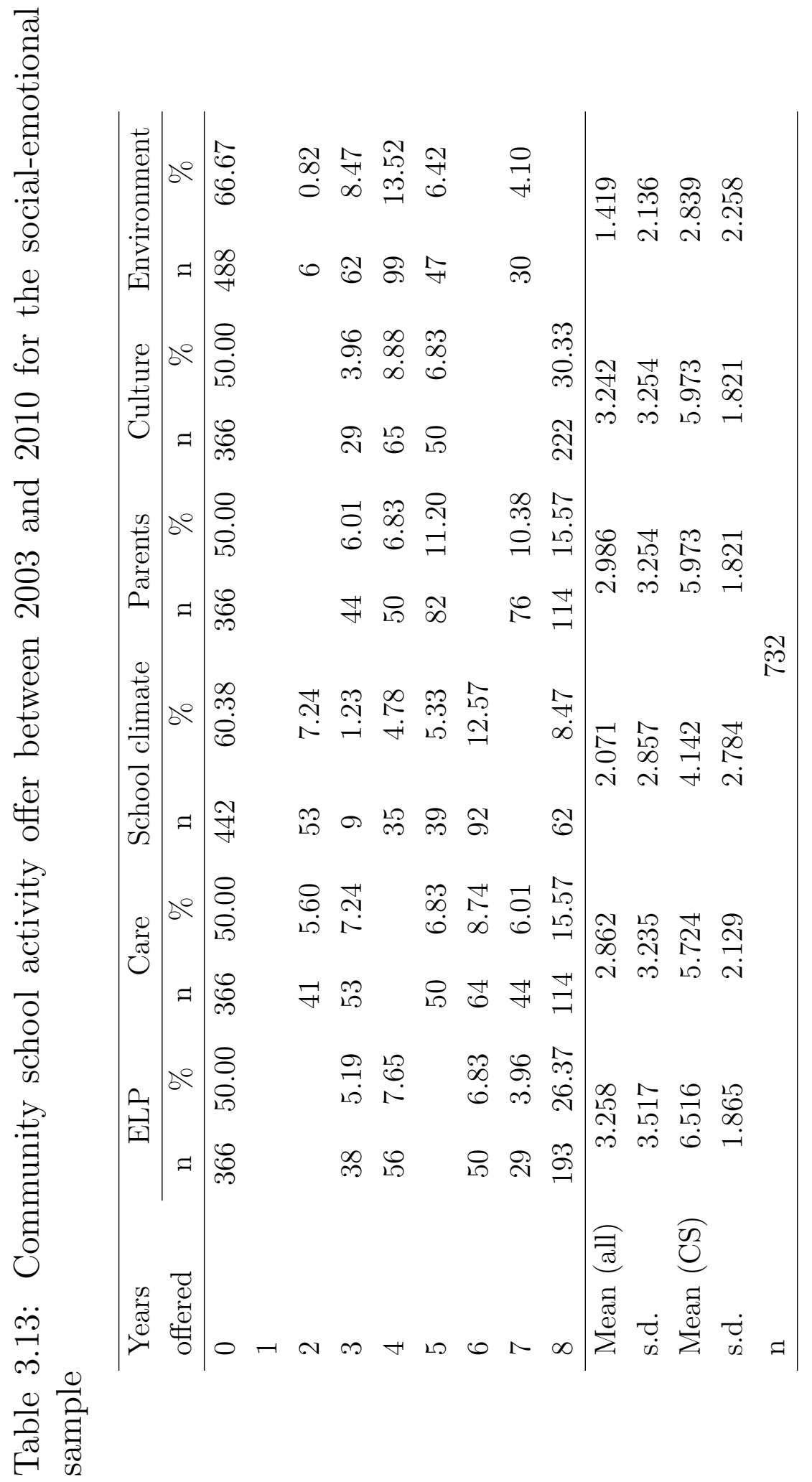


Chapter 3. The Contribution of Community Schooling to Children's Educational Progress in Primary Education

Table 3.14: The effect of community school activities on socialemotional outcomes

\begin{tabular}{|c|c|c|c|}
\hline & $\begin{array}{c}\text { Underperformance } \\
\text { Coefficient } \\
\text { (SE) }\end{array}$ & $\begin{array}{c}\text { Behavior } \\
\text { Coefficient } \\
\text { (SE) }\end{array}$ & $\begin{array}{l}\text { Perseverance } \\
\text { Coefficient } \\
\text { (SE) }\end{array}$ \\
\hline ELP & $\begin{array}{c}.122 \\
(.162)\end{array}$ & $\begin{array}{l}.140 \\
(.172)\end{array}$ & $\begin{array}{l}.011 \\
(.140)\end{array}$ \\
\hline Care & $\begin{array}{l}.117 \\
(.115)\end{array}$ & $\begin{array}{c}-.241 \\
(.091)^{* * *}\end{array}$ & $\begin{array}{l}-.173 \\
(.086)^{* *}\end{array}$ \\
\hline School climate & $\begin{array}{l}.020 \\
(.029)\end{array}$ & $\begin{array}{c}.082 \\
(.040)^{* * *}\end{array}$ & $\begin{array}{c}.076 \\
(.028)^{* * *}\end{array}$ \\
\hline Parents & $\begin{array}{c}.024 \\
(.116)\end{array}$ & $\begin{array}{c}.328 \\
(.040)^{* * *}\end{array}$ & $\begin{array}{c}.139 \\
(.101)\end{array}$ \\
\hline Culture & $\begin{array}{l}(-.235)^{*} \\
(.151)\end{array}$ & $\begin{array}{l}-.214 \\
(.139)\end{array}$ & $\begin{array}{l}.016 \\
(.121)\end{array}$ \\
\hline Environment & $\begin{array}{l}-.017 \\
(.049)\end{array}$ & $\begin{array}{c}-.109 \\
(.040)^{* * *}\end{array}$ & $\begin{array}{c}-.126 \\
(.046)^{* * *}\end{array}$ \\
\hline Constant & $\begin{array}{l}.469 \\
(.975)\end{array}$ & $\begin{array}{l}-.706 \\
(.971)\end{array}$ & $\begin{array}{c}2.427 \\
(.921)^{* * *}\end{array}$ \\
\hline $\mathrm{R}^{2}$ & 0.087 & .149 & .278 \\
\hline $\mathrm{Nr}$ of obs & 732 & 732 & 732 \\
\hline $\begin{array}{l}\text { Note: Standarc } \\
17 \text { Schiedam, } 1 \\
\text { Multiple pupil } \\
* / * * / * * * \text { mean } \\
\text { The activities }\end{array}$ & $\begin{array}{l}\text { errors are clustered } \\
44 \text { control schools). } \\
\text { and school character } \\
\text { s statistically signific } \\
\text { re measured as coun }\end{array}$ & $\begin{array}{l}t \text { the school } \\
\text { tics are cont } \\
\text { nt at the } 10 \\
\text { variables ra }\end{array}$ & $\begin{array}{l}\text { el (121 clusters } \\
\text { led for. } \\
1 \text { percent level. } \\
\text { ng from } 0 \text { to } 8 \text {. }\end{array}$ \\
\hline
\end{tabular}

Table 3.14 shows the estimation results for the effect of community school activities on social-emotional outcomes. The table shows a negative impact of cultural activities on underperformance; hence, there is less underperformance. This is a small effect (Cohen, 2005). Behavior is affected both positively and negatively: Positively, by school climate and parents; negatively by care and school environment. Interestingly, 
3.6. Discussion and conclusion

the negative effects are small effects, the positives ones are large. Perseverance is affected negatively by care and school environment, and positively by school climate. All three are small effects.

Overall, Hypothesis H.3a which assumes that a more frequent exposure to community school activities is better for pupils' educational progress, in terms of social-emotional outcomes, is rejected. The same applies to $H .3 b$ which states that activities that are closer to the centre in Figure 3.1 are more effective. For estimating the school experience, the coefficients differ slightly in magnitude but overall also reject Hypothesis H.3b.

As with the cognitive outcomes, based on the results for socialemotional outcomes the hypothesis that a more intense offer of community school activities is generally beneficial to pupils' educational development is rejected. Again, the length of exposure relates to an increased effect, but the effect can be either positive or negative. Moreover, a clear hierarchy of effects, with more directly pupil related activities being more beneficial, does not seem to exist.

\subsection{Discussion and conclusion}

The aim of this chapter was to shed light on the question whether community schools can contribute to pupils' educational progress. In the above sections a variety of analyses testing three strands of hypotheses were presented. In all analyses community school pupils were compared with look-a-like regular school pupils, who have been identified by a matching procedure.

Hypothesis $H .1$ states that a longer exposure to community school education is beneficial for pupils' educational progress in terms of cog- 
Chapter 3. The Contribution of Community Schooling to Children's Educational Progress in Primary Education

nitive and social-emotional skills. The findings do not confirm this hypothesis, although attending a community school as such was linked to improvements of social-emotional skills. Hypothesis H.2 states that if more budget is allocated to community schools, this is beneficial to pupils' educational progress. This hypothesis was also not confirmed. A potential explanation for the latter result is the fact that the per pupil amounts of the subsidy are low. Overall, the results for Hypotheses $H .1$ and H.2 mainly reveal neutral effects of community school exposure and budget on both the cognitive and the social-emotional outcomes. A small negative effect of community school subsidy on underperformance is found. With respect to cognitive outcomes, community school pupils perform as well as regular school pupils, irrespective of how long they have attended a community school, and irrespective of how much subsidy has been allocated to the community school. The results are robust over several model specifications. This leads to the conclusion that from both a duration and a budgetary perspective, community schools are as effective as regular schools in terms of pupils' cognitive learning outcomes. The latter also holds with respect to behavior and perseverance. It must be kept in mind, however, that the amount per pupil is small; and the averages presented above relate to their entire primary school career.

The results for $H .3 a$ and $H .3 b$ do not test a single indicator but reflect the multifaceted nature of community schools. Some activities have positive effects: in particular, educational learning process (ELP) activities, activities involving parents, and cultural activities. Other activities, particularly care and efforts regarding the school environment, have negative effects on cognitive and social-emotional outcomes. Generally, the effects, both positive and negative, deepen with the in- 
3.6. Discussion and conclusion

tensity of the pupil experience in a community schools, i.e. the years of exposure to the treatment. The effect sizes are mainly large with respect to cognitive outcomes, and range from small to large for the social-emotional outcomes. Overall, different activities have diverse effects on the various outcomes. Therefore, when community schools are evaluated, it is critical to consider specific activities and to take into account what they actually do.

Yet, the unexpected negative effects of activities regarding care and school environment require further reflection. An explanation for the negative effects of care may be that schools offer more care activities if there is a high demand for, for example, social workers or speech therapy. However, this type of selection bias should not occur with a truly effective matching process, which one assumes to control for observed as well as non-observed characteristics such as care demands. If the latter is true, the negative effect of care activities is likely to be a relative effect, indicating that schools are diverting away financial means that other schools use in more effective ways.

The negative results for activities oriented towards the school environment may be explained by the fact that they are not directly focused at the pupil. They are typically activities aimed at serving the neighborhoods of schools, rather than exclusively focusing on pupils. Moreover, transforming school neighborhoods takes time; therefore, the negative effect for school environment may change in the long term.

Given the above findings, it should be mentioned that the negative effects of some community school activities do not necessarily mean that these activities actually harm the children, but there could be an alternative explanation. Therefore, future research is strongly advised to further investigate the relationships between the community school 
Chapter 3. The Contribution of Community Schooling to Children's Educational Progress in Primary Education

activities and the community school outcomes.

With respect to the social-emotional outcomes, it must be kept in mind that these are based on teacher ratings and, consequently, are more subjective than the cognitive outcomes based on standardized national tests. This may explain the higher degree of heterogeneity observed for these outcomes. Subjective teacher behavior would be problematic if teachers in community schools differ structurally from teachers in regular schools in their behavior towards these ratings. But, the subsidy does not correlate with teacher characteristics. There is no indication that the teacher population changes as a result of the community school subsidy. Therefore, it can be assumed that, as school population variables are included in the matching, this accounts for teacher variables as well. However, this is an assumption that cannot be tested. Therefore, future research should consider to what extent teachers are different in community schools from those in regular schools, and to what extent community schools attract a particular teacher population.

From the above analyses some general conclusions can be drawn. Pupils do not benefit in a uniform way from community school education. The above results show that community schools as a whole do not affect pupil outcomes. Furthermore, the subsidy allocated is not meaningful on its own. The findings also suggest that such overarching community school indicators may not be enough to capture their full impact. If community schools are broken down into the six community school activities, they do affect pupils' cognitive and socialemotional learning outcomes. When considering whether a school is a community school or not and deriving conclusions with respect to their effectiveness does not capture the variety of activities that constitute 
3.6. Discussion and conclusion

a community school, and does not focus on the specific activities that drive outcomes for pupils. Therefore, future research will have to elaborate on the community school activities. Moreover, the duration of community school attendance may be further analyzed by panel data that follows pupils over time. More longitudinal research may help to find out whether in the longer run higher funds pay off, while in the observed period this does not seem to be the case.

The community schools evaluated in this study are primary schools which children enter at the age of four. To have substantial and longitudinal positive effects on pupils' learning outcomes it may be argued that this sort of education must start at an earlier age, even before pupils enter primary schools (Nores \& Barnett, 2010). This is because the educational disadvantage children encounter in schools is created even before pupils enter primary education. Community schools which focus on children from an early age have been found to be successful in producing positive outcomes for pupils and their families (Dobbie \& Fryer, 2009). The latter study could provide causal evidence.

Finally, with respect to policymaking, it should be stressed that for pupils' educational learning process, it does not seem important to increase the subsidies allocated to schools. Even though they receive more money, they do not achieve better results. The results suggest that the effects are driven rather by educational and pedagogical processes in the school. It seems most important how schools use the money, while the actual size of the subsidy seems less important. The actual experience of a community school in terms of realized activities seems to matter most. Thus, community schools affect pupils' educational progress through different channels of community school activities. 
Chapter 3. The Contribution of Community Schooling to Children's Educational Progress in Primary Education

\section{Appendix}

Underperformance

The performance of this pupil gives a good idea of his/her talent.

The performance of this pupil is below his/her ability.

This pupil can perform better.

Behavior

This pupil is often impertinent.

This pupil sticks to the rules.

This pupil always tries to dominate the others.

This pupil never quarrels.

Perseverance

This pupil works accurately.

This pupil thinks too soon that his/her work is finished.

This pupil gives up quickly when something does not work. 


\section{Chapter 4}

\section{Differentiated Effects of}

Community Schooling

on Cognitive and

Social-Emotional

Learning Outcomes in

\section{Primary Education}

\subsection{Introduction}

The previous chapter elaborated on the effects of community schooling in primary education with a focus on the average pupil. It showed that for these pupils community school subsidies are not effective. As 
Chapter 4. Differentiated Effects of Community Schooling in Primary Education

outlined in the Introduction (Chapter 1) and the Literature Review (Chapter 2) of this dissertation, most community schools are established in disadvantaged neighborhoods where their major objective is to counteract educational and social disadvantages to enable children to develop their talents as well as possible by offering additional educational and pedagogic opportunities (Blank et al., 2003; Dyson, 2011; Dyson \& Raffo, 2007). As most community schools are supposed to support children from rather deprived socioeconomic backgrounds, this chapter complements the previous one and focuses on differentiated pupil groups. The present chapter describes the effect of a community school subsidy in the Netherlands on the educational outcomes of those pupils who are, in particular, assumed to benefit from the subsidy. These are known as 'carepupils' and pupils whose parents have a relatively low educational attainment. Both characteristics have been identified as putting pupils in a disadvantaged position throughout their educational careers (Bower, 2011; Duncan et al., 1994, 1998; Evans \& Kantrowitz, 2002; McLoyd, 1990; Wilson, 2010). While policymakers and educationalists believe that community schools benefit these specific children, empirical evidence is lacking. Therefore, this chapter is a critical contribution to the previous chapter, as well as to the literature on community schools, as it provides the first evidence on the differentiated effects of community schooling on the cognitive and social-emotional outcomes of disadvantaged pupils in primary schools. Knowing whether community schools produce positive outcomes for these pupil groups is critical for their future design and implementation. 
4.2. Community school subsidy and target groups

\subsection{Community school subsidy and tar- get groups}

\section{The community school subsidy}

Community schools evolve based on the local context and the population in their neighborhood (Dobbie \& Fryer, 2009; Dryfoos, 2005, 2008). Therefore, community schools are best evaluated in specific environments. As in the previous chapter, this chapter also focuses on community school subsidies in the Dutch town of Schiedam. In the academic literature, there is an ongoing discussion about the extent to which such additional spending for disadvantaged pupils is beneficial for their pupils' performance (Gibbons et al., 2012; Leuven, Lindahl, Oosterbeek, \& Webbink, 2007). For example, Leuven et al. (2007) evaluated two subsides for disadvantaged pupils' achievement. Neither of the two subsidies appeared to improve achievement. On the contrary, Gibbons et al. (2012) find that additional spending favors pupils' attainment.

Section 3.2.1 in Chapter 3 elaborates in detail on the community school subsidy in Schiedam and the activities that are financed via this subsidy.

\subsubsection{Community schools for differentiated pupil groups}

Chapter 3 in this dissertation evaluated the effectiveness of the above described subsidy with respect to children's cognitive and social-emotional educational outcomes for the average pupil in community schools. 
Chapter 4. Differentiated Effects of Community Schooling in Primary Education

Overall, that chapter did not find the subsidy to be effective. It may, however, be the case that it failed to find an effect because it did not focus on the primary target population of community schools: namely, disadvantaged pupils. Therefore, in this chapter the focus is on two groups of community school pupils: Carepupils and pupils with loweducated parents. It is these pupils who are supposed to benefit from community school education in particular.

Both groups are relatively prevalent in Schiedam: Compared with the Dutch population there are more carepupils and the average educational level is lower in Schiedam. The underlying assumption of this chapter is that these two pupil groups perform better in community schools than in regular schools. Policymakers and educationalists have positive expectations about community schools; evidence on this assumption is, however, not available.

\section{Carepupils}

The first group of interest are carepupils. Carepupils are identified by their teachers (Driessen et al., 2012). The teacher is asked the following five questions, and if at least one is answered positively a pupil is identified as a carepupil.

- Is a 'backpack' available for the child? A 'backpack' is a typical Dutch subsidy. Pupils who have a backpack have been identified by schools and parents to be in need of additional financial attention. These are pupils with a disability or disorder which requires additional resources for the pupil in order to attend school. This usually refers to an intellectual, sensory, or physical disability; severe psychiatric problems; severe learning or behavioral prob- 
4.2. Community school subsidy and target groups

lems; multiple disabilities; and pupils with a long illness (Ministerie van Onderwijs, Cultuur en Wetenschap, 2013a).

- Does the child have an ambulant guide in the special needs education? The ambulant guide is a support teacher, acting as a personal guide for pupils having difficulties in school. This can be preventive, i.e. to prevent pupils from being placed into special education. At the beginning of the school year, the ambulant guide makes a support plan for the current situation in which the planned actions are described. At the end of the school year, the school reviews this plan.

- Has a procedure been started to place this child in special education? This question refers to whether it is currently planned to transfer this pupil from regular to special education.

- Is an action plan established for this child? Here, an action plan refers to a written agreement in which parents and the school agree upon what the school wants to achieve in the educational process of the pupil, and in what way. Such an action is comparable with an individualized education plan (IEP) in the US (Pretti-Frontczak \& Bricker, 2000).

- Does this child follow an individual learning line? Having an 'individual learning line' implies that a pupil follows a structurally different curriculum for one or more subjects leading to a lower final level.

Overall, carepupils are pupils with particular educational needs, such as pupils with learning and behavioral problems or limitations based 
Chapter 4. Differentiated Effects of Community Schooling in Primary Education

on a physical or sensory nature, which make following education more difficult. Given these problems these pupils need a specific approach or extra educational support (Onderwijsinspectie, 2010; Smeets \& Rispens, 2008). Carepupils can either be in regular or special education. Here, the focus is on carepupils in regular education.

\section{Pupils with lower-educated parents}

The second group are pupils whose parents have a relatively low educational background. Earlier studies have also shown that children with lower-educated parents are at a disadvantaged position throughout their educational careers compared with their peers who have parents with a relatively higher educational level (Bower, 2011; Duncan et al., 1994, 1998; McLoyd, 1990; Wilson, 2010). Earlier studies have shown that pupils with parents with low educational attainment, here defined as lower secondary pre-vocational education (Dutch: voorbereidend middelbaar beroepsonderwijs, VMBO), perform worse than pupils whose parents have relatively higher educational levels (Desforges \& Abouchaar, 2003; Durlak, Weissberg, Dymnicki, Taylor, \& Schellinger, 2011). This educational attainment category refers to the maximum level obtained by any of the parents; thus, parents below lower secondary pre-vocational education also fall into this group. With their more encompassing learning environment, community schools are assumed to support these children and to provide them with educational and pedagogical activities they may not otherwise experience. 


\subsection{Data and hypotheses}

\subsubsection{Data}

To estimate the effect of community school education on pupils' educational progress, three data sources are used. First, detailed subsidyinformation on the community school activities per pupil is used. Second, the COOL ${ }^{5-18}$-data are used. Third, school information on school size and budgeting provided by the Dutch Ministry of Education is used. For a detailed description of the data see Chapter 3, Section 3.3.3.

\subsubsection{Hypotheses about the working mechanisms of community schools}

This chapter considers three working mechanisms whereby community schools may improve educational outcomes for the differentiated pupil groups: namely, (1) whether a pupil attends a community school; (2) how much subsidy has been allocated to the community school; and (3) the frequency of the community school activities offered in the school to a pupil. The earlier chapter on the community school subsidy tested these three working mechanisms but did not find evidence for community schools to be effective. The present chapter focuses on the primary target groups of community schools and tests the following hypotheses:

- (H.1) Length of community school attendance

(H.1a) Carepupils perform better in community schools than in regular schools. 
Chapter 4. Differentiated Effects of Community Schooling in Primary Education

(H.1b) Pupils with lower-educated parents perform better in community schools than in regular schools.

- (H.2) Community school subsidy

(H.2a) The higher the community school subsidy, the better carepupils perform.

(H.2b) The higher the community school subsidy, the better pupils with lower-educated parents perform.

- (H.3) Community school activities

(H.3a) The more frequently community schools offer activities, the better carepupils perform.

(H.3b) The more frequently community schools offer activities, the better pupils with lower-educated parents perform.

These hypotheses are tested for cognitive as well as social-emotional outcomes.

\subsection{Identification strategy: matching}

As the previous chapter, this chapter identifies a control group for the community school pupils in Schiedam by a nearest-neighbor matching approach using Mahalanobis distances. In fact, the same strategy as in Chapter 3 is used. Therefore, subsections 3.4.4. and 3.4.5 in this dissertation inform about the matching variables, samples and the comparability of the samples after the matching. Table 3 in subsection 3.5.1 showed that the treatment and the control group do not differ in any observable characteristics after the matching. It can be assumed 
that this comparability in observable characteristics also refers to the unobserved characteristics.

\subsection{Descriptive statistics}

\subsubsection{Differentiated pupil groups}

Table 4.1 shows the frequencies for the differentiated pupil groups in the cognitive and social-emotional sample. Note that the socialemotional sample is twice as big as the cognitive sample, for two reasons: First, more schools became community schools between 2007 and 2010; second, more observations are available in the corresponding data wave.

Table 4.1: Percentages of pupil groups by community schools and regular schools

\begin{tabular}{lccc}
\hline Pupil characteristic & & Community schools & Regular schools \\
\hline Cognitive sample & & & \\
Carepupil & Yes & $28 \%$ & $24 \%$ \\
& $n$ & 183 & 183 \\
Lower-educated parents & Yes & $48 \%$ & $49 \%$ \\
& $n$ & 183 & 183 \\
Social-emotional sample & & & \\
Carepupil & Yes & $37 \%$ & $25 \%$ \\
& $n$ & 366 & 366 \\
Lower-educated parents & Yes & $42 \%$ & $43 \%$ \\
& $n$ & 366 & 366 \\
\hline
\end{tabular}


Chapter 4. Differentiated Effects of Community Schooling in Primary Education

\subsubsection{Outcome variables}

As in the previous chapter, in this chapter pupils' educational progress is divided into cognitive and social-emotional outcomes.

The cognitive outcomes are based on the CITO-test which Dutch primary school pupils take in the final year of primary education, Grade 8. They are tested in language, mathematics, world orientation, and study skills. These tests are used to calculate a final score. To estimate the impact of community school education on these cognitive outcomes, data from the 2007 wave are used. In this school year, 13 of the 23 primary schools in Schiedam were community schools.

Second, three social-emotional outcome variables are considered. The social-emotional outcomes are based on teacher ratings (see Appendix, Chapter 3). Three underlying social-emotional factors have been identified: Underperformance, behavior, and perseverance. 'Underperformance' includes information on whether a pupil performs below their ability, as perceived by the teacher. This variable is coded reversely. Therefore, a negative coefficient has to be interpreted positively as it implies less underperformance. 'Behavior' measures whether a pupil is often impertinent, and whether a pupil does not behave according to the rules. Finally, 'perseverance' reflects whether a pupil is eager to learn or if s/he gives up when something does not work out easily. Again, pupils are observed in Grade 8 and data from the second wave of the COOL $^{5-18}$-study from the school year 2010/11 are used. In the school year 2010, 14 of the 23 primary schools in Schiedam were community schools. For a more detailed description see subsection 3.4.2.

As in the previous chapter, all outcomes are standardized. Table 
4.2 shows the $25^{\text {th }}, 50^{\text {th }}$ and $75^{\text {th }}$ percentile for each of the outcome variables, and reveals that all measures, except language and underperformance, are slightly positively skewed.

Table 4.2: Standardized outcomes by percentiles

\begin{tabular}{lcccc}
\hline Outcome & $25^{\text {th }}$ percentile & $50^{\text {th }}$ percentile & $75^{\text {th }}$ percentile & $\mathrm{n}$ \\
\hline Cognitive & & & & \\
Mathematics & -.717 & .097 & .731 & 366 \\
Language & -.702 & -.028 & .800 & 366 \\
World orientation & .637 & .083 & .652 & 366 \\
Study skills & -.710 & .086 & .881 & 366 \\
Final score & -.849 & .063 & .874 & 366
\end{tabular}

Social-emotional

\begin{tabular}{lllll} 
Underperformance & -.577 & -.196 & .568 & 732 \\
Behavior & -.476 & .100 & .676 & 732 \\
Perseverance & -.814 & .255 & .611 & 732 \\
\hline
\end{tabular}

Note: The variables are standardized: mean $=0$, standard deviation $=1$.

Before evaluating the effect of the community school subsidy on the outcomes, it is interesting to note how the pupil groups differ with respect to the cognitive and social-emotional outcomes. Pupils are distinguished based on whether they are a carepupil, and whether they have relatively lower-educated parents.

Table 4.3 shows the results from $t$-tests. Significant differences are observed for all outcomes and between all groups of pupils. The only exception is that the difference between community school and regular school pupils is not statistically significant with respect to performance in study skills.

Table 4.4 shows the results from $t$-tests for the social-emotional outcomes. Significant differences in the outcomes are observed between 
Chapter 4. Differentiated Effects of Community Schooling in Primary Education

Table 4.3: Differences in cognitive outcomes between community school and regular school pupils

\begin{tabular}{|c|c|c|c|c|c|c|c|}
\hline Indicator & & $\mathrm{n}$ & $\begin{array}{l}\text { Math. } \\
\text { Mean } \\
\text { (s.d.) }\end{array}$ & $\begin{array}{l}\text { Lang. } \\
\text { Mean } \\
\text { (s.d.) }\end{array}$ & $\begin{array}{c}\text { World Or. } \\
\text { Mean } \\
\text { (s.d.) }\end{array}$ & $\begin{array}{c}\text { Study sk. } \\
\text { Mean } \\
\text { (s.d.) }\end{array}$ & $\begin{array}{c}\text { Final sc. } \\
\text { Mean } \\
\text { (s.d.) }\end{array}$ \\
\hline \multirow[t]{2}{*}{ Carepupil } & Yes & 96 & $\begin{array}{l}-.612 \\
(1.048)\end{array}$ & $\begin{array}{l}-.732 \\
(.892)\end{array}$ & $\begin{array}{l}-.575 \\
(1.048)\end{array}$ & $\begin{array}{l}-.681 \\
(.857)\end{array}$ & $\begin{array}{l}-.761 \\
(.902)\end{array}$ \\
\hline & No & 270 & $\begin{array}{c}.217 \\
(.888)^{* * *}\end{array}$ & $\begin{array}{c}.260 \\
(.904)^{* * *}\end{array}$ & $\begin{array}{c}.204 \\
(.900)^{* * *}\end{array}$ & $\begin{array}{c}.242 \\
(.934)^{* * *}\end{array}$ & $\begin{array}{c}.271 \\
(.889)^{* * *}\end{array}$ \\
\hline $\begin{array}{l}\text { Lower- } \\
\text { educated }\end{array}$ & Yes & 177 & $\begin{array}{c}-.130 \\
(1.005)\end{array}$ & $\begin{array}{l}-.126 \\
(.939)\end{array}$ & $\begin{array}{c}-.114 \\
(.993)\end{array}$ & $\begin{array}{l}-.097 \\
(.961)\end{array}$ & $\begin{array}{l}-.136 \\
(.963)\end{array}$ \\
\hline parents & No & 189 & $\begin{array}{c}.122 \\
(.982)^{* *}\end{array}$ & $\begin{array}{c}.118 \\
(1.043)^{*}\end{array}$ & $\begin{array}{c}.107 \\
(.997)^{*}\end{array}$ & $\begin{array}{c}.091 \\
(1.029)^{*}\end{array}$ & $\begin{array}{c}.127 \\
(1.019)^{* *}\end{array}$ \\
\hline
\end{tabular}

Note: $* / * * / * *$ means statistically significant difference at $1 / 5 / 10$ percent.

care- and non-carepupils in all three outcomes.

Table 4.3 and Table 4.4 clarify the starting point of the analysis. As expected, disadvantaged pupils are performing worse on the outcome measures, both cognitive and social-emotional.

\subsubsection{Treatment variables}

This chapter considers the impact of community schools in three ways: duration, subsidy, and activities. The next sections present the descriptive statistics for these treatment indicators. The descriptives of the treatment indicators are presented for the community school pupils, as well as, for the relevant subsamples, consisting of carepupils and pupils with lower-educated parents. 
Table 4.4: Differences in social-emotional outcomes between community school and regular school pupils

\begin{tabular}{|c|c|c|c|c|c|}
\hline Indicator & & $\mathrm{n}$ & $\begin{array}{l}\text { Underperformance } \\
\text { Mean } \\
\text { (s.d.) }\end{array}$ & $\begin{array}{l}\text { Behavior } \\
\text { Mean } \\
\text { (s.d.) }\end{array}$ & $\begin{array}{l}\text { Motivation } \\
\text { Mean } \\
\text { (s.d.) }\end{array}$ \\
\hline \multirow[t]{2}{*}{ Carepupil } & Yes & 191 & $\begin{array}{c}.222 \\
(.976)\end{array}$ & $\begin{array}{l}-.193 \\
(.971)\end{array}$ & $\begin{array}{l}-.512 \\
(.924)\end{array}$ \\
\hline & No & 541 & $\begin{array}{c}-.078 \\
(.998) * * *\end{array}$ & $\begin{array}{c}.068 \\
(1.003)^{* * *}\end{array}$ & $\begin{array}{c}.181 \\
(.963)^{* * *}\end{array}$ \\
\hline \multirow[t]{2}{*}{$\begin{array}{l}\text { Lower-educated } \\
\text { parents }\end{array}$} & Yes & 307 & $\begin{array}{l}.136 \\
(.957)\end{array}$ & $\begin{array}{c}-.181 \\
(.998)\end{array}$ & $\begin{array}{l}-.250 \\
(.998)\end{array}$ \\
\hline & No & 425 & $\begin{array}{l}-.099 \\
(1.020)\end{array}$ & $\begin{array}{l}.131 \\
(.982)\end{array}$ & $\begin{array}{c}.181 \\
(.963)\end{array}$ \\
\hline
\end{tabular}

Note: $* / * * / * * *$ means statistically significant difference at $1 / 5 / 10$ percent.

\section{Community school duration}

Table 3.5 (Chapter 3) shows the descriptive statistics for the community school duration indicator for the cognitive sample. The table clarifies that pupils in the treatment group have experienced 1, 4, or 7 years of community schooling. The pupils are fairly evenly distributed between those attending a school that was an early adopter of community schooling and those at schools that converted only recently to community schooling.

For the cognitive sample, the average is 3.705 (s.d. 2.596) for community schools pupils. For carepupils in community schools, it is 2.167 (s.d. 2.793) ${ }^{1}$, and for community school pupils with lower-educated parents it is 1.734 (s.d. 2.541$)^{2}$.

\footnotetext{
${ }^{1}$ For non-carepupils in community schools it is 1.741 (s.d. 2.534).

${ }^{2}$ For community schools pupils with relatively higher-educated parents, it is 1.963 (s.d. 2.670).
} 
Chapter 4. Differentiated Effects of Community Schooling in Primary Education

For the social-emotional sample, the average duration is 6.197 (s.d. 2.183) for community school pupils. For carepupils attending a community school, it is 3.440 (s.d. 3.562$)^{3}$, and for community school pupils with lower-educated parents it is 3.130 (s.d. 3.527$)^{4}$.

\section{Community school subsidy}

The subsidy is calculated based on the average amount that has been spent per pupil while s/he was in primary education. In order to disentangle the subsidy from the duration indicator, the preceding number is divided by the number of years a school is a community school. For the cognitive sample, the average is $€ 122.43$ (s.d. 47.96) for community school pupils. For carepupils in community schools it is $€ 127.44$ (s.d. 42.12$)^{5}$, and, for community school pupils with lower-educated parents, it is €122.39 (s.d. 49.04$)^{6}$.

For the social-emotional sample, the average subsidy is $€ 158.99$ (s.d. 53.48$)^{7}$ for community school pupils. For carepupils attending community schools, it is $€ 170.49$ (s.d. 47.95), and, for community school pupils with lower-educated parents it is $€ 174.23$ (s.d. 38.35$)^{8}$.

${ }^{3}$ For non-carepupils in community schools it is 2.978 (s.d. 3.423).

${ }^{4}$ For community school pupils with relatively higher-educated parents, it is 3.075 (s.d. 3.420).

${ }^{5}$ For non-carepupils in community schools, it is $€ 120.43$ (s.d. 50.10).

${ }^{6}$ For community school pupils with relatively higher-educated parents, it is $€ 122.46$ (s.d. 47.19).

${ }^{7}$ For non-carepupils in community schools, it is $€ 154.66$ (s.d. 54.87).

${ }^{8}$ For community school pupils with relatively higher-educated parents, it is $€ 148.039$ (s.d. 59.84). 


\section{Community school activities}

To estimate the effect of the activity offer on the cognitive outcomes, the sum of how often each activity has been offered in the school the individual pupil attends is used.

Table 4.5 shows the descriptive statistics for the activity offer for the cognitive subsamples. The table shows variation across the frequency of the activity offer which is exploited in the below analyses. Cultural activities are offered most frequently to all sub-samples. School environment and school climate are least popular.

Table 4.5: Community school activity offer between 2000 and 2007 for the cognitive sub-samples

\begin{tabular}{|c|c|c|c|c|c|c|}
\hline & ELP & Care & School climate & Parents & Culture & Environment \\
\hline \multicolumn{7}{|c|}{ Community school pupils } \\
\hline Mean & 3.842 & 3.842 & 2.923 & 3.230 & 4.279 & 1.995 \\
\hline s.d. & 2.967 & 2.967 & 3.128 & 2.679 & 3.050 & 2.532 \\
\hline $\mathrm{n}$ & \multicolumn{6}{|c|}{183} \\
\hline \multicolumn{7}{|c|}{ Carepupils in community schools } \\
\hline Mean & 4 & 4.269 & 3.308 & 4.115 & 4.615 & 2.385 \\
\hline s.d. & 2.835 & 3.144 & 3.573 & 3.078 & 3.108 & 2.816 \\
\hline $\mathrm{n}$ & \multicolumn{6}{|c|}{52} \\
\hline \multicolumn{7}{|c|}{ Community school pupils with lower-educated parents } \\
\hline Mean & 3.614 & 3.648 & 2.773 & 3.148 & 4.011 & 1.943 \\
\hline s.d. & 2.961 & 3.006 & 3.165 & 2.731 & 3.087 & 2.521 \\
\hline $\mathrm{n}$ & \multicolumn{6}{|c|}{88} \\
\hline
\end{tabular}

Next, the activities for pupils in the social-emotional sample are shown. For community school pupils, carepupils, and pupils with lower-educated parents. Table 4.6 shows the descriptive statistics for the exposure to the community school activity offer between 2003 and 
Chapter 4. Differentiated Effects of Community Schooling in Primary Education

Table 4.6: Community school activity offer between 2000 and 2007 for the social-emotional sub-samples

\begin{tabular}{|c|c|c|c|c|c|c|}
\hline & ELP & Care & School climate & Parents & Culture & Environment \\
\hline \multicolumn{7}{|c|}{ Community school pupils } \\
\hline Mean & 6.516 & 5.724 & 4.142 & 5.973 & 5.973 & 2.839 \\
\hline s.d. & 1.865 & 2.129 & 2.784 & 1.821 & 1.821 & 2.258 \\
\hline $\mathrm{n}$ & \multicolumn{6}{|c|}{732} \\
\hline \multicolumn{7}{|c|}{ Carepupils in community schools } \\
\hline Mean & 6.860 & 6.140 & 4.610 & 6.230 & 7 & 3.200 \\
\hline s.d. & 1.658 & 1.923 & 2.420 & 1.669 & 1.729 & 2.103 \\
\hline $\mathrm{n}$ & \multicolumn{6}{|c|}{100} \\
\hline \multicolumn{7}{|c|}{ Community school pupils with lower-educated parents } \\
\hline Mean & 6.614 & 5.837 & 4.804 & 6.137 & 6.732 & 3.124 \\
\hline s.d. & 1.950 & 2.341 & 2.626 & 1.920 & 1.933 & 2.091 \\
\hline $\mathrm{n}$ & \multicolumn{6}{|c|}{153} \\
\hline
\end{tabular}

2010, the years during which these pupils are in primary education. Again, cultural activities are very popular; the same holds for educational learning process (ELP) activities. School environment activities are offered least.

\subsection{Estimation strategy}

This chapter tests the broad hypothesis that community schools may be particularly effective for particular pupil groups: namely, carepupils and pupils with lower-educated parents. The next subsections describe how the community school impact is estimated in terms of the three working mechanisms: Duration of exposure to community school education; community school subsidy; and community school activities. 
4.6. Estimation strategy

\subsubsection{Community school attendance}

The first treatment indicator is the duration of the community school attendance. Its effect on the outcomes is estimated by the following model:

$$
Y_{i}=\alpha+b_{1} C S+b_{2} \text { carepupil } * C S+b_{3} \text { carepupil }+b_{4} X+e_{i},
$$

where $Y_{i}$ are the cognitive and social-emotional educational outcomes described above. $\alpha$ is a constant term. $C S$ is the continuous treatment indicator, i.e. the length of community schooling. ${ }^{9} \quad b_{2}$ is the coefficient of interest: the interaction of attending a community school while being a carepupil. ${ }^{10}$ If the above hypotheses are true and carepupils perform better in community schools than in regular schools, $b_{2}$ must be positively significant. A positive effect on underperformance requires a negatively significantly coefficient as it is coded reversely. $X$ are the control variables sex, ethnic origin of the parents, whether a father is present in the family, age of the pupil, school score, grade size, and the presence or initiation of a playgroup and an extended school day program in the school. In addition, when the focus is on carepupils, a control is used for whether that pupil has lower-educated parents, and, when the focus is on pupils with lower-educated parents, a control is used for being a carepupil. $e_{i}$ is a normally distributed

\footnotetext{
${ }^{9}$ The previous chapter distinguished two community school duration perspectives: The pupil perspective, considering how long a pupil has been in a community school, and the school perspective, considering how long the school has received a community school subsidy. Here, the focus is on the pupil perspective.

${ }^{10} \mathrm{It}$ is assumed that a pupil who is coded as a carepupil in Grade 8 has been a carepupil throughout his/her educational career.
} 
Chapter 4. Differentiated Effects of Community Schooling in Primary Education

zero-mean constant variance error term.

To test the robustness of the results, the specification is also estimated with a binary indicator such that community school duration is replaced with a dummy which is 1 for community school pupils and 0 for regular school pupils. Finally, the sample is split; only carepupils are considered and the following model is estimated:

$$
Y_{i}=\alpha+b_{1} C S+b_{2} X+e_{i} .
$$

As in the latter approach only carepupils are considered, interaction terms are not required. However, due to the use of different samples the results are not directly comparable to those of the above specifications.

\subsubsection{Community school subsidy}

Second, the effect of the community school subsidy on the outcomes is estimated by the following model:

$$
\begin{array}{r}
Y_{i}=\alpha+b_{1} C S s u b+b_{2} \text { carepupil }+b_{3} C \text { Sduration }+ \\
b_{4} C S s u b * \text { carepupil }+b_{5} C S d \text { dration } * \text { carepupil }+b_{6} X+e_{i},
\end{array}
$$

where $b_{1}$ is the coefficient for the community school subsidy, which is incorporated as the mean per pupil subsidy, calculated over the years the school was a community school (i.e. it effectively received subsidies for being such a school). $b_{3}$ is the coefficient for the community school duration, as defined in the previous section. Duration is explicitly included, as the model has to account for the fact that the community school subsidy in this setting cannot be considered independently from how long a school has received a subsidy because the correlation be- 
4.6. Estimation strategy

tween time and budget is high (approximately .8 in both samples). Hence, if the duration is not included in the model, the budget does not only express the mere financial effect but also reflects that schools which became community schools earlier also received more money. $b_{4}$ is the coefficient of interest, and informs whether more budget is beneficial for the educational progress of carepupils. $b_{5}$ is an interaction between being a carepupil and the community school duration; it is added as the duration effect may differ for carepupils.

Finally, a robustness check similar to that in the previous section is carried out. A split sample analysis including only carepupils is estimated with the following model:

$$
Y_{i}=\alpha+b_{1} C S s u b+b_{2} C S d u r a t i o n+b_{3} X+e_{i}
$$

\subsubsection{Community school activities}

To estimate the effect of the six community school activities for the two groups of pupils, split sample analyses are carried out. Specifically, subsamples of carepupils and pupils with lower-educated parents are considered. The following model is estimated:

$$
Y_{i}=\alpha+b_{1} C S a c t+b_{2} X+e_{i},
$$

where CSact is a vector of the six community school activities. For robustness, the counterfactual samples are considered as well: Noncarepupils, and pupils whose parents have a relatively higher educational level. In this section, interaction models are not used because in this specification six treatments (i.e. the six activities) are considered jointly which would render the output rather chaotic. 
Chapter 4. Differentiated Effects of Community Schooling in Primary Education

\subsubsection{Estimation procedure}

All specifications are estimated using OLS. The models assume that the individual error terms, $e_{i}$, are independently distributed. However, this assumption is unlikely to hold for pupils who attend the same school. Therefore, the standard errors are clustered at the school level. For all specifications, carepupils can be replaced by lower-educated parents in the model specifications above. ${ }^{11}$

\subsection{Results}

In this section, the estimation results are described. The results for estimating the effect of attending a community school, the subsidy, and the activities on the cognitive and social-emotional outcomes for carepupils and for pupils with parents with low educational degrees are presented in turn. The tables only show the results for cognitive outcomes mathematics and language, and for the social-emotional outcomes the results for underperformance. The results for world orientation, study skills, and the final score, as well as, for motivation and behavior, can be obtained from the researcher. If findings for these outcomes differ substantially from the reported outcomes, they are discussed in the text.

\footnotetext{
${ }^{11}$ In the analyses it is not considered that carepupils and those with relatively lower-educated parents can be overlapping states. These characteristics are controlled for, however, and the correlation is low.
} 


\subsubsection{The effect of community school duration}

Table 4.7 shows the results for the effect of the duration of community schooling on the pupil outcomes. Columns (1), (2) and (3) refer to the analysis for carepupils, columns (4), (5) and (6) refer to the analysis for pupils with lower-educated parents. In the table 'Group' refers to the two differentiated pupil groups: carepupils and pupils with lowereducated parents; 'CS*Group' is the interaction between community school attendance and being a member of the respective group. 


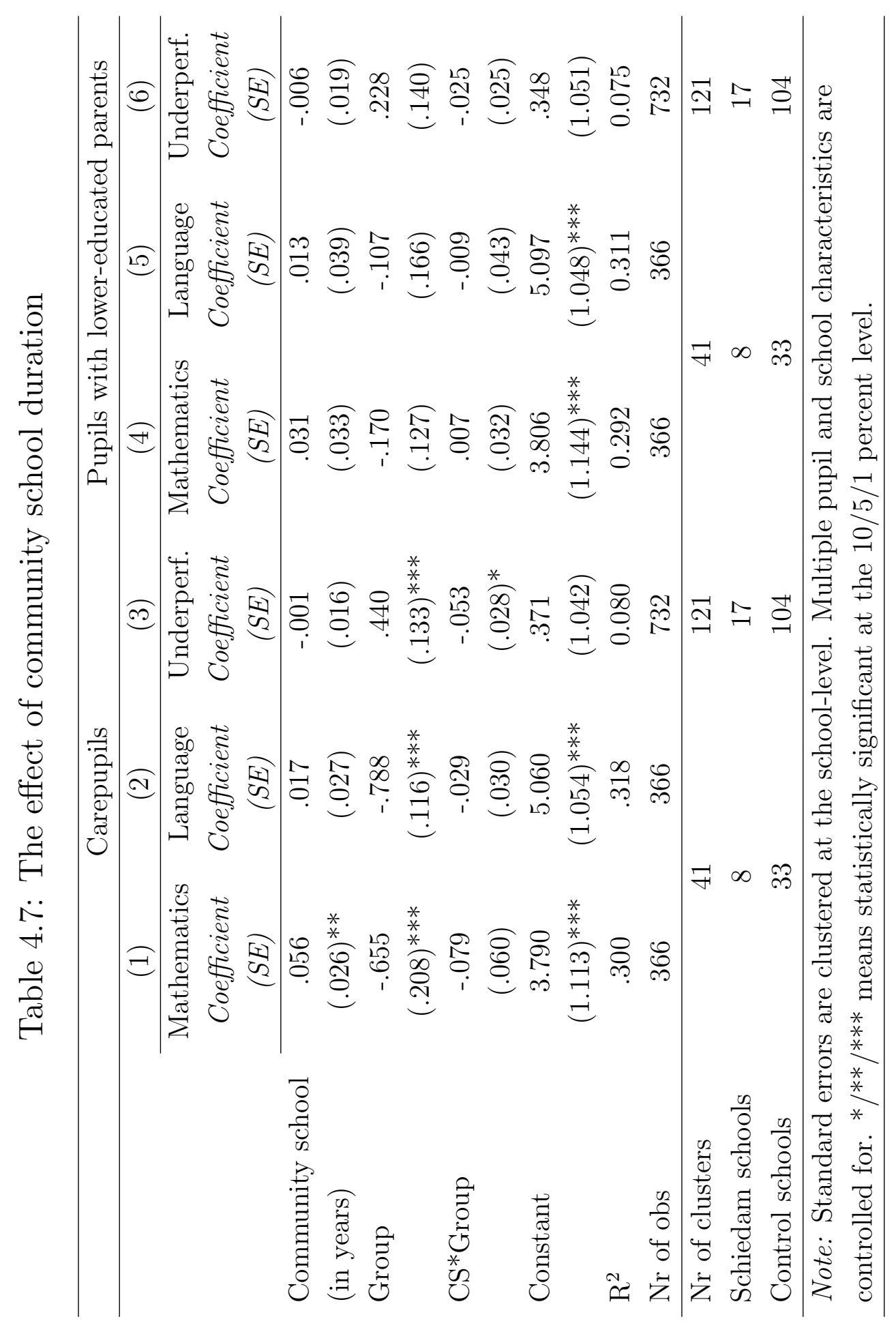




\section{Carepupils}

\section{Cognitive outcomes.}

The results show that, in general, carepupils perform significantly worse than non-carepupils. At the same time the duration of community schooling is positively significant with respect to carepupils' mathematics and world orientation results. The interaction between community school duration and being a carepupil is not significant for any of the outcomes except world orientation, for which it is negative. The insignificant interaction effect combined with a significantly negative coefficient for carepupils points to the conclusion that community schools may be good for pupils, but do not favor carepupils specifically. Pupils tend to perform better on the mathematics and world orientation tests, the longer they have experienced community schooling. Yet, for carepupils, the latter only applies for mathematics, because for world orientation the overall positive effect of community schooling is counterbalanced by a negative effect for carepupils.

A specification with a dummy indicator for having been in a community school has also been tested. The results confirm those in Table 4.7: The coefficient for being a carepupil is negative and statistically significant, and none of the interactions is significant. The community school dummy is negatively significant for language. Another robustness check is carried out by splitting the sample and only considering carepupils $(n=96)$. The community school duration indicator proves not to be significant for any of the outcomes.

All in all, for these outcomes it can be concluded that carepupils do not perform better in community schools compared with regular schools, with the potential exception of the mathematics test. Hence, 
Chapter 4. Differentiated Effects of Community Schooling in Primary Education

Hypothesis $H .1 a$ is rejected for the cognitive outcomes of carepupils.

\section{Social-emotional outcomes.}

Next, the focus is on the social-emotional outcomes of carepupils. Column (3) in Table 4.7 shows the results for underperformance. Generally, carepupils perform worse on underperformance (reversely coded) and perseverance. Longer attendance on its own is not significant. The interaction of being a carepupil and attending a community school longer is negative and statistically significant for underperformance, indicating that when carepupils spend time in community schools their teachers consider them to underperform gradually less. The other outcomes are unaffected.

Again, a dummy specification has also been estimated. The results confirm those in Table 4.7. The only difference is that the dummy for community schools is positive and significant for behavior. Finally, the sample is split and only carepupils are considered $(n=191)$. In this specification an increased number of years in a community school significantly reduces underperformance. Thus, overall, community schools seem to be suited to reduce underperformance specifically for carepupils. As the other outcomes are not affected, hypothesis H.1a is partly rejected for the social-emotional outcomes of carepupils.

\section{Lower-educated parents}

\section{Cognitive outcomes.}

Columns (4) and (5) in Table 4.7 show the results for the effect of an increasingly long community school experience for the cognitive outcomes of pupils with lower-educated parents. The interaction between 
the duration and the dummy for having lower-educated parents is not significant for any of the outcomes. Thus, community schools do not help to increase the cognitive skills of these pupils specifically. An estimation with a dummy specification confirms the findings. The only exception is that the interaction is negative and significant for study skills, suggesting that pupils with lower-educated parents attending community schools perform worse in study skills than those in regular schools. The split sample analysis $(n=307)$ confirms the results in Table 4.7: None of the outcomes is affected by the duration of community school attendance. Therefore, Hypothesis $H .1 b$ is rejected with respect to the cognitive outcomes.

\section{Social-emotional outcomes.}

With respect to the social-emotional outcomes, the results for the effect of an increasing community school attendance of pupils with lowereducated parents show that, generally, pupils with lower-educated parents behave less well and show less perseverance. Attending a community school does not improve these outcomes. The dummy specification confirms the findings. The results from the split sample analysis show a negative effect on underperformance. Overall, Hypothesis H.1b cannot be accepted for the social-emotional outcomes.

\subsubsection{The effect of the community school subsidy}

Table 4.8 shows the results for the effect of the community school budget. As explained above, the duration of attendance of a community school must also be considered in this context. 


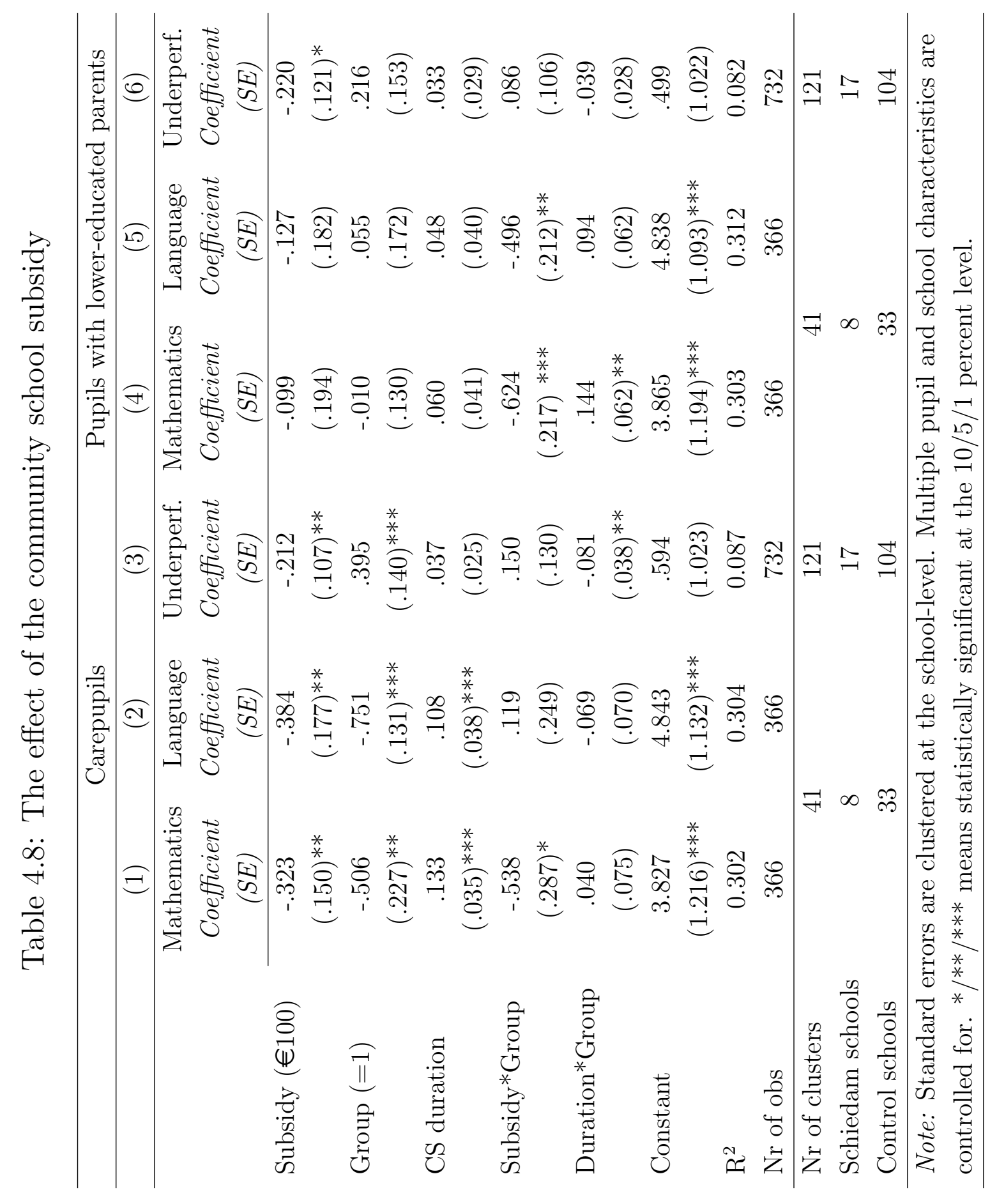




\section{Carepupils}

\section{Cognitive outcomes.}

Surprisingly, the results suggest that more money on its own has a negative impact on all cognitive outcomes of carepupils. The same holds for the coefficient for being a carepupil (except for world orientation). This is as expected, however. It is interesting to see that, when the subsidy is accounted for, the effect of community school duration on all outcomes is significantly positive. This effect was only observed for mathematics and world orientation for the results in the section on community school duration, but there the effect was pronounced less strongly. The interaction of subsidy with being a carepupil is negative and significant for mathematics, suggesting that an increased community school budget relates to worse mathematics skills of carepupils in community schools. For the other outcomes, this interaction is insignificant, suggesting that community schools in terms of subsidy do not contribute to improving carepupils' cognitive skills. Finally, the interaction between duration and being a carepupil is not significant for any of the outcomes. This is broadly in line with the results in Table 4.7.

Again, the robustness of the results is tested by a split sample analysis. The results generally support those in Table 4.8: A negative effect throughout of subsidy on the outcomes, while community school duration is positively significant for mathematics, world orientation, and study skills. Hypothesis H.2a is not accepted for carepupils' educational progress in terms of cognitive learning.

\section{Social-emotional outcomes.}


Chapter 4. Differentiated Effects of Community Schooling in Primary Education

Column (3) in Table 4.8 refers to the results for the subsidy estimations for the social-emotional outcomes for carepupils. Increasing the subsidy has a negative effect on underperformance; being a carepupil, as expected, has a positive effect. The interaction of subsidy and being a carepupil is not significant. Moreover, the interaction effect of duration and care is significantly negative, suggesting that, if carepupils have been longer in community schools, they underperform less. These findings confirm those in Table 4.7. Behavior is not affected at all. With regard to perseverance, the results show that carepupils exhibit less perseverance, an increasing subsidy does not help to increase perseverance, while the negative coefficient for the interaction between duration and being a carepupil suggests that, if carepupils spend more time in community schools, they show less perseverance.

To test the robustness of the results, again a split sample analysis is carried out. The results broadly confirm those in Table 4.8: Longer exposure to community school education relates to reduced underperformance. Differing from the results in Table 4.8, budget itself is not significant for underperformance but positively significant for perseverance. The results also suggest that community school exposure duration negatively affects perseverance. Hence, Hypothesis $H .2 a$ is not accepted for educational progress in terms of social-emotional learning progress.

\section{Lower-educated parents}

\section{Cognitive outcomes.}

The results for the effect of an increasing community school subsidy on the cognitive outcomes of pupils with lower-educated parents (Column 
(4) and (5), Table 4.8) show that the subsidy is not significant for any of the outcomes. The community school duration is significant for world orientation. The interaction of subsidy and having lowereducated parents is negative and significant for mathematics, language, study skills and the final score. A longer period spent in community schools while having lower-educated parents is positively significant for the mathematics performance of these pupils.

These findings are partly confirmed by the split sample analysis: A negative effect throughout of subsidy, while the effect of community school attendance duration is throughout positively significant. Hence, Hypothesis $H .2 b$ is not accepted for educational progress in terms of cognitive learning.

\section{Social-emotional outcomes.}

The results for the effect of subsidy on the social-emotional outcomes of pupils with lower-educated parents show that a higher subsidy negatively affects underperformance. Behavior and perseverance are not affected by the size of the subsidy. The interaction effects are not significant for any outcome. A split sample analysis confirms the findings in Table 4.8. In sum, Hypothesis H.2b is partly rejected for the social-emotional outcomes.

\subsubsection{The effect of community school activities}

To estimate the effect of the community school activities split sample analyses are used, as was explained in subsection 4.6.3. 


\subsubsection{Carepupils}

\section{Cognitive outcomes.}

Columns (1) and (2) in Table 4.9 show the results for the effect of community school activities on the cognitive outcomes of carepupils. These results are mixed. Negative effects for educational activities (educational learning process, ELP) on a selection of outcomes (mathematics, world orientation, and the final score) and of parental activities and school environment on all outcomes are found. Positive effects are found for care activities (with respect to mathematics, world orientation, and the final score) and measures regarding the school climate (with respect to all outcomes). No effect is found for cultural activities.

The same analysis is carried out for the counterfactual sample, the non-carepupils. The results are shown in columns (4) and (5) in Table 4.9. Interestingly, the results differ: ELP positively affects all five outcomes; while care negatively affects all outcomes. Both findings are opposite to the results for carepupils. School climate has a positive effect throughout (as it did for carepupils), as well as parental activities (contrary to carepupils). Again, cultural activities are not significant, and again school environment has a negative effect on all outcomes; and, for this sample, also on world orientation. Although Hypothesis H.3a regarding the positive effect of community school activities on carepupils is not generally accepted, these findings also highlight that community schools can have quite different effects on different pupil groups. 


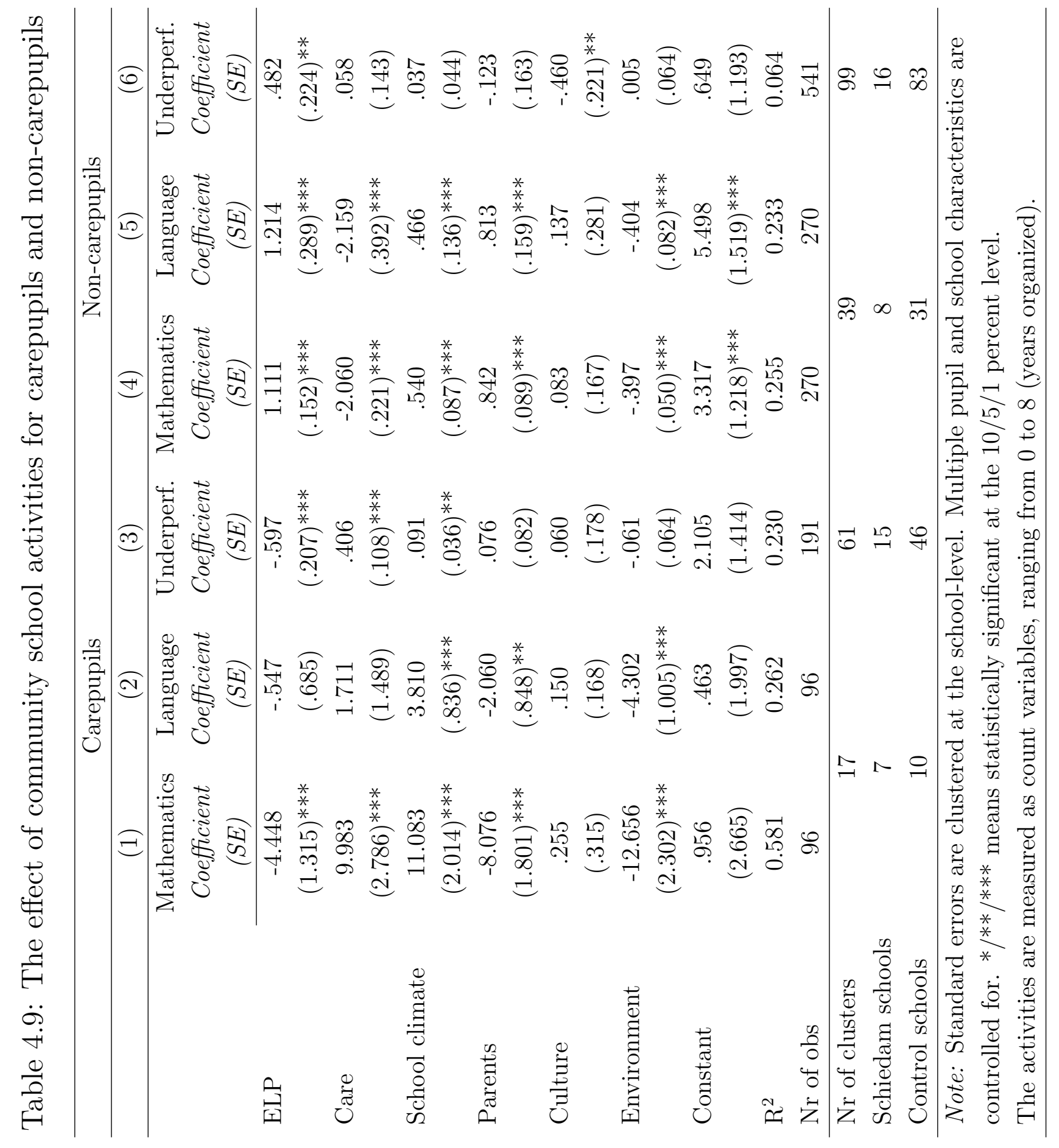


Chapter 4. Differentiated Effects of Community Schooling in Primary Education

\section{Social-emotional outcomes.}

The results for the effect of community school activities on carepupils' social-emotional outcomes are mixed (Column (3), Table 4.9). With respect to underperformance, educational activities have a negative effect, while care and school climate activities have a positive effect. Thus, carepupils do not benefit from care and school climate activities but from educational activities. With regard to behavior, positive effects of school climate activities and a negative effect of school environment are found. Finally, carepupils benefit in terms of perseverance from school climate activities, but not from care and school environment activities. In conclusion, Hypothesis $H .3 a$ is partially rejected with respect to the social-emotional outcomes.

Again, the model is estimated for the counterfactual group, noncarepupils. The results (Column (6), Table 4.9) differ from those for carepupils. ELP is positively significant for underperformance, while cultural activities are significantly negative. Behavior is negatively affected by care activities and school environment and positively by parental activities. Perseverance is negatively affected by school environment.

\section{Pupils with lower-educated parents}

Finally, the extent to which pupils with parents with low educational levels benefit from community school activities is shown in Table 4.10. The impacts for the counterfactual group, pupils with relatively highereducated parents, are also presented (Columns (4), (5), (6)). 


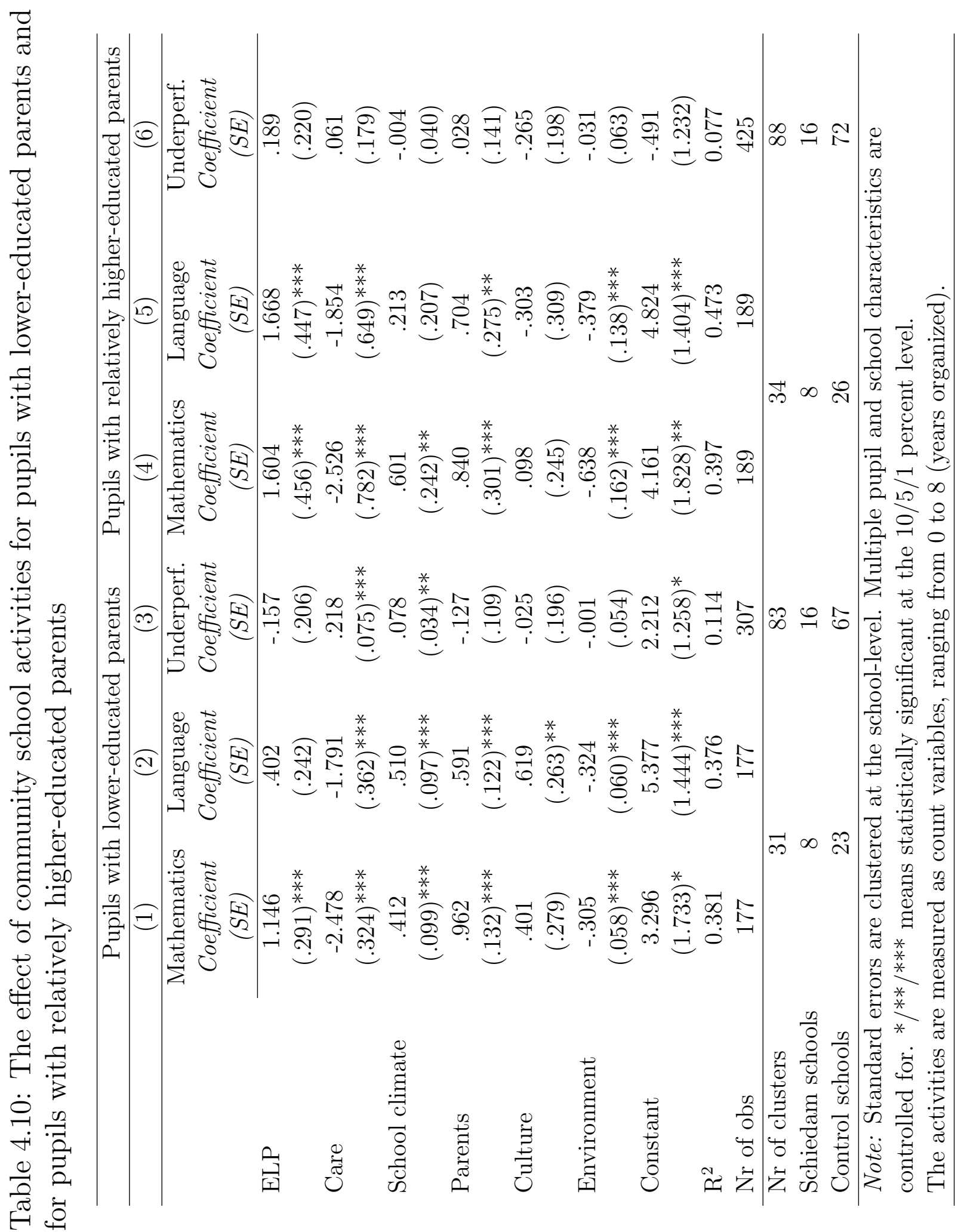


Chapter 4. Differentiated Effects of Community Schooling in Primary Education

\section{Cognitive outcomes.}

Columns (1) and (2) in Table 4.10 show the results for the effect of the community school activities on the cognitive outcomes of pupils with lower-educated parents. These pupils benefit from educational activities in terms of mathematics, world orientation, and the final score. School climate, parents, and cultural activities have a positive effect on all outcomes. Care and school environment activities negatively affect all outcomes. As in the case of the carepupils, Hypothesis H.3b is partially rejected.

Columns (4) and (5) show the results for the cognitive outcomes for pupils who have parents with relatively higher educational levels. These results are similar to those for pupils with lower educational levels. ELP positively affects all outcomes. Care and school environment activities have a negative impact on mathematics, language, study skills and the final score; as shown above, they do also on world orientation. School climate which, as shown above, positively affects all outcomes, here has a positive effect on mathematics, study skills and the final score. Parental activities have a positive impact on mathematics, language, study skills, and the final score; in the above results they also do regarding world orientation. Cultural activities do not affect any of the outcomes, while they do for pupils with lower-educated parents.

\section{Social-emotional outcomes.}

Finally, the effects of the activities on the social-emotional outcomes of pupils with lower-educated parents are described. Underperformance is positively affected by care and school climate activities. Parental ac- 
4.8. Discussion and conclusion

tivities have a positive effect and school environment activities a negative effect on behavior. Perseverance is positively affected by parental activities and negatively by care and school environment activities. Overall, Hypothesis H.3b is not accepted.

The results for pupils with relatively higher-educated parents show that their level of underperformance is not affected by any of the activities. As for the other sample, parental activities have a positive effect, and school environment activities a negative effect on behavior, while perseverance is positively affected by parental activities, and negatively by care and school environment activities.

\subsection{Discussion and conclusion}

This chapter has evaluated the effect of community schooling on pupils who are supposed to benefit from this type of education in particular. With its differentiated focus, this chapter complements the previous chapter which analyzed the effects of community schools on the average pupil. Like the earlier chapter, this chapter has considered community schools from three angles that may drive a community school effect on children's educational progress: The length of community schooling; the subsidy allocated to community schools; and the activities that are offered via this subsidy.

Several hypotheses have guided the analyses in this chapter. Table 4.11 summarizes to what extent these hypotheses are accepted based on the above empirical results. 


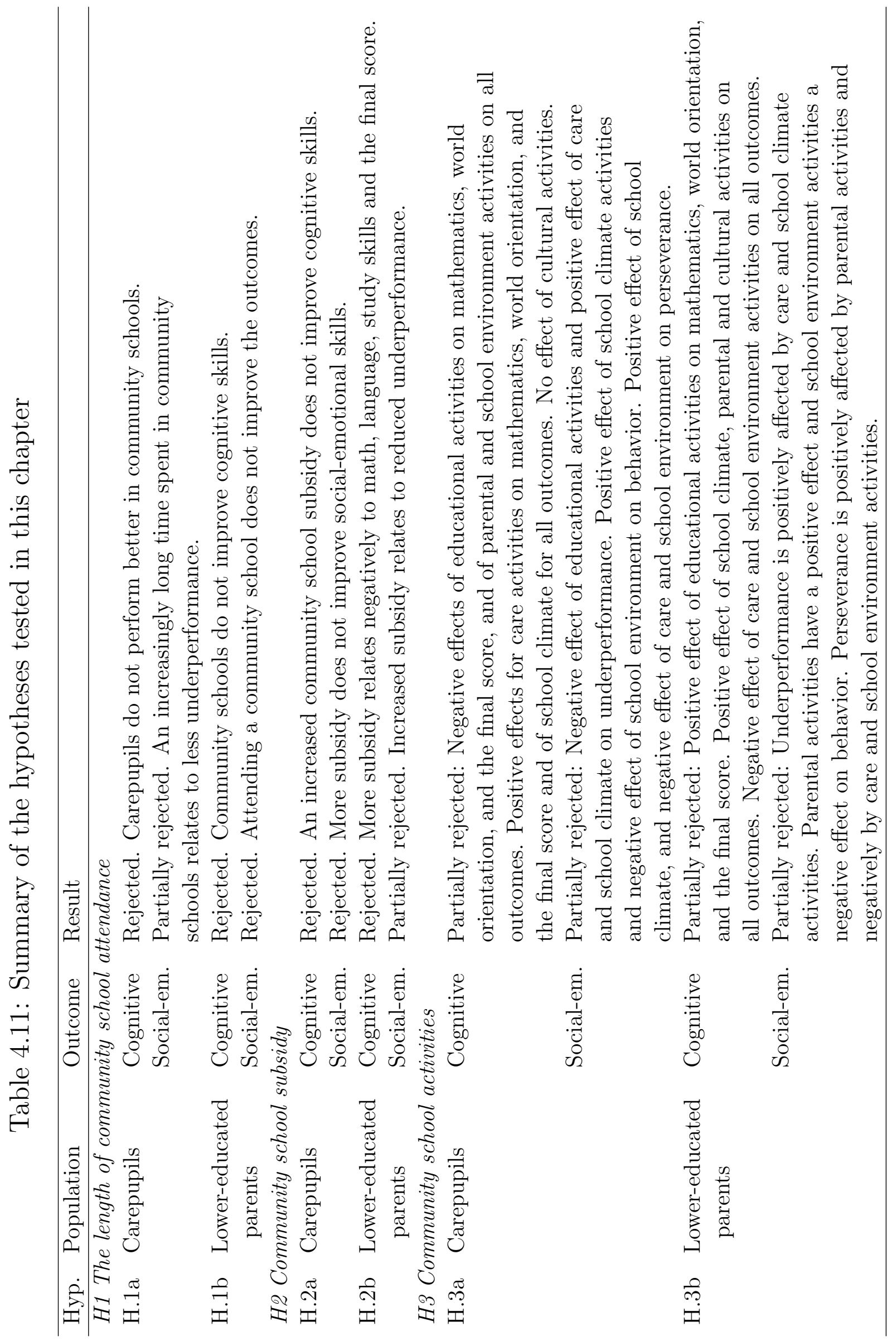


4.8. Discussion and conclusion

From Table 4.11 it is clear that the hypotheses are consistently not accepted. Generally, the length of the experience (duration) and the budget allocated do not seem beneficial for the pupil outcomes, neither generally nor for disadvantaged pupils. Duration, however, becomes statistically significant for some outcomes once the subsidy is included in the estimations. This result is likely to follow from the fact that the municipality did not invite schools to become a community school at random and nor did it allocate resources on a per capita basis. Schools with more disadvantaged pupils received more resources and became community schools first. Controlling for the subsidy, a more lengthy community school experience proves to foster learning outcomes. But this positive duration effect seems to be much weaker than the impact of the pupil composition. Schools with a large group of disadvantaged pupils received more money, but apparently were not able to counterbalance the severely weaker performance of these pupils. Future research may elaborate on the relative importance of the pupil composition of a school. For now, the results illustrate that the mechanisms that drive the impact of community schools on pupil outcomes are complex.

Even though the hypotheses cannot be accepted, some positive conclusions can be drawn from the above. Table 4.11 shows that community schools seem effective with respect to reducing underperformance. This implies that pupils perform better according to their capabilities if they attend a community school. This holds with respect to the length of community school attendance and to the community school subsidy, for both carepupils and pupils with relatively lower-educated parents. This measure of underperformance relates to the objective of talent development of community schools. It is assumed that, com- 
Chapter 4. Differentiated Effects of Community Schooling in Primary Education

pared with regular schools, community schools are better able to develop the talents of all pupils. Consequently, community schools seem suited for developing the talents of both carepupils and pupils of lowereducated parents. However, the effect on underperformance is rather small; therefore, it is debatable if this is enough to characterize community schools as effective.

The lack of an effect of subsidy for the two pupil groups under consideration requires further discussion. When it is stated that subsidy is not beneficial, it should also be mentioned that the activities are financed via this subsidy. As shown above, some of the activities are beneficial to pupil development. Thus, to put it more precisely, while the subsidy does not affect the outcomes of differentiated pupil groups, it is critical which activities are financed from this budget. This again illustrates the complexity of the process of how community schools affect educational learning outcomes.

Regarding the effects of the community school activities, this study has revealed important insights into the working mechanisms of community schools. Overall, the results are mixed for the differentiated pupil groups. The analyses for the community school activities in terms of the split sample analyses show that considering different populations within community schools reveals that the schools do indeed differently affect the outcomes. Not all activities seem to support pupils' educational progress; for example, the results suggest that, in terms of cognitive learning outcomes, care activities are beneficial to carepupils but not to non-carepupils. The results are partly contrary. For example, ELP and care activities have opposite effects on the cognitive outcomes of care- and non-carepupils, where carepupils benefit from care activities. This finding is highly policy-relevant, in the sense that to support 
4.8. Discussion and conclusion

particular pupil groups in their educational process, different interventions are required. Therefore, educationalists in community schools have to be selective in the activities they offer to whom. Moreover, for future evaluations of community schools, this heterogeneity of the effects implies that they should not only consider the average pupil but also zoom in on particular pupil groups, as otherwise effects may be averaged out.

Overall, the results in the main analyses and the robustness tests are consistent. In some cases, the main coefficient is slightly significant, while in the robustness checks they are marginally not significant. In general, for carepupils the effects differ more from the average pupil group considered in the previous chapter. For example, the effects of the community school activities are partly turned around. Thus, it may be the case that the findings in Chapter 3 are driven by the relatively high number of non-care pupils in the data. For pupils with lower-educated parents, the results are relatively consistent with those in the earlier chapter.

The absence of a general community school effect suggests that, if policymakers and educationalists focus on improving children's educational progress, it may be more effective to invest in subsidies that target children more precisely than all-embracing comprehensive efforts. The community school approach may not be powerful enough to tackle the specific problems of specific pupils.

Finally, there are some limitations with respect to the above analyses. First of all, the population in Schiedam differs from the Dutch average population. In particular, in Schiedam, there is a relatively high number of carepupils and people (thus also parents) who, on average, are lower-educated (Statistics Netherlands, 2012). Therefore, 
Chapter 4. Differentiated Effects of Community Schooling in Primary Education

the above results cannot necessarily be generalized to the Netherlands, although they may be highly relevant for relatively deprived municipalities. Another limitation of the above analysis is, as was also the case in the previous chapter, that it is not observed whether an individual pupil participates in a specific activity. Moreover, again, as in Chapter 3, teacher characteristics have not been observed. Finally, it is not clear how the schools actually allocated the money originating from the subsidy. While they had to state on what they allocated it, this may not always be what actually happened in reality. 


\section{Chapter 5}

The Impact of

Community Schools on

Student Dropout in

Lower Secondary

Pre-Vocational

Education ${ }^{1}$

${ }^{1}$ This chapter is based on: Heers, M., Van Klaveren, C., Groot, W. \& Maassen van den Brink, H. (2014). The Impact of Community Schools on Student Dropout in Pre-vocational Education. Economics of Education Review, 41, 105-119. doi: 10.1016/j.econedurev.2014.05.003. 
Chapter 5. The Impact of Community Schools on Student Dropout in Lower Secondary Pre-Vocational Education

\section{$5.1 \quad$ Introduction}

In the two previous chapters (3 and 4 ), the focus was on community schools in primary education. As outlined in the introduction of this dissertation, in the Netherlands, community schools have also been set up in secondary education. Therefore, this chapter focuses on community schools in secondary education, more precisely on lower secondary pre-vocational education. Moreover, the focus is no longer on community schools in Schiedam but on those in Rotterdam, where they are particularly popular in secondary education. The outcome that is analyzed in this chapter is early school leaving.

Policymakers, researchers, and educational practitioners are seeking effective approaches to reduce dropout (Rumberger, 2011; Thyssen, De Witte, Groot, \& Maassen van den Brink, 2011). This is because it involves costs at the personal, societal, and the fiscal level (De Witte \& Rogge, 2013). At the personal level, dropouts are more likely to become unemployed (Gesthuizen, De Graaf, \& Kraaykamp, 2005; Rumberger \& Lamb, 2003; Solga, 2002; Strom \& Boster, 2007; Van der Steeg \& Webbink, 2006); have lower lifetime earnings (McNeal, 1995); and have a lower health status (Groot \& Maassen van den Brink, 2007; McNeal, 1995). At the societal level, the costs of dropout entail a higher risk of criminal involvement (Groot \& Maassen van den Brink, 2010; Lochner \& Moretti, 2004; Strom \& Boster, 2007); lower social cohesion (e.g. Milligan, Moretti, \& Oreopoulos, 2004); lower economic growth (Hanushek \& Wössmann, 2007); and lower levels of political and social participation (McNeal, 1995). Finally, at the fiscal level higher dropout rates entail lower tax revenues and higher expenditures for social benefits, such as unemployment and health benefits (De Witte \& Rogge, 2013; 


\subsection{Introduction}

Psacharopoulos, 2007). Despite the recognition that reducing dropout is of importance, and despite the efforts made to reduce and to prevent dropout, many students still leave secondary and vocational education without a diploma.

Although various measures have been taken to reduce and prevent dropout, it is unclear how dropout can be effectively reduced or prevented, mainly because it is not the result of one specific problem, but of an accumulation of various problems that students experience at home, in their neighborhood, or at school (Rumberger, 2011; Thyssen et al., 2011).

Community schools recognize that a variety of factors are underlying educational problems, and that these may eventually lead to student dropout. Therefore, these schools attempt to modernize education so that it better accommodates students' personal needs and provides a more attractive learning environment. As outlined in Chapter 2 , community schools can be characterized as a combination of three activities: cooperation with external organizations; parental involvement; and extracurricular activities. The literature review in Chapter 2 has also shown that the correlational literature on the relationship between the community school activities and dropout is promising in this respect, as it mainly points towards less dropout if students participate in community school activities. For example, it has been shown that higher student attendance and lower student dropout are observed if schools cooperate more intensely with external institutions, such as youth care and health services (Epstein \& Sheldon, 2002). More parental involvement in the educational process is positively correlated with the probability of leaving secondary education with a diploma (Epstein, 1992; Rumberger et al., 1990). Finally, the empirical litera- 
Chapter 5. The Impact of Community Schools on Student Dropout in Lower Secondary Pre-Vocational Education

ture suggests that extracurricular activities can contribute to reducing student dropout, and the benefits of extracurricular involvement tend to be highest for students in deprived neighborhoods (Davalos et al., 1999; Mahoney \& Cairns, 1997). For example, participation in extracurricular activities relates to higher levels of student motivation, engagement, and connectedness, which are negatively correlated with student dropout (Archambault et al., 2009; Mahoney, Lord, \& Carryl, 2005). Moreover, several studies identify an association between participation in extracurricular activities and lower dropout probabilities (Blum et al., 2000; Mahoney, 2000; Mahoney \& Cairns, 1997; McNeal, 1995). Overall, the literature review suggests that community schools may contribute to counteract student dropout. This literature is mainly correlational, however. The review concludes that the empirical evidence on the effectiveness of the different community school activities tends to be merely descriptive. As a result, there is a lack of empirical evidence that community schools reduce or prevent dropout in secondary education, even though a rapid increase in the number of secondary community schools is observed.

The objective of this chapter is to examine whether community schools in the Netherlands have effectively reduced dropout in prevocational education. The focus is on the pre-vocational education track, because dropout is particularly high in that track. Moreover, this chapter focuses on student dropout for the city of Rotterdam, because this city is a frontrunner in the Netherlands and has many community schools.

For this purpose, unique registration data of the Ministry of Education are used containing all Rotterdam students who were enrolled in pre-vocational education between 2004 and 2008 (i.e. four school 


\subsection{Introduction}

years). To identify the impact of community schools, this chapter exploits the fact that community schools, as defined by the community school development subsidies, were not created before the beginning of the school year 2006/2007. Given this setting, the community school impact on student dropout can be estimated by means of a 'differencein-differences' model. Moreover, as the student population of community schools differs from the student population of comparison schools, an iterative matching procedure is applied to ensure that only comparable students are compared in the difference-in-differences analysis. This is required as the descriptive statistics indicate that the difference in student population is not caused by students who selectively attend community schools, but is caused by the fact that community schools offer different (and higher-level) learning tracks within pre-vocational education.

Van Elk, Van der Steeg, and Webbink (2013) provide causal evidence on the effect of what is called the "Neighborhood School Program' (NSP) ${ }^{2}$ in Rotterdam. This program has been designed to increase school enrollment and employment among multi-problem school dropouts aged 16 to 23. Participants receive an integrated set of educational, work, and health services, as well as counseling by a personal coach. But the authors find that this program does not have a statistically significant effect on school enrollment.

This chapter emphasizes that the community school intervention that is evaluated in this chapter is not well-defined by the municipality as there is no uniform definition of community schools. In this chapter, they are defined as receiving a community school development subsidy from the Municipality of Rotterdam. As outlined above,

\footnotetext{
${ }^{2}$ Dutch: Wijkschool.
} 
Chapter 5. The Impact of Community Schools on Student Dropout in Lower Secondary Pre-Vocational Education

Dutch community schools can be characterized by a combination of the three above-mentioned activities. These activities are financed by the received subsidy. If community schools offer a more effective education package than traditional schools, in the sense that it reduces dropout, the estimation results should show this. The community school subsidy has the primary goal of developing the talents of all students, while reduced dropout is expected to be a concomitant outcome (De Vos et al., 2010).

This chapter is structured as follows. Section 5.2 presents Dutch secondary education, the community school subsidy, the data, and the descriptive statistics. Section 5.3 deals with selection into community schools. Section 5.4 describes the identification strategy and the estimation model. Section 5.5 describes the results. Section 5.6 discusses and concludes.

\subsection{Dutch secondary education, data, and descriptives}

\subsubsection{Dutch secondary education}

In the Netherlands, children are assigned to different secondary education levels at the age of 12 . Primary schools give a secondary school advice on these levels, which is based on: (1) test scores achieved by children on a standardized national test in the final year of elementary school (the CITO scores used as outcome variables in Chapters 3 and 4); and (2) the schools' personal judgment of the ability of the child. Children are assigned to three different educational tracks after 
5.2. Dutch secondary education, data, and descriptives

elementary school: pre-vocational education; senior general secondary education; and pre-university education. ${ }^{3}$ Pre-vocational education takes four years, and prepares children for vocational education; senior general secondary education takes five years and prepares children for higher professional education; and pre-university education takes six years and prepares children for academic education at universities.

This chapter focuses on pre-vocational education, the lowest secondary educational track with the highest dropout rates. Table 5.1 illustrates this.

Table 5.1: Dropout in Rotterdam by educational track and school year (in percentages)

\begin{tabular}{lcccc}
\hline Educational track & $2004 / 2005$ & $2005 / 2006$ & $2006 / 2007$ & $2007 / 2008$ \\
\hline Pre-vocational education & 3.74 & 3.89 & 2.62 & 2.55 \\
Senior general secondary educ. & 1.35 & 1.61 & 1.63 & 1.53 \\
Pre-university education & 0.72 & 0.61 & 0.84 & 0.53 \\
\hline
\end{tabular}

Pre-vocational education is the biggest track, attended by more students than all the other tracks (Van der Veen, 2011). Table 5.2 illustrates this for Rotterdam (R) compared with the whole Netherlands (NL). In Rotterdam, the fraction of students in pre-vocational education is higher compared with the national average.

\footnotetext{
${ }^{3}$ In the Netherlands, these education levels are referred to as, respectively, Voorbereidend middelbaar beroepsonderwijs (VMBO), Hoger algemeen voortgezet onderwijs(HAVO), and Voorbereidend wetenschappelijk onderwijs (VWO).
} 
Chapter 5. The Impact of Community Schools on Student Dropout in Lower Secondary Pre-Vocational Education

Table 5.2: Educational tracks in Rotterdam and in the Netherlands by school year (in percentages)

\begin{tabular}{lcccccccc}
\hline Educational track & $2004 / 2005$ & \multicolumn{2}{c}{$2005 / 2006$} & \multicolumn{2}{c}{$2006 / 2007$} & \multicolumn{2}{c}{$2007 / 2008$} \\
& $\mathrm{R}$ & $\mathrm{NL}$ & $\mathrm{R}$ & $\mathrm{NL}$ & $\mathrm{R}$ & $\mathrm{NL}$ & $\mathrm{R}$ & $\mathrm{NL}$ \\
\hline Pre-vocational & 53.54 & 45.54 & 52.32 & 43.91 & 49.43 & 41.99 & 48.43 & 40.49 \\
General secondary & 22.65 & 24.72 & 22.52 & 25.33 & 23.74 & 26.04 & 23.90 & 26.55 \\
Pre-university & 23.81 & 29.74 & 25.17 & 30.76 & 26.83 & 31.97 & 27.67 & 32.96 \\
\hline
\end{tabular}

Within pre-vocational education, four learning tracks are distinguished that each take four years: a basic track; a middle-management track; a mixed track; and a theoretical track. The basic track is the least academic and lowest level track. The middle-management track is meant for students who learn theory best by applying it. The mixed educational track focuses on students who have least difficulty with studying, and who want to prepare themselves for a particular profession. This track combines theoretical and practical education. The theoretical educational track is relatively the most difficult track. To be accepted in this education track, students must have achieved a certain test score on the standardized national test. ${ }^{4}$ For the other educational tracks no minimum test score is required. Finally, it is also possible that a student follows a combination of the above-mentioned four tracks.

With respect to student dropout, the minimum school leaving age has to be taken into consideration. In the Netherlands, the 'Compulsory Education Age Law' states that students have to attend school compulsorily until the age of 16 . Furthermore, students without a ba-

${ }^{4}$ To be precise: children must have a test score of at least 528 to be admitted to the theoretical track of the pre-vocational education track. The test scores vary between 501 and 550 and are based on four tests that pupils take in the final year of primary education. 
5.2. Dutch secondary education, data, and descriptives

sic qualification are compelled to obtain a qualification between the age of 16 and 18 .

Finally, it is worth mentioning that a particularity of the Dutch education system is the freedom of school choice. This element of the Dutch education system is comparable to US charter schools that can be attended by choice; this means that students do not have to live in a particular catchment area in order to be eligible to attend a school in that area (Imberman, 2011). Thus, students receive secondary school level advice from their elementary school, but usually the same educational track is offered by several schools so students together with their parents can freely choose a particular secondary school. In the empirical analysis it is important to take into account this free school choice, because as a result community schools may attract a selective student population. If community schools are considered as 'better' schools, they may attract 'better' students, while relatively better students may avoid these community schools if they are considered to be schools for disadvantaged children. In Rotterdam, disadvantaged children are not the target group of community schools, as community schools are intended to develop the talents of all students. Within Dutch secondary education, the largest proportion of community schools are found in pre-vocational education (De Blaay et al., 2007). This also holds for Rotterdam (De Vos et al., 2010).

\subsubsection{Community school subsidy}

Community schools receive a community school development subsidy from the Municipality of Rotterdam. To receive a subsidy, schools have to apply by submitting an activity plan and a description of their 
Chapter 5. The Impact of Community Schools on Student Dropout in Lower Secondary Pre-Vocational Education

vision. Almost all schools that applied for the subsidy also received it. Some schools decided not to apply for the subsidy as they did not consider it relevant for their school, in particular given the amount of extra work it implies.

The objective of the subsidy is to develop the talents of all students by offering them challenging and attractive development opportunities. This is supposed to enhance students' learning performance and reduce dropout. By means of these activities community schools are expected to reduce dropout (De Vos et al., 2010). The yearly amount a school receives ranges from $€ 40$ to $€ 80$ per student, and includes a base amount of up to $€ 60,000$. 75 percent of the subsidy is spent on community school activities, and 50 to 70 percent of the community school students participate in activities that are financed via this subsidy. Schools are responsible for organizing the activities. The actual frequency with which activities are offered ranges from 1 to 5 times per week. The share of students participating in each of the six activities are as follows: 51 percent participate in educational activities; 58 percent in sports and games; 59 percent in arts and culture activities; and 50 percent in social competence activities (for all educational tracks). Moreover, around one-third of the parents participates (De Vos et al., 2010). Not all students are aware of the activities that are offered. This proportion differs per activity, for instance, 82 percent of the students are aware that sports activities are offered. The latter may point to a selection effect: For instance, it may happen that students who are generally more motivated than others are better informed about the activities. Interviews with principals and students reveal that participants are enthusiastic about the activities.

Even though regular schools may also have community school facil- 
5.2. Dutch secondary education, data, and descriptives

ities and activities (e.g. offer extracurricular activities), these schools generally do not offer the same number of these activities or facilities to their students.

\subsubsection{Data}

Because there was no accurate estimate of the number of students who dropped out of secondary education, the Ministry of Education developed a student tracking system. In this system, Dutch students receive a personal identification number, which allows the central government to track students along the course of their educational careers (De Witte \& Van Klaveren, 2012). This chapter uses information from this tracking system, which is called the Bron ${ }^{5}$ data, in order to examine how many students are dropping out of secondary education. These registration data contain information for all students in secondary education for the school years 2004/2005 to 2007/2008 on student dropout and student characteristics (e.g. ethnicity, gender, family structure), and contain information on the neighborhood (by means of the zip code).

Table 5.3 indicates when community school development subsidies were given during the observed school years. The table indicates a 1 if community school subsidies were given, and a 0 if no community school subsidies were given. The table shows that subsidies were only given in the school years 2006/2007 and 2007/2008. Schools are labeled as 'community schools' if they received a community school subsidy in or after the school year 2006/2007. To distinguish community schools from regular schools, subsidized schools are also referred to as com-

\footnotetext{
${ }^{5}$ Basis Register Onderwijsnummer (Basic Registration Educational Number).
} 
Chapter 5. The Impact of Community Schools on Student Dropout in Lower Secondary Pre-Vocational Education

munity schools before the provision of the subsidy. The particular difference-in-differences setting displayed by Table 5.3 is exploited in this chapter. In total, 20 schools received a community school subsidy in the school years 2006/2007 and 2007/2008.

Table 5.3: Community school subsidy allocation by school type and school year

\begin{tabular}{lcccc}
\hline & $\begin{array}{c}2004 / 2005 \\
\text { No subsidies }\end{array}$ & $\begin{array}{c}2005 / 2006 \\
\text { Segubsidies }\end{array}$ \\
\hline Regular School & 0 & 0 & 0 & 0 \\
Community School & 0 & 0 & 1 & 1 \\
\hline
\end{tabular}

Table 5.4 shows the data structure for seven observed student cohorts. Each student cohort represents the educational careers over the observation period of students who were enrolled in the same grade during a particular school year. This data structure is of importance because in Section 5.4 regular school students are matched to community school students conditionally on background characteristics and the cohort identifier in Table 5.4.

Students in the fourth cohort start with the pre-vocational education track in school year 2004/2005 and would normally graduate after four years. Students in cohorts 5, 6, and 7 begin their pre-vocational education later than school year 2004/2005 and, as a result, it is not observed whether these students graduate. It is, however, observed whether these students drop out during the observation period. Under normal circumstances, students in the first three cohorts graduate before school year 2007/2008, because they began their pre-vocational education track in school year 2003/2004 or earlier. For these students the 'artificial' Grades 5, 6, and 7 (printed in italics) are assigned so the 
5.2. Dutch secondary education, data, and descriptives

dropout status can be identified for all students until the school year $2007 / 2008$.

The group of students who are observed during all four school years are referred to as the observations (obs.) balanced panel. The number of students in this balanced panel decreases over the observed school years. This happens because students switched schools (either to another school outside Rotterdam or to another education track) or repeated a grade. The number of students in cohorts 5, 6, and 7 who are indicated by the observations inflowing panel includes students who start with pre-vocational education in the school year 2005/2006 or later. The table shows that 2,908 students began with a pre-vocational education track in school year 2005/2006, and that in the following years the inflowing panel grew somewhat as more students entered pre-vocational education.

Table 5.4: Structure of the observed student cohorts

\begin{tabular}{lccccc}
\hline \multicolumn{6}{c}{ Grades } \\
Cohort & $2004 / 2005$ & $2005 / 2006$ & $2006 / 2007$ & $2007 / 2008$ & Panel \\
\hline 1 & 4 & 5 & 6 & 7 & Balanced \\
2 & 3 & 4 & 5 & 6 & \\
3 & 2 & 3 & 4 & 5 & \\
4 & 1 & 2 & 3 & 4 & \\
\hline 5 & - & 1 & 2 & 3 & Inflowing \\
6 & - & - & 1 & 2 & \\
7 & - & - & - & 1 & \\
\hline Obs. balanced p. & 12,857 & 12,905 & 12,604 & 12,166 & \\
Obs. inflowing p. & \multicolumn{7}{c}{$6,904,967$} & 7,193 & \\
Obs. per year & 12,835 & 15,813 & 17,938 & 19,359 & \\
Total observations & \multicolumn{5}{c}{} \\
\hline
\end{tabular}


Chapter 5. The Impact of Community Schools on Student Dropout in Lower Secondary Pre-Vocational Education

\subsubsection{Student characteristics}

In Table 5.5 the student population of community schools (CS) is compared with the student population of regular schools (RS) for the different school years. The table shows the means and standard deviations (s.d.) of several student characteristics that are related to dropout, and shows the proportion of students who dropped out of pre-vocational education. The registration data used in this chapter contain information on all students, and therefore observed differences between the two considered student populations are, by definition, representative. Below the most important differences between the student populations of community schools and regular schools are highlighted.

The association between students' socioeconomic background and academic achievement is well documented (Baker et al., 2002; Crane, 1996; OECD, 2011; Sirin, 2005). In particular, students with a lower socioeconomic status are more likely to drop out of education (e.g. Sirin, 2005). The student characteristics in Table 5.5 that are related to socioeconomic status are: ethnic minority status; living in a sin-

gle parent family; living in a disadvantaged area; and residential value (i.e. the average housing value in the neighborhood where the students live $)^{6}$. The table clearly shows that community schools have a disadvantaged student population, in the sense that students are more often non-Dutch; live in single parent families; live in disadvantaged $\operatorname{areas}^{7}$; and live in houses with a lower residential value. In contrast to what is expected, the final table row shows that community school dropout is lower than regular school dropout, even though community

\footnotetext{
${ }^{6}$ Table 5.5 shows the value divided by a thousand.

${ }^{7}$ Disadvantaged areas are areas that are labeled as deprived areas by the government, and to improve the situation these areas receive additional subsidies.
} 
5.2. Dutch secondary education, data, and descriptives

schools have a disadvantaged student population. It is, however, not possible to link these observations to the performance of community or regular schools: First of all, because community schools only started to exist from school year 2006/2007; and, second, because the student proportions in different pre-vocational tracks differ between both school types. This last point is discussed in more detail later in this subsection.

When the focus is on changes in the student population that occur over time, the table shows that both school types have a student population of approximately the same age, but community school students tend to be somewhat younger as of the school year 2005/2006. Moreover, the table indicates that the student population of regular schools changes with respect to ethnic minority, living in a single parent family and living in a disadvantaged area, between the school years 2004/2005 and 2005/2006 and that the population remains the same after school year $2005 / 2006$. The change in population characteristics is caused by the students who were not in pre-vocational education in school year 2004/2005 and started their pre-vocational education in a later school year (i.e. students of the inflowing panel). It is important to recognize that the community school student population remains rather constant over time, and that the regular school student population changes over time may point to a selection effect, where certain types of students are more likely to select themselves in a regular or community school. 


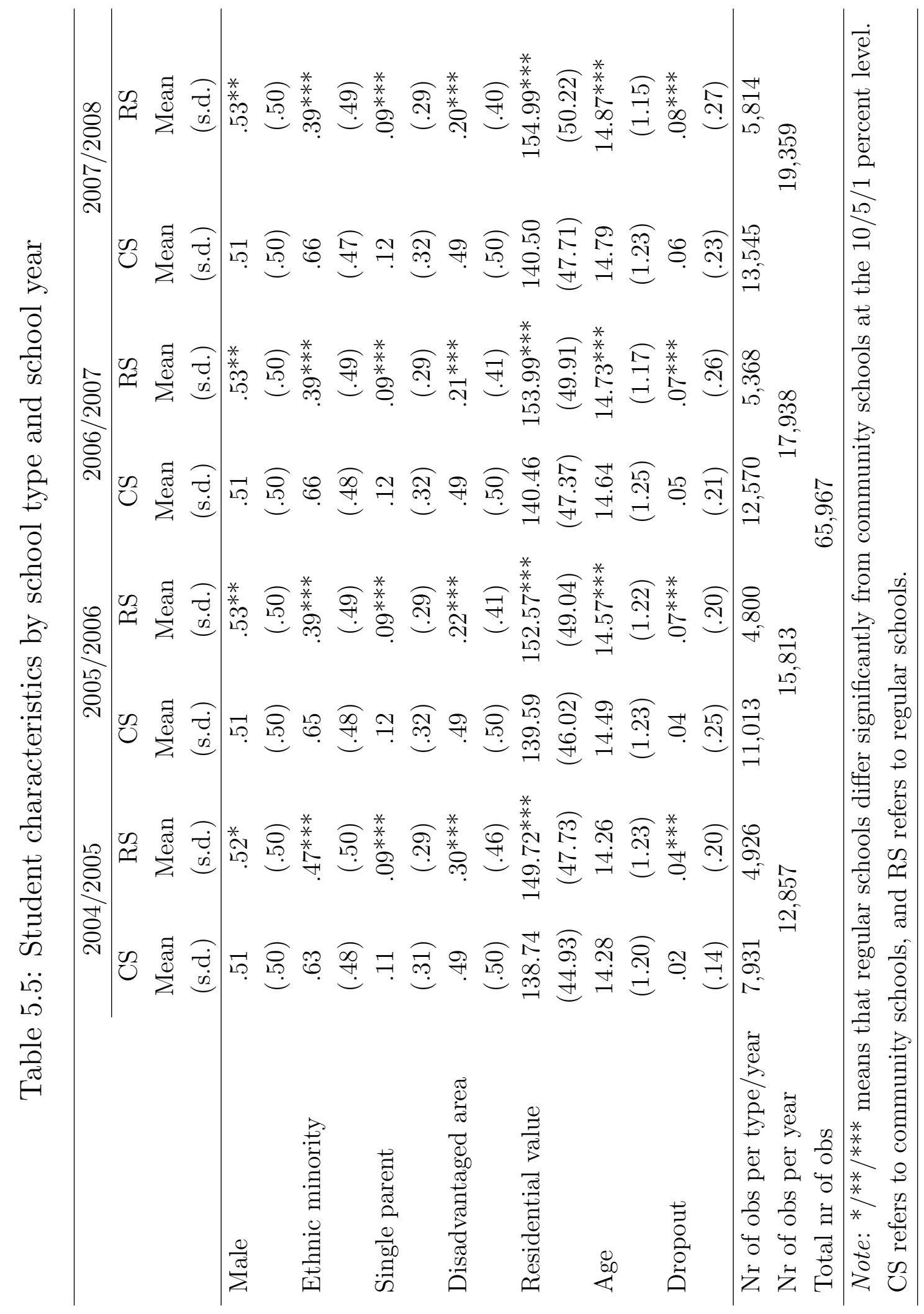


5.2. Dutch secondary education, data, and descriptives

This section explained earlier that students in pre-vocational education are assigned to different tracks within the pre-vocational education track, mainly based on the test score children have obtained in primary education on the standardized national test. Table 5.6 shows how students are distributed over the different educational tracks within prevocational education, separately for community schools and regular schools. The first four tracks presented in the first column are the standard tracks offered by schools, and the last track, labeled as 'combined', represents different combinations of the four standard tracks.

The table shows that community school and regular school students are very differently distributed over the education tracks. Regular school students are mostly assigned to a basic vocational, middle management (mngt.) or a theoretical track and are about equally distributed over these tracks. Even though community school students are often assigned to a basic vocational or a middle management track, almost half of the community school students are assigned to the theoretical track. At 0.46, the proportion is considerably higher than the proportion of students that is assigned to this track in regular schools (about 0.29 ) in 2008. It is crucial to take into account the observed differences in Table 5.6 when evaluating the impact of community schools on dropout. On the one hand, theoretical track students in community schools are less likely to drop out as these students have achieved higher test scores on the national test in primary education, but, on the other hand, they may be more likely to drop out of education because the theoretical track is a more difficult track. As students can always switch to lower (or higher) educational tracks within pre-vocational education it can be considered to be more likely that the higher proportion of theoretical track students is associated with less dropout, 
Chapter 5. The Impact of Community Schools on Student Dropout in Lower Secondary Pre-Vocational Education

which appears to be consistent with the dropout proportions presented in Table 5.5.

Table 5.6: Educational tracks in pre-vocational education by school type and school year

\begin{tabular}{lcccccccc}
\hline Track & \multicolumn{2}{c}{$2004 / 2005$} & \multicolumn{2}{c}{$2005 / 2006$} & \multicolumn{2}{c}{$2006 / 2007$} & \multicolumn{2}{c}{$2007 / 2008$} \\
& CS & RS & CS & RS & CS & RS & CS & RS \\
& Mean & Mean & Mean & Mean & Mean & Mean & Mean & Mean \\
& (s.d.) & (s.d.) & (s.d.) & (s.d.) & (s.d.) & (s.d.) & (s.d.) & (s.d.) \\
\hline Basic vocational & .10 & .21 & .12 & .24 & .13 & .26 & .14 & .27 \\
& $(.30)$ & $(.40)$ & $(.33)$ & $(.43)$ & $(.33)$ & $(.44)$ & $(.35)$ & $(.44)$ \\
Middle-mngt. & .18 & .23 & .19 & .25 & .20 & .28 & .22 & .28 \\
& $(.384)$ & $(.42)$ & $(.39)$ & $(.44)$ & $(.40)$ & $(.45)$ & $(.41)$ & $(.45)$ \\
Mixed & .07 & .06 & .08 & .05 & .07 & .04 & .060 & .04 \\
& $(.26)$ & $(.24)$ & $(.27)$ & $(.21)$ & $(.25)$ & $(.20)$ & $(.24)$ & $(.20)$ \\
Theoretical & .46 & .26 & .45 & .27 & .46 & .27 & .46 & .29 \\
& $.50)$ & $(.44)$ & $(.50)$ & $(.44)$ & $(.50)$ & $(.45)$ & $(.50)$ & $(.45)$ \\
Combined & .18 & .24 & .16 & .20 & .14 & .15 & .13 & .12 \\
& $(.39)$ & $(.43)$ & $(.37)$ & $(.40)$ & $(.35)$ & $(.36)$ & $(.33)$ & $(.33)$ \\
\hline Obs type/year & 7,931 & 4,926 & 11,013 & 4,800 & 12,570 & 5,368 & 13,545 & 5,814 \\
Obs year & 12,857 & 15,813 & 17,938 & 19,359 \\
Obs & \multicolumn{7}{c}{65,967} \\
\hline Note: CS refers to community schools, and RS refers to regular schools. \\
\hline
\end{tabular}

In conclusion, the descriptive statistics of Tables 5.5 and 5.6 indicate that community school students are more likely to drop out because of disadvantaged background characteristics, but at the same time community school students more often follow a theoretical track, which implies a lower dropout risk. The lower dropout rates for community schools in Table 5.5 may, therefore, indicate that community schools are doing a good job (because they keep students with disadvantaged characteristics in education), or that community schools have 
5.3. Selection into community schools

better performing students who are, by definition, less likely to drop out. In order to estimate the impact of community schools on student dropout we should therefore control for the latter.

\subsection{Selection into community schools}

In Section 5.2 it was explained that the freedom of school choice applies to Dutch secondary education, and that, therefore, community schools may attract a selective student group. This section examines whether there is selective participation in community school education, as it may bias the measured impact of community schools on dropout. Community schools may, for example, attract better students (over time) because schools improve their education program using the community school subsidies. Thus, if dropout between community and regular schools is compared, the impact of being a community school, as well as the impact of having a better student population, is measured. This would lead to a biased community school estimate. Moreover, it is possible that better schools attract better students and, at the same time, are more successful in applying for community school subsidies. By comparing dropout between community schools and regular schools, the impact of differences in school quality and the impact of community schools is measured.

To examine whether there is selective participation of students in community school education, the background characteristics of the students who enter community and regular schools in each school year (i.e. first graders) are examined. If there is selection into community school education it should be observed that student background characteristics change over the school years, and, for example, that better 
Chapter 5. The Impact of Community Schools on Student Dropout in Lower Secondary Pre-Vocational Education

students select themselves into community schools.

Table 5.7 shows the means and standard deviations of the background characteristics for first graders per school year, separately for community schools and regular schools. The table only presents background characteristics that can be associated with the socioeconomic status of students, because these characteristics are informative for whether there is selective participation in community school education. The table shows that the characteristics of community school first graders are very similar to those presented in Table 5.5 and do not vary over the school years. Schools which became community schools in either 2006/2007 or 2007/2008 thus attracted a similar student population during the entire observation period. It can be concluded that, therefore, there is no selective participation in community school education based on the observed characteristics of first-grade students because this requires that the characteristics of the student population change over the years.

The results for regular schools are similar to those of Table 5.5 and indicate that the characteristics of the average student become somewhat more disadvantaged between the school years 2004/2005 and $2005 / 2006$, and remain the same after the school year 2005/2006. An exception is the proportion of students who come from single-parent families. This proportion tends to increase slightly over the school years. 


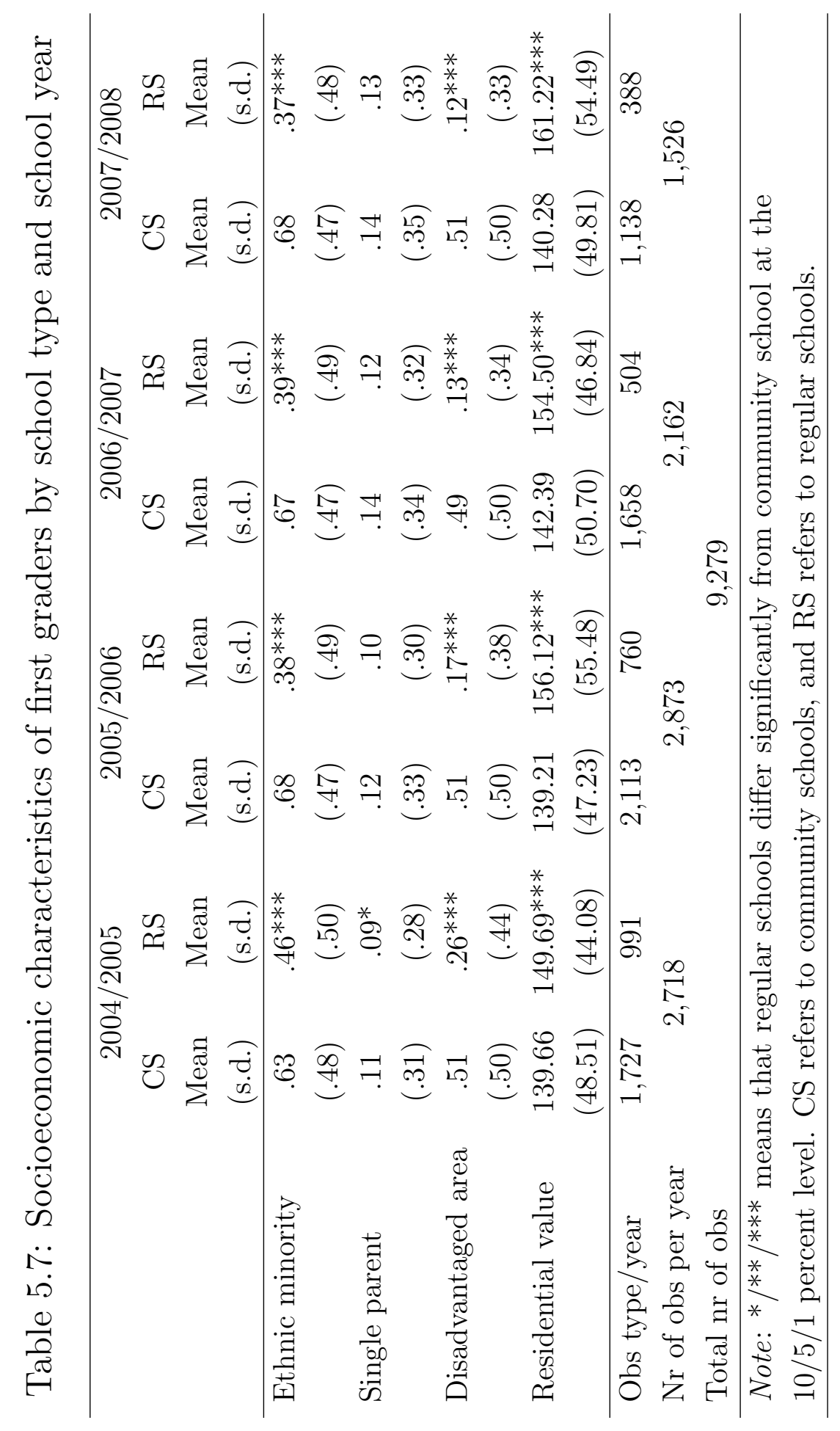


Chapter 5. The Impact of Community Schools on Student Dropout in Lower Secondary Pre-Vocational Education

Table 5.8 shows how first graders are distributed over the different education tracks within pre-vocational education in each school year. Compared with Table 5.6, it is again observed that community school students more often follow a theoretical learning track than regular school students. As discussed in Section 5.2.4, it is likely that in a dropout comparison between community schools and regular schools this will translate into a relatively lower dropout rate for community schools. However, the table does not support the hypothesis that better students select themselves into community schools over time, because the proportion of students who follow a theoretical learning track decreases over time. However, it cannot be excluded that, as postulated above, community schools were simply better schools in the past, and have therefore attracted more students who follow a theoretical learning track, and were also more successful in applying for community school subsidies.

An interesting difference with respect to the proportions in Table 5.6 is that first graders more often choose combined learning tracks, and that this is at the expense of the proportion of students who follow a basic vocational or middle-management learning track. 
5.4. Identification strategy and estimation model

Table 5.8: Educational tracks attended by first graders by school type and school year

\begin{tabular}{|c|c|c|c|c|c|c|c|c|}
\hline \multirow[t]{4}{*}{ Track } & \multicolumn{2}{|c|}{$2004 / 2005$} & \multicolumn{2}{|c|}{$2005 / 2006$} & \multicolumn{2}{|c|}{$2006 / 2007$} & \multicolumn{2}{|c|}{$2007 / 2008$} \\
\hline & CS & $\mathrm{RS}$ & $\mathrm{CS}$ & $\mathrm{RS}$ & CS & $\mathrm{RS}$ & CS & $\mathrm{RS}$ \\
\hline & Mean & Mean & Mean & Mean & Mean & Mean & Mean & Mean \\
\hline & (s.d.) & (s.d.) & (s.d.) & (s.d.) & (s.d.) & (s.d.) & (s.d.) & (s.d.) \\
\hline \multirow[t]{2}{*}{ Basic vocational } & .02 & .06 & .04 & .09 & .02 & .06 & .03 & .14 \\
\hline & $(.14)$ & $(.24)$ & $(.21)$ & $(.29)$ & $(.13)$ & $(.23)$ & $(.17)$ & $(.35)$ \\
\hline \multirow[t]{2}{*}{ Middle-mngt. } & .09 & .08 & .08 & .09 & .08 & .11 & .04 & .06 \\
\hline & $(.29)$ & $(.27)$ & $(.27)$ & $(.28)$ & $(.27)$ & $(.31)$ & $(.18)$ & $(.25)$ \\
\hline \multirow[t]{2}{*}{ Mixed } & .07 & .01 & .06 & .01 & 0 & 0 & 0 & .01 \\
\hline & $(.25)$ & $(.10)$ & $(.23)$ & $(.11)$ & $(-)$ & $(-)$ & $(-)$ & $(.11)$ \\
\hline \multirow[t]{2}{*}{ Theoretical } & .39 & .25 & .41 & .22 & .42 & .18 & .31 & .08 \\
\hline & $(.49)$ & $(.43)$ & $(.49)$ & $(.42)$ & $(.49)$ & $(.39)$ & $(.46)$ & $(.27)$ \\
\hline \multirow[t]{2}{*}{ Combined } & .43 & .60 & .41 & .58 & .48 & .65 & .62 & .70 \\
\hline & $(.50)$ & $(.49)$ & $(.49)$ & $(.49)$ & $(.50)$ & $(.48)$ & $(.48)$ & $(.46)$ \\
\hline Obs type/year & 1,727 & 991 & 2,113 & 760 & 1,658 & 504 & 1,138 & 388 \\
\hline Obs year & \multicolumn{2}{|c|}{2,718} & \multicolumn{2}{|c|}{2,873} & \multicolumn{2}{|c|}{2,162} & \multicolumn{2}{|c|}{1,526} \\
\hline Total obs & \multicolumn{6}{|c|}{9,279} & & \\
\hline
\end{tabular}

\subsection{Identification strategy and estimation model}

In this section, the identification strategy to estimate the impact of community school education on students' dropout probabilities is outlined. The intuition of the identification strategy is presented in Table 5.9. Outcome measure $y_{i t, C}$ indicates whether student $i$ dropped out of pre-vocational education in school year $t^{8}$, and subscript $C$ refers to

${ }^{8}$ For convenience, the school year 2004/2005 is referred to as 2005, and, similarly, the later school years. 
Chapter 5. The Impact of Community Schools on Student Dropout in Lower Secondary Pre-Vocational Education

the school type, where $C=1$ refers to students who go to a school that becomes a community school in $t=2007$ or 2008 , and $C=0$ refers to students who go to a regular school.

Table 5.9: Intuition of the difference-in-differences identification strategy

\begin{tabular}{lcccc}
\hline & \multicolumn{4}{c}{ School year: } \\
& $t=2005$ & $t=2006$ & $t=2007$ & $t=2008$ \\
Regular School $(C=0)$ & $y_{i t, 0}$ & $y_{i t, 0}$ & $y_{i t, 0}$ & $y_{i t, 0}$ \\
Community School $(C=1)$ & $y_{i t, 1}$ & $y_{i t, 1}$ & $y_{i t, 1}$ & $y_{i t, 1}$ \\
\hline
\end{tabular}

First, the identification strategy is outlined by considering only the school years 2006 and 2007. Later the estimation model is straightforwardly extended. The school years 2006 and 2007 are chosen because in 2006 no subsidies were given and in 2007 community school subsidies were given. It follows that the community school impact on student dropout can be estimated by means of a difference-in-differences (DiD) strategy. In this DiD setting, dropout differences are compared between 2006 and 2007 (i.e. the first difference) and between students from community schools and regular schools (i.e. the second differences). The non-parametric estimate for the community school impact for student $i$ can be written as:

$$
\left[y_{i 2007,1}-y_{i 2006,1} \mid C_{i}=1\right]-\left[y_{i 2007,0}-y_{i 2006,0} \mid C_{i}=0\right] .
$$

The left-hand side represents the difference in dropout between 2007 and 2006 for students who attended a community school. The righthand side represents the reference group and presents the dropout difference between 2007 and 2006 for students who attended a regular 


\subsection{Identification strategy and estimation model}

school. As discussed in Section 5.2.4, it should be taken into account that community school students have different background characteristics compared with regular school students, and, therefore, the following parametric regression model is estimated:

$$
\begin{array}{r}
y_{i t}=\alpha_{0}+\alpha_{1} C_{i}+\alpha_{2} T_{i t}+\alpha_{3} C_{i} \cdot T_{i t}+X_{i t}^{\prime} \beta+\epsilon_{i}, \\
t=2006,2007, i=1, \ldots, N,
\end{array}
$$

where the community school indicator $C_{i}$ equals 1 if student $i$ attended a community school, and 0 otherwise. $T$ is a school year indicator which is 1 for school year 2007 and 0 for school year 2006. $X_{i}$ are student and school background characteristics that may influence $y_{i t}$, besides the community school and school year indicators, and $\epsilon_{i}$ is a normally-distributed zero-mean constant variance error term.

The first-difference estimation parameters are $\alpha_{1}$ and $\alpha_{2}$. These parameters measure, respectively, the dropout difference between community schools and regular schools for school year 2006, and the dropout difference between 2006 and 2007. The impact of community schools on student dropout is measured by $\alpha_{3}$, the parameter of interest. Essentially, this parameter measures whether student dropout difference between community schools and regular schools for school year 2006 are different from those for school year 2007, while taking into account the student population difference and the constant dropout difference between 2006 and 2007.

To consider also the other school years, the estimation model in 5.2 is reformulated as follows: 
Chapter 5. The Impact of Community Schools on Student Dropout in Lower Secondary Pre-Vocational Education

$$
\begin{array}{r}
y_{i t}=\alpha_{0}+\alpha_{1} C_{i}+\sum_{t=2006}^{2008} \alpha_{2} T_{i t}+\sum_{t=2006}^{2008} \alpha_{3} C_{i} \cdot T_{i t}+X_{i t}^{\prime} \beta+\epsilon_{i}, \\
t=2005, \ldots, 2008, i=1, \ldots, N .
\end{array}
$$

The model now includes school-year indicators for the school years 2006 to 2008, such that the reference school year is 2005. The model includes three interaction effects: one interaction effect for each year, except for the reference year. Similar to equation 5.2, $\alpha_{1}$ measures the student dropout difference between community schools and regular schools for school year 2005 (the reference year). The interaction effect associated with school year 2006 (i.e. $\alpha_{3,2006}$ ) essentially measures whether the dropout difference between community schools and regular schools for school year 2005 are different than those for school year 2006, while controlling for student population differences and constant dropout differences over time. Because schools did not receive any community school subsidies in 2006 (see Table 5.9), estimation parameter $\alpha_{3,2006}$ should not be statistically and significantly different from $\alpha_{1}$. Community school subsidies were, however, given to schools in 2007 and 2008, and if community schools did effectively reduce student dropout in these years, the results should show that $\alpha_{3,2007}$ and $\alpha_{3,2008}$ are both greater than $\alpha_{1}$ and $\alpha_{3,2006}$.

The model assumes that individual error terms, $\epsilon_{i}$, are independently distributed, and this assumption is unlikely to hold. Therefore, in the empirical analysis, the standard errors are clustered at the student level, such that it is taken into account that the error terms per student are correlated. Additionally and as a robustness check, the model 
5.4. Identification strategy and estimation model

is estimated with clustered standard errors at the school level. Because the estimation results were similar to those when using clustered standard errors at the student level, only the latter results are shown.

Because community school status is measured at the school level, it is not possible to estimate a school fixed effect model.

The estimation parameter, $\alpha_{3}$, in the the $\mathrm{DiD}$ model measures the causal impact of community schools on student dropout if community school students are comparable to regular school students in both observable and unobservable characteristics. Because students are not randomly assigned to community and regular schools, it is not possible to show that both student populations are comparable in their unobservable characteristics. Sections 5.2 and 5.3, moreover, show that community school students are systematically different from regular school students in the learning tracks that they follow and in several background characteristics. As a consequence the community school student population includes students who are non-comparable to any student in the regular school student population, and, even though these population differences are controlled for in equation 5.3, these differences may still impose a bias on the measured community school impact on student dropout (see De Witte \& Van Klaveren, 2012; De Witte, Van Klaveren, \& Smets, 2011, for an elaborate discussion). The regular school student population, therefore, does not accurately represent the counterfactual outcome for community school students because characteristic differences influence the probability of attending a community school, as well as the probability of dropping out of pre-vocational education. Therefore, this chapter adopts an iterative matching approach (De Witte et al., 2011), which is outlined below. 
Chapter 5. The Impact of Community Schools on Student Dropout in Lower Secondary Pre-Vocational Education

\subsubsection{Matching procedure}

As in Chapter 3 and 4, this chapter also adopts a nearest-neighbor matching approach using Mahalanobis distances. Essentially, this approach matches each community school student to the best look-alike regular school student based on a vector of observable background characteristics, $\mathbf{x}$. These background characteristics are similar to the background characteristics included in equation 5.3, or, more specifically, are similar to the background characteristics that are mentioned in Tables 5.5 and 5.6. This chapter matches students based on observable characteristics in the school year 2007/2008, because all students in the observation period are observed in this school year and not in earlier school years (see also the cohorts that are defined in Table 5.4). The background characteristics that are considered in the matching are: gender, ethnic minority, single parent, disadvantaged area, educational track, grade, cohort, and the school-level characteristics school size, and the proportion of ethnic minority students in the school. For a more detailed description of this matching estimator see Chapter 3.

The robustness of the results is tested by applying kernel and propensity score matching. The empirical results generated by these alternative matching estimators were comparable to those generated by the Mahalanobis matching estimator.

\subsubsection{Iterative matching procedure}

There are more community school students than regular school students and, as a consequence, it is not possible to match all community students to regular school students if it is not allowed to match regular school students multiple times to community school students (i.e. 
5.4. Identification strategy and estimation model

matching with replacement). ${ }^{9}$ However, if it is allowed to match regular school students more than once to community school students, then a small group of regular school students may drive the estimated effect. In a first attempt to overcome this problem, the matching analysis is performed twice, and first regular school students are matched to community school students (matching model I) and then community school students are matched to regular students (matching model II, which is referred to as inverse matching). It is important to recognize, that matching model I estimates the average treatment effect on the treated (ATET), while matching model II estimates the average treatment effect of the untreated (ATEU). Thereby, the matching models estimate the impact of community school education on student dropout for two different types of student populations: namely, those representing community school students (matching model I), and those representing regular school students (matching model II). The advantage of matching model II is that students from the larger-sized community school pool are drawn and matched to the regular school students, so on average the quality of the match increases.

For matching model II it is, however, still the case that the student size of the community school population is not much bigger than the student size of the regular school population and, thus, it may still be that a small group of community school students drives the estimated effect. To account for this, the distribution of the matching estimator is simulated by using an iterative matching procedure. Below, the matching procedure is described for matching model I and this procedure runs as follows. In Step 1, 200 community school students are selected at random (based on a variable that assigns a pseudo-random

${ }^{9}$ This subsection relies on Cameron and Trivedi (2005) and De Witte et al. (2011). 
Chapter 5. The Impact of Community Schools on Student Dropout in Lower Secondary Pre-Vocational Education

number to each student drawn from a uniform distribution). In Step 2, regular school students are matched. In Step 3, the average treatment effect on the treated is determined. These three steps are repeated 500 times so that the distribution of the treatment effect on the treated is simulated. The mean of this distribution corresponds to the estimated treatment effect, while its standard deviation indicates the reliability of the estimate. The distribution of the matching estimator is, moreover, not necessarily normally distributed.

To test the robustness of this iterative matching procedure the procedure is repeated with a varied number of students that are selected at random in Step 1 (i.e. 50 and 100 students were selected). The smaller the number of students who are randomly selected in Step 1, the smaller is the probability that one single community school student is matched multiple times to multiple regular school students. The results show that the iterative matching results remain approximately the same if the number of students who are randomly selected in Step 1 is varied, and therefore this chapter shows only the estimation results when 200 regular school students are selected at random. ${ }^{10}$ To obtain a consistent estimate from the difference-in-differences estimation, the 'common trends assumption' has to be met. This assumption implies that, if the treated had not been treated they would have experienced a change in outcomes equal to that observed among the non-treated. Because of the combination of a DiD analysis and a matching analysis, the common trend assumption is relaxed (Blundell \& Costa Dias, 2009). If there are different trends for different students (e.g. given their background characteristics which put them at-risk for dropout),

\footnotetext{
${ }^{10}$ The results in the case where 50 or 100 community school students were selected are available upon request.
} 
5.4. Identification strategy and estimation model

then this applies to both community school and regular school students. Therefore, the matching reduces the likelihood of having different underlying common trends. While the matching addresses the differences in the observed characteristics, schools may have different motivations for deciding to apply for the subsidy. Moreover, some school characteristics are included in the matching: school size and the share of non-Western ethnic minorities. Furthermore, as Table 5.5 shows, during the two years before the introduction of the subsidy, both school types had a similar trend.

\subsubsection{Matching results and changes in background characteristics over time}

Students are matched based on observable student and school characteristics for the school year 2007/2008, because all students in the observation period are observed in this school year, but not necessarily in earlier school years. It should, however, be taken into account that schools became community schools in school year 2006/2007 or $2007 / 2008$, and if students select themselves non-randomly into community schools, student background characteristics may have changed over time. Therefore, the DiD model is estimated for the sample produced by the iterative matching procedure and control for student and school characteristics over time. In this way it is examined whether the matching estimator is affected by changes in background characteristics over time.

To ensure that the DiD estimation results for the full population are comparable to the results for the sample that is constructed by the iterative matching procedure (in terms of standard errors), it is 
Chapter 5. The Impact of Community Schools on Student Dropout in Lower Secondary Pre-Vocational Education

important that both samples contain the same number of student observations (i.e. about 65,000). Recognizing that each iteration uses information on 400 students (i.e. 200 community school students and 200 regular school students), and taking into account that, on average, students are in the data for 3.34 years, it follows that data from 49 of the 500 iterations should be randomly selected. These 49 iterations provide information of approximately $400 \cdot 3.34 \cdot 49=65,464$ students. $^{11}$

\subsection{Estimation results}

Table 5.10 presents the estimation results for equation 5.3, with and without control variables. The estimation results naturally indicate that student dropout increased over time which reflects that more students of the rather balanced student panel drop out of pre-vocational education during the observation period. The community school indicator $\alpha_{1}$ shows that community school dropout was lower than regular school dropout in school year 2004/2005. In Section 5.4, it was explained that the parameters of interest are the parameters associated with the interaction variables. Therefore, these parameters of interest are mentioned between brackets in Table 5.10. Community school subsidies were given to schools in the school years 2007 and 2008 (i.e. school years 2006/2007 and 2007/2008), and, if community schools effectively reduced student dropout in these years, $\alpha_{3,2007}$ and $\alpha_{3,2008}$ should both be lower than $\alpha_{1}$ and $\alpha_{3,2006}$.

\footnotetext{
${ }^{11}$ The deviation from this number in the actual population is because the selected students are not exactly 3.34 years in the data.
} 
5.5. Estimation results

Table 5.10: Results for the difference-in-differences estimation for the full population

\begin{tabular}{|c|c|c|}
\hline & $\begin{array}{c}(1) \\
\text { Coef. } \\
(\mathrm{SE})\end{array}$ & $\begin{array}{c}(2) \\
\text { Coef. } \\
(\mathrm{SE})\end{array}$ \\
\hline $\mathrm{CS}\left[\alpha_{1}\right]$ & $\begin{array}{c}-.312^{* * *} \\
(.045)\end{array}$ & $\begin{array}{c}-.329 * * * \\
(.056)\end{array}$ \\
\hline Year 2006 & $\begin{array}{l}.229 * * * \\
(.020)\end{array}$ & $\begin{array}{l}.290 * * * \\
(.024)\end{array}$ \\
\hline Year 2007 & $\begin{array}{l}.274^{* * *} \\
(.023)\end{array}$ & $\begin{array}{l}.437^{* * *} \\
(.028)\end{array}$ \\
\hline Year 2008 & $\begin{array}{c}.311 \\
(.025)\end{array}$ & $\begin{array}{l}.580 * * * \\
(.031)\end{array}$ \\
\hline $\mathrm{CS}^{*} 2006\left[\alpha_{3,2006}\right]$ & $\begin{array}{l}.055^{*} \\
(.033)\end{array}$ & $\begin{array}{l}.072^{*} \\
(.040)\end{array}$ \\
\hline $\mathrm{CS}^{*} 2007\left[\alpha_{3,2007}\right]$ & $\begin{array}{c}.102^{* * *} \\
(.036)\end{array}$ & $\begin{array}{l}.131^{* * *} \\
(.044)\end{array}$ \\
\hline $\mathrm{CS}^{*} 2008\left[\alpha_{3,2008}\right]$ & $\begin{array}{c}.130 * * * \\
(.038)\end{array}$ & $\begin{array}{l}.163^{* * *} \\
(.047)\end{array}$ \\
\hline Constant & $\begin{array}{c}-1.725^{* * *} \\
(.032)\end{array}$ & $\begin{array}{c}-9.150^{* * *} \\
(.317)\end{array}$ \\
\hline Clustered student-level SEs & Yes & Yes \\
\hline Controls & No & Yes \\
\hline Community school duration & No & No \\
\hline Pseudo $\mathrm{R}^{2}$ & 0.0147 & 0.1625 \\
\hline Nr of observations & 65,967 & 65,967 \\
\hline $\begin{array}{l}\text { Note: } * / * * / * * * \text { means statis } \\
\text { CS refers to community scho }\end{array}$ & $\begin{array}{l}\text { cally signif } \\
\text { ls, and RS }\end{array}$ & $\begin{array}{l}\text { 10/5/1 percent level. } \\
\text { ular schools. }\end{array}$ \\
\hline
\end{tabular}

The estimation results do not support that $\alpha_{3,2007}$ and $\alpha_{3,2008}$ are both lower than $\alpha_{1}$ and $\alpha_{3,2006}$, and indicate that dropout differences between community schools and regular schools diminished over time. 
Chapter 5. The Impact of Community Schools on Student Dropout in Lower Secondary Pre-Vocational Education

Section 5.2.4 has shown, however, that community schools structurally offer more theoretical learning tracks than regular schools, and have a relatively disadvantaged student population. The estimation results shown in Table 5.10 therefore include regular school students who are non-comparable to community school students. This may impose a bias on the measured community school impact on student dropout. To address this problem the iterative matching procedure as described in Section 5.4 is adopted.

The student characteristics for the matched community and regular schools, and for the original population and the constructed control sample are shown in Table 5.11. By construction of the iterative matching procedure, the characteristics of matched regular school students are similar to those of the matched school population. This holds for all school years. Therefore, if the difference-in-differences model (i.e. equation 5.3) is estimated, it accurately controls for differences in background characteristics. 
5.5. Estimation results

Table 5.11: Student characteristics for the full population (F) and the matched sample (M) by school type and school year

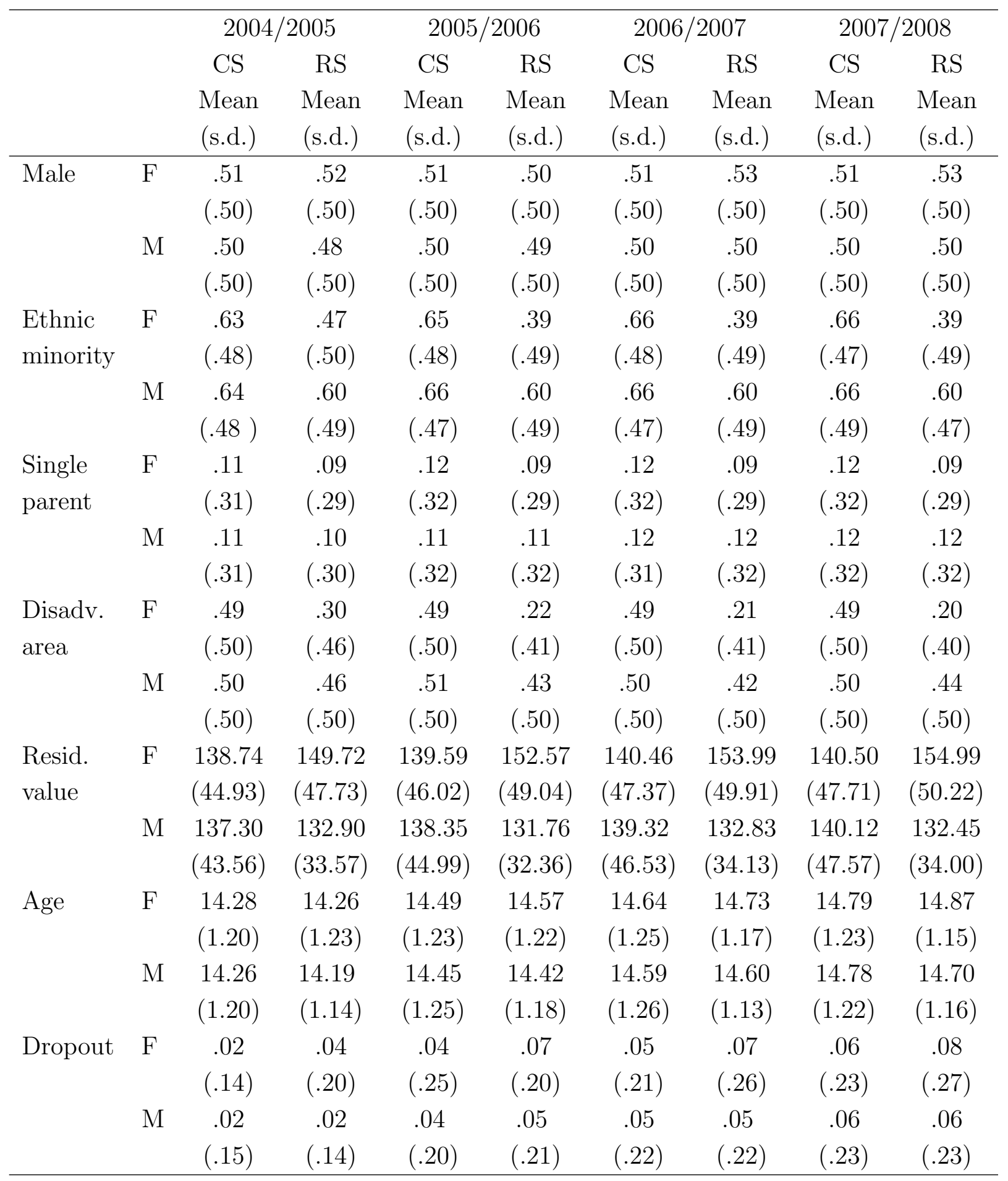

Note: CS refers to community schools, and RS refers to regular schools. 
Chapter 5. The Impact of Community Schools on Student Dropout in Lower Secondary Pre-Vocational Education

Figure 1 shows the distribution of the average treatment effect on the treated for the school year 2007/2008 based on the 500 simulations. The figure shows the simulated dropout difference between community school students and matched regular school students. Intuitively, a negative value means that the average dropout is lower in community schools, and a positive value means that the average dropout is higher in community schools. The mean dropout difference is -.00131 with a standard deviation of .012. This suggests that, on average, there is less dropout in community schools for the simulated sample for the school year 2008. The result of the Shapiro-Wilk test $(W=.994)$ indicates that the distribution of the ATET is not normally distributed. Therefore, a non-parametric Wilcoxon signed-rank test is applied to test whether the mean dropout difference is significantly different from zero. The test statistic indicates that the distribution of the mean differs significantly from zero $(z=-2.406 ; p=0.0161)$.

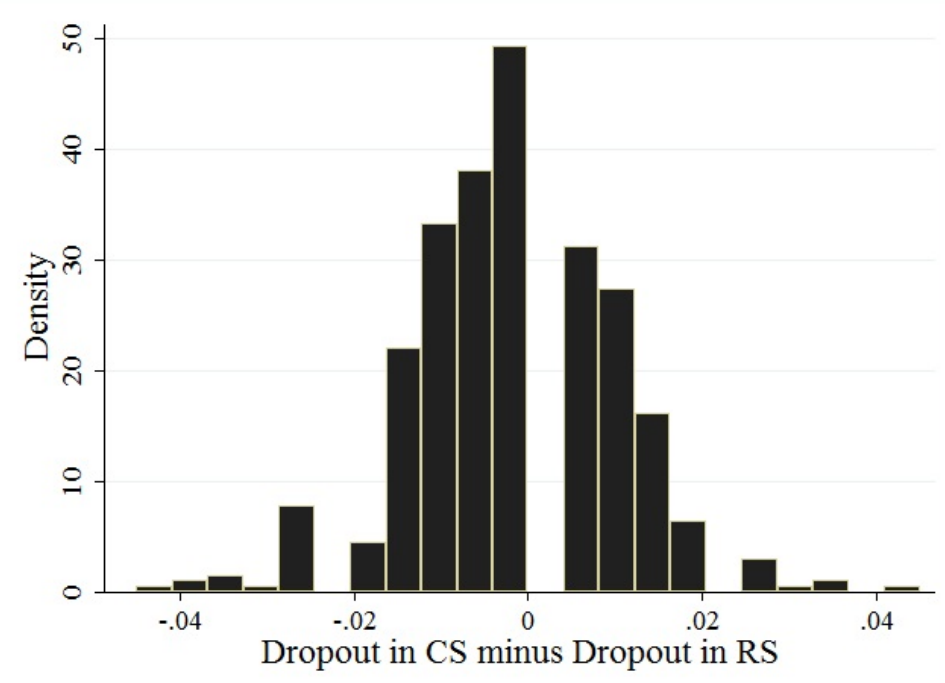

Figure 5.1: Distribution of the average treatment effect on the treated 
5.5. Estimation results

The iterative matching procedure is performed for 2008 and therefore it may happen that changes in population background characteristics that influence the probability of attending a community school, as well as of dropping out of pre-vocational education, drive the matching results. Therefore, the observed changes in background characteristics that occur over time are taken into account by estimating the difference-in-differences model for the matched sample.

The difference-in-differences estimation results are shown in Table 5.12. Column (1) presents the full population results of Table 5.10. Column (2) presents the estimation results when the differencein-differences model is estimated for the matched sample where regular school students are matched to community school students (i.e. Model I). Column (3) shows the matching results for matching community school students to regular school students (i.e. Model II). The community school indicator for the matched samples (2) and (3) shows that community school dropout is not statistically different from dropout in regular schools in the school year 2004/2005. This is as expected, because schools did not receive community school subsidies in this school year, and because the matching analysis ensured that community school students are compared with comparable regular school students. In these estimations, the standard errors are clustered by student-id (clust. stud.-level SEs). 
Chapter 5. The Impact of Community Schools on Student Dropout in Lower Secondary Pre-Vocational Education

Table 5.12: Results for the difference-in-differences estimation for the full population and the matched samples

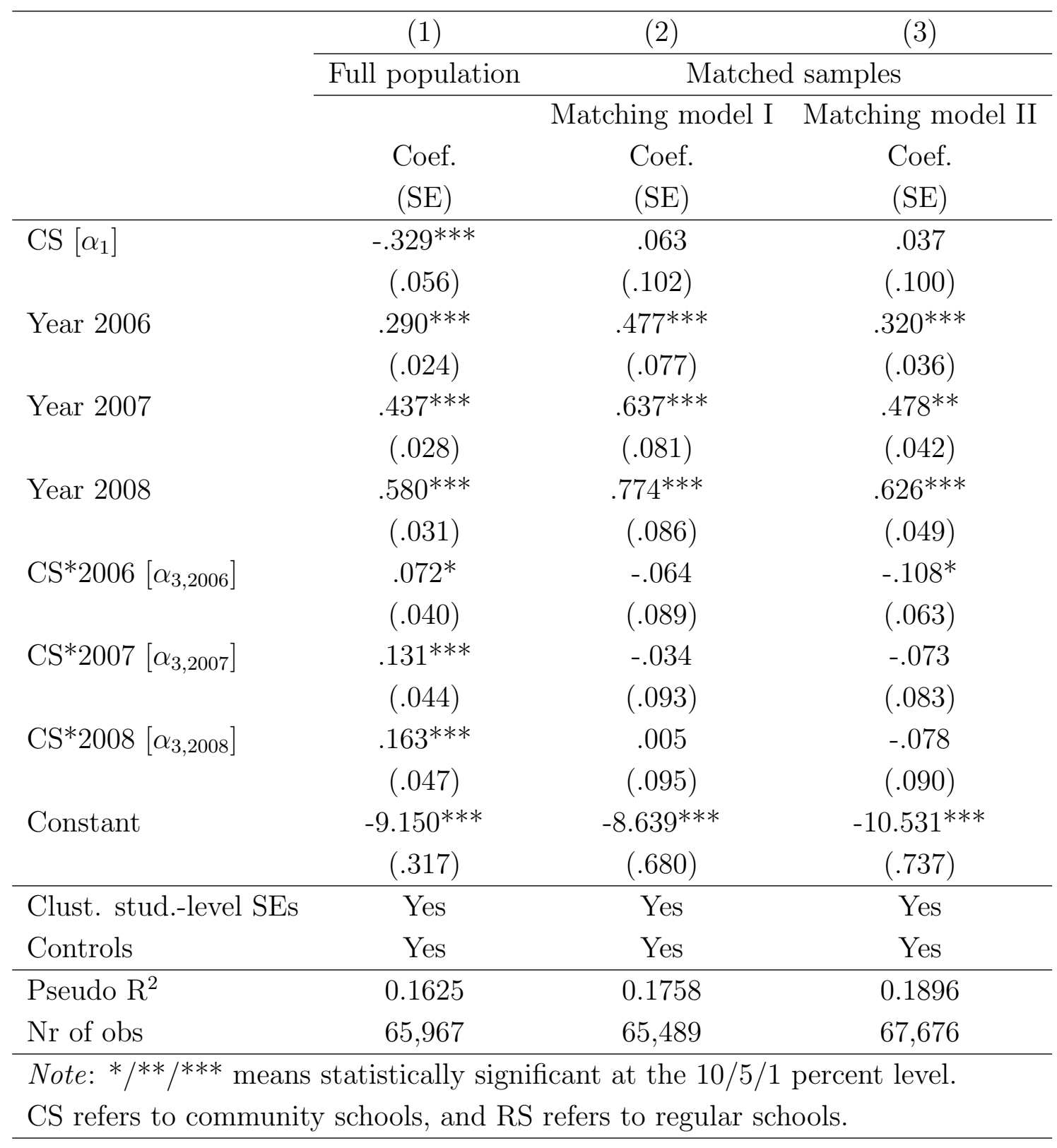

The estimation results in columns (2) and (3) indicate that $\alpha_{3,2007}$ and $\alpha_{3,2008}$ are not significantly different from $\alpha_{1}$. This suggests that community schools perform as well as regular schools with regard to 
reducing dropout. Moreover, the estimation results for the matched sample show that the estimation results for the full population are biased, in the sense that community schools seem to perform 'less well', (i.e. dropout differences between community schools and regular schools diminished over time), even though this is caused by the fact that non-comparable regular students are compared with community school students. Overall, the findings indicate that compared with regular schools community schools are neither more nor less effective in reducing dropout in pre-vocational education. ${ }^{12} 13$

\subsection{Discussion and Conclusion}

The importance of dropout prevention and reduction is continuously highlighted by policymakers and schools. As a consequence, various measures are taken to prevent and reduce dropout, but it remains unclear how dropout can be effectively reduced or prevented, mainly because it is not the result of one specific problem, but an accumulation of problems that students are experiencing at home, in their neighborhood, or at school. Community schools recognize that a variety of factors are underlying educational problems and that these may eventually lead to student dropout. They offer a holistic educational program to accommodate students in their personal needs. Practically, this means that these schools cooperate more with external organizations, stimulate parental involvement in the educational process, and

${ }^{12}$ The same analysis is carried out for all matched observations, as well as for the balanced sub-sample. The results correspond to those presented in Table 5.12.

${ }^{13}$ The results are consistent if the school year 2004/2005 is left out and 2005/2006 is used as the base year. 
Chapter 5. The Impact of Community Schools on Student Dropout in Lower Secondary Pre-Vocational Education

organize more extracurricular activities. However, despite the increasing number of community schools, there has been no empirical evidence that these schools reduce student dropout more than regular schools.

This chapter examines the impact of community schools in Rotterdam on student dropout, and focuses on pre-vocational education, as dropout is particularly high in this educational track (see Table 5.1). Community schools are schools that receive a community school subsidy from the Municipality of Rotterdam for the various activities that they undertake to improve students' educational outcomes. In order to estimate the impact of these subsidies on student dropout, unique registration data of the Ministry of Education are used, in which Rotterdam students enrolled in pre-vocational education were tracked between the school years 2004/2005 and 2007/2008.

To identify the community school impact on student dropout, the fact that community school subsidies were not given before the beginning of school year 2006/2007 is exploited. This setting allowed estimating the community school impact by means of a difference-indifferences estimation model.

The difference-in-differences estimates from this model show that community schools perform worse than regular schools, in the sense that dropout differences between community and regular schools diminished over time, while community school dropout was lower than regular school dropout in 2005. However, the descriptive statistics show that community schools structurally offer more theoretical learning tracks (i.e. more difficult learning tracks within pre-vocational education) than regular schools, and have, moreover, a relatively disadvantaged student population. Therefore, the community school student population includes students who are non-comparable to any stu- 
5.6. Discussion and Conclusion

dent in the regular school student population, which imposes a bias on the measured community school impact.

In order to address this problem the difference-in-differences estimation model is combined with an iterative matching procedure that ensures that only comparable regular school students are compared with community school students. The empirical findings when a more fair comparison is made between community school and regular school students show that community schools were as effective as regular schools in reducing student dropout. It can be concluded that community schools are as effective as regular schools in reducing dropout in pre-vocational education, but that the community school subsidy does not seem to have contributed to reduce student dropout.

Next, some alternative explanations are formulated on why community schools perform as well as regular schools in reducing dropout. These hypotheses provide a basis for future research on community schools.

First, as described above, not all students know that the activities are offered, and amongst those who know that the activities are offered not all students participate. This may imply that more motivated students are better informed about the activities on offer, and are more inclined to participate. Therefore, students who could benefit most from participation in these activities are less likely to participate. The latter may point to a selection effect.

Second, the neutral effect may be due the activities offered. Activities, except the ones in the category educational offer, do not have pedagogical goals. Research on the effects of extracurricular activities on dropout is inconsistent. For example, the literature shows that sports, the activity with the highest participation rates, does not only 
Chapter 5. The Impact of Community Schools on Student Dropout in Lower Secondary Pre-Vocational Education

have positive benefits for students but is often associated with risky behaviors such as increased alcohol consumption (Feldman \& Matjasko, 2005). Third, it is not observed exactly on which students the money is spent. Moreover, as the subsidy does not have a primary educational goal this may explain the absence of an effect on dropout. Finally, it may take longer for community schools to reduce dropout rates (Claassen et al., 2008; De Vos et al., 2010). Therefore, future research has to look at the long-term effects of community school attendance on educational outcomes.

Finally, it should be emphasized that community school students may benefit from community school education in a different way, as community schools offer a more attractive learning environment. For example, the study by De Vos et al. (2010) suggests that students attending community schools enjoy going to school more compared with those attending regular schools. Moreover, our findings may indicate that community schools (on average) do not invest the community school funds effectively with respect to reducing dropout. However, community schools may effectively improve other educational outcomes, or may effectively reduce dropout if funds were better invested. As argued above, community schools have a more holistic view of children's education and development than regular schools. An advantage of this holistic view is that it focuses on students, their families, and the students' living environment. A disadvantage of the holistic view is that community school programs do not define accurately which activities are undertaken and how these activities improve students' educational outcomes. Therefore, to be evaluated rigorously on their effectiveness, community school programs and their objectives have to be more clearly defined. 


\section{Chapter 6}

\section{Conclusions and}

\section{Discussion}

As evidence on the effects of community schools is generally lacking, this dissertation contributes to the literature on community schools. The findings and conclusions from the previous chapters are combined in this final chapter and discussed. Table 6.1 shows the contributions of this dissertation by summarizing its major findings per chapter. 


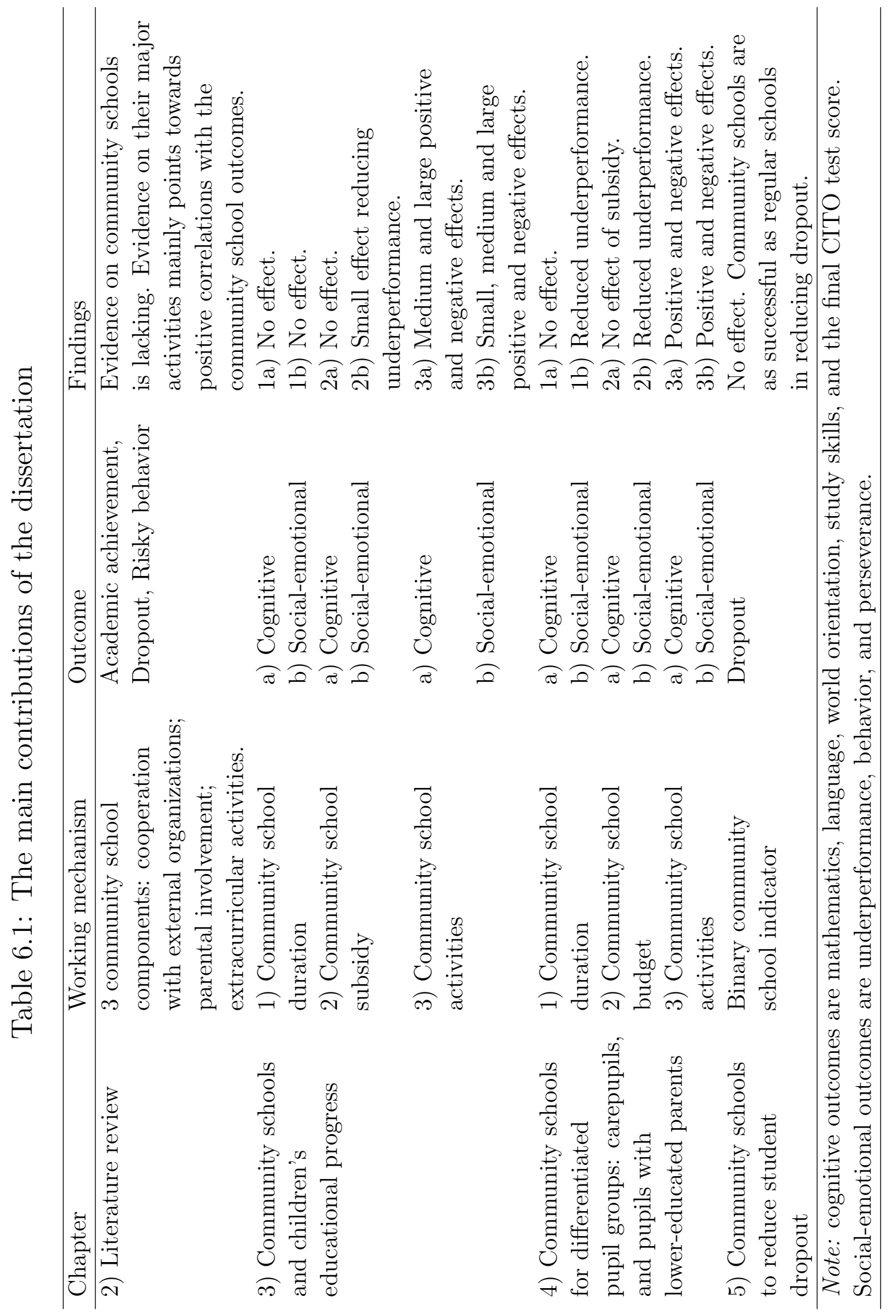




\subsection{Conclusions}

This section presents the conclusions which can be drawn from this dissertation. These general conclusions combine the insights from the different chapters of the dissertation. The conclusions are printed in bold. Each conclusion is supported by a discussion that evolves from the findings in the previous chapters of this dissertation.

Given the structure of the above empirical analyses, in the conclusions community schools are always compared to regular schools. Thus, for all conclusions, the reference group is comparable students attending regular schools. 'Regular schools' here refers to public schools that do not receive a community school subsidy.

1. Compared with comparable pupils from regular primary schools, pupils in community schools do not have better results in the cognitive learning outcomes mathematics, language, world orientation, study skills, and the final CITO test score.

The results show that contrary to the positively formulated assumptions and hypotheses, community schools do not improve pupils' cognitive learning outcomes. Cognitive learning outcomes in this context refer to the scores from the CITO test that children take in the final year of primary education. Children are tested in mathematics, language, world orientation, and study skills. Together, these constitute a final score.

The results are robust and hold for different community school indicators: the length of community school attendance, and the amount of the financial resources. Attending a community school as such does 
not improve the results; neither does the length of the period spent in a community school. A reason for the non-effectiveness of community schools regarding cognitive learning outcomes may be that the additional activities offered in community schools do not exclusively and not strongly enough focus on increasing cognitive skills for clear cognitive learning outcomes to materialize. This explanation is in line with Dobbie and Fryer (2009) who find that high-quality schools (e.g. in terms of high-quality teachers) are more important for improvements in academic outcomes than community programs which seem insufficient for improving educational achievement. Alternatively, the observed period, which varies from 1 to 8 years, may, on average, be too short and positive outcomes may need longer to manifest themselves. The consistently non-positive community school effect also holds for the two differentiated pupil groups: carepupils, and pupils with lower-educated parents.

\section{Community schools improve the social-emotional} teacher-rated pupil outcome 'underperformance', but do not improve 'behavior' and 'perseverance'.

Apart from cognitive outcomes, community schools also seek to improve social-emotional outcomes. The three outcomes considered in this dissertation are: underperformance, behavior, and perseverance. 'Underperformance' measures whether a pupil performs below his/her ability. 'Behavior' measures whether a pupil is often impertinent, and does not behave according to the rules. 'Perseverance' reflects whether a pupil is eager to learn or if $\mathrm{s} /$ he gives up when something does not work out easily. An important characteristic of these outcomes is that 
they are teacher-rated, and therewith biased with their subjective impression.

The results provide mixed evidence for the effects of community schooling on the three outcomes: behavior and perseverance are consistently not affected, while underperformance is consistently influenced. Generally, these findings also hold for the differentiated pupil groups: both a longer time spent in a community school and a higher subsidy allocated to community schools reduce underperformance for carepupils. A higher subsidy reduces underperformance for pupils with lower-educated parents; a longer period spent in community schools does not. These results illustrate that different community school indicators have different effects. Therefore, considering whether a school is a community school or not is not enough, but different indicators, such as the length of such schooling, the subsidy, and the activities provide important different and complementing insights into community school effectiveness.

The observed reduction in underperformance indicates that community schools are supporting and encouraging students to perform better according to their individual capabilities. An alternative explanation is that teachers in community schools are particularly good at challenging, encouraging, and supporting children and thereby help them to underperform less.

3. Community school activities in primary education related to culture, school climate, and parental involvement have a positive effect on cognitive and social-emotional learning outcomes. Care and school environment activities have 
a negative effect on cognitive and social-emotional learning outcomes. The effects of the activities on carepupils and pupils with lower-educated parents vary.

The Municipality of Schiedam assumes that there is an increasingly strong impact of community school activities on cognitive and social-emotional learning outcomes in the following order: educational learning process, care, school climate, parental involvement, cultural activities, and school environment activities. However, the empirical results in this dissertation do not support this assumption, and show that, in fact, the impacts of these community school activities on cognitive outcomes are mixed. In addition to the above, the cognitive outcomes are also positively affected by educational learning process and parental involvement activities.

It is interesting to observe that the general direction, positive or negative, of the activity effects are consistent for the cognitive and social-emotional outcomes: cultural, school climate, and parental involvement activities have a positive effect throughout, whereas care and school environment activities have a negative effect throughout. The positive effects have been hypothesized and are intuitive. But, while positive effects have also been hypothesized for care and school environment activities, the results show consistent negative effects. A potential explanation for the negative effect of school environment is that those activities do not focus on the pupil but on the neighborhood. The negative effect of care activities might be explained by higher demands for care leading to a larger offer. However, this explanation should not hold, because the matching analysis used in this study creates a control group with similar characteristics (care needs and cognitive abilities). It is important to add that the negative effect 
of care activities on cognitive outcomes holds for non-carepupils, but that carepupils benefit from care activities in terms of improved mathematics, world orientation, and final scores. Non-carepupils further benefit from school climate activities regarding all outcomes. Simultaneously, carepupils are negatively affected by educational activities regarding mathematics, world orientation, and the final CITO score and by parental activities and school environment regarding all outcomes. Hence, the same activity offered in community schools can have different effects on different pupil groups.

Overall, going to a community school does not improve the educational outcomes, and nor does the community school subsidy prove to be effective. It is via the channels of different activities through which community school subsidies are allocated to the students that children can benefit from community schooling.

Finally, in the context of community school activities some shortcomings with respect to the research design should be discussed. First of all, the data do not include information at the pupil level about the participation in specific community school activities. In the analyses, an indicator of how often a school has offered a certain activity, or, more precisely, has reported that it has used the subsidy to offer that activity, has been applied. Monitoring which pupils participate in which activities, and how often would allow more robust results in this respect.

4. Compared to comparable students from regular schools, community school students in secondary pre-vocational education run the same dropout risk. 
Community schools are expected to help their students graduate from secondary schools (see Chapter 2). The dissertation does not support this assumption, and finds that in comparison to comparable students in regular schools, community school students run the same dropout risk. This finding refers to pre-vocational secondary schools in Rotterdam. In the debate about how to reduce the number of highschool dropouts, community schools do not seem to be an effective tool.

Several potential explanations can be found for this finding. First of all, the community school intervention is not very intense and rather loosely defined: not all students in community schools participate in community school activities, and participation is usually restricted to a few hours per week. It is also problematic that dropout reduction is not the primary goal of the subsidy, but is expected to be a 'by-product'. Overall, current policymaking assumes a chain of relationships that eventually reduce dropout. This chain broadly implies that community schools increase motivation, leading to improved grades, which, in turn, leads to reduced dropout. These assumptions are not based on scientific evidence, and, therefore, it is not surprising that a reduction in dropout is not observed.

Finally, it is interesting to note that the non-reduction in dropout in community schools is in line with the results of Van Elk et al. (2013) who find that what is called a 'Neighborhood School Program', an intervention similar to community schools that has also been set up in Rotterdam, does not have a statistically significant effect on school enrollment. 
6.1. Conclusions

\section{Allocating an additional budget to community schools does not improve students' educational outcomes.}

The results in Chapters 3 and 4 show that allocating an additional budget to community schools does not benefit students in primary education. An exception is the reduction in the social-emotional outcome 'underperformance'. The results for secondary education in Chapter 5 show that nor do community school subsidies provided by the Municipality of Rotterdam produce educational benefits in terms of reduced dropout rates. Overall, despite receiving additional money community schools do not perform better. Some of the findings in Chapter 4 even point to a negative relation between the community school budget and cognitive learning outcomes.

In general, the amounts invested per pupil are relatively low so that they may not allow an intervention with a clear scope and high quality content. For example, in Schiedam, per school year, approximately $€ 520$ are spent per community school pupil. In addition, the absence of a budget effect may be related to the fact that the processes concerning how exactly the money is invested are not entirely clear. It is also not exactly clear whether too little money is invested or whether it is not allocated effectively, or both. It is clear, however, that the way the subsidies are currently allocated is not beneficial for pupils' learning outcomes. Therefore, instead of further providing subsidies in the present form, policymaking has to find better and more effective ways of allocating the available funds if the aim is to increase student performance.

The analyses in Chapters 3 and 4 have further shown that, while the budget itself is not important, the channels via which the subsidy is allocated to the students are important: the activities of community 
schools do impact pupil outcomes. Therefore, a policy recommendation is to target the money more specifically to different activities, some of which have been shown to produce positive effects instead of providing lump-sum payments. The latter is also motivated by the fact that the allocation of these lump sums to community school activities within schools is not entirely transparent.

\section{Further research must identify community school ef-} fects from different perspectives.

From the literature review it is clear that causal evidence on the effectiveness of community schools is lacking but needed. Literature on specific community school activities is available, but there is a lack of evidence on the full community school package. Interestingly, compared with the correlational studies, the few causal studies included in the literature review are less positive about the relationships, and more in line with the empirical results from this dissertation. The tension between the positive impressions evolving from the literature review, as opposed to the generally neutral effects found in the empirical chapters emphasizes that to take the right (policy) decisions regarding community school implementations correlational studies are an important starting point but are not sufficient.

This dissertation has provided evidence on the (non-)effectiveness of community schools. In the empirical chapters, several robustness checks and sensitivity analyses were provided. Nonetheless, the estimates may still be affected by some issues. Most importantly, the core assumption of the matching procedures that are applied in the empirical chapters is that, as they account for observed characteristics, 
they also account for unobserved factors. The matching procedures account for many factors at the student, family, and school level, and by means of $t$-statistics it was shown that no statistically significant differences remain after the matching. Nevertheless, it cannot be ruled out that both groups still differ in terms of unobserved characteristics. For example, students may participate in activities outside the school on a private basis. Another example is that contextual characteristics such as peers and students living in different communities may still differ between community school students and their matched counterparts from regular schools. Furthermore, teacher selection into different school types is not observed, and it is not known why some parents decide to send their child to a community school, while others do not. These examples illustrate that, even though the matching procedures approach reality as well as the available data allow, there are still concerns that future research should investigate.

One solution for solving the problem of unobservable characteristics would be the implementation of community schools on an experimental basis. If students are randomly assigned to community and regular schools, unobservable characteristics are randomly distributed as well. However, such randomly controlled trials (RCTs) are not easily set up. For example, strong political support is needed (Bouguen \& Gurgan, 2012). Furthermore, settings like community schools require longitudinal experiments which are difficult to implement. For instance, it would be unethical not to allow control students to join sports clubs, as these are also a core community school activity. Another concern is the external validity of RCTs. While the internal validity is typically strong, it is less clear whether, and to what extent, an estimated impact in one context is valid for different contexts (Bouguen \& Gurgan, 
2012). What is more, in an experimental community school setting the Hawthorne effect is likely to materialize: Students (as well as teachers and parents) may behave differently as they are aware of being involved in an intervention. This would lead to biased results and seriously threaten their internal validity. Thus, even though RCTs are often promoted as the "gold standard" (Cartwright, 2007, p. 11), they are not perfectly suited for evaluating community schools. Overall, alternatives to the methodologies used in this dissertation exist but they also have flaws and are not necessarily superior to those applied in the dissertation.

Another important line for future research on community schools is exploiting them from a more qualitative point of view, in particular in combination with the quantitative approaches presented in this dissertation. Such a mixed methods approach would be particularly useful to shed more light on the working mechanisms in community schools and may potentially allow researchers to provide explanations beyond the hypotheses made in the dissertation on why specific results are observed. Combining the methodologies applied in this dissertation with advanced qualitative methodologies would also allow researchers to make more in-depth statements about what the results imply for individual students. The latter implies, for example, looking into how an individual student experiences care activities and how this experience translates into a particular outcome, such as his/her motivational behavior. This would also be useful as given the methodological choices made in this dissertation, the terms 'effect' and 'impact' have mainly been used in their statistical senses.

Future research on community school effectiveness is also strongly encouraged to conduct more longitudinal studies than, given the data 
6.2. Contextualization of the results of the dissertation

available for this dissertation, was feasible. Ideally, such data follow students even before they enter primary education, tracks them throughout their educational careers, and includes detailed information on schools as well as on children's socio-economic living conditions. The benefit of such an approach would be twofold: First, it would allow researchers to investigate if and to what extent community school effects materialize over time. Second, in these analyses, researchers could consider a large set of factors, such as early educational experiences, that can shed light on the working mechanisms of community schools in children's educational careers.

While this dissertation has made a contribution to the knowledge gap in the context of community school effectiveness, some gaps remain. With respect to further research, generally, additional data would allow complementary analyses. For example, including teacher information, such as teachers' experience and qualifications would provide additional insights. It would also be valuable to be able to use panel data sets that include information on students even before they enter formal education and follow them through primary and secondary community school education.

\subsection{Contextualization of the results of the dissertation}

In this final chapter of the dissertation, it is interesting to put the findings into the context of the literature, particularly the literature reviewed in Chapter 2. Some issues that will be discussed in this subsection have already been raised above. Overall, this dissertation has 
revealed rather negative or neutral findings compared with the more positive findings from the studies identified in the literature review. The literature review has shown that community schools, with the three major activities they undertake - cooperation with external organizations, parental involvement and extracurricular activities - can mostly be expected to affect students positively or are neutral. In sum, the results from the empirical chapters of this dissertation do not support the positive assumptions for which several potential explanations exist.

First of all, in this dissertation, populations and contexts different from those in the literature review have been analyzed, an issue that has already been raised in Section 2.5. For example, in the literature review, mostly US-based samples have been considered which differ in several aspects from the situation in the Netherlands where amongst others different poverty levels and community characteristics are observed. Considering the Harlem Children's Zone (Dobbie \& Fryer, 2009), it can be argued that this intervention is starting from a lower academic level compared with community schools in the Netherlands. Therefore, in comparison with Dutch community schools there is more room for improving students' educational outcomes which may explain the different findings.

On the contrary, relating to the results in Chapter 5, showing an absence of a community school effect, an evaluation in a similar context has found a comparable effect: Van Elk et al. (2013) who find that the 'Neighborhood School Program' does not have a statistically significant effect on school enrollment; this is in line with the findings of the dissertation.

Another difference from most of the literature on community schools 
6.2. Contextualization of the results of the dissertation

is that in this dissertation, community schools have been defined by receiving a community school subsidy, which is not always the case in other contexts and research articles. The choice to focus on community school subsidies was made to clearly identify them.

Moreover, the literature review has considered the three major community school activities separately, and this dissertation has considered community schools mostly as 'one entity'. It seems that such 'all-atonce' educational strategies have a working mechanism that differs from that in the settings of the separate activities. Another characteristic of the community school setting investigated in this dissertation that may explain the relatively negative findings compared with the literature is that the amounts invested per student are quite low (for example, approximately $€ 519$ per student per school year, Section 3.5.3). The spending per student in the Harlem Children's Zone varies from $\$ 16,000$ to an average of $\$ 5,000$, depending on the specific program components children participate in (Hanson, 2013; Otterman, 2010). The relatively low amounts in the community school settings analyzed in this dissertation may not allow an intervention with a clear scope and high quality content.

Another potential reason explaining that community school effectiveness in Schiedam and Rotterdam differs from the expectations raised by the literature is that the children (Chapter 3 and 4) - and even more adolescents (Chapter 5) - considered in this dissertation are already too far in their educational careers for a community school intervention to have an impact. The latter explanation is based on studies that have shown that interventions at a young age are most effective and must start even before children enter primary education (Cunha, Heckman, Lochner, \& Masterov, 2006; Heckman \& Masterov, 
2007; Nores \& Barnett, 2010).

Finally, the differences between the results presented in the vast amount of the literature and the findings from this dissertation can be explained by the use of different methodologies. Most of the literature in the review (Chapter 2) is correlational, while here quasiexperimental methodologies have been used which allow capturing community school effects to a better extent than correlational studies.

\subsection{Policy implications and valorization}

The community school policies and subsidies analyzed in this dissertation consistently prove that community schools as a whole are as effective as regular schools. At the same time, for different community school activities both positive and negative effects on student outcomes have been found. Therefore, policymakers are recommended to no longer provide community school subsidies as is currently done. Instead, the available money should be invested in more targeted policies: If policymakers want to encourage specific outcomes for particular students, they should invest in activities that have been shown to be effective. For instance, this dissertation has shown that cultural activities have a large positive effect on mathematics, language, study skills, and the final CITO score. In addition, some activities have different and partly opposite - effects on different student groups: an example is that care activities have a positive effect on carepupils' cognitive learning outcomes but a negative one on non-carepupils'. A potential policy reaction is that policies are designed in a way that not every activity is offered to each pupil, but that distinct student groups are 
6.3. Policy implications and valorization

targeted by different activities.

The recommended targeted policies are expected to be effective as they can be implemented based on evidence, some of which has been established by this dissertation. The suggested targeted activity approach suggests rather small-scale interventions which would be more narrowly defined than community schools and allow a clear scope and focus on specific activities and target groups. Practically, such alternative policies could consist of an 'activity menu' from which schools can choose. This would allow schools to respond to students' heterogeneous needs and preferences. The 'menu' should consist of activities for which there is evidence that they 'work' and are effective in terms of improving the pursued outcomes. Following this suggestion, future policymaking can, for example, support carepupils, and offer activities exclusively for them.

Implementing more targeted policies is, however, not the only potential policy reaction. Other reactions may be that municipalities invest higher funds that might allow a higher quality offer of community school activities. Alternatively, allowing community schools to improve and learn over time is another option for policymakers to react to the above findings. However, based on the findings of this dissertation the effectiveness of such measures cannot be proven and, therefore, if policymakers decide to take these measures, this should be accompanied with high quality research on community schools.

Finally, given that community schools are as effective as regular schools leads to the question why any additional funding should be allocated to them. The findings of this dissertation suggest that there is no reason to give them preferential treatment in the form of subsidies compared with regular schools. 
Chapter 6. Conclusions and Discussion 


\section{References}

Adelman, H., \& Taylor, L. (2008). Community schools: Working toward institutional transformation. Los Angeles, CA. Retrieved from http://smhp.psych.ucla.edu/pdfdocs/ csinstitutionaltrans.pdf

Agnew, R., \& Petersen, D. M. (1989). Leisure and delinquency. Social Problems, 36(4), 332-350. doi: 10.2307/800819

Alexander, K. L., Entwisle, D. R., \& Horsey, C. S. (1997). From first grade forward: Early foundations of high school dropout. Sociology of Education, 70 (2), 87-107. doi: 10.2307/800819

Alspaugh, J. W. (1998). The relationship of school and community characteristics to high school drop-out rates. The Clearing House, 71 (3), 184-188. doi: 10.1080/00098659809599356

Anderson, S. A., Sabatelli, R. M., \& Kosutic, I. (2007). Families, urban neighborhood youth centers, and peers as contexts for development. Family Relations, 56(4), 346-357. doi: 10.1111/j.17413729.2007.00464.x

Archambault, I., Janosz, M., Fallu, J.-S., \& Pagani, L. S. (2009). Student engagement and its relationship with early high school dropout. Journal of Adolescence, 32(2), 651-570. doi: 10.1016/j.adolescence.2008.06.007

Bahr, S. J., Maughan, S. L., Marcos, A. C., \& Li, B. (1998). Family, religiosity, and the risk of adolescent drug use. Journal of Marriage and the Family, 60(4), 979-992. doi: 10.2307/353639 
Baker, D., Goesling, B., \& LeTendre, G. (2002). Socioeconomic status, school quality and national economic development: A cross-national analysis of the 'Heyneman-Loxley effect' on mathematics and science achievement. Comparative Education Review, 46(3), 291-312. doi: $10.1086 / 341159$

Barnes, G. M., Hoffmann, J. H., Welte, J. W., Farrell, M. P., \& Dintcheff, B. A. (2006). Effects of parental monitoring and peer deviance on substance use and delinquency. Journal of Marriage and Family, 68(4), 1084-1104. doi: 10.1111/j.1741-3737.2006.00315.x

Becker, H. J., \& Epstein, J. L. (1982). Parent involvement: A survey of teacher practices. The Elementary School Journal, 83(2), 85-102. doi: $10.1086 / 461297$

Benson, L., Harkavy, I., Johanek, M. C., \& Puckett, J. (2009). The enduring appeal of community schools. American Educator, 33(2), 22-47. Retrieved from http://www.aft.org/pdfs/americaneducator/summer2009/ enduringappeal.pdf

Bireda, S. (2009). A look at community schools. Washington, DC: Center for American Progress.

Blank, M. J., Jacobson, R., \& Melaville, A. (2012). Achieving results through community school partnerships. How district and community leaders are building effective, sustainable relationships. Washington, DC: Center for American Progress.

Blank, M. J., Melaville, A., \& Shah, B. (2003). Making the difference, research and practice in community schools. Washington, DC: Coalition for Community Schools.

Blau, D. M. (1999). The effect of income on child development. The Review of Economics and Statistics, 81(2), 261-276. doi: $10.1162 / 003465399558067$

Blum, R. W., Beuhring, T., \& Rinehart, P. M. (2000). Protecting teens: Beyond race, income and family structure. Minneapolis, MN: Center for Adolescent Health, University of Minnesota. 
References

Blundell, R., \& Costa Dias, M. (2009). Alternative approaches to evaluation in empirical microeconomics. The Journal of Human Resources, 44 (3), 565-640. doi: 10.1353/jhr.2009.0009

Bontje, D., Studulski, F., \& Van der Vegt, A. L. (2006). De brede school in de praktijk. Handreiking voor brede scholen in het voortgezet onderwijs. Utrecht: Sardes.

Bouguen, A., \& Gurgan, M. (2012). Randomized controlled experiments in education. Paris: European Expert Network on Economics of Education (EENEE).

Bower, C. B. (2011). Social policy and the achievement gap: What do we know? Where should we head? Education and Urban Society, 45(1), 3-36. doi: 10.1177/0013124511407488

Broh, B. A. (2002). Linking extracurricular programming to academic achievement: Who benefits and why? Sociology of Education, 75(1), 69-95. doi: $10.2307 / 3090254$

Broman, C. L., Reckase, M. D., \& Freedman-Doan, C. R. (2006). The role of parenting in drug use among Black, Latino, and White adolescents. Journal of Ethnicity in Substance Abuse, 5(1), 39-50. doi: $10.2307 / 3090254$

Brown, P. C. (2006). Involving parents in the education of their children. Urbana, IL: ERIC Clearinghouse on Elementary and Early Childhood Education.

Cameron, A. C., \& Trivedi, P. K. (2005). Microeconometrics: Methods and applications. Cambridge: Cambridge University Press.

Cartwright, N. (2007). Are RCTs the Gold Standard? BioSocieties, 2(1), 11-22. doi: 10.1017/S1745855207005029

Chin, T., \& Phillips, M. (2004). Social reproduction and childrearing practices: Social class, children's agency, and the summer activity gap. Sociology of Education, $77(3), 185-210$. doi: $10.1177 / 003804070407700301$ 
Christenson, S. L., Rounds, T., \& Gorney, D. (1992). Family factors and student achievement: An avenue to increase students' success. School Psychology Quarterly, 7(3), 178-206. doi: $10.1037 / \mathrm{h} 0088259$

Claassen, A. (2009). De prestaties van leerlingen op de basisscholen in Schiedam. Nijmegen: ITS - Radboud Universiteit Nijmegen. Retrieved from http://www. bureauvtv.nl/file/ variatie $\% 20$ in $\% 20$ brede $\% 20$ scholen.pdf

Claassen, A., Knipping, C., Koopmans, A., \& Vierke, H. (2008). Variatie van brede scholen en hun effecten. Nijmegen: ITS - Radboud Universiteit Nijmegen.

Clark, R. (2002). Ten hypotheses about what predicts student achievement for African American students and all other students: What the research shows. In W. R. Allen, M. B. Spencer, \& C. O'Connor (Eds.), African American Education (Vol. 2:, pp. 155-177). Oxford, UK: Elsevier Service.

Coalition for Community Schools. (2009). Community schools across the nation. Washington, DC: Coalition for Community Schools.

Coalition for Community Schools. (2013). What is a community school? Retrieved from http://www.communityschools.org/

Cochran, M., \& Henderson, C. R. (1986). Family matters: Evaluation of the parental empowerment program. Ithaka, NY: Cornell University.

Cohen, J. (2005). Statistical power analysis for the social sciences. Cambridge: Cambridge University Press.

Coley, L. R., Morris, E. J., \& Hernandez, D. (2004). Out-of-school care and problem behavior trajectories among low-income adolescents: Individual, family, and neighborhood characteristics as added risks. Child Development, 75(3), 948-965. doi: 10.1111/j.14678624.2004.00716.x 
References

Cooper, H., Valentine, J. C., Nye, B., \& Lindsay, J. J. (1999). Relationships between five after-school activities and academic achievement. Journal of Educational Psychology, 91(2), 369-378. doi: 10.1037/0022-0663.91.2.369

Covay, E., \& Carbonaro, W. (2010). After the bell: Participation in extracurricular activities, classroom behavior, and academic achievement. Sociology of Education, 83(1), 20-45. doi: $10.1177 / 0038040709356565$

Crane, J. (1996). Effects of home environment, SES, and maternal test scores on mathematics achievement. The Journal of Educational Research, 89(5), 305-314. doi: 10.1080/00220671.1996.9941332

Crowson, R. L., \& Boyd, W. L. (1993). Coordinated services for children: Designing arks for storms and seas unknown. American Journal of Education, 101(2), 140-179. doi: 10.1086/444037

Cummings, C., Dyson, A., Muijs, D., Papps, I., Pearson, D., Raffo, R., ... Crowther, D. (2007). Evaluation of the full service extended schools initiative: Final report. Manchester: University of Manchester, Department for Education and Skills.

Cunha, F., Heckman, J. J., Lochner, L. J., \& Masterov, D. V. (2006). Interpreting the evidence on life cycle skill formation. In E. Hanushek \& F. Welch (Eds.), Handbook of the Economics of Education (pp. 697-812). Amsterdam: North Holland.

Dahl, G. B., \& Lochner, L. (2012). The impact of family income on child achievement: Evidence from the earned income tax credit. American Economic Review, 102(5), 1927-1956. doi: 10.1257/aer.102.5.1927

Davalos, D., Chavez, E., \& Guardiola, R. (1999). The effects of extracurricular activity, ethnic identification, and perception of school on student dropout rates. Hispanic Journal of Behavioral Sciences, 21(1), 61-78. doi: 10.1177/0739986399211005

Dawson, M., \& Zunderdorp, R. (2002). Brede schoolontwikkeling in Nederland. Notitie ten behoeve van de brede dialoog over de kansen 
en risico's van de brede school ontwikkeling in Nederland. Den Haag: Zunderdorp Beleidsadvies Management.

De Blaay, N., Van Leijenhorst, J., El Khetabi, Z., Van der Grinten, M., Marlet, G., \& Larsen, V. (2007). Maatschappelijke kostenbatenanalyse brede school. Utrecht: Berenschot, Oberon, Stichting Atlas voor Gemeenten.

Denton, R. E., \& Kampfe, C. M. (1994). The relationship between family variables and adolescent substance abuse: A literature review. Adolescence, 29(114), 475-495.

Desforges, C., \& Abouchaar, A. (2003). The impact of parental involvement, parental support and family education on pupil achievement and adjustment: A literature review. Nottingham: Department of Education and Skills. Retrieved from https://www.education.gov.uk/publications/eOrdering Download/ DCSF-Parental

De Vos, W., Severins, S., De Boom, J., Meeuwisse, M., \& Hermus, P. (2010). Met meer plezier naar school. Een onderzoek naar de effecten van brede scholen in het Rotterdamse voortgezet onderwijs. Rotterdam: Risbo, Erasmus Universiteit Rotterdam.

De Witte, K., \& Rogge, N. (2013). Dropout from secondary education: All's well that begins well. European Journal of Education, 48(1), 131-149. doi: 10.1111/ejed.12001

De Witte, K., \& Van Klaveren, C. (2012). Comparing students by a matching analysis - on early school leaving in Dutch cities. Applied Economics, 44(28), 3679-3690. doi: 10.1080/00036846.2011.579069

De Witte, K., Van Klaveren, C., \& Smets, A. (2011). Selective Migration in New Towns: Influence on Regional Accountability in Early School Leaving (Working Paper No. 11(03)). Retrieved from the Top Institute for Evidence Based Education Research (TIER) website http://www.tierweb.nl/assets/files/UM/Working\%20papers/ Selective $\% 20$ Migration $\% 20$ in $\% 20$ New $\% 20$ Towns $\% 20$ okt . $\% 202011$.pdf. 
References

Dienst Uitvoering Onderwijs. (2012). Financiële gegevens primair onderwijs jaarrekeningen 2007 tot en met 2011. Retrieved from http://www.duo.nl/Images/Po\%20$\% 20$ Gegevensboek\%20po\%202007-\%202011_7-37472.pdf

Dobbie, W., \& Fryer, R. G. (2009). Are high quality schools enough to close the achievement gap? Evidence from a social experiment in Harlem (Working Paper No. 15473). Retrieved from the National Bureau of Economic Research (NBER) website http://www . nber.org/papers/w15473.

Driessen, G., Mulder, L., \& Roeleveld, J. (2012). Cohortonderzoek ${ }^{5-18}$. Technisch rapport basisonderwijs, tweede meting 2010/11. Nijmegen: ITS - Radboud Universiteit Nijmegen. Retrieved from http://www.cool5-18.nl/pdf-bestanden/ Cohortondezoek $\% 20$ Cool5-18\%202012.pdf

Dryfoos, J. G. (2000). Evaluation of community schools: Findings to date. Washington, DC: Coalition for Community Schools.

Dryfoos, J. G. (2005). Full-service community schools: A strategy not a program. New Directions for Youth Development, 107, 7-14. doi: $10.1002 / y d .124$

Dryfoos, J. G. (2008). Centers of hope. Full-service community schools can improve the lives of children in poverty. Poverty and Learning, 65(7), 38-43.

Dumais, S. (2006). Elementary school students' extracurricular activities: The effects of participation on achievement and teachers' evaluations. Sociological Spectrum, 26(2), 117-147. doi: $10.1080 / 02732170500444593$

Duncan, G. J., Brooks-Gunn, J., \& Klebanov, P. K. (1994). Economic deprivation and early childhood development. Child Development, 65(2), 296-318. doi: 10.1111/j.1467-8624.1994.tb00752.x

Duncan, G. J., Yeung, W. J., Brooks-Gunn, J., \& Smith, J. R. (1998). How much does childhood poverty affect the life chances of children? American Sociological Review, 63(3), 406-423. doi: $10.2307 / 2657556$ 
Durlak, J. A., Weissberg, R. P., Dymnicki, A. B., Taylor, R. D., \& Schellinger, K. B. (2011). The impact of enhancing students' social and emotional learning: A meta-analysis of school-based universal interventions. Child Development, 82(1), 405-432. doi: 10.1111/j.1467-8624.2010.01564.x

Dyson, A. (2011). Full service and extended schools, disadvantage, and social justice. Cambridge Journal of Education, 41(2), 177-193. doi: 10.1080/0305764X.2011.572864

Dyson, A., \& Raffo, C. (2007). Education and disadvantage: The role of community-oriented schools. Oxford Review of Education, 33(3), 297-31. doi: 10.1080/03054980701324685

Eccles, J. S., \& Barber, B. L. (1999). Student council, volunteering, basketball or marching band. What kind of extracurricular involvement matters? Journal of Adolescent Research, 14(1), 10-43. doi: $10.1177 / 0743558499141003$

Eccles, J. S., Barber, B. L., Stone, M., \& Hunt, J. (2003). Extracurricular activities and adolescent development. Journal of Social Issues, 59(4), 865-889. doi: 10.1046/j.0022-4537.2003.00095.x

Emmelot, Y., Van der Veen, I., \& Ledoux, G. (2006). De brede school: kenmerken verwachtingen en mogelijkheden. Pedagogiek, 26(1), 64-81. Retrieved from http://www.pedagogiek-online.nl/index.php/pedagogiek/ article/ viewFile/297/296

Epstein, J. L. (1992). School and family partnerships. In M. C. Alkin, M. Linden, K. Noel, \& K. Ray (Eds.), Encyclopedia of educational research (6th ed., pp. 1139-1151). New York, NY: McMillan.

Epstein, J. L., Clark, L., Salinas, K. C., \& Sanders, M. G. (1997). Scaling up school-family-community connections in Baltimore: Effects on student achievement and attendance. Paper presented at the Annual Meeting of the American Educational Research Association, Chicago, IL. 
References

Epstein, J. L., \& Sheldon, S. B. (2002). Present and accounted for: Improving student attendance through family and community involvement. The Journal of Educational Research, 95(5), 308-318. doi: 10.1080/00220670209596604

Evans, G. W., \& Kantrowitz, E. (2002). Socioeconomic status and health: The potential role of environmental risk exposure. Annual Review of Public Health, 23, 303-331. doi: 10.1146/annurev.publhealth.23.112001.112349

Fan, X. (2001). Parental involvement and students' academic achievement: A growth modeling analysis. The Journal of Experimental Education, 70(1), 27-61. doi: 10.1080/00220970109599497

Fan, X., \& Chen, M. (1999). Parental involvement and students' academic achievement: A meta-analysis. Paper presented at the Annual Meeting of the American Educational Research Association, Montreal, CA.

Feldman, A. F., \& Matjasko, J. L. (2005). The role of school-based extracurricular activities on adolescent development: A comprehensive review and future directions. Review of Educational Research, 75 (2), 159-210. doi: 10.3102/00346543075002159

Fletcher, A. C., Nickerson, P., \& Wright, K. L. (2003). Structured leisure activities in middle childhood: Links to well-being. Journal of Community Psychology, 31(6), 641-659. doi: 10.1002/jcop.10075

Franzini, L., Caughy, M. O. B., Nettles, S. M., \& O'Campo, P. (2008). Perceptions of disorder: Contributions of neighborhood characteristics to subjective perceptions of disorder. Journal of Environmental Psychology, 28(1), 83-93. doi: 10.1016/j.jenvp.2007.08.003

Fries, D., Carney, K. J., Blackman-Urteaga, L., \& Savas, S. A. (2012). Wraparound services: Infusion into secondary schools as a dropout prevention strategy. NASSP Bulletin, 96(2), 119-136. doi: $10.1177 / 0192636512443282$

Gemeente Rotterdam. (2008). Subsidiekader Brede School VO 20062010. Rotterdam: Gemeente. 
Gesthuizen, M., De Graaf, P., \& Kraaykamp, G. (2005). The changing family background of the low-educated in the Netherlands: Socioeconomic, cultural, and socio-demographic resources. European Sociological Review, 21(5), 441-452. doi: 10.1093/esr/jci031

Gibbons, S., McNally, S., \& Viarengo, M. (2012). Does additional spending help urban schools? An evaluation using boundary discontinuities (Discussion Paper No. 6281). Retrieved from the Institute for the Study of Labor (IZA) website http://ftp.iza.org/dp6281.pdf.

Goldschmidt, P., Huang, D., \& Chinen, M. (2007). The long-term effects of after-school programming on educational adjustment and juvenile crime: A study of the LA's BEST after-school program. Los Angeles, CA: CRESST/University of California.

Groot, W., \& Maassen van den Brink, H. (2007). The health effects of education. Economics of Education Review, 26(2), 186-200. doi: 10.1016/j.econedurev.2005.09.002

Groot, W., \& Maassen van den Brink, H. (2010). The effects of education on crime. Applied Economics, 42(3), 279-289. doi: $10.1080 / 00036840701604412$

Guest, A., \& Schneider, B. (2003). Adolescents' extracurricular participation in context: The mediating effects of schools, communities, and identities. Sociology of Education, 76(2), 89-109. doi: $10.2307 / 3090271$

Hanson, D. (2007). Assessing the Harlem Children's Zone (Discussion Paper No. 8). Retrieved from the Center for Policy Innovation website http://report.heritage.org/cpi_dp08.

Hanushek, E., \& Wössmann, L. (2007). The role of education quality in economic growth (Policy Research Working Paper No. 4122). Retrieved from the World Bank Group website https://openknowledge.worldbank.org/bitstream/handle /10986/7154/wps4122. pdf? sequence=1.

Harlem Children's Zone. (2013). The beginning of the children's zone. Retrieved from http://www.hcz.org/about-us/history 
References

Harris, A., \& Goodall, J. (2008). Do parents know they matter? Engaging all parents in learning. Educational Research, 50(3), 277289. doi: $10.1080 / 00131880802309424$

Hart, J. L., O'Toole, S. K., Price-Sharps, J. L., \& Shaffer, T. W. (2007). The risk and protective factors of violent juvenile offending: An examination of gender differences. Youth Violence and Juvenile Justice, 5(4), 367-384. doi: 10.1177/1541204006297367

Heckman, J., \& Masterov, D. V. (2007). The productivity argument for investing in young children. Review of Agricultural Economics, 29(3), 446-493. doi: 10.1111/j.1467-9353.2007.00359.x

Henderson, A. T., \& Berla, N. (1994). A new generation of evidence: The family is critical to student achievement. Washington, DC: National Committee for Citizens in Education.

Hermanns, J. (2006). Verbetert de brede school het functioneren in school? Kind en Adolescent Review, 13(1), 110-112.

Hill, N. E., \& Taylor, L. C. (2004). Parental school involvement and children's academic achievement: Pragmatics and issues. Current Directions in Psychological Science, 13(4), 161-164. doi: 10.1111/j.0963-7214.2004.00298.x

Hoffmann, J. P. (2006). Extracurricular activities, athletic participation, and adolescent alcohol use: Gender-differentiated and schoolcontextual effects. Journal of Health and Social Behavior, 47(3), 275-290. doi: 10.1177/002214650604700306

Hoffmann, J. P., \& Xu, J. (2002). School activities, community service, and delinquency. Crime Delinquency, 48(4), 568-591. doi: $10.1177 / 001112802237130$

Holland, A., \& Andre, T. (1987). Participation in extracurricular activities in secondary school: What is known, what needs to be known? Review of Educational Research, 57(4), 437-466. doi: 10.3102/00346543057004437 
Hoover-Dempsey, K. V., Battiato, A. C., Walker, J. M. T., Reed, R. P., DeJong, J. M., \& Jones, K. P. (2001). Parental involvement in homework. Educational Psychologist, 36(3), 195-209. doi: 10.1207/S15326985EP3603_5

Ho Sui-Chu, E., \& Willms, J. D. (1996). Effects of parental involvement on eighth-grade achievement. Sociology of Education, 69(2), 126141. doi: $10.2307 / 2112802$

Imberman, S. A. (2011). Achievement and behavior in charter schools: Drawing a more complete picture. The Review of Economics and Statistics, 93(2), 416-435. doi: 10.1162/REST_a_00077

Jacobson, R., \& Blank, M. J. (2011). Expanding the learning day: An essential component of the community schools strategy. New Directions for Youth Development, 131, 55-67. doi: 10.1002/yd.408

Jeynes, W. H. (2003). A meta-analysis: The effects of parental involvement on minority children's academic achievement. Education and Urban Society, 35(2), 202-218. doi: 10.1177/0013124502239392

Jeynes, W. H. (2007). The relationship between parental involvement and urban secondary school student academic achievement: A meta-analysis. Urban Education, 42(1), 82-110. doi: $10.1177 / 0042085906293818$

Jordan, W. J., \& Nettles, S. M. (2000). How students invest their time outside of school: Effects on school-related outcomes. Social Psychology of Education, 3(4), 217-243. doi: 10.1023/a:1009655611694

Jungbluth, P., Roede, E., \& Roeleveld. (2001). Validering van het PRIMA-leerlingprofiel. Reeks secundaire analyses op de PRIMAcohort bestanden. Amsterdam: SCO-Kohnstamm Instituut.

Kisker, E. E., \& Brown, R. S. (1996). Do school-based health centers improve adolescents' access to health care, health status, and risktaking behavior? Journal of Adolescent Health, 18(5), 335-343. doi: 10.1016/1054-139X(95)00236-L

Klein, S. P., \& Bolus, R. (2002). Improvements in math and reading scores of students who did and did not participate in the Foundations 
References

After School Enrichment Program during the 2001-2002 school year. Santa Monica, CA: Gansk Associates.

Kruiter, J., Kooij, D., Klein, T., Kieft, M., \& Steerneman, L. (2009). Brede School-bericht Schiedam. Utrecht: Oberon, onderzoek en advies en Gemeente Schiedam.

Kruiter, J., Oomen, C., Dubbelman, E., Van der Linden, J., Hulsen, M., Kooij, D., \& Van der Grinten, M. (2012). Jaarbericht brede school 2011. Utrecht: Oberon. Retrieved from http://www.oberon.eu/Beheer/DynamicMedia/ publicaties/BS-jaarbericht2011.pdf

Ladd, H. F., \& Fiske, E. B. (2009). Weighted student funding for primary schools: An analysis of the Dutch experience (Working Paper No. SAN09-02). Retrieved from the Duke Sanford School of Public Policy website http://files.eric.ed.gov/fulltext/ED507401.pdf.

Landers, D. M., \& Landers, D. M. (1978). Socialization via interscholastic athletics: Its effects on delinquency. Sociology of Education, 51 (4), 299-303. doi: 10.2307/2112368

Lareau, A. (1987). Social class differences in family-school relationships: The importance of cultural capital. Sociology of Education, 60 (2), 73-85. doi: $10.2307 / 2112583$

Lareau, A. (2003). Unequal childhoods: Class, race, and family. Berkeley, CA: University of California Press.

Lauer, P. A., Akiba, M., Wilkerson, S. B., Apthorp, H. S., Snow, D., \& Martin-Glenn, M. L. (2006). Out-of-school-time programs: A meta-analysis of effects for at-risk students. Review of Educational Research, 76 (2), 275-313. doi: 10.3102/00346543076002275

Leuven, E., Lindahl, M., Oosterbeek, H., \& Webbink, D. (2007). The effect of extra funding for disadvantaged pupils on achievement. The Review of Economics and Statistics, 89(4), 721-736. doi: $10.1162 /$ rest.89.4.721 
Lieberman, G. A., \& Hoody, L. L. (1998). Closing the achievement gap: Using the environment as an integrating context for learning. San Diego, CA: State Education and Environment Roundtable.

Limbos, M. A. P., \& Casteel, C. (2008). Schools and neighborhoods: Organizational and environmental factors associated with crime in secondary schools. Journal of School Health, 78(10), 539-544. doi: 10.1111/j.1746-1561.2008.00341.x

Little, P. M. D., Wimer, C., \& Weiss, H. B. (2008). After school programs in the $21^{\text {st }}$ century: Their potential and what it takes to achieve it. Cambridge, MA: Harvard Graduate School of Education.

Lochner, L., \& Moretti, E. (2004). The effect of education on crime: Evidence from prison inmates, arrests, and selfreports. American Economic Review, 94(1), 155-189. doi: $10.1257 / 000282804322970751$

López, G. R., Scribner, J. D., \& Mahitivanichcha, K. (2001). Redefining parental involvement: Lessons from high-performing migrantimpacted schools. American Educational Research Journal, 38(2), 253-288. doi: 10.3102/00028312038002253

Mahoney, J. L. (2000). School extracurricular activity participation as a moderator in the development of antisocial patterns. Child Development, 71 (2), 502-516. doi: 10.1111/1467-8624.00160

Mahoney, J. L., \& Cairns, R. (1997). Do extracurricular activities protect against early school dropout? Developmental Psychology, 33(2), 241-253. doi: 10.1037/0012-1649.33.2.241

Mahoney, J. L., Lord, H., \& Carryl, E. (2005). Afterschool program participation and the development of child obesity and peer acceptance. Applied Developmental Science, 9(4), 202-215. doi: 10.1207/s1532480xads0904_3

Mahoney, J. L., \& Stattin, H. (2000). Leisure activities and adolescent antisocial behavior: The role of structure and social context. Journal of Adolescence, 23(1), 113-127. doi: 10.1006/jado.2000.0302 
References

Marsh, H. W. (1992). Extracurricular activities: Beneficial extension of the traditional curriculum or subversion of academic goals? Journal of Educational Psychology, 84 (4), 553-562. doi: 10.1037/00220663.84.4.553

Mayberry, M., Espelage, D., \& Koenig, B. (2009). Multilevel modeling of direct effects and interactions of peers, parents, school, and community influences on adolescent substance use. Journal of Youth and Adolescence, 38 (8), 1038-1049. doi: 10.1007/s10964-009-9425-9

McHale, J., Vinden, P., Bush, L., Richer, D., Shaw, D., \& Smith, B. (2005). Patterns of personal and social adjustment among sportinvolved and non-involved urban middle school children. Sociology of Sport Journal, 22(2), 119-136.

McLoyd, V. C. (1990). The impact of economic hardship on black families and children: Psychological distress, parenting, and socioemotional development. Child Development, 61(2), 311-346. doi: 10.1111/j.1467-8624.1990.tb02781.x

McMahon, T. J., Ward, N. D., Pruett, M. K., Davidson, L., \& Griffith, E. E. H. (2000). Building full-service schools: Lessons learned in the development of interagency collaboratives. Journal of Educational and Psychological Consultation, 11(1), 65-92. doi: 10.1207/s1532768Xjepc1101_05

McNeal, R. B. (1995). Extracurricular activities and high school dropouts. Sociology of Education, 68(1), 62-81. doi: $10.2307 / 2112764$

McNeal, R. B. (1999). Parental involvement as social capital: Differential effectiveness on science achievement, truancy, and dropping out. Social Forces, 78(1), 117-144. doi: 10.1093/sf/78.1.117

Melaville, A., Berg, A. C., \& Blank, M. J. (2006). Community-based learning. Engaging students for success and citizenship. Washington, DC: Coalition for Community Schools. Retrieved from http://www . communityschools.org/assets/1/AssetManager/ CBLFinal.pdf 
Miedel, W. T., \& Reynolds, A. J. (1999). Parent involvement in early intervention for disadvantaged children: Does it matter? Journal of School Psychology, 37(4), 379-402. doi: 10.1016/S00224405(99)00023-0

Miliotis, D., Sesma, A., \& Masten, A. S. (1999). Parenting as a protective process for school success in children from homeless families. Early Education Development, 10(2), 111-133. doi: $10.1207 / \mathrm{s} 15566935$ eed 1002

Milligan, K., Moretti, E., \& Oreopoulos, P. (2004). Does education improve citizenship? Evidence from the United States and the United Kingdom. Journal of Public Economics, 88(9), 1667-1695. doi: 10.1016/j.jpubeco.2003.10.005

Ministerie van Onderwijs, Cultuur en Wetenschap. (2013a). Wat is leerlinggebonden financiering (rugzak)? Retrieved from http://www.rijksoverheid.nl/onderwerpen/passendonderwijs/vraag-en-antwoord/wat-is-leerlinggebondenfinanciering-rugzak.html

Ministerie van Onderwijs, Cultuur en Wetenschap. (2013b). Werken in het onderwijs: Arbeidsvoorwaarden. Retrieved from http://www.werkeninhetonderwijs.nl/vervolg.php?h_id=1s _id=67v_id=3d_id=17titel=Arbeidsvoorwaard

Ministerie van Onderwijs, Cultuur en Wetenschap. (2014). Wat is een brede school? Retrieved from http://www.rijksoverheid.nl/onderwerpen/basisonderwijs/ vraag-en-antwoord/wat-is-een-brede-school.html

Moffitt, T. E. (1993). Adolescence-limited and life-course-persistent antisocial behavior: A developmental taxonomy. Psychological Review, 100(4), 674-701. doi: 10.1037/0033-295X.100.4.674

Mounts, N. S. (2002). Parental management of adolescent peer relationships in context: The role of parenting style. Journal of Family Psychology, 16(1), 58-69. doi: 10.1037/0893-3200.16.1.58 
References

Muijs, D. (2007). Leadership in extended schools. School Leadership and Management, 27(4), 347-362. doi: $10.1080 / 13632430701563296$

Muijs, D., West, M., \& Ainscow, M. (2010). Why network? Theoretical perspectives on networking. School Effectiveness and School Improvement, 21(1), 5-26. doi: 10.1080/13632430701563296

Nelson, P. T. (1989). Involving families in substance abuse prevention. Family Relations, 38(3), 306-310. doi: 10.2307/585057

Nettles, S. M. (1991). Community involvement and disadvantaged students: A review. Review of Educational Research, 61(3), 379406. doi: $10.2307 / 1170637$

Noailly, J., Vujiv, S., \& Aouragh, A. (2009). The effects of competition on the quality of primary schools in the Netherlands (Discussion Paper No. 120). Retrieved from the Netherlands Bureau for Economic Policy Analysis (CPB) website http://www.cpb.nl/en/publication/effects-competitionquality- primary-schools-netherlands.

Nores, M., \& Barnett, W. S. (2010). Benefits in early childhood interventions across the world: (Under) Investing in the very young. Economics of Education Review, 29(2), 271-282. doi: 10.1016/j.econedurev.2009.09.001

Oberon. (2010). Brede school ontwikkeling Schiedam. Utrecht: Oberon, onderzoek en advies.

OECD. (2011). Against the odds: Disadvantaged students who succeed in school. Paris: OECD Publishing. Retrieved from http://www .oecd-ilibrary.org/education/against-the-odds -9789264090873-en

Ofsted. (2006). Extended services in schools and children's centres (No. HMI2609). Manchester: Office of Her Majesty's Chief Inspector of Schools. Retrieved from http://www.ofsted.gov.uk/resources/extended-servicesschools-and-childrens-centres 
Onderwijsinspectie. (2010). Leerlingenzorg. Retrieved from http://www . onderwijsinspectie.nl/binaries/content/assets/ Onderwijsverslagen/2010/Hoofdstuk+12+-+printversie.pdf

Oomen, C., Kruiter, J., Van der Grinten, M., Van der Linden, J., \& Dubbelman, E. (2009). Jaarbericht Brede School 2009. Utrecht: Oberon. Retrieved from http://www.bredeschool.nl/fileadmin/Documenten/ BSjaarbericht2009.pdf

Otterman, S. (2010, October 12, 2010). Lauded harlem schools have their own problems. New York Times. Retrieved from http://www . nytimes. com/2010/10/13/education/13harlem.html

Perry-Burney, G. D., \& Takyi, B. K. (2002). Self esteem, academic achievement, and moral development among adolescent girls. Journal of Human Behavior in the Social Environment, 5 (2), 15-27. doi: 10.1300/J137v05n02_02

Picard, F., Ruelens, L., \& Nicaise, I. (2004). Naar een brede school in Vlaanderen? Leuven: Katholieke Universiteit.

Pomerantz, E. M., Moorman, E. A., \& Litwack, S. D. (2007). The how, whom, and why of parents' involvement in children's academic lives: More is not always better. Review of Educational Research, 77(3), 373-410. doi: 10.3102/003465430305567

Posner, J. K., \& Vandell, D. L. (1999). After-school activities and the development of low-income urban children: A longitudinal study. Developmental Psychology, 35(3), 868-879. doi: 10.1037/00121649.35.3.868

Pretti-Frontczak, K., \& Bricker, D. (2000). Enhancing the quality of individualized education plan (IEP) goals and objectives. Journal of Early Intervention, 23(2), 92-105. doi: $10.1177 / 105381510002300204$

Psacharopoulos, G. (2007). The costs of school failure. A feasibility study. Paris: European Expert Net- 
References

work on Economics of Education (EENEE). Retrieved from http://www. eenee.de/portal/page/portal/EENEEContent/

Raffo, C., \& Dyson, A. (2007). Full service extended schools and educational inequality in urban contexts - new opportunities for progress? Journal of Education Policy, 22(3), 263-282. doi: $10.1080 / 02680930701269160$

Rodríguez, L. F., \& Conchas, G. Q. (2009). Preventing truancy and dropout among urban middle school youth: Understanding community-based action from the student's perspective. Education and Urban Society, 41(2), 216-247. doi: $10.1177 / 0013124508325681$

Rumberger, R. W. (1987). High school dropouts: A review of issues and evidence. Review of Educational Research, 57(2), 101-121. doi: 10.3102/00346543057002101

Rumberger, R. W. (2011). Dropping out. Why students drop out of high school and what can be done about it. Cambridge: Harvard University Press.

Rumberger, R. W., Ghatak, R., Poulos, G., Ritter, P. L., \& Dornbusch, S. M. (1990). Family influences on dropout behavior in one California high school. Sociology of Education, 63(4), 283-299.

Rumberger, R. W., \& Lamb. (2003). The early employment and further education experiences of high school dropouts: A comparative study of the United States and Australia. Economics of Education Review, 22(4), 353-366. doi: 10.1016/S0272-7757(02)00038-9

Shah, S. C., Brink, K., London, R., Masur, S., \& Quihuis, G. (2009). Community schools evaluation toolkit. A starter guide for community school staff who want to use data to tell their story and improve their community schools. Stanford, CA: Coalition for Community Schools and John W. Gardner Center for Youth and Their Communities at Stanford University.

Sheldon, S. B., \& Epstein, J. L. (2005). Involvement counts: Family and community partnerships and mathematics achieve- 
ment. Journal of Educational Research, 98(4), 196-206. doi: 10.3200/JOER.98.4.196-207

Shulruf, B., Tumen, S., \& Tolley, H. (2008). Extracurricular activities in school, do they matter? Children and Youth Services Review, 30(4), 418-426. doi: 10.1016/j.childyouth.2007.10.012

Siebenbruner, J., Englund, M. M., Egeland, B., \& Hudson, K. (2006). Developmental antecedents of late adolescence substance use patterns. Development and Psychopathology, 18(2), 551-571. doi: 10.1017/S0954579406060287

Sirin, S. R. (2005). Socioeconomic status and academic achievement: A meta-analytic review of research 1990-2000. Review of Educational Research , 75 (3), 417-453. doi: 10.3102/00346543075003417

Smeets, E., \& Rispens, J. (2008). Op zoek naar passend onderwijs. Overzichtsstudie van de samenhang tussen regulier en speciaal (basis)onderwijs. Nijmegen: ITS - Radboud Universiteit Nijmegen.

Solga, H. (2002). Stigmatization by negative selection: Explaining less educated people's decreasing employment opportunities. European Sociological Review, 18(2), 159-178. doi: 10.1093/esr/18.2.159

Spee, I., \& Seuren, W. (2003). Levensbreed leren - Brede scholen in het voortgezet onderwijs en integraal jeugbeleid. 's-Hertogenbosch: KPC Groep.

Spreitzer, E. (1994). Does participation in interscholastic athletics affect adult development? A longitudinal analysis of an 18-24 age cohort. Youth and Society, 25(3), 368-387. doi: 10.1177/0044118X94025003004

Statistics Netherlands. (2012). Cijfers. Retrieved from http://www.cbs.nl

Stearns, E., \& Glennie, E. J. (2010). Opportunities to participate: Extracurricular activities' distribution across and academic correlates in high schools. Social Science Research , 39(2), 296-309. doi: 10.1016/j.ssresearch.2009.08.001 
References

Strom, R. E., \& Boster, F. J. (2007). Dropping out of high school: A meta-analysis assessing the effect of messages in the home and in school. Communication Education, 56(4), 433-452. doi: $10.1080 / 03634520701413804$

Thompson, D. R., Iachan, R., Overpeck, M., Ross, J. G., \& Gross, L. A. (2006). School connectedness in the health behavior in school-aged children study: The role of student, school, and school neighborhood characteristics. Journal of School Health, 76 (7), 379-386. doi: 10.1111/j.1746-1561.2006.00129.x

Thyssen, G., De Witte, K., Groot, W., \& Maassen van den Brink, H. (2011). The effectiveness and meaningfulness of policy measures aimed at preventing school dropout: an explorative literature review [Working Paper]. Top Institute for Evidence Based Education Research (TIER).

Tweede Kamer der Staten-Generaal, Overheid. (2000). Kamerstuk: Brief van de staatssecretarissen van onderwijs, cultuur wetenschap, sociale zaken werkgelegenheid en volksgezondheid, welzijn sport. Retrieved from https://zoek. officielebekendmakingen.nl/dossier/26999/ kst-26999-1? result Index=1 sorttype $=1$ sortorder $=4$

Valkestijn, M. (2002). Brede school. In L. R. Verplanke, E. Duyvendak, Tonkens, \& E. Van Vliet (Eds.), Open deuren. Sleutelwoorden van lokaal sociaal beleid (pp. 19-25). Utrecht: NIZW/Verwey-Jonker Instituut.

Vandell, D. L., Reisner, E. R., \& Pierce, K. M. (2007). Outcomes linked to high-quality afterschool programs: Longitudinal findings from the Study of Promising Afterschool Programs. Flint, MI: Charles Stewart Mott Foundation.

Van der Steeg, M., \& Webbink, D. (2006). Dropping out from school in the Netherlands: Magnitude, policy, and results (Discussion Paper No. 107). Retrieved from the Netherlands Bureau for Economic Policy Analysis (CPB) website http://www.cpb.nl/en/publication/dropping-out-schoolnetherlands-magnitude-policy-and-results. 
Van der Veen, G. (2011). Jaarboek onderwijs in cijfers 2011. Den Haag/Heerlen: Centraal Bureau voor de Statistiek.

Van Elk, R., Van der Steeg, M., \& Webbink, D. (2013). The effects of a special program for multi-problem school dropouts on educational enrolment, employment and criminal behavior. Den Haag: Netherlands Bureau for Economic Policy Analysis. CPB Document 241.

Van Velsen, J. (2011). Verschijningsvormen Brede Scholen 2011. Den Haag: Landelijke Steunpunt Brede Scholen.

Verheijke, J. (2003). Op zoek naar de oorsprong van de Brede School in Zweden: inspiratie aan de bron. Alkmaar: Europees Platform voor het Nederlandse Onderwijs.

Walraven, G., \& Van Wissen, M. (2001). Trends in research on community schools in Europe and the United States. In M. Valkestijn, V. de Burgwal, \& G. (Eds.), New opportunities for children and youth (pp. 15-24). Utrecht: Netherlands Institute for Care and Welfare.

Wilson, W. J. (2010). Why both social structure and culture matter in a holistic analysis of inner-city poverty. The ANNALS of the American Academy of Political and Social Science, 629(1), 200-219. doi: $10.1177 / 0002716209357403$

Yatchew, A. (1998). Nonparametric regression techniques in economics. Journal of Economic Literature, 36(2), 669-721. doi: $10.2307 / 2565120$

Zarrett, N., Fay, K., Li, Y., Carrano, J., Phelps, E., \& Lerner, R. M. (2009). More than child's play: Variable and patterncentered approaches for examining effects of sports participation on youth development. Developmental Psychology, 45 (2), 368-382. doi: $10.1037 / \mathrm{a} 0014577$

Zhao, Z. (2004). Using matching to estimate treatment effects: Data requirements, matching metrics and Monte Carlo evidence. The Review of Economics and Statistics, 86(1), 91-107. doi: 10.1162/003465304323023705 


\section{Summary}

\section{Introduction}

Community schools are becoming increasingly popular. In the Netherlands, they are set up as a response to the fact that children from lower socioeconomic status families (SES) are put at a disadvantaged position throughout their educational careers. Among other things, financial restrictions prevent these children from easily participating in extracurricular activities.

Community schools differ from traditional schools by having more intense cooperation with other institutions in their neighborhoods, for example, youth care. Moreover, they closely involve parents, and offer a wide range of extracurricular activities. This integrated set of educational and social services is expected to contribute to more educational equality between children from different socioeconomic backgrounds, and to favor their academic achievement.

With the activities they undertake, community schools are expected to affect a multitude of outcomes. These include improved academic achievement, as well as outcomes at the neighborhood level, such as increased social cohesion and reduced crime rates. Evidence on whether community schools do indeed contribute to improving learning outcomes is lacking, however. Currently, there are, officially, 1600 commu- 
nity schools in primary and 420 in secondary education in the Netherlands. The increase in the number of community schools is concomitant with heavy public spending, in terms of community school subsidies provided by Dutch municipalities. For example, between 2000 and 2012 , the Municipality of Schiedam invested approximately $€ 4.6$ million in community school subsidies. Knowing whether this spending pays off is critical for the further development of community schools.

This dissertation builds on the rather descriptive evidence base, and provides indications of the (lack of a) causal effect of Dutch community schools on cognitive and social-emotional learning outcomes. Community schools in both primary and secondary education are considered.

\section{Literature review on community school ac- tivities and outcomes}

Literature on the effectiveness of community schools is lacking. Therefore, Chapter 2 in this dissertation 'disaggregates' community schools into their major activities and outcomes. The literature on the relationship between these activities: namely, cooperation with external organizations, parental involvement, and extracurricular activities, with the community school outcomes of academic performance, dropout, and risky behavior is reviewed. The results can be considered a proxy for the potential effectiveness of community schools.

The literature is mostly correlational and generally positive about the relationship between the community school activities and outcomes. It yields that these activities lead to better academic performance, as well as to reduced dropout and risky behavior, and that 
Summary

there is a considerable potential for community schools to improve the three student-level outcomes: academic performance, reduced dropout, and reduced risky behavior.

A study on the Harlem Children's Zone in New York City provides causal evidence for improved academic achievement as a result of close and structured cooperation between schools and external organizations. However, the study also shows that high-quality schools are more important than the community programs in the project (Dobbie \& Fryer, 2009). Parental involvement and participation in extracurricular activities correlate mostly positively with academic achievement. The literature further indicates that extracurricular activities correlate with reduced dropout and risky behavior. With respect to risky behavior, a quasi-experimental study of Goldschmidt et al. (2007) provides causal evidence for a reduction of delinquency based on activity participation. For drug use, such causal studies are not available. Cooperation with external institutions and parental involvement correlates negatively with dropout and risky behavior, suggesting that students benefit from these activities. Overall, the correlational nature of the evidence may not point at effective community school activities but instead represent a reversed causality, and other (unobserved) factors may simultaneously influence the outcome variables and the presence of the community school activities. Therefore, it is difficult to draw general conclusions about the effects of the community school activities. More evidence on causal relationships is needed to be able to conclude whether, and then how, the activities affect the outcomes. Hence, the following chapters of the dissertation make an important contribution to the literature as they provide empirical evidence on the effectiveness of community schools. 


\section{Community school effectiveness in primary education}

Chapters 3 and 4 evaluate how community schools in primary education in Schiedam impact pupils' cognitive and social-emotional learning outcomes. Schiedam is a particularly interesting context for evaluations of community schools, as the municipality has decided to transform all its primary schools into community schools. The cognitive learning outcomes are based on a national test that pupils take in the final year of primary education, the CITO-test. This includes pupils' performance in mathematics, reading, world orientation, study skills and their final score. The social-emotional outcomes are based on teacher-ratings and include underperformance (Does a pupil's performance match his/her capabilities?), behavior (Does a pupil behave well in class and towards others?), and perseverance (Does a pupil easily give up if something does not work out easily?). Community schools are evaluated regarding these outcomes from three perspectives: how long pupils have attended a community school; the budget allocated to community schools; and how often the six community school activities are offered.

The six activities are educational learning activities (e.g. additional language and mathematics classes); care activities (e.g. the presence of a speech therapist in the school); activities focusing on the school climate (e.g. assertiveness training); activities involving parents (e.g. language classes for parents); cultural activities (e.g. participation in music classes or theatre performances); and activities focusing on the school environment (e.g. neighborhood residents refurbishing the school yard).

In all analyses, community school pupils are compared with similar 
Summary

pupils in regular schools. This similarity is established by a 'matching procedure' which identifies for each community school pupil the most comparable pupil who attends a regular school. This procedure allows a fair comparison to be made between community school and regular school pupils so that the effect of community schooling can be identified.

The next sections describe the findings for all pupils and for differentiated pupil groups, in turn.

\section{Community school effects for all pupils}

Chapter 3 focuses on the community school effects on all pupils in the sample. The results show that just attending a community school does not affect pupils' cognitive or social-emotional skills. Furthermore, neither the length of the experience, nor the size of the subsidy has a robust effect on cognitive or social-emotional outcomes.

While positive effects of all activities on all outcomes have been hypothesized, both positive and negative effects are found. The impacts of the six community school activities with respect to the cognitive learning outcomes, mathematics, language, world orientation, study skills, and the final score are mixed. Positive effects of the educational learning process, school climate, and parental involvement on all five cognitive outcomes are observed. Cultural activities have a positive effect on mathematics, language, study skills and the final score. Negative effects are observed for care and school environment activities on all outcomes. All effects are large, except that the effect of cultural activities on mathematics is small, and their effect on study skills is medium.

In addition, effects of the activities are identified with respect to 
the social-emotional outcomes. Overall, the effects of the six activities and their impacts on the social-emotional outcomes are mixed. A small negative effect of cultural activities on underperformance is observed, implying that there is less underperformance. Behavior is affected both positively and negatively: positively by school climate and parental involvement activities, and negatively by care and school environment activities. The negative effects are small effects, the positives ones are large. Perseverance is affected negatively by care and school environment, and positively by school climate activities. All three effects are small.

Interestingly, the general directions, positive and negative, of the effects are consistent for the cognitive and the social-emotional outcomes: cultural, school climate, and parental involvement activities have a positive effect throughout on the outcomes, whereas care and school environment activities have a negative impact.

\section{Differentiated pupil groups: carepupils and pupils with lower-educated parents}

Most community schools have the objective to support students from disadvantaged backgrounds in particular. Therefore, Chapter 4 zooms in on these pupils and yields important insights regarding policymaking on community schools for different pupil groups. It elaborates on the differentiated effects of the impact of community schooling on the cognitive and social-emotional outcomes of 'carepupils', who are pupils with particular educational and social needs, and pupils with relatively lower-educated parents. These parents have a pre-vocational educational level at most. Again, the three potential working mechanisms (duration of community school experience, community school 
Summary

subsidy, and the frequency of the community school activity offer) are considered.

Overall, the findings do not support the hypothesis that community schooling improves the educational outcomes of either pupil group. A potential exception is that carepupils perform better on the mathematics test if they attend a community school longer. Overall, contrary to the positive expectations, an increased budget seems to have a negative effect on the cognitive outcomes of both pupil groups. Moreover, the duration of community school attendance is beneficial for the educational achievement of both groups only when the budget is held constant. At the same time, carepupils benefit in terms of reduced underperformance from a longer time spent in a community school, as well as from a higher budget. For pupils with lower-educated parents, only a higher budget seems to reduce underperformance.

Breaking down community schools into the six activities reveals that some community school activities have opposed effects on the cognitive learning outcomes of carepupils and non-carepupils. For pupils with lower-educated parents, the effects of community school activities are more consistent. For the two groups both positive and negative effects of the activities are observed. Carepupils are negatively affected by educational activities regarding mathematics, world orientation, and the final score, and by parental activities and school environment regarding all outcomes. Simultaneously, they are positively affected by care activities - with respect to mathematics, world orientation, and the final score - as well as by school climate activities regarding all outcomes. Cultural activities do not have a significant effect. A critical finding is that for non-carepupils the results differ: educational learning process activities positively affect all five outcomes; in contrast, care negatively affects all outcomes. Both findings are op- 
posite to the results for carepupils. School climate has a positive effect throughout (as it does for carepupils) and so do parental activities (but not for carepupils). As for carepupils, the effect of cultural activities is not significant. Moreover, school environment activities have a negative effect on all outcomes; for carepupils they do not affect world orientation. These findings are highly policy relevant, as they show that the same activity offered in community schools can have diverse effects on pupils conditional on their care needs.

Finally, pupils with lower-educated parents and those with higher educated parents are compared regarding the impact of the community school activities on cognitive outcomes. The findings show that pupils with lower-educated parents benefit from educational activities in terms of mathematics, world orientation, and the final score. Activities in the fields school climate, parents and culture positively affect all outcomes, whereas care and school environment activities negatively affect all outcomes. Pupils with parents with relatively higher educational levels are similarly affected. Educational learning activities positively affect all outcomes. Care and school environment activities have a negative impact on mathematics, language, study skills, and the final score; for pupils with lower-educated parents they also do on world orientation. School climate, which positively affects all outcomes of pupils with lower-educated parents, has a positive effect on mathematics, study skills, and the final score for pupils with higher-educated parents. Parental activities have a positive impact on mathematics, language, study skills, and the final score; while, for pupils with lowereducated parents, they also do regarding world orientation. Cultural activities do not impact any of the outcomes, while they do for pupils with lower-educated parents. Overall, the effects are more consistent for pupils whose parents have different levels of education compared 
Summary

with pupils with a different carepupil status.

The findings clarify that teachers have to be selective when they decide which activities they offer to which pupil groups, as the different groups can be affected very differently.

\section{Community schools in secondary education}

The second part of the empirical analysis (Chapter 5) focused on community schools in secondary education, and has analyzed the effect of community school attendance on students' probability to drop out of school early. School dropout prevention is highly ranked on the political agenda in many countries as leaving school without a diploma is expensive at the individual, as well as at the societal level. It remains unclear, however, how dropout can be effectively reduced, as multiple factors determine student dropout. Compared with traditional schools, community schools offer a broader approach towards education and growing up, and a common expectation towards community schools is that they can contribute to reduce student dropout. The focus is on secondary pre-vocational education because, usually, students in this educational track run a relatively high dropout risk. Moreover, the focus is on Rotterdam which is a frontrunner in the Netherlands in implementing community schools. Use is made of unique registration data on all Rotterdam students who were enrolled in pre-vocational education between 2004 and 2008. The impact of community schools is identified by exploiting the fact that community schools were not created before the beginning of the school year 2006/2007. Again, community school students are compared with similar students in regular schools. The results suggest that community schools are as effective as regular schools with respect to dropout reduction and that community 
school subsidies do not contribute to reducing dropout. Therefore, if policymakers aim to reduce dropout, community schools do not seem to be the right tool.

\section{Conclusions, policy implications, and val- orization}

Several conclusions can be drawn from this dissertation. First, compared with similar pupils from regular schools, pupils in community schools do not have better results in the cognitive learning outcomes mathematics, language, world orientation, study skills, and the final CITO test score. This holds both for the duration of the community school experience and for the budget allocated to community schools in primary education. A second conclusion is that community schools improve the social-emotional teacher-rated outcome 'underperformance' but do not improve pupils' 'behavior' and 'perseverance'. Third, mixed results are revealed with respect to the community school activities. Community school activities related to culture, school climate and parental involvement have a positive effect on cognitive and socialemotional learning outcomes. Care and school environment activities have a negative effect on cognitive and social-emotional learning outcomes. Moreover, the effects of the activities on carepupils and pupils with lower-educated parents vary. Another conclusion is that, compared with comparable students from regular schools, community school students in secondary pre-vocational education run the same dropout risk. Thus, this type of community school subsidy is not effective either. Overall, it can be concluded that allocating an additional budget to community schools does not improve students' educational 
Summary

outcomes. Finally, to complement the evidence provided in this dissertation, future research must identify community school effects. This can be done by using additional data, and outcomes beyond those considered in this dissertation could be analyzed.

The findings of this dissertation can be translated into policy advice. On the whole, community schools are as effective as regular schools, but, at the same time, some community school activities do have positive effects on student outcomes, particularly for some student groups. Therefore, community school subsidies should no longer be provided in their present form. They should no longer be provided as a lump sum, and policies should target particular student groups. Furthermore, specific activities should be offered to achieve defined outcomes. A practical suggestion is to offer an 'activity-menu' to schools that they can use to offer specific activities to heterogeneous student groups. Such alternative initiatives would no longer fall under the umbrella of community schools. Finally, given that community schools are as effective as regular schools leads to the question why any additional funding should be allocated to community schools. The findings of this dissertation suggest that there is no reason to give them preferential treatment in the form of subsidies compared with regular schools. 
Summary 


\section{Samenvatting}

\section{Introductie}

Brede scholen worden steeds populairder. Op dit moment zijn er in Nederland officieel 1600 brede scholen in het voortgezet onderwijs en 420 in het basisonderwijs. De toename van het aantal brede scholen hangt direct samen met een grote hoeveelheid publieke middelen die vanuit gemeenten voor brede scholen beschikbaar zijn, in de vorm van subsidies. De gemeente Schiedam bijvoorbeeld heeft tussen 2000 en 2012 ongeveer $€ 4,6$ miljoen euro besteed aan subsidies voor brede scholen.

Het verschil tussen traditionele en brede scholen is vooral de intensieve samenwerking van brede scholen met andere organisaties in de wijk, zoals de kinderopvang. Ook worden ouders meer betrokken bij brede scholen en organiseren deze scholen veel extra-curriculaire activiteiten. De verwachting is dat dit samenhangend geheel van onderwijs en sociale activiteiten bijdraagt aan betere onderwijsprestaties en zorgt voor een grotere onderwijsgelijkheid tussen kinderen met verschillende sociale achtergronden. Er is echter nog geen bewijs voorhanden dat brede scholen daadwerkelijk bijdragen aan verhoogde onderwijsprestaties. Toch is het cruciaal voor de verdere ontwikkeling van brede scholen om te weten of deze subsidies effectief zijn. Dit proef- 
Samenvatting

schrift onderzoekt of brede scholen de onderwijs prestaties en socialemotionele uitkomsten van kinderen positief kunnen beïnvloeden.

Het proefschrift bouwt voort op bestaande beschrijvende onderzoeken en vult die aan met bewijs van het effect van Nederlandse brede scholen op cognitieve en sociaal-emotionele onderwijsuitkomsten. Hiervoor worden brede scholen in het basisonderwijs in Schiedam en in het voortgezet onderwijs in Rotterdam onderzocht. Deze keuze wordt gemaakt omdat beide steden voorloper in brede school ontwikkeling zijn. Omdat Schiedam heeft besloten alle basisscholen tot brede school om te vormen is Schiedam een interessante onderzoeksgemeente. In Rotterdam zijn 59 van 72 (82 percent) van de scholen in het voortgezet onderwijs brede scholen.

\section{Literatuurstudie naar activiteiten en uitkomsten van brede scholen}

Er is tot op heden geen literatuur te vinden waarin het effect van brede scholen geëvalueerd wordt met een methode die als effectmeting kan gelden. Hoofdstuk 2 gaat daarom in op de relatie tussen de hoofdactiviteiten en de belangrijkste uitkomsten van brede scholen en beschouwt deze indicaties van verband als een proxy voor het potentiële effect van brede scholen. De hoofdactiviteiten die in de literatuur aan bod komen, zijn samenwerkingen met externe organisaties, ouderbetrokkenheid en extra-curriculaire activiteiten. In de literatuur wordt de relatie tussen deze activiteiten en onderwijsprestaties, uitval en risicogedrag besproken. De hoofdbevindingen zijn dat er een positieve relatie is tussen activiteiten van brede scholen en uitkomsten. Uit de literatuur komt naar voren dat deze activiteiten samenhangen met 
Samenvatting

hogere onderwijsprestaties, lagere schooluitval en minder risicogedrag. Deze literatuur heeft een correlationeel karakter. Het is daardoor niet eenvoudig allesomvattende conclusies te trekken over het effect van de activiteiten van brede scholen. Er is meer bewijs nodig om te kunnen concluderen of en op welke manier deze activiteiten effect hebben op onderwijsuitkomsten. Derhalve levert dit proefschrift een belangrijke bijdrage aan de literatuur, aangezien de toegepaste hoofdstukken empirisch bewijs leveren over het effect van brede scholen.

\section{Het effect van brede scholen in het basisonderwijs}

Hoofdstukken 3 en 4 evalueren hoe brede basisscholen in Schiedam cognitieve en sociaal-emotionele leeruitkomsten van leerlingen beïnvloeden. Cognitieve leeruitkomsten komen van alle onderdelen van de CITOtoets uit groep 8. Het gaat hier om rekenen, taal, wereldoriëntatie, studievaardigheden en de totaalscore. De sociaal-emotionele uitkomstmaat is gebaseerd op het oordeel van de docent. Het gaat hier om onderpresteren, gedrag en werkhouding. Brede scholen worden op deze uitkomsten geëvalueerd vanuit drie invalshoeken: hoe lang de leerling op de brede school zit, het budget dat de brede scholen krijgen en hoe vaak de brede scholen bepaalde activiteiten aanbieden. Er worden zes typen onderscheiden in de activiteiten die brede scholen in Schiedam aanbieden: onderwijsactiviteiten, zorgactiviteiten, activiteiten gericht op het schoolklimaat, activiteiten waarbij ouders betrokken zijn, culturele activiteiten, en activiteiten die zich op de schoolomgeving richten. In alle analyses worden leerlingen van brede scholen vergeleken met vergelijkbare leerlingen van reguliere scholen. 
Samenvatting

De vergelijkbaarheid komt tot stand door een 'matching procedure' te gebruiken, waarin er voor iedere brede school-leerling een zo vergelijkbaar mogelijke reguliere leerling wordt gezocht. Door deze procedure is het mogelijk een eerlijke vergelijking te maken tussen brede en regulieren scholen.

De meeste brede scholen hebben voornamelijk als doel om achtergestelde leerlingen te ondersteunen. Daarom wordt in de proefschrift zowel naar alle leerlingen, als naar specifieke, achtergestelde leerlingen in de steekproef gekeken.

\section{Effecten van brede scholen voor alle leerlingen}

Hoofdstuk drie bespreekt het effect van brede scholen op alle leerlingen in de steekproef. De resultaten tonen aan dat naar een brede school gaan op zich geen invloed heeft op de cognitieve en sociaal-emotionele vaardigheden van leerlingen. Bovendien heeft noch de duur van de brede school-ervaring, noch de hoogte van het budget een eenduidig effect op cognitieve of sociaal-emotionele onderwijsuitkomsten.

Uit de resultaten komen bovendien zowel positieve als negatieve effecten van de afzonderlijke activiteiten naar voren. Dit is verbazingwekkend omdat verondersteld werd dat alle activiteiten van brede scholen een positief effect zouden hebben op onderwijsuitkomsten. Wisselnde effecten van de zes activiteiten van de brede scholen op de cognitieve leeruitkomsten worden gevonden (rekenen, taal, wereldoriëntatie, studievaardigheden en de totaalscore). Positieve effecten zijn zichtbaar bij onderwijsactiviteiten, activiteiten gericht op het schoolklimaat en activiteiten gericht op ouderbetrokkenheid op de vijf cognitieve leeruitkomsten. Culturele activiteiten hebben een positief effect op rekenen, taal, studievaardigheden en de totaalscore. Er zijn 
Samenvatting

negatieve effecten van zorgactiviteiten en van activiteiten gericht op de schoolomgeving op alle leeruitkomsten.

Over het algemeen blijkt dat de effecten van de zes activiteiten en hun impact op de sociaal-emotionele leeruitkomsten wisselend is. Zo blijkt er een klein negatief effect van culturele activiteiten op onderpresteren. Dit geeft aan dat leerlingen minder onderpresteren. Gedrag wordt positief beïnvloed door activiteiten gericht op het schoolklimaat en op ouderbetrokkenheid, en negatief door zorgactiviteiten en activiteiten gericht op de schoolomgeving. Werkhouding wordt negatief beïnvloed door zorgactiviteiten en activiteiten met betrekking tot de schoolomgeving. Activiteiten met betrekking tot het schoolklimaat hebben dan weer een positief effect.

\section{Gedifferentiëerde leerlinggroepen: zorgleerlingen en leerlingen met laaggeschoolde ouders}

De meeste brede scholen hebben als doel om achtergestelde leerlingen te ondersteunen. Daarom gaat hoofdstuk 4 specifiek in op deze leerlingen. Dit stuk focust op de effecten van brede scholen op cognitieve en socioemotionele onderwijsuitkomsten van zorgleerlingen en van leerlingen met laaggeschoolde ouders. De eerstgenoemde groep zijn leerlingen met erkende bijkomende educatieve en sociale behoeften. De tweede groep zijn leerlingen met ouders die ten hoogste een VMBO opleiding afgerond hebben. Opnieuw worden de drie potentiële invloedsmechanismen - duur van de brede school-ervaring, hoogte van het budget en de frequentie van de brede school activiteiten - bestudeerd.

De hypothese dat brede scholen de onderwijsuitkomsten van elke leerling verbeteren wordt over het algemeen niet door de bevindingen ondersteund. In tegenstelling tot de verwachtingen, heeft een 
Samenvatting

toegenomen budget een negatief effect op de cognitieve leeruitkomsten van beide groepen leerlingen. Tegelijkertijd zijn er minder zorgleerlingen die onderpresteren als ze langer op een brede school zitten of als het budget van deze brede school toeneemt. Voor leerlingen met laaggeschoolde ouders lijkt een hoger budget het onderpresteren te verminderen.

Wat de zes activiteiten van brede scholen betreft wordt duidelijk dat sommige activiteiten een tegengesteld effect hebben op de cognitieve leeruitkomsten van zorgleerlingen en niet-zorgleerlingen. Voor leerlingen met laaggeschoolde ouders blijken de resultaten meer consistent. Voor beide groepen worden echter, net zoals in de algemene analyse, zowel positieve als negatieve effecten van de activiteiten geobserveerd.

Voor zorgleerlingen hebben onderwijsactiviteiten een negatief effect op rekenen, wereldoriëntatie en de totaalscore. Activiteiten gericht op ouderbetrokkenheid en activiteiten gericht op de schoolomgeving hebben een negatief effect op alle onderwijsuitkomsten. Tegelijkertijd is er een positief effect van de zorgactiviteiten op de rekenscore, wereldoriëntatiescore en de totaalscore van zorgleerlingen. Ook is er een positief effect voor zorgleerlingen van activiteiten gericht op het schoolklimaat op alle onderwijsuitkomsten. De resultaten verschillen voor niet-zorgleerlingen: voor hen hebben onderwijsactiviteiten een positieve invloed op alle onderwijsuitkomsten. Zorgactiviteiten beïnvloeden alle onderwijsuitkomsten negatief. Zowel activiteiten met betrekking tot het schoolklimaat en activiteiten waarbij ouders betrokken zijn hebben een positief effect op alle onderwijsuitkomsten. Verder blijkt dat de activiteiten die zich op de schoolomgeving richten, een negatief effect hebben op alle uitkomsten. Deze bevindingen zijn erg beleidsrelevant aangezien ze aantonen dat eenzelfde activiteit in een 
Samenvatting

brede school een verschillend effect kan hebben op leerlingen, afhankelijk van de zorg die ze nodig hebben.

Ten slotte worden leerlingen met laaggeschoolde ouders vergeleken met leerlingen met hoger geschoolde ouders met betrekking tot de impact van brede school activiteiten op cognitieve onderwijsuitkomsten. De resultaten tonen aan dat leerlingen met laaggeschoolde ouders voordeel halen uit onderwijsactiviteiten op het gebied van rekenen, wereldoriëntatie, en de totaalscore. Activiteiten die gericht zijn op het schoolklimaat, ouderbetrokkenheid en cultuur hebben een positieve invloed op alle leeruitkomsten. Dit terwijl zorgactiviteiten en activiteiten gericht op de schoolomgeving een negatief effect hebben op alle leeruitkomsten. Leerlingen met hoger geschoolde ouders worden op eenzelfde manier beïnvloed. Onderwijsactiviteiten hebben een positief effect op alle onderwijsuitkomsten. Zorgactiviteiten en activiteiten gericht op de schoolomgeving hebben een negatieve impact op rekenen, taal, studievaardigheden en de totaalscore van deze leerlingen. Voor leerlingen met laaggeschoolde ouders hebben de zorgactiviteiten en activiteiten over de schoolomgeving ook een negatieve invloed op wereldoriëntatie. De activiteiten die zich richten op schoolklimaat hebben een positief effect op alle leeruitkomsten van leerlingen met laaggeschoolde ouders. Laatstgenoemde activiteiten hebben een positief effect op rekenen, studievaardigheden en de totaalscore van leerlingen met hoger geschoolde ouders. Activiteiten gericht op het betrekken van ouders hebben een positief effect op rekenen, taal, studievaardigheden en de totaalscore van leerlingen met hoger geschoolde ouders. Voor leerlingen met laaggeschoolde ouders is er ook een positieve invloed op wereldoriëntatie. Culturele activiteiten hebben geen impact op de onderwijsuitkomsten van leerlingen met hoger geschoolde ouders. Dit is wel het geval voor leerlingen met laaggeschoolde ouders. 


\section{Brede scholen in het voortgezet onderwijs}

Hoofdstuk 5 richt zich op brede scholen in het voortgezet onderwijs en analyseert het effect van naar een brede school gaan op de kans dat leerlingen voortijdig de school verlaten. Vergeleken met traditionele scholen bieden brede scholen een bredere aanpak van onderwijs en ontwikkeling. De verwachting is dat brede scholen significant kunnen bijdragen aan het reduceren van voortijdig schoolverlaten. Hoofdstuk 5 focust op het $\mathrm{VMBO}$, omdat over het algemeen leerlingen binnen het VMBO een relatief hoog risico lopen op voortijdig schoolverlaten. Daarnaast ligt de focus op Rotterdam. Er wordt gebruik gemaakt van unieke registratie data van alle leerlingen uit Rotterdam die ingeschreven waren in het VMBO tussen 2004 en 2008. Het effect van brede scholen kan worden gemeten meten doordat er vr het schooljaar 2006/ 2007 nog geen brede scholen waren. Leerlingen van brede scholen worden wederom vergeleken met leerlingen van reguliere scholen. Het resultaat suggereert dat brede scholen even effectief zijn als reguliere scholen in het reduceren van voortijdig schoolverlaten en dat subsidies voor brede scholen hier geen bijdrage aan leveren. Als beleidsmakers ernaar streven om voortijdig schoolverlaten te reduceren blijken brede scholen hiervoor niet de juiste oplossing. 
Samenvatting

\section{Conclusies, beleidsimplicaties en valorisatie}

Er kunnen meerdere conclusies worden getrokken uit dit proefschrift. Ten eerste, vergeleken met vergelijkbare leerlingen van reguliere scholen, hebben leerlingen van brede scholen geen betere resultaten op het gebied van cognitieve leeruitkomsten voor de onderdelen rekenen, taal, wereldoriëntatie, studievaardigheden en de totaalscore van de CITO-toets. Dit geldt voor zowel de duur van de brede school ervaring als voor het budget dat toegewezen is aan brede scholen in het basisonderwijs. Een tweede conclusie is dat brede scholen de door de leraar gerapporteerde sociaal-emotionele uitkomstmaat 'onderpresteren' wel verbeteren, maar niet de uitkomstmaten 'gedrag' en 'werkhouding'. Ten derde zijn er wisselende resultaten met betrekking tot de activiteiten van brede scholen. Activiteiten van brede scholen met betrekking tot cultuur, schoolklimaat en ouderbetrokkenheid hebben een positief effect op cognitieve en sociaal-emotionele leeruitkomsten. Zorgactiviteiten en schoolomgeving activiteiten hebben een negatief effect op cognitieve en sociaal-emotionele leeruitkomsten. Bovendien varieert het effect van de activiteiten ook voor specifieke doelgroepen zoals zorgleerlingen en leerlingen met laag opgeleide ouders. Een andere conclusie is dat, vergeleken met vergelijkbare leerlingen van reguliere scholen, leerlingen van brede scholen in het VMBO hetzelfde risico lopen op voortijdig schoolverlaten. Over het algemeen kan geconcludeerd worden dat het toewijzen van extra budget aan brede scholen de onderwijsuitkomsten niet verbetert.

De bevindingen uit dit proefschrift kunnen vertaald worden in beleidsadvies. Gegeven de ineffectiviteit van brede scholen moeten brede school-subsidies niet langer gegeven worden in hun huidige vorm. Brede 
scholen zijn net zo effectief als reguliere scholen. Tegelijkertijd hebben sommige brede school-activiteiten een positief effect op leerlinguitkomsten, in het bijzonder voor sommige groepen leerlingen. Brede schoolsubsidies zouden niet langer verstrekt moeten worden als lumpsum en het beleid zou beter moeten worden toegespitst op specifieke groepen leerlingen. Bovendien moeten er specifieke activiteiten worden aangeboden om vooraf vastgelegde doelen te bereiken. In aanmerking nemend dat brede scholen net zo effectief zijn als reguliere scholen, ontstaat de vraag waarom er extra budget zou moeten worden toegewezen aan brede scholen. Dit suggereert ook dat er geen reden is om brede scholen voorrang te geven met betrekking tot het verlenen van subsidies. 


\section{Biography}

Marieke Heers was born on September 16, 1984, in Dortmund, Germany. She holds a German-French B. A. (European Business Studies) from the University of Paderborn (Germany) and the University of Le Mans (France) and a M. Sc. (Business Administration, Strategic Human Resource Management, cum laude) degree from Radboud University Nijmegen. After graduating in 2009, Marieke joined the Top Institute for Evidence Based Education Research at Maastricht University as a Ph.D. candidate. During her doctoral studies, she has been a visiting scholar at Teachers College at Columbia University in New York City. Her work has been published in the Economics of Education Review.

Marieke has presented parts of this dissertation at various international conferences and workshops, including the Annual Congress of the European Society for Population Economics $(2012$, 2013), the International Workshop on the Applied Economics of Education (2012) and the Lisbon Research Workshop on Economics, Statistics and Econometrics of Education (2013).

As of June 2014, Marieke is a post-doctoral researcher at the Institut National d'Etudes Démographiques in Paris. 


\section{Top Institute for Evidence Based Education Research (TIER)}

The Top Institute for Evidence Based Education Research (TIER) is an inter-university institute that conducts research to develop evidence based education. The institute has three partners: the University of Amsterdam, Maastricht University and the University of Groningen and is located in Amsterdam, Maastricht and Groningen.

TIER contributes to the improvement of the quality of education in the Netherlands by promoting an evidence based approach as a guiding principle in education policy and practice. It accomplishes this by developing (cost) effective education interventions that are grounded in scientific research. TIER research is funded by the Ministry of Education, Culture and Science and the participating universities through the NWO and complies with the quality standards and evaluation standard used by NWO.

The following books recently appeared in the TIER Research Series:

I. C. Haelermans (2012). On the productivity and efficiency of education. The role of innovation in Dutch secondary education.

II. L. van Welie (2013). They Will Get There! Studies on Educational Performance of Immigrant youth in the Netherlands.

III. S. Cabus (2013). An Economic Perspective on School Dropout Prevention using Microecnometric Techniques.

IV. I. Cornelisz (2013). School choice, competition and achievement: Dutch compulsory education.

V. M. Heers (2014). The effectiveness of community schools: Evidence from the Netherlands. 